\title{
Evaluation of diagnosis and treatment of nasopharyngeal carcinoma in Indonesia
}

Citation for published version (APA):

Fles, R. (2016). Evaluation of diagnosis and treatment of nasopharyngeal carcinoma in Indonesia: the necessity of a multilevel approach. [Doctoral Thesis, Maastricht University]. Proefschriftmaken.nl I| Uitgeverij BOXPress. https://doi.org/10.26481/dis.20161221rf

Document status and date:

Published: 01/01/2016

DOI:

10.26481/dis.20161221rf

Document Version:

Publisher's PDF, also known as Version of record

\section{Please check the document version of this publication:}

- A submitted manuscript is the version of the article upon submission and before peer-review. There can be important differences between the submitted version and the official published version of record.

People interested in the research are advised to contact the author for the final version of the publication, or visit the DOI to the publisher's website.

- The final author version and the galley proof are versions of the publication after peer review.

- The final published version features the final layout of the paper including the volume, issue and page numbers.

Link to publication

\footnotetext{
General rights rights.

- You may freely distribute the URL identifying the publication in the public portal. please follow below link for the End User Agreement:

www.umlib.nl/taverne-license

Take down policy

If you believe that this document breaches copyright please contact us at:

repository@maastrichtuniversity.nl

providing details and we will investigate your claim.
}

Copyright and moral rights for the publications made accessible in the public portal are retained by the authors and/or other copyright owners and it is a condition of accessing publications that users recognise and abide by the legal requirements associated with these

- Users may download and print one copy of any publication from the public portal for the purpose of private study or research.

- You may not further distribute the material or use it for any profit-making activity or commercial gain

If the publication is distributed under the terms of Article $25 \mathrm{fa}$ of the Dutch Copyright Act, indicated by the "Taverne" license above, 
Evaluation of diagnosis and treatment of nasopharyngeal carcinoma in Indonesia

The necessity of a multilevel approach 
Copyright @ Renske Fles, Maastricht 2016

Cover by Distorsigrafis

Layout by Nauka Amsterdam

Printed by BoxPress

ISBN: 978-94-6295-543-1 


\title{
Evaluation of diagnosis and treatment of nasopharyngeal carcinoma in Indonesia
}

\author{
The necessity of a multilevel approach
}

\section{PROEFSCHRIFT}

ter verkrijging van de graad van doctor aan de Universiteit Maastricht, op gezag van de Rector Magnificus, prof dr. Rianne M. Letschert, volgens het besluit van het College van Decanen, in het openbaar te verdedigen

op woensdag 21 december 2016 om 14.00 uur

door

Renske Fles 


\section{Promotor:}

Prof. dr. I.B. Tan

\section{Copromotores:}

Dr. ir. M.K. Schmidt (Antoni van Leeuwenhoek)

Prof. dr. S.M. Haryana (Universitas Gadjah Mada)

\section{Beoordelingscommissie:}

Prof. dr. B. Kremer (voorzitter)

Prof. dr. M.W.M. van den Brekel (Antoni van Leeuwenhoek)

Dr. F.J.P. Hoebers

Prof. dr. A.J.J.A. Scherpbier

Prof. dr. ir. M.P. Weijenberg

The research presented in this dissertation was funded the Dutch Cancer Society. 


\section{Table of contents}

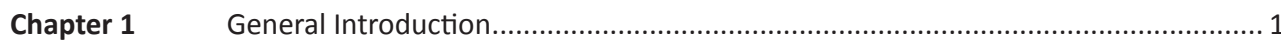

Chapter 2 Primary treatment results of nasopharyngeal carcinoma

in Yogyakarta, Indonesia

\section{Patient delay}

Chapter 3 The role of health-seeking behavior of Indonesian patients in delaying the diagnosis of nasopharyngeal carcinoma.....

Chapter $4 \quad$ Use of traditional, complementary and alternative medicine delays

diagnosis of nasopharyngeal carcinoma in Indonesia.

Doctor's delay

Chapter $5 \quad$ Knowledge of general practitioners about

nasopharyngeal cancer at the puskesmas in

Yogyakarta, Indonesia

Chapter 6 Short-term effect of different teaching methods on nasopharyngeal

carcinoma for general practitioners in Jakarta Indonesia.....

Chapter 7 Effectiveness of a multicentre nasopharyngeal carcinoma awareness

programme in Indonesia.

System delay

Chapter 8 A prospective study: Current problems in radiotherapy for nasopharyngeal

carcinoma in Yogyakarta, Indonesia......

Chapter 9 The impact of the overall radiotherapy time on clinical outcome of patients with nasopharyngeal carcinoma; a retrospective study

Chapter 10 General discussion and future prospects.

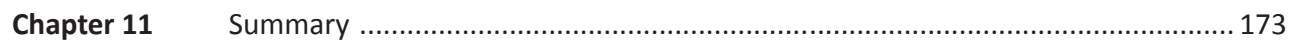

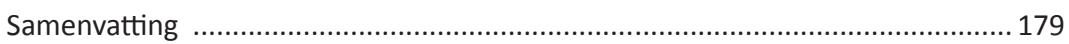

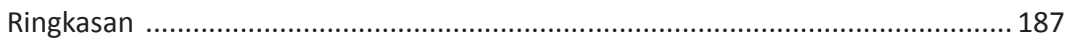

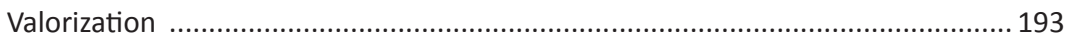

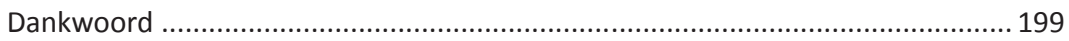

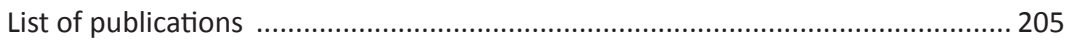

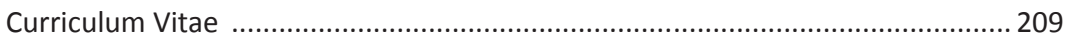





\section{Introduction}

In 2012 an estimated 14.1 million new cancer cases were confirmed worldwide, which resulted in 8.2 million deaths[1]. In the past, cancer was a disease which occurred predominantly in high income countries, however it is now becoming an increasing burden for low and middle income countries. This is due to an increase in typical health risk factors associated with western lifestyle such as smoking, increased body weight, physical inactivity and changes in reproduction pattern. Furthermore, more infection-related cancers occur in low and middle income countries[2]. In 2012, Fifty-seven per cent of all new cancer patients and 65 per cent of the cancer deaths occur in low and middle come countries[3-5]. The gap in survival rates between high income countries and low and middle income countries is strikingly big $^{3}$. To gain more insight into these disparities, global investigations in cancer control are needed. Prevention programs like tobacco and obesity control, vaccination programs and early detection programs could save an estimate of 2.4 to 3.7 million lives[3]. The majority of these lives will be saved in low and middle income countries[3].

Access to health care can be defined as having the possibility to access a service, a provider or an institution. It can further be described as the opportunity or ease with which consumers or communities are able to use appropriate services in proportion to their needs[6-8]. Limited access to health care in low and middle income countries is often caused by limited resources and an unequal distribution of these resources. The total number of health services can be seen as an indicator to which extent people in need receive the appropriate treatment[9].

Radiotherapy is one of the cornerstones in the treatment of cancer. In high income countries 50 per cent of cancer patients receive radiotherapy at some stage of the treatment. This radiotherapy utilization rate differs per cancer site. According to evidence-based guidelines, radiotherapy is part of the treatment in 74 per cent of all head and neck cancers and the mean number of fractions required is $22[10,11]$. However, in low and middle income countries the percentage of people who actually have access to radiotherapy facilities is as low as 25 per cent[12]. In 2014 there were 30 countries in Africa and Asia without any radiotherapy facilities at all[13]. 


\section{Nasopharyngeal carcinoma}

Nasopharyngeal Carcinoma (NPC) is a rare malignancy in most parts of the world, with an incidence rate of less than 1 per 100000 person-years[14]. However, in specific sub-populations in South East Asia, the Artic and Africa, NPC is one of the most frequently encountered malignancies[1,15,16]. Ninety-two per cent of patients are diagnosed in developing countries[1]. This geographical and ethnic distribution suggests that both genetic and environmental factors play a role in the development of NPC. Additionally, especially in endemic areas, NPC is correlated with the Epstein-Barr Virus (EBV). However, EBV alone is not a sufficient cause of NPC, because virtually all adults worldwide are infected with the virus, yet only a small proportion of individuals develop NPC[17-19].

The next paragraphs cover the following topics in greater detail: tumor location, etiology, pathology, presentation, diagnosis and staging, treatment and survival of NPC.

\section{Location}

The nasopharynx is a small tubular space delineated by the nasal cavity (anteriorly) and the skull base (superiorly). In the lateral wall the orifice of the Eustachian tubes can be found with the fossa of Rosenmüller. Inferiorly the nasopharynx tapers and continues as the oropharynx. Most frequently NPC originates from the fossa of Rosenmüller[20] (figure 1).

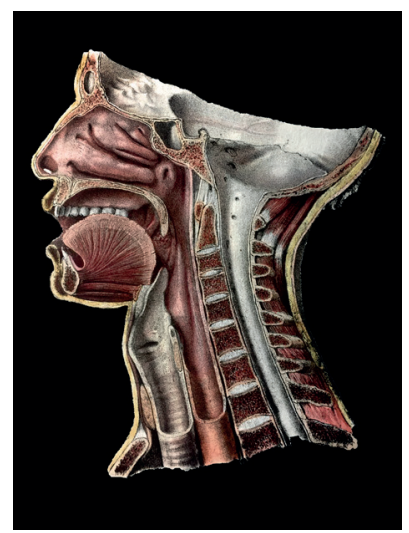

Figure 1 | Anatomy of the pharynx. The pharynx consists of three parts; the nasopharynx, oropharynx and hypopharynx ${ }^{1}$.

1 Hirschfeld 


\section{Etiology}

Well-established risk factors for NPC next to EBV are: family history of NPC, ethnicity and gender[21-24]. Environmental and lifestyle risk factors are the consumption of salted fish[21,25-29], usage of herbal medicine[25,30], wood dust exposure and other occupational exposures such as fume, smoke and chemicals[31-33]. Multiple studies reported also on the increased risk of NPC caused by smoking[34-36] and alcohol[37,38].

\section{Pathology}

The 1991 WHO classification distinguishes two histological types of NPC. These are the keratinizing squamous cell carcinoma and the non-keratinizing carcinoma. The non-keratinizing carcinoma is subdivided into differentiated or undifferentiated. However, most clinicians still use the 1974 WHO classification differentiating three types of NPC: well-differentiated keratinizing squamous cell carcinoma (WHO 1), non-keratinizing carcinoma (WHO 2), and undifferentiated carcinoma (WHO 3). The latter two are strongly related to the EBV, especially in endemic areas[20,39].

\section{Presentation}

The symptoms of NPC are often non-specific and can mimic a common flue, making NPC a challenging disease to diagnose at an early stage. The symptoms can be subdivided into four different categories, namely: (1) tumor mass in the nasopharynx causing blood tinged secretion, nasal obstruction and sometimes epistaxis; (2) dysfunction of the Eustachian tube inducing fullness, hearing loss and tinnitus; (3) skull base erosion and palsy of the 3rd, 4th, 5th and 6th nerves provoking headache, diplopia, facial pain and numbness including eye symptoms like strabismus and lagopthalmus; and (4) a painless mass in the neck[39].

\section{Diagnosis and staging}

Biopsy is used for the initial diagnosis of NPC, followed by imaging which is crucial in determining local extensions and regional and/ or distant metastasis. Imaging preferably comprises of: chest radiograph, computed tomography (CT) and/or magnetic resonance imaging (MRI) of the nasopharynx, skull base and neck, and positron emission tomography-CT (PET-CT) and nasopharyngoscopy. To stage NPC, 
the classification system of the Union for International Cancer Control (UICC) and the American Joint Committee staging system on Cancer (AJCC) (table 1) can be used.

Table 1 | The TNM-staging according to UICC and AJCC 7th edition

\begin{tabular}{|c|c|c|c|}
\hline \multicolumn{4}{|c|}{ Tumor in the nasopharynx } \\
\hline$T 1$ & \multicolumn{3}{|c|}{ Nasopharynx, oropharynx or nasal cavity without parapharyngeal extension } \\
\hline$T 2$ & \multicolumn{3}{|c|}{ Parapharyngeal extension } \\
\hline T3 & \multicolumn{3}{|c|}{ Bony structures of skull base and/or paranasal sinuses } \\
\hline T4 & \multicolumn{3}{|c|}{ Intracranial, cranial nerves, hypopharynx, orbit, infratemporal fossa/masticator space } \\
\hline \multicolumn{4}{|c|}{ Regional lymph nodes } \\
\hline NO & \multicolumn{3}{|c|}{ None } \\
\hline N1 & \multicolumn{3}{|c|}{$\begin{array}{l}\text { Unilateral cervical, unilateral or bilateral retropharyngeal lymph nodes, above supraclavicular fossa; } \\
<6 \mathrm{~cm}\end{array}$} \\
\hline N2 & \multicolumn{3}{|c|}{ Bilateral cervical above supraclavicular fossa; $<6 \mathrm{~cm}$} \\
\hline N3a & \multicolumn{3}{|c|}{$\mathrm{N} 3 \mathrm{a}>6 \mathrm{~cm}$} \\
\hline$N 3 b$ & \multicolumn{3}{|c|}{ N3b Supraclavicular fossa } \\
\hline \multicolumn{4}{|c|}{ Distant metastasis } \\
\hline MO & \multicolumn{3}{|c|}{ None } \\
\hline M1 & \multicolumn{3}{|c|}{ Distant metastasis } \\
\hline \multicolumn{4}{|c|}{ Anatomical Stage Groups } \\
\hline Stage & $\mathrm{T}$ & $\mathrm{N}$ & M \\
\hline 1 & 1 & 0 & 0 \\
\hline \multirow[t]{2}{*}{11} & 1 & 1 & 0 \\
\hline & 2 & $0-1$ & 0 \\
\hline \multirow[t]{2}{*}{ III } & $1-2$ & 2 & 0 \\
\hline & 3 & $0-2$ & 0 \\
\hline IVa & 4 & $0-2$ & 0 \\
\hline$I V b$ & Any & 3 & 0 \\
\hline$I V c$ & any & any & 1 \\
\hline
\end{tabular}

\section{Treatment and survival}

The standard treatment for primary NPC is radiotherapy or, in more advanced stages of the disease, radiotherapy combined with chemotherapy. Concurrent chemo-radiotherapy is the standard treatment for locally advanced tumors and shows an average 3-year overall survival of 70-80 per cent [39-42]. Most of the studies with high survival rates are derived from clinics with advanced and readily available treatment facilities. As mentioned before, approximately 90 per cent of NPC patients are diagnosed in low and middle income countries with less advanced 
equipment and limited treatment possibilities[43,44]. Considering the fact that only a small percentage of patients start treatment, one can expect the actual NPC survival rates in low- and middle-income countries to differ from the results presented in international literature.

\section{Indonesia}

Indonesia is the fifth most populated country in the world and has the world's largest Muslim majority (87.2 per cent of the population). The country, with over 261 million inhabitants, is one of the largest archipelagos in the world consisting of 17508 islands. Indonesia consists of 34 provinces, divided into districts and subdistricts. The province of Central Java, including the special region Yogyakarta has more than 36 million inhabitants.

During the economic crisis Indonesia outperformed neighboring countries and was one of the few countries boasting economic growth ${ }^{2}$. After the peak in 2012, economic growth in Indonesia slowed down. Indonesia is struggling with unemployment, inadequate infrastructure, poverty, corruption and unequal distribution of resources, including health care. Health expenditures comprise 3.2 per cent of the gross domestic product (2013) with 11.3 per cent of the population living below the poverty line (national poverty line which is set at 22.5 US\$ per person per month $\left.{ }^{3}\right)$.

\section{Yogyakarta ${ }^{4}$}

Yogyakarta was founded in 1756 as a result of a civil war within the kingdom of Mataram. In the early $18^{\text {th }}$ century, Pakubuwono II ruled this Islamic kingdom. After his death the kingdom was split in two due to a conflict between his son and his brother, encouraged by the Dutch who tried to colonize the area. After the independence of the Republic of Indonesia, Yogyakarta became part of the republic. Since then, the region has become known as the special region of Yogyakarta. The current governor of the Special Region of Yogyakarta is sultan Hamengkoeboewono X, who was crowned in 1989 after the death of his father.

2 Sources: forbes.com/places/Indonesia (accessed September 19 2016)

3 Source: cia.gov/library/publications/the-world-factbook/geos/id.html (accessed September 19 2016)

4 Source: ootprintravel.nl/indonesie/reisgids-java/Yogyakarta (accessed September 19 2016) 


\section{Health care system}

Indonesia's health care system includes public health services, private health services, non-profit organizations, religious organizations and foreign aid. In 2014 private health expenditure comprised 63 per cent of total health care expenditure. Of this, there was no pricing or quality regulation, making patients vulnerable to excessive treatment and expenses. Furthermore, 47 per cent of the total health expenditure (25 295 million US\$) was out-of-pocket payment. In 2011 there were 1 720 hospitals in Indonesia distributed over the populated islands. At primary level there were on average 3.5 primary health care centers available per 10000 people. The number of primary health care centers can be seen as sufficient. Nevertheless, there were only 0.20 doctors, 0.97 nurses and 0.51 midwives per 1000 people available. In addition, dispersion among the different provinces varied greatly[45]. In urban areas there were 0.36 doctors per 1000 people available, whereas in rural areas there were only 0.06 doctors for every 1000 people. We can conclude that the minority of doctors are based in rural areas where the majority of the population lives[46].

Health care is decentralized and the responsibility for health care provision is largely in the hands of regional governments[47]. This decentralization has resulted in a partial breakdown of health information systems and has led to unclear reporting and referral responsibilities. Referral between health care facilities is often done by doctors or paramedics and depends on patients' health care insurance[48]. In 2012, 150 million Indonesians had health care insurance, and at least 100 million Indonesians had no insurance at all. In January 2014 Indonesia introduced universal health care (UHC), the Badan Penyelenggara Jaminan Sosial (BPJS). For a monthly fee of 2.2 US\$ people have access to a third-class ward. Second-class ward is available for 3.6 US\$ a month and for 5.1 US\$ a month citizen with a BPJS can join the first-class ward. The insurance is also covering more expensive medical interventions like dialysis, open-heart surgery and cancer therapies, independent on type of health insurance[49,50]. Now that more people have health care access, the introduction of UHC has revealed the burden on limited health care facilities. The number of available hospital beds is insufficient and waiting time for treatment has increased[51] $]^{5}$. In cancer care this problem is even more apparent. There is a shortage of radiotherapy units in Indonesia. Gondhowiardjo et al. raised their

5 Jakarta post 01-04-2016 
concerns regarding this issue. In 2008 there were 35 radiation units available in Indonesia[52]. At the ESTRO (European society for radiotherapy and oncology) meeting held in Yogyakarta November 2014 Gondhowiardjo revealed this number increased to 41 accelerators. This results in 0.16 units per million inhabitants, compared to on average 5.9 units per million inhabitants according to European guidelines[53,54].

\section{Nasopharyngeal carcinoma in Indonesia}

NPC is a health problem in Indonesia and is endemic in specific ethnic groups like the Javanese and Sundanese population[55]. NPC is the most frequent cancer of the head and neck area and ranks as the fourth most common tumor found in males. Estimated incidence is 5.5 per 100000 person-years in both sexes and even 8.3 in male (figure 2)[43]. These incidence rates are most likely underestimated due to the lack of data management and cancer registries in Indonesia. The majority of patients (75-90 per cent) in Indonesia are diagnosed with loco-regionally advanced disease[55]. Little is known about the treatment outcome of these NPC patients due to a lack of follow-up data.

The Global Cancer Atlas - World

C11: Nasopharynx | Incidence - Male

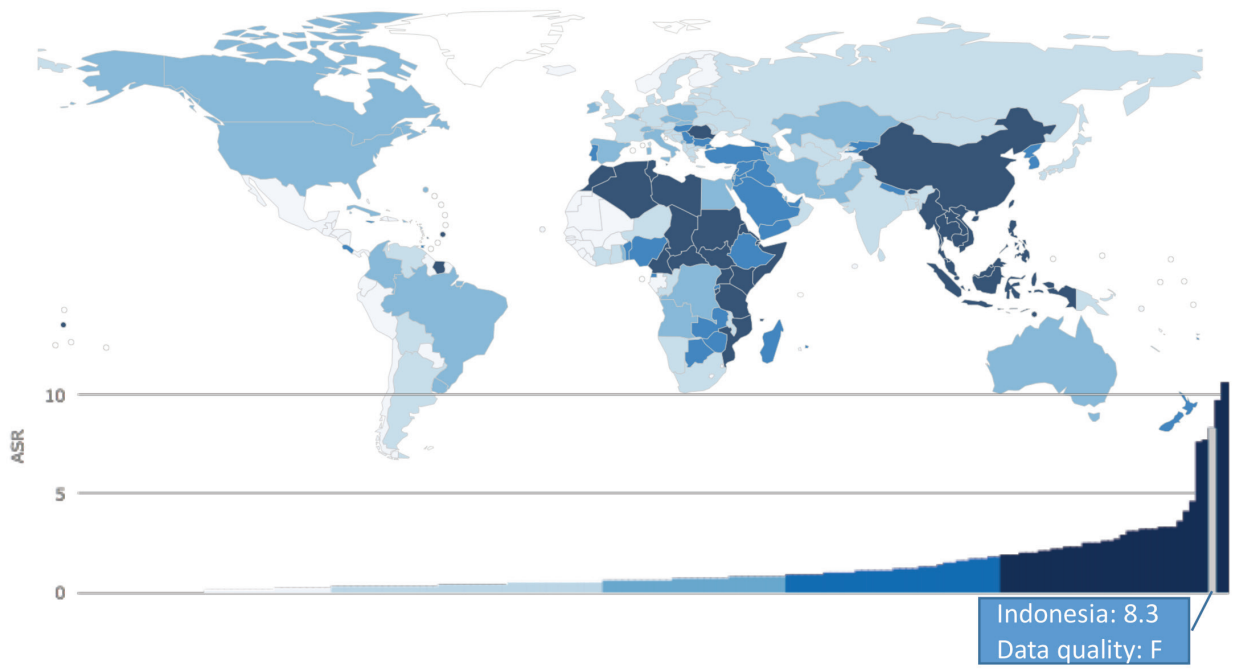

Figure 2 | NPC incidence worldwide in male

The estimated age-standardized incidence in males in Indonesia is 8.3 per 100 000. Data quality $(F)$ reflects there is only frequency data available and no national coverage. 


\section{Total patient delay}

This thesis focuses on Total Patient Delay and treatment outcome of patients diagnosed with NPC in Indonesia. It is preferable for cancer to be treated within the first month after diagnosis[56,57]. Any delay in cancer diagnosis and treatment could have a negative effect on the treatment outcome[58-62]. This delay has been a topic of concern for many years[63-66]. The 'General Model of Total Patient Delay' describes the different processes from the onset of symptoms until treatment starts. The three main intervals are: the interval between the onset of the symptoms until the first visit to a physician (patient delay), between the first visit until diagnosis (doctors delay), and between diagnosis and start of treatment (system delay) $[67,68]$. 


\section{Outline of this thesis}

The main objective of this thesis is to reveal the drawbacks in the management of diagnosis and treatment of NPC in Yogyakarta, Indonesia and their effect on treatment outcomes. Following more insight in the process, small interventions were introduced to minimize delay to diagnosis and improve treatment outcomes.

Chapter $\mathbf{2}$ of this thesis is one of the first publications focusing on the treatment results of NPC patients in Yogyakarta, Indonesia. The treatment outcomes reveal the urge of an improvement of the current referral, diagnosis and treatment system of the patients diagnosed with NPC.

Patient delay: In chapter $\mathbf{3}$ we investigate patients' behavior regarding the health care system in relation to possible patient delay. Chapter 4 reveals the correlation between the usage of traditional complementary and alternative medicine and a delay to diagnosis.

Doctors delay: Chapters 5, 6 and 7 focus on the delay in diagnosis caused by the limited knowledge of the health care workers working in the primary heath care centers. First we explored the general knowledge of the doctors in the primary health care centers (chapter 5), followed by different trainings programs for all health care workers working in the primary health care centers (chapter 6). In chapter 7 we investigate the effect of the implementation of the NPC awareness program in multiple centers. In addition, we were able to evaluate the long term effect of the training program.

System delay: Chapters $\mathbf{8}$ and $\mathbf{9}$ emphasize the current problems in radiotherapy for NPC patients. Main problems are the prolonged treatment time and the diagnosis to treatment interval.

Chapter 10: Here the results obtained in this thesis and future prospects are discussed. 


\section{References}

1. Ferlay J, soerjomataram I, Ervik M, Dikshit R, Eser S. GLOBOCAN 2012 v1. 0, Cancer Incidence and Mortality Worldwide: IARC CancerBase No. 11. 2013, International Agency for Research on Cancer. http://globocan. iarc. fr; 2014.

2. Torre LA, Siegel RL, Ward EM, Jemal A. Global Cancer Incidence and Mortality Rates and Trends--An Update. Cancer Epidemiology Biomarkers \& Prevention. American Association for Cancer Research; 2016;25: 16-27. doi:10.1158/1055-9965.EPI-15-0578

3. de Souza JA, Hunt B, Asirwa FC, Adebamowo C, Lopes G. Global Health Equity: Cancer Care Outcome Disparities in High-, Middle-, and Low-Income Countries. Journal of Clinical Oncology. American Society of Clinical Oncology; 2016;34: 6-13. doi:10.1200/ JCO.2015.62.2860

4. Bray F, Jemal A, Grey N, Ferlay J, Forman D. Global cancer transitions according to the Human Development Index (2008-2030): a population-based study. Lancet Oncol. 2012;13: 790-801. doi:10.1016/S1470-2045(12)70211-5

5. Boyle P, Levin B. International Agency of Research Against Cancer: World cancer report 2008. Lyon: Agency of Research Against Cancer: World Health Organization; 2008.

6. Daniels N. Equity of Access to Health Care: Some Conceptual and Ethical Issues. The Milbank Memorial Fund Quarterly Health and Society. 1982;60:51. doi:10.2307/3349700

7. Whitehead M. The concepts and principles of equity and health. Int J Health Serv. 1992;22: 429-445.

8. Levesque J-F, Harris MF, Russell G. Patient-centred access to health care: conceptualising access at the interface of health systems and populations. International Journal for Equity in Health. International Journal for Equity in Health; 2013;12: 1-1. doi:10.1186/14759276-12-18

9. Dye C, Boerma T, Evans D, Harries A, Lienhardt C. The World Health Report 2013. Geneva; 2013.

10. Barton MB, Jacob S, Shafiq J, Wong K, Thompson SR, Hanna TP, et al. Estimating the demand for radiotherapy from the evidence: a review of changes from 2003 to 2012. Radiother Oncol. 2014;112: 140-144. doi:10.1016/j.radonc.2014.03.024

11. Atun R, Jaffray DA, Barton MB, Bray F, Baumann M. Expanding global access to radiotherapy. The Lancet. 2015. doi:10.1016/s1470-2045(15)00222-3

12. The Advisory Group on increasing access to Radiotherapy Technology in low and middle income countries. In: cancer.iaea.org. 8 Feb 2012 pp. 1-8.

13. Coleman MP. Cancer survival: global surveillance will stimulate health policy and improve equity. Lancet. 2014;383: 564-573. doi:10.1016/S0140-6736(13)62225-4

14. Yu MC, Yuan J-M. Epidemiology of nasopharyngeal carcinoma. Seminars in Cancer Biology. 2002;12: 421-429. doi:10.1016/S1044-579X(02)00085-8

15. Parkin DM, Whelan SL, Ferlay J, Teppo L. Cancer incidence in five continents Vol. VIII. IARC scientific Publications; 2002.

16. Ferlay J, soerjomataram I, Ervik M, Dikshit R, Eser S, Mathers C, et al. Cancer Incidence and Mortality Worldwide: IARC CancerBase No. 11. In: globocan.iarc.fr.

17. Chang ET, Adami H-O. The enigmatic epidemiology of nasopharyngeal carcinoma. Cancer Epidemiol Biomarkers Prev. American Association for Cancer Research; 2006;15: 1765-1777. doi:10.1158/1055-9965.EPI-06-0353

18. Hildesheim A, Wang C-P. Genetic predisposition factors and nasopharyngeal carcinoma risk: a review of epidemiological association studies, 2000-2011: Rosetta Stone for NPC: genetics, viral infection, and other environmental factors. Seminars in Cancer Biology. 2012;22: 107-116. doi:10.1016/j.semcancer.2012.01.007

19. Adham M, Greijer AE, Verkuijlen SAWM, Hedy J, Fleig S, Rachmadi L, et al. EpsteinBarr virus DNA load in nasopharyngeal brushings and whole blood in nasopharyngeal 
carcinoma patients before and after treatment. Clin Cancer Res. 2013;19: 2175-2186. doi:10.1158/1078-0432.CCR-12-2897

20. Barnes L, Everson JW, Reichart P, Sidransky D. WHO histological classification of tumours. Lyon; 2005.

21. Guo X, Johnson RC, Deng H, Liao J, Guan L, Nelson GW, et al. Evaluation of nonviral risk factors for nasopharyngeal carcinoma in a high-risk population of Southern China. Int J Cancer. 2009;124: 2942-2947. doi:10.1002/ijc.24293

22. Ji X, Zhang W, Xie C, Wang B, Zhang G, Zhou F. Nasopharyngeal carcinoma risk by histologic type in central China: impact of smoking, alcohol and family history. Int J Cancer. 2011;129: 724-732. doi:10.1002/ijc.25696

23. Jia W-H, Qin H-D. Non-viral environmental risk factors for nasopharyngeal carcinoma: A systematic review. Seminars in Cancer Biology. Elsevier Ltd; 2012;22: 117-126. doi:10.1016/j.semcancer.2012.01.009

24. Jia W-H, Feng B-J, Xu Z-L, Zhang X-S, Huang P, Huang L-X, et al. Familial risk and clustering of nasopharyngeal carcinoma in Guangdong, China. Cancer. 2004;101: 363-369. doi:10.1002/cncr.20372

25. Jia W-H, Luo X-Y, Feng B-J, Ruan H-L, Bei J-X, Liu W-S, et al. Traditional Cantonese diet and nasopharyngeal carcinoma risk: a large-scale case-control study in Guangdong, China. BMC Cancer. 2010;10: 446. doi:10.1186/1471-2407-10-446

26. Ren Z-F, Liu W-S, Qin H-D, Xu Y-F, Yu D-D, Feng Q-S, et al. Effect of family history of cancers and environmental factors on risk of nasopharyngeal carcinoma in Guangdong, China. Cancer Epidemiol. 2010;34: 419-424. doi:10.1016/j.canep.2010.04.011

27. Gallicchio L, Matanoski G, Tao XG, Chen L, Lam TK, Boyd K, et al. Adulthood consumption of preserved and nonpreserved vegetables and the risk of nasopharyngeal carcinoma: A systematic review. Int J Cancer. 2006;119: 1125-1135. doi:10.1002/ijc.21946

28. Armstrong RW, Imrey PB, Lye MS, Armstrong MJ, Yu MC, Sani S. Nasopharyngeal carcinoma in Malaysian Chinese: salted fish and other dietary exposures. Int I Cancer. 1998;77: 228-235.

29. Ning JP, Yu MC, Wang QS, Henderson BE. Consumption of salted fish and other risk factors for nasopharyngeal carcinoma (NPC) in Tianjin, a low-risk region for NPC in the People's Republic of China. J Natl Cancer Inst. 1990;82: 291-296.

30. Hildesheim A, West S, DeVeyra E, De Guzman MF, Jurado A, Jones C, et al. Herbal medicine use, Epstein-Barr virus, and risk of nasopharyngeal carcinoma. Cancer Res. 1992;52: 3048-3051.

31. Armstrong RW, Armstrong MJ, Yu MC, Henderson BE. Salted fish and inhalants as risk factors for nasopharyngeal carcinoma in Malaysian Chinese. Cancer Res. 1983;43: 2967-2970.

32. Vaughan TL, Stewart PA, Teschke K, Lynch CF, Swanson GM, Lyon JL, et al. Occupational exposure to formaldehyde and wood dust and nasopharyngeal carcinoma. Occup Environ Med. 2000;57: 376-384.

33. Yang XR, Diehl S, Pfeiffer R, Chen C-J, Hsu W-L, Dosemeci M, et al. Evaluation of risk factors for nasopharyngeal carcinoma in high-risk nasopharyngeal carcinoma families in Taiwan. Cancer Epidemiol Biomarkers Prev. 2005;14: 900-905. doi:10.1158/10559965.EPI-04-0680

34. Fachiroh J, Sangrajrang S, Johansson M, Renard H, Gaborieau V, Chabrier A, et al. Tobacco consumption and genetic susceptibility to nasopharyngeal carcinoma (NPC) in Thailand. Cancer Causes Control. 2012;:-. doi:10.1007/s10552-012-0077-9

35. Cheng YJ, Hildesheim A, Hsu MM, Chen IH, Brinton LA, Levine PH, et al. Cigarette smoking, alcohol consumption and risk of nasopharyngeal carcinoma in Taiwan. Cancer Causes Control. 1999;10: 201-207. 
36. Xu F-H, Xiong D, Xu Y-F, Cao S-M, Xue W-Q, Qin H-D, et al. An epidemiological and molecular study of the relationship between smoking, risk of nasopharyngeal carcinoma, and Epstein-Barr virus activation. J Natl Cancer Inst. 2012;104: 1396-1410. doi:10.1093/jnci/djs320

37. Chen L, Gallicchio L, Boyd-Lindsley K, Tao X, Robinson K, Lam TK, et al. Alcohol Consumption and the Risk of Nasopharyngeal Carcinoma: A Systematic Review. Nutrition \& Cancer. 2009;61: 1-15. doi:10.1080/01635580802372633

38. Marron M, Boffetta P, Zhang ZF, Zaridze D, Wunsch-Filho V, Winn DM, et al. Cessation of alcohol drinking, tobacco smoking and the reversal of head and neck cancer risk. International Journal of Epidemiology. 2010;39: 182-196. doi:10.1093/ije/dyp291

39. Wei WI, Sham JST. SeminarNasopharyngeal carcinoma. Lancet. 2005;365: 2041-2054. doi:10.1016/S0140-6736(05)66698-6

40. Wei WI, Kwong DLW. Current management strategy of nasopharyngeal carcinoma. Clin Exp Otorhinolaryngol. 2010;3: 1-12. doi:10.3342/ceo.2010.3.1.1

41. Lee AWM, Lin JC, Ng WT. Current Management of Nasopharyngeal Cancer. YSRAO. Elsevier Inc; 2012;22: 233-244. doi:10.1016/j.semradonc.2012.03.008

42. Xiang Y-Q, Lv X, Xia W-X, Ke L-R, Yang J, Qiu W-Z, et al. Comparison of the short-term efficacy between docetaxel plus carboplatin and 5-fluorouracil plus carboplatin in locoregionally advanced nasopharyngeal carcinoma. OTT. Dove Press; 2016; Volume 9: 5123-5131. doi:10.2147/OTT.S103729

43. Ferlay J, Soerjomataram I, Dikshit R, Eser S, Mathers C, Rebelo M, et al. Cancer incidence and mortality worldwide: sources, methods and major patterns in GLOBOCAN 2012. Int J Cancer. 2015;136: E359-86. doi:10.1002/ijc.29210

44. Lam K-O, Lee AWM, Choi C-W, Sze HCK, Zietman AL, Hopkins KI, et al. Global Pattern of Nasopharyngeal Cancer: Correlation of Outcome With Access to Radiation Therapy. Int J Radiat Oncol Biol Phys. 2016;94: 1106-1112. doi:10.1016/j.ijrobp.2015.11.047

45. Structutal Policy Country Notes Indonesia. 2013 Feb pp. 1-22.

46. Rokx C, Giles J, Satriawan E, Marzoeki P, Harimurti P, Yavuz AE. New Insights into the Provision of Health Services in Indonesia: A Health Workforce Study - ISBN: 9780821382981. 2010;: 1-160.

47. Plianbangchang S. WHO Country Cooperation Strategy 2007-2011 Indonesia. 2007. Medeiros R, editor. Ref Type: Data File. 2012. doi:10.1371/journal.pone.0032756

48. world health Organization. World health statistics 2013. Geneva: World Health Organization.

49. Widjaja M, Simanjuntak RA. "Social protection in East Asia - Current state and challenges," ERIA Research Project Report 2010, No. 9.

50. Satriana S, Schmitt V. Towards a nationally defined social protection floor in Indonesia. 2012. pp. 1-94.

51. Ripe for investment: the Indonesian health care industry post introduction of universal health coverage. 2015 Jun pp. 1-76.

52. Gondhowiardjo SA, Prajogi GB, Sekarutami SM. History and growth of radiation oncology in Indonesia. Biomed Imaging Interv J. 2008;4. doi:10.2349/biij.4.3.e42

53. Bentzen SM, Heeren G, Cottier B, Slotman B, Glimelius B, Lievens Y, et al. Towards evidence-based guidelines for radiotherapy infrastructure and staffing needs in Europe: the ESTRO QUARTS project. Radiotherapy and Oncology. 2005;75: 355-365. doi:10.1016/j.radonc.2004.12.007

54. MD DER, PhD JI, MD YA, MSc YP, MD PS, PhD MB, et al. Radiotherapy capacity in European countries: an analysis of the Directory of Radiotherapy Centres (DIRAC) database. Lancet Oncology. Elsevier Ltd; 2013;14: e79-e86. doi:10.1016/S1470-2045(12)70556-9 
55. Adham M, Kurniawan AN, Muhtadi Al, Roezin A, Hermani B, Gondhowiardjo S, et al. Nasopharyngeal carcinoma in Indonesia: epidemiology, incidence, signs, and symptoms at presentation. Chin J Cancer. 2012;:-. doi:10.5732/cjc.011.10328

56. Jensen AR, Nellemann HM, Overgaard J. Tumor progression in waiting time for radiotherapy in head and neck cancer. Radiother Oncol. 2007;84: 5-10. doi:10.1016/j. radonc.2007.04.001

57. Webb CJ, Benton J, Tandon S, Jones TM, Roland NJ. Head and neck cancer waiting times. Clin Otolaryngol. Blackwell Publishing Ltd; 2007;32: 293-296. doi:10.1111/j.13652273.2007.01490.x

58. Afzelius P, Zedeler K, Sommer H, Mouridsen HT, Blichert-Toft M. Patient"s and doctor"s delay in primary breast cancer. Prognostic implications. Acta Oncol. 1994;33: 345-351.

59. Richards MA, Westcombe AM, Love SB, Littlejohns P, Ramirez AJ. Influence of delay on survival in patients with breast cancer: a systematic review. The Lancet. 1999;353: 1119-1126.

60. Jensen AR, Mainz J, Overgaard J. Impact of delay on diagnosis and treatment of primary lung cancer. Acta Oncol. 2002;41: 147-152.

61. Fortin A, Bairati I, Albert M, Moore L, Allard J, Couture C. Effect of treatment delay on outcome of patients with early-stage head-and-neck carcinoma receiving radical radiotherapy. Radiation Oncology Biology. 2002;52: 929-936.

62. Chen P-C, Liu W-S, Huang W-L, Wu C-J, Yang C-C, Lee C-C. The impact of time factors on overall survival in patients with nasopharyngeal carcinoma: a population-based study. Radiation Oncology. Radiation Oncology; 2016;: 1-7. doi:10.1186/s13014-016-0638-2

63. Pack GT, Gallo JS. The Culpability for Delay in the Treatment of Cancer. The American Journal of Cancer. American Association for Cancer Research Journals; 1938;33: 443462. doi:10.1158/ajc.1938.443

64. Antonovsky A, Hartman H. Delay in the Detection of Cancer: A Review of the Literature. Health Education \& Behavior. Health Education \& Behavior; 1974;2: 98-128.

65. Andersen BL, Cacioppo JT. Delay in seeking a cancer diagnosis: delay stages and psychophysiological comparison processes. Br J Soc Psychol. 1995;34 ( Pt 1): 33-52.

66. Hansen RP, Olesen F, Sørensen HT, Sokolowski I, Søndergaard J. Socioeconomic patient characteristics predict delay in cancer diagnosis: a Danish cohort study. BMC Health Serv Res. BioMed Central; 2008;8: 49. doi:10.1186/1472-6963-8-49

67. Olesen F, Hansen RP, Vedsted P. Delay in diagnosis: the experience in Denmark. Br J Cancer. Nature Publishing Group; 2009;101: S5-S8. doi:10.1038/sj.bjc.6605383

68. Hansen RP, Vedsted P, Sokolowski I, Søndergaard J, Olesen F. Time intervals from first symptom to treatment of cancer: a cohort study of 2,212 newly diagnosed cancer patients. BMC Health Serv Res. BioMed Central; 2011;11: 284. doi:10.1186/1472-6963$11-284$ 


\section{Chapter 2}

\section{Primary treatment results of nasopharyngeal carcinoma}

in Yogyakarta, Indonesia

MA. Wildeman

R. Fles

C. Herdini

SR. Indrasari

AD. Vincent

M. Tjokronagoro

SD. Stoker

J. Kurnianda

KW. Taroeno-Hariadi

O. Hamming-Vrieze

JM. Middeldorp

B. Hariwiyanto

SM. Haryana

IB. Tan

PLoS One, 2013 May vol.8 p. e63706 


\section{Abstract}

Introduction: Nasopharyngeal Carcinoma (NPC) is a major health problem in southern and eastern Asia. In Indonesia NPC is the most frequent cancer in the head and neck area. NPC is very sensitive to radiotherapy resulting in 3-year disease-free and overall survival of approximately $70 \%$ and $80 \%$, respectively. Here we present routine treatment results in a prospective study on NPC in a top referral; university hospital in Indonesia.

Methods: All NPC patients presenting from September 2008 till January 2011 at the ear, nose and throat (ENT) department of the Dr. Sardjito General Hospital, Universitas Gadjah Mada, Yogyakarta, Indonesia, were possible candidates. Patients were included if the biopsy was a histological proven NPC without distant metastasis and were assessed during counselling sessions prior to treatment, as being able to complete the entire treatment.

Results: In total 78 patients were included for treatment analysis. The median time between diagnosis and start of radiotherapy is 120 days. Forty-eight (62\%) patients eventually finished all fractions of radiotherapy. The median duration of the radiotherapy is 62 days for 66 Gy. Median overall survival is 21 months ( $95 \% \mathrm{Cl}$ 18-35) from day of diagnosis.

Conclusion: The results presented here reveal that currently the treatment of NPC at an Indonesian hospital is not sufficient and cannot be compared to the treatment results in literature. Main reasons for these poor treatment results are (1) a long waiting time prior to the start of radiotherapy, (2) the extended overall duration of radiotherapy and (3) the advanced stage of disease at presentation. 


\section{Introduction}

Cancer has become a leading cause of death and morbidity in low and middleincome countries. While this has been recognized for at least twenty years, healthcare systems in these countries often cannot deliver the prevention and care needed to overcome this challenge [1-4]. Most publications that address this issue are based on cancer incidence and barely report on treatment results and survival. The main reason for this is the lack of appropriate data collection in developing countries. There is a clear need for improved cancer control systems in developing country settings [5]. Recently we have introduced a Clinical Trial Data Management service (CTDMS) to monitor treatment results of Nasopharyngeal Carcinoma (NPC) in a university hospital setting in Yogyakarta, Indonesia [6].

In southern and eastern Asia NPC is a major health problem. In Indonesia NPC is the most frequent cancer in the head and neck area and ranks as the 4th most common tumour found in males. The undifferentiated histological subtype, NPC WHO III, is the most prevalent NPC type in South-East Asia and Indonesia. This type of cancer is causally associated with the Epstein-Barr virus (EBV) [7]. The incidence is estimated 6 per 100,000, leading to 12,000 new cases per year [8-10]. Due to the insufficient national cancer registration system, the actual number is most probably much higher. NPC is very sensitive to radiotherapy at early stage (stage I-II), but this type of treatment is not generally available for many patients in developing countries and unfortunately can induce complications after treatment if not properly administered. Since the location of the tumour has a close contact with the base of skull, the brain stem and spinal cord, radiation is hindered by dose limitations on these organs at risk. For advanced NPC (stage III-IV), standard-care is concurrent chemo radiation therapy with high-dose radiation combined with cisplatin-based regimens. This treatment approach may result in 3-year diseasefree and overall survival of approximately $70 \%$ and $80 \%$, respectively $[11,12]$. A recent meta-analysis confirmed the clinical benefit of concurrent chemo radiation therapy (CCRT) compared with radiation alone (RT) in the treatment of stage III and IV NPC in endemic areas [13]. Nearly all treatment results on NPC presented in the literature derive from top-end hospitals and clinical trial settings. Here we present a prospective study on routine treatment results of NPC at a university hospital in Indonesia. 


\section{Patients and Methods}

\section{Patients Eligibility}

All NPC patients presenting from September 2008 till January 2011 at the ear, nose and throat (ENT) department of the Dr Sardjito General Hospital, Universitas Gadjah Mada, Yogyakarta, Indonesia, were analysed. Patients were examined by CT-scan, chest X-ray, ultrasound of the abdomen and bone survey. Patients were included in the study if the biopsy was a histological proven NPC without distant metastasis and were assessed during counselling sessions prior to treatment, as being able to complete the entire treatment. Tissue analysis was performed at the pathology department of the Dr Sardjito hospital; WHO- histological classification was done according to the UICC 2002 criteria and EBV-encoded small RNA (EBER) staining was done with commercial reagents according to the manufacturer's instructions (Dako, PNA-kit). Other inclusion criteria were measurable disease and a curative intent treatment plan. Patients were not eligible if they had NPC as a second malignancy.

\section{Treatment}

Due to different health insurances of the patients, different treatment regimens have been administered. All patients received 66-70 Gray (Gy) (2 Gy per fraction for 5 days) external beam radiotherapy and in all cases treatment planning was 2 dimen- sional. The type of chemotherapy and the number of courses, and whether applied concurrent or as neo-adjuvant, was adjusted for the type of insurance and waiting time for radiotherapy at that time. Options of chemotherapy include 3-4 cycles cisplatinum- based induction chemotherapy and chemo-concurrent radiother- apy (CCRT). In induction setting either cisplatin and 5 fluorouracil (5 FU) (PF regimen) or combination of docetaxel, cisplatin and 5 FU (TPF regimen) are administered. Radiotherapy is carried out 1 month after induction chemotherapy. During the course of radiotherapy some patients also received a 6-7 cycles of weekly carboplatin AUC 2. In the setting of CCRT, a weekly 6-7 cycles of low-dose platinum $(40 \mathrm{mg} / \mathrm{m} 2)$ cooperated with radio- therapy. Due to the poor physical condition of some patients with a advanced stage of disease, it was not possible to treat these patients with CCRT Rafter neoadjuvant chemotherapy. 


\section{Therapy Assessment}

Eight weeks after treatment the response was monitored by CT- scan, chest X-ray, ultrasound of the abdomen and bone survey. In case of histological proven local persistent or recurrent disease patients were offered to be treated with photodynamic therapy PDT). In case of persistent neck lymph nodes patient were treated with a modified radical neck dissection.

\section{Follow Up}

All patients had a regular follow-up schedule consisting of 3 monthly visits during the first two years after radiotherapy. In case of suspicion for tumour recurrence radiological examinations were performed. In case of a local or regional recurrence patients were treated with photodynamic therapy (PDT) with separate treatment of the neck.

\section{Photodynamic Therapy (PDT)}

Drug administration of Foscan ${ }^{\circledR}$, light administration and treatment procedures of the PDT are completely similar to and described previously in Nyst et al 2012 [14]. Patients received the dose level and the drug light interval recommended for the treatment of patients with squamous-cell carcinoma of the head and neck. These parameters are drug dose, $0.15 \mathrm{mg} / \mathrm{kg}$ Foscan ${ }^{\circledR}$; drug-light interval: 48 or 96 hours; light dose: $20 \mathrm{~J} / \mathrm{cm} 2$.

\section{Statistical Methods}

The association between treatment type (CCRT vs other) and response (CR vs nonCR) was assessed using the univariate Fisher exact test and multivariable logistic regression, adjusting for sex (male vs. female), type of insurance (poor vs. government vs. self-finance) and AJCC stage (I-II vs III vs IV). In this analysis patients not receiving treatment were excluded, and patients for which no tumor assessment was available were assumed to be non- responders. A sensitivity analysis is performed excluding patients for which no tumor assessment was available. In these analyses the level of significance was set at 0.05. Overall (OS) and disease free survival (DFS) durations were calculated from date of diagnosis of NPC. For OS duration was until date of death from any cause or date, while for DFS duration was until development of recurrence or death from any cause. In both cases in the absence of an event patients 
were censored at the date of last contact. The Kaplan- Meier technique was used to estimate survival. All analyses were performed using the R-software version 2.15.2.

\section{Results}

In total 188 patients presented with NPC during September 2008 till January 2011. Seventy-eight patients were included for treatment analysis, as they were considered able to complete treatment protocol based on intake counselling. The median age of the patients was 49 years (range 17-78), 50 patients were male and 28 were female patients. Only 2 patients had early stage disease at entry being stage I or IIA, and 76 patients presented with loco-regional advanced stage IIB and higher. All 78 patients had an EBER-positive, histological proven NPC and were WHO type III. Reasons for exclusion were insufficient funding to afford a curative treatment ( $n=27 ; 25 \%$ ), no sufficient funding to afford staging procedures ( $n=24,22 \%$ ), no pathology available $(n=24,22 \%)$, decided to go for traditional treatments $(n=16$, $15 \%)$, eleven patients presented with distant metastasis at diagnosis ( $n=11,10 \%)$, six patients due to logistic reasons (7\%) and two refused the protocol (2\%). Patient characteristics are listed in table 1 . Types of chemo- therapy regimen administered are listed in table 2.

Table 1 | Patient characteristics and type of treatment

\begin{tabular}{|c|c|c|c|c|c|c|}
\hline & NONE* & $\begin{array}{l}\text { CONCURRENT } \\
+\mathrm{RT}\end{array}$ & $\begin{array}{l}\text { NEO ADJUVANT } \\
+ \text { CONCURRENT } \\
+ \text { RT }\end{array}$ & $\begin{array}{l}\text { NEO } \\
\text { ADJUVANT } \\
+ \text { RT }\end{array}$ & RT & TOTAL \\
\hline & $N=8$ & $N=18$ & $N=9$ & $N=41$ & $N=2$ & $N=78$ \\
\hline \multicolumn{7}{|l|}{ Age } \\
\hline Median & 48 & 49 & 45 & 51 & 38 & 49 \\
\hline (Range) & $(41-72)$ & $(17-73)$ & $(27-54)$ & $(23-78)$ & $(29-47)$ & $(17-78)$ \\
\hline \multicolumn{7}{|l|}{ Gender } \\
\hline $\mathbf{F}$ & $1(12 \%)$ & $8(44 \%)$ & $2(22 \%)$ & $16(39 \%)$ & $1(50 \%)$ & 28 ( $36 \%)$ \\
\hline$M$ & $7(88 \%)$ & $10(56 \%)$ & 7 ( 78\%) & 25 (61\%) & $1(50 \%)$ & 50 ( 64\%) \\
\hline \multicolumn{7}{|l|}{ T stage } \\
\hline $\mathrm{T} 1$ & $2(25 \%)$ & $2(11 \%)$ & 1 ( $11 \%)$ & 10 ( $24 \%)$ & $1(50 \%)$ & $16(21 \%)$ \\
\hline T2a & 1 ( $12 \%)$ & $2(11 \%)$ & $0(0 \%)$ & $5(12 \%)$ & $0(0 \%)$ & $8(10 \%)$ \\
\hline $\mathrm{T} 2 \mathrm{~b}$ & 0 ( 0\%) & $4(22 \%)$ & $1(11 \%)$ & $5(12 \%)$ & $1(50 \%)$ & $11(14 \%)$ \\
\hline T3 & $1(12 \%)$ & 7 ( 39\%) & 7 ( 78\%) & 17 ( 41\%) & 0 ( $0 \%)$ & 32 ( 41\%) \\
\hline T4 & $4(50 \%)$ & $3(17 \%)$ & $0(0 \%)$ & $4(10 \%)$ & $0(0 \%)$ & $11(14 \%)$ \\
\hline
\end{tabular}




\begin{tabular}{|c|c|c|c|c|c|c|}
\hline & NONE* & $\begin{array}{l}\text { CONCURRENT } \\
+\mathrm{RT}\end{array}$ & $\begin{array}{l}\text { NEO ADJUVANT } \\
+ \text { CONCURRENT } \\
+ \text { RT }\end{array}$ & $\begin{array}{l}\text { NEO } \\
\text { ADJUVANT } \\
+ \text { RT }\end{array}$ & RT & TOTAL \\
\hline \multicolumn{7}{|l|}{ N stage } \\
\hline NO & $0(0 \%)$ & $1(6 \%)$ & $2(22 \%)$ & $5(12 \%)$ & $1(50 \%)$ & $9(12 \%)$ \\
\hline N1 & $3(38 \%)$ & $6(33 \%)$ & $1(11 \%)$ & $4(10 \%)$ & $1(50 \%)$ & 15 ( $19 \%)$ \\
\hline N2 & $0(0 \%)$ & $8(44 \%)$ & $2(22 \%)$ & $12(29 \%)$ & $0(0 \%)$ & $22(28 \%)$ \\
\hline N3a & $2(25 \%)$ & $3(17 \%)$ & $3(33 \%)$ & 15 ( $37 \%)$ & $0(0 \%)$ & 23 ( $29 \%)$ \\
\hline N3b & $3(38 \%)$ & $0(0 \%)$ & $1(11 \%)$ & $5(12 \%)$ & $0(0 \%)$ & $9(12 \%)$ \\
\hline \multicolumn{7}{|l|}{ AJCC stage } \\
\hline I & $0(0 \%)$ & $0(0 \%)$ & $0(0 \%)$ & $0(0 \%)$ & $1(50 \%)$ & $1(1 \%)$ \\
\hline IIA & $0(0 \%)$ & $0(0 \%)$ & $0(0 \%)$ & $1(2 \%)$ & $0(0 \%)$ & $1(1 \%)$ \\
\hline IIB & $0(0 \%)$ & $3(17 \%)$ & $1(11 \%)$ & $1(2 \%)$ & $1(50 \%)$ & $6(8 \%)$ \\
\hline III & $0(0 \%)$ & $9(50 \%)$ & $4(44 \%)$ & $15(37 \%)$ & $0(0 \%)$ & $28(36 \%)$ \\
\hline IVA & $3(38 \%)$ & $3(17 \%)$ & $0(0 \%)$ & $3(7 \%)$ & $0(0 \%)$ & $9(12 \%)$ \\
\hline IVB & $5(62 \%)$ & $3(17 \%)$ & $4(44 \%)$ & $21(51 \%)$ & $0(0 \%)$ & $33(42 \%)$ \\
\hline \multicolumn{7}{|c|}{ Type of insurance } \\
\hline $\begin{array}{l}\text { Government } \\
\text { insurance }\end{array}$ & $0(0 \%)$ & $1(6 \%)$ & $3(33 \%)$ & $1(2 \%)$ & $1(50 \%)$ & $6(8 \%)$ \\
\hline Poor insurance & 7 ( $88 \%)$ & 17 ( 94\%) & $3(33 \%)$ & 39 ( 95\%) & $0(0 \%)$ & $66(85 \%)$ \\
\hline Self-finance & $1(12 \%)$ & $0(0 \%)$ & $3(33 \%)$ & $1(2 \%)$ & $1(50 \%)$ & $6(8 \%)$ \\
\hline
\end{tabular}

*The 8 patients who haven't received any treatment died before the start of treatment.

Table 2 | Type of chemotherapy administered

\begin{tabular}{|c|c|c|c|c|}
\hline & Concurrent + RT & $\begin{array}{l}\text { Neo adjuvant + } \\
\text { concurrent + RT }\end{array}$ & Neo adjuvant + RT & Total \\
\hline & $N=18$ & $N=9$ & $N=40$ & $N=78$ \\
\hline \multicolumn{5}{|c|}{ Neo adjuvant chemotherapy } \\
\hline Carboplatin, 5 fu & & & $2(5 \%)$ & $2(3 \%)$ \\
\hline Cisplatin, $5 \mathrm{fu}$ & & & $36(88 \%)$ & $36(46 \%)$ \\
\hline Docetaxel, cisplatin, 5 fu & & $9(100 \%)$ & $1(2 \%)$ & $10(13 \%)$ \\
\hline Paclitaxel, cisplatin & & & $1(2 \%)$ & $1(1 \%)$ \\
\hline \multicolumn{5}{|l|}{ Concurrent chemotherapy } \\
\hline Carboplatin & $1(6 \%)$ & $7(78 \%)$ & & $8(10 \%)$ \\
\hline Cisplatin & 17 ( 94\%) & $1(11 \%)$ & & $18(23 \%)$ \\
\hline
\end{tabular}




\section{Radiotherapy}

The median time between diagnosis and start of radiotherapy is 120 days (range 13-500). Twelve (15\%) patients died before the start of radiotherapy due to disease progression or in two cases due to side effects of the neo-adjuvant chemotherapy treatment. Four patients did not return for radiotherapy due to concern about the side effects after the neo-adjuvant chemotherapy and two patients had, despite counselling, insufficient funding to be treated with radiotherapy.

Forty-eight (62\%) patients eventually finished all fractions of radiotherapy. The median duration of the radiotherapy is 62 days (range 46-140 days) for 66 Gy.

\section{Response to Treatment}

Twenty three (29\%) patients died of disease progression before treatment response could be assessed. Five patients dropped out due to insufficient funding, 5 stopped treatment early due to side effects and 6 stopped treatment due to concern for side effects. Eventually 39 (50\%) patients had a treatment response measure- ment 8 weeks after treatment. Twenty-three (29\%) achieved a complete response. Ten patients experienced local persistent disease, in two patients regional persistent disease was found and two patients developed distant metastasis. Two patients had local and regional persistent disease, one of them also developed distant metastasis. The improvement in response rate after receiving concurrent chemo-radiotherapy was significant $(p=0.002)$. Ad- justing for sex, insurance type and AJCC stage did not change this result ( $p=0.001$ ), nor did the exclusion of patients non-evaluable for response (univariate $p=0.02$; multivariable $p=0.02$ ).

\section{Survival}

Median overall survival is 21 months (95\% Cl: 18-35) from day of diagnosis. The median disease free survival from day of diagnosis is 20 months (95\% Cl: 18-24). In figure $1 \mathrm{~A}$ and figure 1B Kaplan Meijer curves present the survival probability for overall survival and disease free survival respectively. 
OS

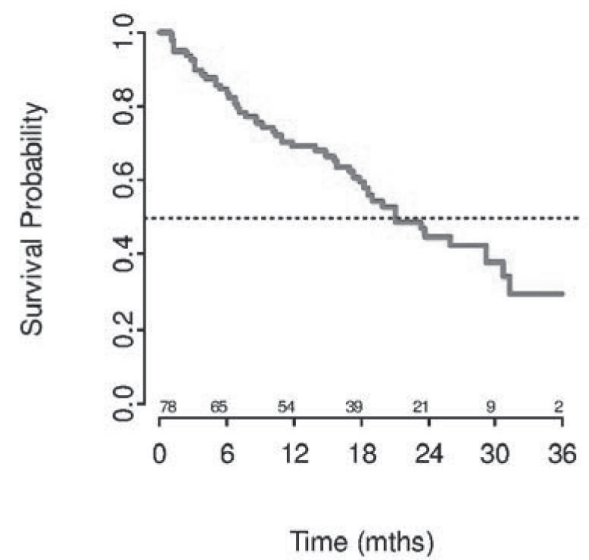

DFS

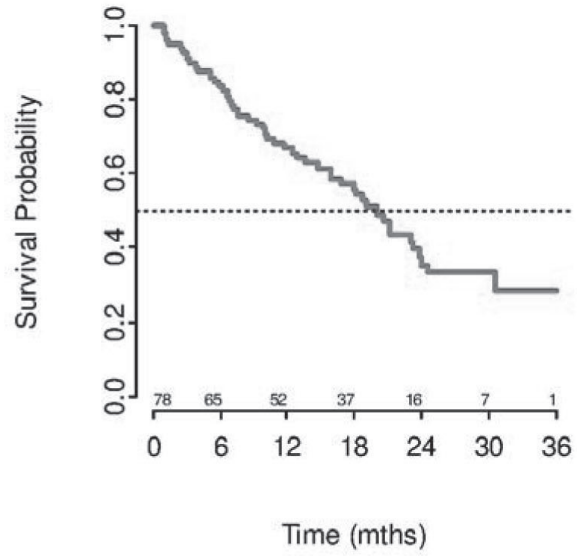

Figure 1A and figure 1B | Kaplan Meijer curves present the survival probability for overall survival and disease free survival respectively.

\section{Photodynamic Therapy}

Six patients with local persistent disease, which was discovered during therapy assessment after fulfilment of the regular treatment, and one patient with a local recurrence, discovered during follow up, has been treated with PDT. All patients had a complete response 12 weeks after illumination, three patients developed regional recurrences and one patient died due to the regional recurrence.

\section{Discussion}

The results presented here reveal that currently the treatment of NPC at an Indonesian academic hospital is not sufficient and cannot be compared to the treatment results in literature $[11,12]$. Of the patients evaluable for response only $29 \%$ had a complete response directly after treatment, with the median overall survival being 21 months after diagnosis. Main reasons for these poor treatment results are (1) a long waiting time prior to the start of radiotherapy, (2) the extended overall duration of radiotherapy and (3) the advanced stage of disease at presentation.

Cancer is becoming a growing problem in low and middle- income countries. Since it is ill-defined how many of the patients actually make it to the hospital and receive 
a biopsy that is registered, the actual NPC incidence remains unclear. NPC is the commonest head and neck cancer in Indonesia with most patients presenting with an advanced stage of disease which poses a heavy burden on the population. A major problem is that patients cannot afford treatment or are afraid of treatment toxicity, causing them to refrain from treatment or seek alternative options. This resulted in nearly $61 \%$ of the excluded NPC patients being non-compliant with the inclusion criteria for this study. However, the NPC treatment results presented here reveal an additional problem, this being the limited capacity for proper treatment. In 2008 there were 18 linear accelerators and 17 Cobalt-60 teletherapy machines available in Indonesia with a population of 229 million, nevertheless 6 of them were under commission. Resulting in 0.13 accelerator per million inhabitants [15]. This in comparison to Europe were 5.5 accelerator is available per million inhabitants in the high, 3.5 per million in the medium and 2 per million in the low resource countries [16]. The recommended number of treatment units per population differs widely, in Europe guidelines of 25 low to high income countries recommended on average 5.9 per million [17].

Although Indonesia is a rising economy, meeting these criteria will not be feasible on short term. Expanding radiotherapy facilities is a time and money-consuming project. For building a new radiotherapy facility and have it installed for treatment the average time is approximately 5 years. Expansion of staffing (radiation oncologists, physicists, technologists) takes even longer, since proper education and training is necessary [16].

When patients with poor insurance in Yogyakarta finally complete diagnosis and imaging to stage the disease, they have to wait on average 4 months to start radiotherapy treatment. At this time $13 \%$ have already succumbed to disease progression. Despite optimal counselling in this study cohort, five patients who started treatment did not finish the treatment properly because they could not afford the costs of the entire treatment. Importantly, we noted that most patients who eventually started treatment received insufficient radiotherapy treatment. Optimally, a total dose of 66 to 70 Grey should be given in 33 to 35 fractions and the best therapy response is achieved when the total dose is administered in 45 to 47 days. Every day the radiotherapy is postponed a loss of the effective dose occurs. This will influence the treatment success to a great extent $[18,19]$. 
The median duration of radiotherapy treatment in this study was 62 days. This prolonged treatment time together with the 2 -dimensional radiotherapy technique based on CT imaging only (i.e. not using MRI to assess disease extent) are the main causes of the poor response rate $[20,21]$. In part this prolonged treatment duration is often caused by the radiotherapy facility being intermittently operational, due to poor maintenance of the equipment. Other causes for this delay may be due to poor efficiency in administration and communication at and between hospital departments and poor patient and doctor compliance to protocols and timelines. Further research is required to reveal these causes and can eventually contribute to improve overall treatment time.

The late stage of NPC at presentation in the hospital is another unfavourable prognostic factor. One possible reason for the high percentage of patients with advanced NPC could be due to poor diagnosis by general practitioners (GP) and thereby a delay in referral. In our previous study we assessed the knowledge on NPC of the GPs working in the Primary Health Care Centres in the Yogyakarta region [22]. Our results indicate that the knowledge of GPs is insufficient, with many of them not being aware of the high incidence of NPC in their region.

In Malaysia prior studies have proved that the lack of awareness and knowledge of primary health care workers is one of the main reasons for delayed diagnosis [23]. Given that presenting stage is the most important prognostic factor, appropriate training of GPs is critical. The relevance of adequate referral by GPs for head and neck carcinomas has been shown by Alho et al. [24], who found that $20 \%$ of 221 patients, subsequently to being diagnosed with head and neck carcinoma, were initially sent home without referral. The risk of death in this group was significantly higher when compared with the patients who were immediately referred or received a follow up appointment.

The same group from Finland, has also shown that the time between GP referral and final diagnosis is a significant factor in patient outcome in other head and neck cancer [25]. Long delay in primary care resulted in a significantly worse prognosis in patients with laryngeal carcinoma [26].

All patients analyzed in the presented study had WHO type III positive NPC. Prior studies have shown that EBV-related markers can be used for screening and prognostic monitoring. These markers include EBV (IgA) serology and EBV-DNA load 
in nasopharyngeal brushings or blood. NPC patients have characteristic aberrant IgG and IgA antibody reactivity to several EBV encoded antigens as well as increased EBV-DNA in blood plasma, derived from shed (apoptotic) tumor fragments into the circulation. Increased IgA antibody levels are found against early antigen (EA), viral capsid antigen (VCA) and the latent Epstein- Barr nuclear antigen 1 (EBNA1) as well as inhibitory antibodies to the EBV specific DNAse $[27,28]$. These antibody responses against defined viral antigens are the basis of a proposed screening test for NPC in high-risk populations [29-31]. Recent insight in the molecular basis and diversity of anti EBV IgA and IgG responses allowed the development of more defined serological tools [32-36]. Importantly, such initial NPC-risk analysis can be done in the regional hospital setting with small volumes of blood, collected by finger prick sampling on filter paper, thus providing a cheap approach [35,37]. The fingerpick sample might also allow EBV-DNA load measurement, since DNA is a rather stable molecule in dried blood. Furthermore, the nasopharyngeal brushing with EBV marker assessment, may provide a promising method for detecting tumor presence in situ, by measuring EBV- DNA and RNA in parallel. Such brushings can be taken with simple tools under nasal-endoscope guidance [38-42].

Future education programs should include referencing to the available improved EBV-based diagnostic procedures for NPC- risk screening and early detection. Improved education combined with a screening method could be a cheap and sensitive screening method for NPC in Indonesia and other high incidence countries. Application of these methods in patients with chronic complaints in the head and neck, not responding to traditional antibiotic and anti-allergic medication has already yielded successful detection of early stage NPC cases in the Sardjito hospital patient population [43].

Currently we enrolled NPC awareness program in Jakarta, Yogyakarta and Surabaya. Short time efficacy of the training programs has been published recently [44]. Hopefully in the future this program can be expanded to include more regions of Indonesia.

The patients treated with PDT participate in an ongoing phase II trial, the results on PDT treatment for persistent and recurrent disease will be presented in more detail when the study has been completed. Still worth mentioning is that out of the seven patients who were treated with PDT, six of them are still alive. This is 17 per cent of 
all included NPC patients who are still alive. Based on our experiences and taking into account the poor treatment results currently for primary NPC in Indonesia, we assume that PDT can successfully be used in the future as part of the primary treatment. We hypothesize that PDT can be applied for NPC during the waiting time for radiotherapy, without compromising the options for all other possible treatment modalities. Perhaps the physical condition of the patients remains in such a good condition that at time the treatment can start patient can receive CCRT, which showed to have the best improved response rate.

The easiest ways of addressing current problems would be establishing sufficient radiotherapy facilities in Indonesia, however this will take decades. In the mean while our goal has to be to assure that patients who will be treated have an effective treatment and the right candidates are selected. Early detection of NPC, new treatment regimens to overcome the waiting time, a counselling system that supports only those patients who have a real opportunity to complete the treatment and improved maintenance for the radiotherapy facility are feasible short-term solutions to improve treatment outcome in the near future. 


\section{References}

1. Sloan FA GH, ed. Cancer control opportunities in low- and middle-income countries. Washington DC: Institute of Medicine of the National Academies. 2007.

2. Boyle, P. and Levin, B. World Cancer Report 2008;IARC Library Cataloguing in Publication Data. International Agency for Research on Cancer (IARC); 2008.

3. Ferlay J, Shin HR, Bray F, Forman D, Mathers C, Parkin DM. Estimates of worldwide burden of cancer in 2008: GLOBOCAN 2008. Int J Cancer 2010 December 15;127(12):2893-917.

4. Farmer P, Frenk J, Knaul FM, Shulman LN, Alleyne G, Armstrong L et al. Expansion of cancer care and control in countries of low and middle income: a call to action. Lancet 2010 October 2;376(9747):1186-93.

5. Kanavos P. The rising burden of cancer in the developing world. Ann Oncol 2006 June;17 Suppl 8:viii15-viii23.

6. Wildeman MA, Zandbergen J, Vincent A, Herdini C, Middeldorp JM, Fles R et al. Can an online clinical data management service help in improving data collection and data quality in a developing country setting? Trials 2011;12:190.

7. Gulley ML. Molecular diagnosis of Epstein-Barr virus related diseases. the journal of molecular diagnosis 3[1]. 2010. Ref Type: Magazine Article

8. Devi BC, Tang TS, Corbex M. Reducing by half the percentage of late-stage presentation for breast and cervix cancer over 4 years: a pilot study of clinical downstaging in Sarawak, Malaysia. Ann Oncol 2007 July;18(7):1172-6.

9. Curado M.P., Edwards B., Shin H.R. Cancer Incidence in Five Continents, Vol. IX. 2007. IARC Scientific Publications No. 160, Lyon, IARC. 2007. Ref Type: Data File

10. Adham M, Kurniawan AN, Muhtadi Al, Roezin A, Hermani B, Gondhowiardjo S et al. Nasopharyngeal carcinoma in Indonesia: epidemiology, incidence, signs, and symptoms at presentation. Chin J Cancer 2012 February 7.

11. Al Sarraf M, LeBlanc M, Giri PG, Fu KK, Cooper J, Vuong T et al. Chemoradiotherapy versus radiotherapy in patients with advanced nasopharyngeal cancer: phase III randomized Intergroup study 0099. J Clin Oncol 1998 April;16(4):1310-7.

12. Wee J, Tan EH, Tai BC, Wong HB, Leong SS, Tan T et al. Randomized trial of radiotherapy versus concurrent chemoradiotherapy followed by adjuvant chemotherapy in patients with American Joint Committee on Cancer/International Union against cancer stage III and IV nasopharyngeal cancer of the endemic variety. J Clin Oncol 2005 September 20;23(27):6730-8.

13. Zhang L, Zhao C, Ghimire B, Hong MH, Liu Q, Zhang $Y$ et al. The role of concurrent chemoradiotherapy in the treatment of locoregionally advanced nasopharyngeal carcinoma among endemic population: a meta-analysis of the phase III randomized trials. BMC Cancer 2010;10:558.

14. Nyst HJ, Wildeman MA, Indrasari SR, Karakullukcu B, van Veen RL, Adham M et al. Temoporfin mediated photodynamic therapy in patients with local persistent and recurrent nasopharyngeal carcinoma after curative radiotherapy: A feasibility study. Photodiagnosis Photodyn Ther 2012 September;9(3):274-81.

15. Gondhowiardjo S, Prajogi G, Sekarutami S. History and growth of radiation oncology in Indonesia. Biomed Imaging Interv J 2008 July;4(3):e42.

16. Slotman BJ, Cottier B, Bentzen SM, Heeren G, Lievens $Y$, van den Bogaert W. Overview of national guidelines for infrastructure and staffing of radiotherapy. ESTRO-QUARTS: work package 1. Radiother Oncol 2005 June;75(3):349-54.

17. Bentzen SM, Heeren G, Cottier B, Slotman B, Glimelius B, Lievens $Y$ et al. Towards evidence-based guidelines for radiotherapy infrastructure and staffing needs in Europe: the ESTRO QUARTS project. Radiother Oncol 2005 June;75(3):355-65. 
18. Levendag PC, Lagerwaard FJ, Noever I, dePan C, vanNimwegen A, Wijers O et al. Role of endocavitary brachytherapy with or without chemotherapy in cancer of the nasopharynx. Int J Radiat Oncol Biol Phys 2002 March 1;52(3):755-68.

19. Akimoto T, Mitsuhashi N, Hayakawa K, Sakurai H, Murata O, Ishizeki K et al. Split-course accelerated hyperfractionation radiotherapy for advanced head and neck cancer: influence of split time and overall treatment time on local control. Jpn J Clin Oncol 1997 August;27(4):240-3.

20. Lee N, Puri DR, Blanco Al, Chao KS. Intensity-modulated radiation therapy in head and neck cancers: an update. Head Neck 2007 April;29(4):387-400.

21. Lee AW, Sze WM, Au JS, Leung SF, Leung TW, Chua DT et al. Treatment results for nasopharyngeal carcinoma in the modern era: the Hong Kong experience. Int J Radiat Oncol Biol Phys 2005 March 15;61(4):1107-16.

22. Fles R, Wildeman MA, Sulistiono B, Haryana SM, Tan IB. Knowledge of general practitioners about nasopharyngeal cancer at the Puskesmas in Yogyakarta, Indonesia. BMC Med Educ 2010;10:81.

23. Prasad U, Pua KC. Nasopharyngeal carcinoma: a delay in diagnosis. Med J Malaysia 2000 June;55(2):230-5.

24. Alho OP, Teppo H, Mantyselka P, Kantola S. Head and neck cancer in primary care: presenting symptoms and the effect of delayed diagnosis of cancer cases. CMAJ 2006 March 14;174(6):779-84.

25. Koivunen P, Rantala N, Hyrynkangas K, Jokinen K, Alho OP. The impact of patient and professional diagnostic delays on survival in pharyngeal cancer. Cancer 2001 December 1;92(11):2885-91.

26. Teppo H, Koivunen P, Hyrynkangas K, Alho OP. Diagnostic delays in laryngeal carcinoma: professional diagnostic delay is a strong independent predictor of survival. Head Neck 2003 May;25(5):389-94.

27. Cevenini R, Donati M, Caliceti U, Moroni A, Tamba I, Rumpianesi F. Evaluation of antibodies to Epstein-Barr virus in Italian patients with nasopharyngeal carcinoma. J Infect 1986 March;12(2):127-31.

28. Chen JY, Chen CJ, Liu MY, Cho SM, Hsu MM, Lynn TC et al. Antibodies to Epstein-Barr virus-specific DNase in patients with nasopharyngeal carcinoma and control groups. J Med Virol 1987 September;23(1):11-21.

29. Ji MF, Wang DK, Yu YL, Guo YQ, Liang JS, Cheng WM et al. Sustained elevation of EpsteinBarr virus antibody levels preceding clinical onset of nasopharyngeal carcinoma. $\mathrm{Br} J$ Cancer 2007 February 26;96(4):623-30.

30. Tamada A, Makimoto K, Yamabe H, Imai J, Hinuma Y, Oyagi A et al. Titers of Epstein-Barr virus-related antibodies in nasopharyngeal carcinoma in Japan. Cancer 1984 February 1;53(3):430-40.

31. de Vathaire F, Sancho-Garnier H, de The H, Pieddeloup C, Schwaab G, Ho JH et al. Prognostic value of EBV markers in the clinical management of nasopharyngeal carcinoma (NPC): a multicenter follow-up study. Int J Cancer 1988 August 15;42(2):17681.

32. Fachiroh J, Schouten T, Hariwiyanto B, Paramita DK, Harijadi A, Haryana SM et al. Molecular diversity of Epstein-Barr virus IgG and IgA antibody responses in nasopharyngeal carcinoma: a comparison of Indonesian, Chinese, and European subjects. J Infect Dis 2004 July 1;190(1):53-62.

33. Fachiroh J, Paramita DK, Hariwiyanto B, Harijadi A, Dahlia HL, IndrasariSR et al. Single-assay combination of Epstein-Barr Virus (EBV) E. J Clin Microbiol 2006 April;44(4):1459-67.

34. Paramita DK, Fachiroh J, Artama WT, van Benthem E, Haryana SM, Middeldorp JM. Native early antigen of Epstein-Barr virus, a promising antigen for diagnosis of nasopharyngeal carcinoma. J Med Virol 2007 November;79(11):1710-21. 
35. Fachiroh J, Prasetyanti PR, Paramita DK, Prasetyawati AT, Anggrahini DW, Haryana SM et al. Dried-blood sampling for epstein-barr virus immunoglobulin $\mathrm{G}(\operatorname{IgG})$ and IgA serology in nasopharyngeal carcinoma screening. J Clin Microbiol 2008 April;46(4):1374-80.

36. Paramita DK, Fachiroh J, Haryana SM, Middeldorp JM. Two-step Epstein-Barr virus immunoglobulin A enzyme-linked immunosorbent assay system for serological screening and confirmation of nasopharyngeal carcinoma. Clin Vaccine Immunol 2009 May;16(5):706-11.

37. Ji MF, Yu YL, Cheng WM, Zong YS, Ng PS, Chua DT et al. Detection of Stage I nasopharyngeal carcinoma by serologic screening and clinical examination. Chin J Cancer 2011 February;30(2):120-3.

38. Lin JC, Wang WY, Chen KY, Wei YH, Liang WM, Jan JS et al. Quantification of plasma Epstein-Barr virus DNA in patients with advanced nasopharyngeal carcinoma. N Engl J Med 2004 June 10;350(24):2461-70.

39. Stevens SJ, Verkuijlen SA, Hariwiyanto B, Harijadi, Fachiroh J, Paramita DK et al. Diagnostic value of measuring Epstein-Barr virus (EBV) DNA load and carcinomaspecific viral mRNA in relation to anti-EBV immunoglobulin A (IgA) and IgG antibody levels in blood of nasopharyngeal carcinoma patients from Indonesia. J Clin Microbiol 2005 July;43(7):3066-73.

40. Stevens SJ, Verkuijlen SA, Hariwiyanto B, Harijadi, Paramita DK, Fachiroh J et al. Noninvasive diagnosis of nasopharyngeal carcinoma: nasopharyngeal brushings reveal high Epstein-Barr virus DNA load and carcinoma-specific viral BARF1 mRNA. Int J Cancer 2006 August 1;119(3):608-14.

41. Tune CE, Liavaag PG, Freeman JL, van den Brekel MW, Shpitzer T, Kerrebijn JD et al. Nasopharyngeal brush biopsies and detection of nasopharyngeal cancer in a high-risk population. J Natl Cancer Inst 1999 May 5;91(9):796-800.

42. Tong JH, Tsang RK, Lo KW, Woo JK, Kwong J, Chan MW et al. Quantitative Epstein-Barr virus DNA analysis and detection of gene promoter hypermethylation in nasopharyngeal (NP) brushing samples from patients with NP carcinoma. Clin Cancer Res 2002 August;8(8):2612-9.

43. Hutajulu SH. Clinical, Virological and Host Epigenetic Markers for Early Identification of Nasopharyngeal Carcinoma in High Risk Populations in Indonesia 2012.

44. Wildeman MA, Fles R, Adham M, Mayangsari ID, Luirink I, Sandberg M et al. Shortterm effect of different teaching methods on nasopharyngeal carcinoma for general practitioners in Jakarta, Indonesia. PLoS One 2012;7(3): 


\section{PATIENT DELAY}

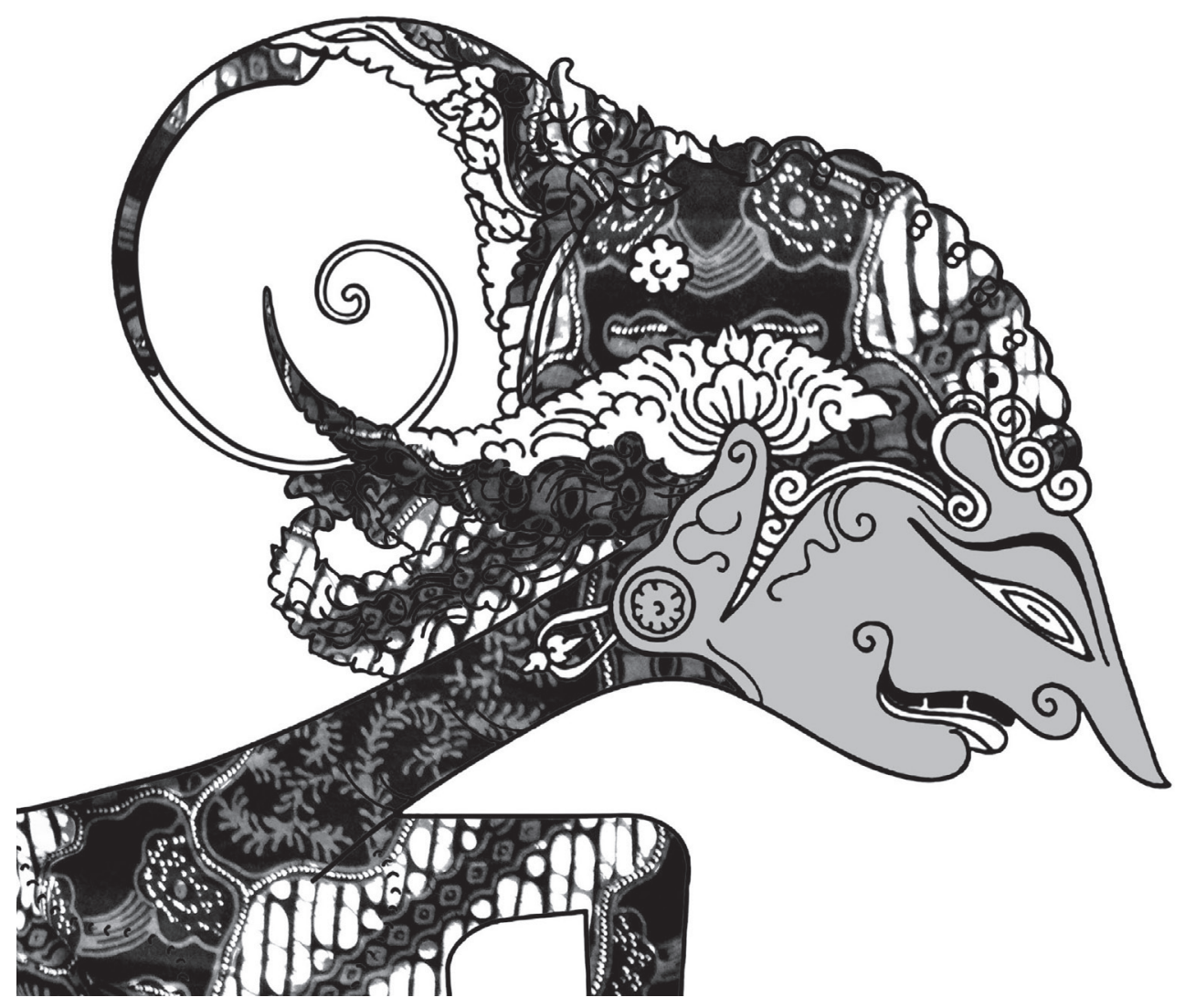




\section{Chapter 3}

The role of health-seeking behavior of Indonesian patients in delaying the diagnosis of nasopharyngeal carcinoma

R. Fles

ACRK. Bos

Supriyati

D. Rachmawati

E. Waliyanti

IB. Tan

SM. Haryana

MK. Schmidt

FST. Dewi 


\section{Abstract}

Background: With an estimate of 13000 newly diagnosed patients, nasopharyngeal carcinoma (NPC) is one of the most common types of cancer in male in Indonesia. Most patients are diagnosed with an advanced stage of disease. This study aimed to explore health behavior of patients diagnosed with NPC and the possible causes of patients' delay in diagnosis of NPC.

Methods: A qualitative research method was used to gain better insight in patient behavior. Twelve patients were interviewed using semi-constructed interview guideline. All interviews were recorded, transcribed verbatim and analyzed according a standard content analysis framework.

Results: Most patients had limited knowledge regarding NPC and its causes. Fifty percent of the patients had a delay of six months from onset of symptoms to diagnosis. Main reasons for this delay were the unawareness of the patients influenced by their environment, economic status, family, culture and religion. Perceived barriers seeking medical help were direct non-medical costs not covered by the health insurance, complex and time-consuming insurance and referral system, and negative experience in the past. Health insurance did motivate people to seek medical help.

Conclusion: This study provides more insight in patients' motivations to delay seeking medical help and can help in the design of education programs. In order to improve awareness of the above-mentioned causes for delay community-based education programs are highly warranted and should focus on the recognition of NPC symptoms and possible solutions to overcome the main barriers at an earlier stage. 


\section{Background}

Cancer mortality is rising in middle and low income countries, whereas increased number of cancer survivors can be found in middle and high income countries[1]. A delayed diagnosis of cancer is more often found in developing countries due limited availability and approachability of health care. The patients' ability and willingness to undertake action, depending on social-economic status, attitude, financial situation, cultural aspects, and religion, plays a roll [2-5]. In addition, patients are often embarrassed to discuss abnormalities $[4,6]$ or lacking trust in medical consultation[7].

With over 13000 new diagnosed patients yearly, nasopharyngeal carcinoma (NPC) is one of the most frequently encountered types of cancer in Indonesia, especially in male, with a high mortality[8]. Early symptoms of NPC are nonspecific and mimic a normal upper airway infection making it a difficult disease to be recognized by the general practitioners working in the primary healthcare centers. A previous study conducted in Yogyakarta, Indonesia, showed that most patients are diagnosed with an advanced stage of NPC disease and had a median overall survival of less than 2 years [9].

Since January 2014 the Indonesian government implemented a new insurance scheme: The National Health Insurance or Jaminan Kesehatan Nasional. The social security provider can be divided in two groups: Penerima Bantuan Luran (PBI) for beneficiaries of insurance premium subsidies, and non-PBI for non-beneficiaries of insurance premium subsidies. PBI targets the (borderline) poor people and their family members; non-PBI targets those with a monthly wage and their family members. The BPJS is compulsory for every Indonesian and dissolves all other health insurances. Participation to contribute to this health care scheme by all Indonesians is expected and the government is committed to reach universal health coverage by 2019 [10]. The BPJS puts a huge pressure on the current health care system due to the increase in individuals seeking medical care without the necessary increase in health care capacity [11]. 
In Javanese culture health is seen as a requirement to complete daily activities, and as long Javanese are not hindered in their daily activities they consider themselves as healthy.[5] Javanese men are breadwinners of the family and decision makers after consulting family members and considering their partner's opinion. Women on the other hand are caretakers for health.[5] The ability of patients in Indonesia to seek medical help is often depending on the role of the family $[12,13]$. The importance of the family is reflected in the proverb: 'mangan ora mangan waton kumpul' (even if there is no food to eat, being together is the most important thing)[14].

The aim of this qualitative study was to explore the health behavior and the possible causes of patients' delay in diagnosis of NPC. Identified factors responsible for patients'-delay may be used for the development of community-based interventions focusing on minimizing patients' delay in NPC diagnosis and better outcome.

\section{Methods}

\section{Participants and procedure}

Between March 2014 and June 2014 newly diagnosed patients with NPC at the Ear, Nose and Throat department of the dr. Sardjito hospital were approached to participate. Inclusion criteria were: age above 18 years, histopathological confirmed NPC diagnosis, in waiting time for radiotherapy, and understands and speaks Bahasa Indonesia or Javanese. Patients who had a psychiatric treatment history or were too ill to complete the interview were excluded (one interviewed patient was excluded in retrospect). The Medical and Health Research Ethic Committee of the Gadjah Mada University, Yogyakarta, Indonesia approved the study.

All eligible patients received a short oral explanation regarding the study while visiting the outpatient clinic. Anonymity of the respondents was guaranteed and all patients signed for informed consent. Each interview lasted approximately 60 minutes and was conducted in Bahasa Indonesia or Javanese. To ensure patients were at ease, a trained interviewer conducted the interviews at their home. Participants were asked about their demographic characteristics, including age, religion, insurance status, level of education, and employment status. This was 
followed by an in-depth semi-structured interview on topics regarding NPC using the health belief model categories: perceived susceptibility, perceived severity, perceived benefits, perceived barriers, and cues to action [15].

Each interview was recorded, transcribed verbatim, and translated into English; and subsequently reviewed by a bilingual team member $(A B)$, and coded according to content analysis using MaxQDA11. Following emergent design, each interview was coded and categorized (by FD and SS) to decide on new probing questions and the saturation of answers according to theoretical saturation. Saturation was reached after 12 interviews. Participant inclusion ended when no new concepts arose from the last two interviews. Key themes were pre-determined (i.e. perceived susceptibility and severity, perceived benefits and barriers, cues to action, and the influence of culture and religion). All codes derived from the interviews were compiled into categories and merged into the main themes using MAXQDA11. This was done in two steps: after six interviews and at the end of data collection. Intercoder agreement was obtained and final coding and categorization was performed by two researchers (RF and $A B$ ); differences were discussed until consensus was reached. Trustworthiness was achieved through different background of the authors and location of the interviews.

\section{Results}

\section{Characteristics of the participants}

This study is based on the data from 12 interviewed NPC patients. For two patients, a relative of the patient participated during the interview since the patient insisted on it. Two-third of the patients were male; mean age was 44 years; and all participants were Muslim with Javanese origin (Table 1). Six participants had a lower educational level. Most patients had BPJS-PBI, the insurance for (borderline) poor people. All patients had an advanced stage of disease of which two of them already had distant metastasis at diagnosis. For ten patients the delay in diagnosis after first symptoms was more than three months. Patients visited on average 3.6 different health care institutes or health care workers before their appointment at the Ear Nose Throat department of the dr. Sardjito hospital (range 0-11). 
Table 1 | characteristics of the participants

\begin{tabular}{|c|c|c|c|}
\hline Patient characteristic & Category & $\mathbf{n}$ & (\%) \\
\hline \multirow[t]{2}{*}{ Gender } & Male & 8 & 66,7 \\
\hline & Female & 4 & 33,3 \\
\hline \multirow[t]{4}{*}{ Age } & $<35$ & 3 & 25,0 \\
\hline & $35-45$ & 3 & 25,0 \\
\hline & $45-55$ & 4 & 33,3 \\
\hline & $>55$ & 2 & 16,7 \\
\hline \multirow[t]{2}{*}{ Ethnicity } & Javanese & 12 & 100,0 \\
\hline & Other & 0 & 0,0 \\
\hline \multirow[t]{2}{*}{ Religion } & Islam & 12 & 100,0 \\
\hline & Other & 0 & 0,0 \\
\hline \multirow[t]{6}{*}{ Level of Education } & No school & 1 & 8,3 \\
\hline & Not completed primary school & 0 & 0,0 \\
\hline & Graduated primary school & 5 & 41,7 \\
\hline & Graduated junior high & 3 & 25,0 \\
\hline & Graduated high school & 2 & 16,7 \\
\hline & Graduated from university & 1 & 8,3 \\
\hline \multirow[t]{5}{*}{ Occupation } & Housewife & 3 & 25,0 \\
\hline & Entrepreneur & 3 & 25,0 \\
\hline & Civil servant/Police/Army & 1 & 8,3 \\
\hline & Farmer/Fisherman/Labor & 4 & 33,3 \\
\hline & Student & 1 & 8,3 \\
\hline \multirow[t]{4}{*}{ Marital Status } & Not married & 2 & 16,7 \\
\hline & Divorced & 0 & 0,0 \\
\hline & Widow & 1 & 8,3 \\
\hline & Married & 9 & 75,0 \\
\hline \multirow[t]{2}{*}{ Types of Insurance } & BPJS-PBI & 10 & 83,3 \\
\hline & BPJS-non-PBI & 2 & 16,7 \\
\hline \multirow[t]{4}{*}{ Stage Disease } & III & 1 & 8,3 \\
\hline & IVA & 2 & 16,7 \\
\hline & IVB & 7 & 58,3 \\
\hline & IVC & 2 & 16,7 \\
\hline \multirow{4}{*}{$\begin{array}{l}\text { Time from first Symptoms till } \\
\text { Diagnosis in Months }\end{array}$} & $<3$ & 2 & 16,7 \\
\hline & {$[3-6>$} & 4 & 33,4 \\
\hline & {$[6-9>$} & 5 & 41,7 \\
\hline & $\geq 9$ & 1 & 8,3 \\
\hline
\end{tabular}




\section{Perceived susceptibility and severity (Quotes 1-7; table 2)}

Most patients $(n=10)$ had never heard of NPC before or say they had limited basic knowledge regarding NPC and its causes $(n=8)$. They stated that they only received oral information from the doctor directly after diagnosis and no written information was available. Some patients gathered information regarding the symptoms and the risk factors via their doctor, family, friends, or internet. However, not all patients were interested in gaining knowledge regarding the disease. All they wanted was to get treatment and cure. Several patients changed their life-style (i.e. quit smoking), family life-style, and/or food consumption (not using flavor enhancers like MSGs and minimizing the consumption of salty fish).

Most respondents waited for several months before seeking medical help and some did not realize that delaying the diagnosis could worsen the disease. The median delay of seeking medical help was 5.5 months (range 1-12), while the respondents observed that symptoms got more severe. Patients did not recognize the first symptoms of NPC. The symptoms were often considered to be harmless, since they did not hinder the patients in their daily activities. Symptoms described by the patients as mild were ringing sound in the ear, headache, running nose, nose bleeding, double vision, and symptoms like a common flu. Some patients described the pain or a mass in their neck as mild and non-severe, although neck mass is one of the symptoms of more advanced stage of disease. When symptoms like headache and enlarged neck lymph nodes did not disappear over time this was a trigger to seek medical help. One patient, who described severe pain in the bones, was later diagnosed with distant metastasis.

\section{Perceived benefits and barriers (Quotes 8-13; table 2)}

Most patients were unaware of the severity of their disease and mainly expecting to get rid of their symptoms like headache. The biggest motivation for patients to seek medical help was to get healthy again.

Although many patients mentioned positive experiences with the health care system, all patients shared negative experiences with the health care services resulting in a barrier to seek medical help. Patients often encountered physicians who were unaware of the disease, resulting in misdiagnosis and time-consuming 
referrals, followed by long queues due to limited treatment capacity. In addition, while waiting, patients were often confronted with more severe cancer patients, which frightened the patients even more. All these experiences ultimately formed barriers for the patients to continue visiting the health care services and they often looked for alternatives.

Medical costs often resulted in patients postponing medical treatment. Although BPJS is covering most of the costs, patients only started applying for this insurance once the need for medical help was inevitable. Applying for the BPJS is time consuming and this insurance does not cover costs like transportation. Frequently, patients had to travel long distances and had to rent a car. In addition, not all patients wanted to use the insurance since they felt that the treatment and service is different when they pay the treatment themselves.

Unawareness and fear for side effects of the treatment, made patients reluctant to be diagnosed or even start treatment. Experiences in their surroundings (e.g. family or friends) regarding chemotherapy and radiotherapy scared the patients.

\section{Cues to action (Quotes 14-17; table 2)}

If patients had been more aware of the severity of the disease and the need for treatment from the onset of the first symptoms, they would have sought medical help at an earlier stage. Some patients suggested creating more community-based awareness by using printed media such as folders and flyers about the symptoms and risk factors of NPC and how to changes in life-style may minimize the risk of getting NPC. In addition, improving the referral system and queuing system for registration would help patients to overcome these barriers and seek medical help at an earlier time point.

Although the transportation costs are still not covered by the health insurance and can be seen as a barrier to seek for medical help, the introduction of the health insurance did motivate patients to take action. In the past, treatment was unaffordable for some patients, and the introduction of the BPJS insurance has changed this situation. 


\section{Culture and religion (Quotes 18-23; table 2)}

According to our findings the participants were strongly bound to the Javanese culture and religion, for that reason these two aspects were added to the health belief model (figure 1). Religion and the support of family members to get diagnosed or undergo treatment play a large role in the Indonesian culture. Family support is needed to cover possible extra costs. Supported by family and friends, most patients start with traditional, complementary, and alternative medicine (TCAM) before medical treatment. The main motivation to use TCAM is to minimize the symptoms, and patients were unaware of the underlying disease. Patients often stated that TCAM is easier to get and more affordable, however, they also stated that a limited reduction of the symptoms was experienced.

The one-way style of communication of health care providers instead of a more partnership communication style, which is embedded in the Indonesian culture, often forms a barrier for the patient. The dominant role of the doctor hinders the patients to ask questions. Patients are too modest to ask more information or to question the treatment options.

All patients were Muslim. Their strong beliefs in God makes that they accept the consequences of the disease and they surrender to god, resulting in a more passive health behavior to seek medical help.

Individual perceptions

Modifying factors

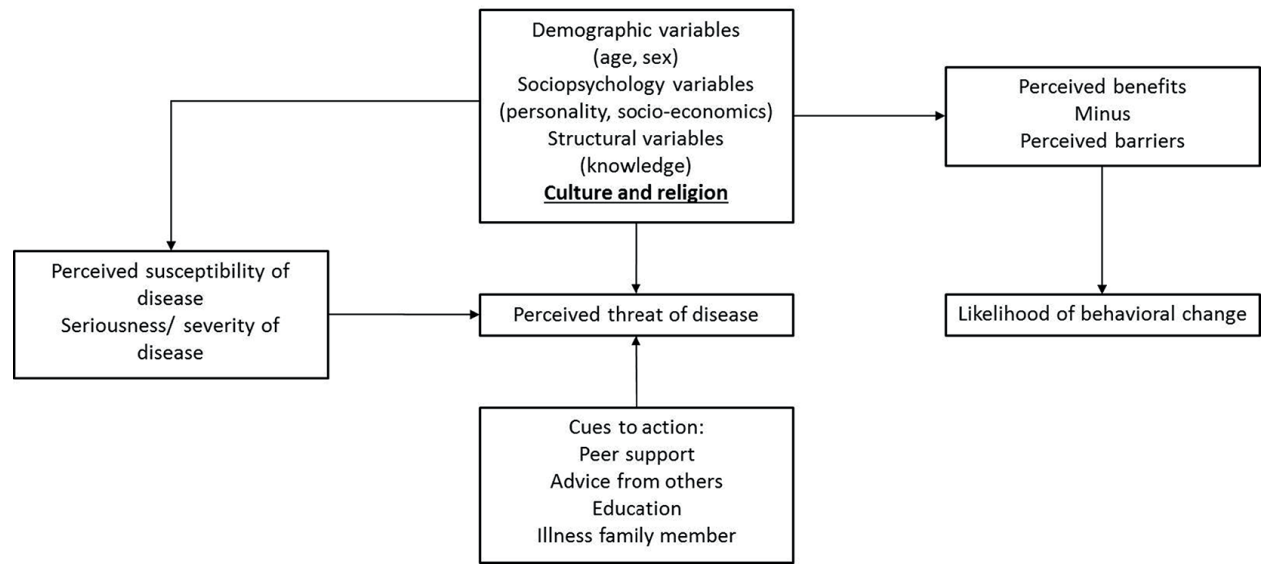

Figure 1: Health Believe Model according to Hochbaum, Rosenstock and Kegels[15] with of culture and religion added as modifying factors by the authors. 
Table 2 | quotes of the participants

\begin{tabular}{|c|c|c|}
\hline NR & PATIENT & QUOTE \\
\hline 1 & 7 & "I never heard of NPC before [...] even my doctor was surprised [...] I was just shocked". \\
\hline 2 & 4 & "Well, yeah, I have the illness, but I didn't ask what caused it [...] I just want to be cured". \\
\hline 3 & 8 & "I totally changed my lifestyle. I totally quit smoking and I also eat vegetable, it feels good". \\
\hline 4 & 4 & $\begin{array}{l}\text { "if I would not have waited, but went straight to the dr. Sardjito hospital, I ouwld still be like } \\
\text { this" }\end{array}$ \\
\hline 5 & 6 & $\begin{array}{l}\text { "At first, I had a headache, I was dizzy and all the bones in my left side from the bottom are } \\
\text { painful; then my son told me to go check it in the hospital". }\end{array}$ \\
\hline 6 & 5 & $\begin{array}{l}\text { "I had a small mass in my neck, more than one year ago, then I had a biopsy. But the mass } \\
\text { came back five months ago. During the time I regularly had blood in my sputum and a } \\
\text { headache, but I did not think that was serious." }\end{array}$ \\
\hline 7 & 9 & $\begin{array}{l}\text { "I had a ringing sound in one of my ears. After a while I went to the doctor, but he said that } \\
\text { I was fine, so I thought it was just flu. But then I had a terrible headache and I had a mass in } \\
\text { my neck. The mass really felt abnormal, so I went to the doctor again." }\end{array}$ \\
\hline 8 & 9 & $\begin{array}{l}\text { "According to the theory I would get cured [...] the chemo would make the illness less and the } \\
\text { radiotherapy would eliminate it". }\end{array}$ \\
\hline 9 & 8 & "I was diagnosed with a bronchitis [...] after several months the lumps in my neck appeared". \\
\hline 10 & 1 & $\begin{array}{l}\text { "I got a tonsil operation, I thought I would be cured, but I still had a headache }[\ldots] \text { I went to } \\
\text { eleven different doctors before I got to the Ear Nose Throat doctor }[\ldots] \text { now we only have to } \\
\text { wait for the chemotherapy". }\end{array}$ \\
\hline 11 & 4 & $\begin{array}{l}\text { "I do not have any money [...] so I postpone to go to dr. Sardjito hospital, because chemotherapy } \\
\text { is expensive". }\end{array}$ \\
\hline 12 & 9 & $\begin{array}{l}\text { "I would like to pay no matter what, my son told me not to use BPJS they would treat us like } \\
\text { less important". }\end{array}$ \\
\hline 13 & 3 & $\begin{array}{l}\text { "There was a patient from Banyumas; she had a blackened face, I'm only afraid I will get that } \\
\text { too when I start radiotherapy". }\end{array}$ \\
\hline 14 & 8 & $\begin{array}{l}\text { "My suggestion is there should be posters in the street so they know about the danger of } \\
\text { smoking [...] I often see young kids on the street smoking, only thing I can do is tell them } \\
\text { about the risk of getting cancer, because I already have the experience". }\end{array}$ \\
\hline 15 & 7 & $\begin{array}{l}\text { "I went for } 8 \text { times to dr. Sardjito hospital [...] until all papers were complete. I was there until } \\
\text { I fainted [...] we had to go there and there". }\end{array}$ \\
\hline 16 & 8 & "The queue for the registration is very long [...] this is an obstacle; this should be easier". \\
\hline 17 & 3 & $\begin{array}{l}\text { "About the costs, it is hard [...] but the cost to go there by bus is too much [...] For the } \\
\text { treatment we now use BPJS, the insurance before only gave us a discount, but now we do not } \\
\text { have to pay for the treatment". }\end{array}$ \\
\hline 18 & 10 & $\begin{array}{l}\text { "My health was decreasing, so my family and kids quickly decided to get medical treatment } \\
{[\ldots] \text { We would do everything to be able to pay for it [...] it was money from the family". }}\end{array}$ \\
\hline 19 & $2^{*}$ & $\begin{array}{l}\text { "We didn't tell my father about his disease... we are afraid that he will get stressed [..] He } \\
\text { knows that he is sick". }\end{array}$ \\
\hline 20 & 2 & $\begin{array}{l}\text { "I don't know the names of all the herbs; knowledge is inherited from previous generations, } \\
\text { my grandparents [...] I'm using alternative treatment because I just want to be cured. Besides } \\
\text { that, it is more affordable". }\end{array}$ \\
\hline 21 & 10 & $\begin{array}{l}\text { I do want to know more clearly, well, because I am only a patient so I keep quiet [...] maybe if } \\
\text { I asked something, the doctor would be offended. }\end{array}$ \\
\hline 22 & 7 & "If God allows I will be cured" \\
\hline 23 & 10 & $\begin{array}{l}\text { "I am not afraid, the most important thing is that I totally surrender to have this illness, hope } \\
\text { God will take it away". }\end{array}$ \\
\hline
\end{tabular}




\section{Discussion}

This study addressed the health behavior of newly diagnosed Indonesian patients with NPC before medical treatment. Environment, economic status, complex and time-consuming insurance and referral system, unawareness, negative experience in the past, family, culture and religion of the patient influenced this behavior. Cultureembedded barriers are often difficult to distinguish within one's own culture. It was of great asset that the research team was multicultural and the phenomena could be looked at from different angles. In this way cultural-based barriers where discovered. By adding cultural and religious aspects to the health belief model, the model became more representative of the different factors associated with delay to diagnosis of people suffering from the first symptoms of NPC.

Delay of seeking medical help, treatment delay, and treatment non-adherence in Indonesian women with breast cancer were distinguished in three main clusters namely: patients related, treatment related, and patient-health provider relationship related, by Iskandarsyah et al.[16]. Similar clusters were found in our study although we only looked at the delay of seeking medical help.

In the Malaysian study of Prasad et al., patients with NPC presented themselves within a reasonable time to a doctor, however, for one third of the patients it took more than six months until diagnosis [17]. In our study we specific looked at the time between the onset of the symptoms until the diagnosis instead of time until the first visit to a doctor. This since all patients except one, visited multiple health authorities before diagnosed at the ENT department at the dr. Sardjito hospital. We found that for fifty per cent of the patients it took more than six months until diagnosis.

Although NPC has a high incidence in Indonesia, participants were not aware of the causes and severity of the disease. This lack of knowledge regarding NPC seemed to influence the stage at diagnosis, and patients' perception of the susceptibly and severity of the disease. These findings confirm that knowledge is a key predictor in patients' delay. This is in concordance with other studies regarding patients' delay for breast cancer diagnosis in developing countries [16,18-20]. Most participants reported the first symptoms of NPC as harmless and compared it with a common flu. As a result, all patients were diagnosed with an advanced stage of disease accompanied by enlarged lymph nodes in the neck. The misinterpretation of cancer 
symptoms is a problem that has been reported elsewhere [21,22]. Additionally, patients were not aware of the consequences of the delay to diagnosis.

The costs of the treatment, if not covered by the insurance, and the cost of the transportation to the hospital caused a major treatment related delay. This is in line with other studies looking at treatment outcomes for childhood cancer in Indonesia $[23,24]$. Although the insurance stimulates patients to seek medical help, patients still struggle with direct non-medical costs.

Indonesian culture often shows hierarchical respect towards people with a higher social status and elderly, and maintaining the harmony between one and another is seen as important [25]. This respect towards medical staff often leads to unmet information needs and low satisfaction with the provided information. This may lead to unfavorable outcomes, lower illness perception, and lower health-related quality of life [26-29].

We should note that in the interviews there might have been some recall bias. All patients were diagnosed with an advanced stage of disease. Although their condition was good enough to participate, one can imagine it was hard to memorize the onset of the symptoms and the exact referral path. Often the recollection of the patients was based on public holiday or other events. However, the level of details in which patients could recall suggests valid interviews.

\section{Conclusion}

Half of the patients with NPC were diagnosed more than six months after the onset of the symptoms with an advanced stage of disease. Main reasons for this delay were the unawareness of the patients influenced by their environment, economic status, family, culture and religion. With the complex and time-consuming insurance and referral system, negative experience in the past and direct non-medical cost not covered by health insurance as biggest barriers. Better and different information services in combination with better referral are the key for NPC suspects to minimize this delay to diagnosis. Community-based education is needed and should focus on recognition of NPC symptoms and possible solutions to overcome the main barriers at an earlier stage. 


\section{References}

1. Jemal A, Center MM, DeSantis C, Ward EM. Global Patterns of Cancer Incidence and Mortality Rates and Trends. Cancer Epidemiology Biomarkers \& Prevention. 2010;19:1.

2. Freitas $A G Q$, Weller M. Patient delays and system delays in breast cancer treatment in developed and developing countries. Cien Saude Colet. ABRASCO - Associação Brasileira de Saúde Coletiva; 2015;20:3.

3. Levesque J-F, Harris MF, Russell G. Patient-centred access to health care: conceptualising access at the interface of health systems and populations. International Journal for Equity in Health. International Journal for Equity in Health; 2013;12:1.

4. Siminoff L, Thomson M, Dumenci L. Factors associated with delayed patient appraisal of colorectal cancer symptoms. Psycho-Oncology. 2014;23.

5. Dewi FST, Weinehall L, Ohman A. "Maintaining balance and harmony": Javanese perceptions of health and cardiovascular disease. Glob Health Action. 2010;3.

6. Öztürk Ç, Fleer J, Hoekstra HJ, Hoekstra-Weebers JEHM. Delay in Diagnosis of Testicular Cancer; A Need for Awareness Programs. PLoS ONE; 2015;10.

7. De Nooijer J, Lechner L, De Vries H. Help-seeking behaviour for cancer symptoms: perceptions of patients and general practitioners. Psycho-Oncology. 2001;10.

8. Ferlay J, soerjomataram I, Ervik M, Dikshit R, Eser S. GLOBOCAN 2012 v1. 0, Cancer Incidence and Mortality Worldwide: IARC CancerBase No. 11 [Internet]. 2013, International Agency for Research on cancer: http://globocan.iarc.fr; accessed $12 \mathrm{Jul}$ 2016.

9. Wildeman MA, Fles R, Herdini C, Indrasari RS, Vincent AD, Tjokronagoro M, et al. Primary treatment results of Nasopharyngeal Carcinoma (NPC) in Yogyakarta, Indonesia. PLoS ONE. 2013;8.

10. BPJS Kesehatan: A new medicare system ? [Internet]. 2014 [cited 2014 Apr 28]. pp. 1-2. Available from: http://www.kpmg.com/ID/en/IssuesAndlnsights/ArticlesPublications/ Documents/IES-Bulletin-February-2014.pdf. Accessed 12 Jun 2016

11. Satriana S, Schmitt V. Towards a nationally defined social protection floor in Indonesia. International Labour Organization 2012. pp. 1-94.

12. Effendy C, Vissers K, Tejawinata S, Vernooij-Dassen M, Engels Y. Dealing with Symptoms and Issues of Hospitalized Patients with Cancer in Indonesia: The Role of Families, Nurses, and Physicians. Pain Pract. 2014;15

13. Anggraeni MD, Ekowati W. Family role in the achievement of post radical mastectomy self-integrity patients. Int J Public Health Res. 2011.

14. Subandi MA. Family Expressed Emotion in a Javanese Cultural Context. Cult Med Psychiatry. Springer US; 2011;35.

15. Glanz K, Rimer BK, Viswanath K. Health behavior and health education. 4 ed. JosseyBass Publisher; 2008. pp. 1-590.

16. Iskandarsyah A, de Klerk C, Suardi DR, Soemitro MP, Sadarjoen SS, Passchier J. Psychosocial and cultural reasons for delay in seeking help and nonadherence to treatment in Indonesian women with breast cancer: A qualitative study. Health Psychol 2014;33

17. Prasad U, Pua KC. Nasopharyngeal Carcinoma: A delay in Diagnosis. Medical Journal Malaysia. 2000;2.

18. Agarwal G, Ramakant P, Forgach ERS, Rendón JC, Chaparro JM, Basurto CS, et al. Breast cancer care in developing countries. World J Surg. Springer-Verlag; 2009;33.

19. Memon ZA, Shaikh AN, Rizwan S, Sardar MB. Reasons for Patient's Delay in Diagnosis of Breast Carcinoma in Pakistan. Asian Pac. J. Cancer Prev. 2013;14. 
20. Taib NA, Yip CH, Low WY. Recognising symptoms of breast cancer as a reason for delayed presentation in Asian women--the psycho-socio-cultural model for breast symptom appraisal: opportunities for intervention. Asian Pac. J. Cancer Prev. 2011;12.

21. Brouha XDR, Tromp DM, de Leeuw JRJ, Hordijk G-J, Winnubst JAM. Laryngeal cancer patients: Analysis of patient delay at different tumor stages. Head Neck. 2005;27.

22. Hall N, Birt L, Banks J, Emery J, Mills K, Johnson M, et al. Symptom appraisal and healthcare-seeking for symptoms suggestive of colorectal cancer: a qualitative study. BMJ Open; 2015:5.

23. Mostert S, Gunawan S, Wolters E, van de Ven P, Sitaresmi M, Dongen JV, et al. Socioeconomic Status Plays Important Roles in Childhood Cancer Treatment Outcome in Indonesia. Asian Pac. J. Cancer Prev. 2012;13.

24. Sitaresmi MN, Mostert S, Schook RM, Sutaryo, Veerman AJP. Treatment refusal and abandonment in childhood acute lymphoblastic leukemia in Indonesia: an analysis of causes and consequences. Psycho-Oncology. 2010;19.

25. Claramita M, Nugraheni MDF, Van Dalen J, Van der Vleuten C. Doctor-patient communication in Southeast Asia: a different culture? Adv in Health Sci Educ. 2012;18.

26. Davies NJ, Kinman G, Thomas RJ, Bailey T. Information satisfaction in breast and prostate cancer patients: implications for quality of life. Psycho-Oncology. 2008;17.

27. Husson O, Thong MSY, Mols F, Oerlemans S, Kaptein AA, van de Poll-Franse LV. Illness perceptions in cancer survivors: what is the role of information provision? PsychoOncology. 2013;22.

28. Llewellyn CD, Horne R, McGurk M, Weinman J. Development and preliminary validation of a new measure to assess satisfaction with information among head and neck cancer patients: The satisfaction with cancer information profile (SCIP). Head Neck. 2006;28.

29. Llewellyn CD, McGurk M, Weinman J. How satisfied are head and neck cancer (HNC) patients with the information they receive pre-treatment? Results from the satisfaction with cancer information profile (SCIP). Oral Oncol. 2006;42. 


\title{
Chapter 4
}

Use of traditional, complementary and alternative medicine delays diagnosis of nasopharyngeal carcinoma in Indonesia

\author{
R. Fles \\ JO. Schutter \\ FST. Dewi \\ Supriyati \\ F. Amelia \\ D. Hartati \\ L. Lazuardi \\ C. Herdini \\ J. Fachiroh \\ SR. Indrasari \\ SM. Haryana \\ MK. Schmidt \\ IB. Tan
}




\begin{abstract}
Background: Although nasopharyngeal carcinoma (NPC) is rare throughout the world, it is highly prevalent and one of the leading causes of cancer death in Indonesia. NPC has a good prognosis when treated at an early stage. Nevertheless, most patients with NPC are diagnosed with an advanced stage of disease. First NPC specific symptoms are difficult to distinguish since they mimic a normal upperairway infection. Delay in diagnosis complicates treatment and reduces survival probability.
\end{abstract}

Traditional, Complementary and Alternative Medicine (TCAM) are ingrained in Indonesian culture. Understanding this use is of great importance since reliance on TCAM may affect help-seeking behaviour. As little is known about TCAM use among patients with NPC before diagnosis, we aimed to establish its frequency and its effect on the delay in diagnosis of this specific patient group.

Methods: A questionnaire based on a desk-study was submitted to 141 consecutive newly diagnosed NPC patients at the dr. Sardjito hospital in Yogyakarta. Participants completed the questionnaire with a surveyor. All participants signed informed consent.

Results: The majority of the patients were diagnosed with an advanced stage of disease (93.6\%). In total, 83 per cent of participants had used TCAM before diagnosis. Bivariate analysis shows that TCAM users were younger (47 versus 54 years) ( $p=0.007$ ) and slightly higher educated ( 40.5 versus 56 who did not finish primary school) ( $p=0.04)$. A significant relationship was found concerning use of TCAM products and the interval between first visit to their physician and diagnosis (period 2-3); this interval was longer for those using TCAM products ( $p=0.006$ ). Those who never used any form of TCAM were diagnosed earlier than those who did use TCAM at any given time between in the referral process (mean delay 24 weeks versus 41 weeks $p=0.03$ ). Patients did not report their TCAM use to their general practitioner $(n=74)$.

Conclusion: Most NPC patients used TCAM before diagnosis. Our findings show that those we never used TCAM product or underwent any kind of TCAM procedures are referred at an earlier time point. 


\section{Introduction}

Nasopharyngeal carcinoma (NPC) is rare throughout the world, however in Indonesia it is highly prevalent with an estimate of 15,000 new cases per year, making NPC one of the leading causes of cancer death in Indonesia, especially in males [1,2]. This might be an underestimation due to poor cancer registries [3]. NPC has a good prognosis when treated in early stage. However, in Indonesia most patients arrive at the hospital with advanced stage. At the dr. Sardjito Hospital in Yogyakarta more than 87 per cent the NPC patients are diagnosed with advanced stage of the disease $[4,5]$. Therefore, identifying factors causing a delay in diagnosis is highly warranted.

Various forms of Traditional, Complementary and Alternative Medicine (TCAM) have been used globally [6-8]. In general, TCAM refers to health care practices not offered within hospital facilities or by clinical practitioners [9]. In developing countries, it is estimated that 80 per cent of the population uses TCAM as part of their basic health care [10-13]. This use is strongly embedded in daily life and stems from historical and cultural factors $[6,8,10,14,15]$. Also, TCAM has been widely used among cancer patients in developed and developing countries. The exact number of cancer patients using TCAM worldwide varies between 10-80 per cent [16-20]

In Indonesia TCAM is classified as: (1) traditional medicine based on physical skills, e.g. massage, bone-setting, acupressure, acupuncture, chiropractic, and cupping, and (2) traditional medicine based on the use of herbal, animal and/or trace mineral formulas e.g. aromatherapy and homeopathy [21]. Among these Indonesian herbal medicines the so-called jamu are the most popular and widely used [22].

Characteristics of TCAM users in Indonesia are different from TCAM users in western countries. In western countries TCAM is mostly used by women and people with higher educational level and higher income $[7,19]$. TCAM users in Indonesia are typically elderly patients with no difference between men and women. In addition, married people with a lower educational level, lower income and living in more rural areas are more likely to use TCAM. The most common motivations for using TCAM are trust, past negative experience with conventional therapy, TCAM as being better accessible and affordable than conventional medicine, or, in the perception of the patient, the disease is not severe enough for conventional treatment [23]. 
Understanding the reliance on TCAM is of great importance since it may affect help-seeking behaviour. The use of TCAM by cancer patients can lead to treatment delay and low compliance to conventional treatment [24-26]. Little is known about TCAM use among patients with NPC before diagnosis. With this quantitative study we wished to establish its frequency and its effect on the delay in diagnosis of this specific patient group. The results of this study can be used for future communitybased interventions to improve early diagnosis of NPC patients in Indonesia.

\section{Methods}

\section{Procedure and participants}

Based on desk research potential types of TCAM were identified and used to develop the questionnaire. All relevant data were gathered from following sources: international publications, national publications or reports of the Universitas Gadjah Mada. All information was online available and written in English or Bahasa Indonesia. In a pilot study, the first versions of the questionnaire were checked for its content, the clarity of the questions, and the completeness of the questions. Only minor adjustments based on this pilot study were made. Questionnaires were completed at the outpatient clinic in the presence of a trained surveyor. Information regarding tumor stage was gathered from the NPC registry database.

NPC patients, diagnosed at the Ear, Nose and Throat department of the dr. Sardjito hospital between November 2013 and January 2015, were asked to participate. Inclusion criteria were: (1) age above 18, (2) histopathological confirmed for NPC; (3) not started radiotherapy yet. Patients who had a psychiatric treatment history or were too ill to complete the interview were excluded. The medical ethical committee of the dr. Sardjito hospital, Yogyakarta, Indonesia approved this quantitative study. All participants signed informed consent.

\section{Questionnaire design}

The design of the questionnaire can be found in annex 1 . The first part of the questionnaire consisted of questions regarding patient characteristics such as gender, marital status, educational level, religion, and ethnic background. Here also a numerical rating scale for pain assessment was added in which 0 indicated no pain and 10 indicated severe pain. 
The second part of the questionnaire enabled us to ask about TCAM usage at different time points and focused on the length of time between the onset of the symptoms and the diagnosis and the different kind of TCAM used by the patients. Here a distinction was made between TCAM procedures and TCAM products. Since the referral system until diagnosis consists of multiple steps, this part of the questionnaire was divided in three different periods. The first period is from the onset of the symptoms until the patients visit a physician at a primary health care center. The second period represents the time between the primary health care center until the first appointment at the district hospital. The last period, represents the time between the referral from the district hospital until the date of diagnosis (figure 1). The last part of the questionnaire contained general questions regarding TCAM, how patients gathered their information and if they shared TCAM usage with their clinicians.

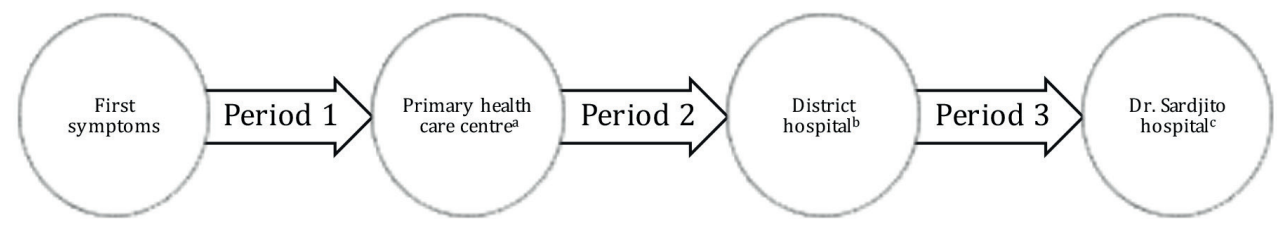

Figure 1 | Three periods of assessment of NPC patients' way to diagnosis: aPrimary health care center functioning at community level, there is a lot of variance in capacity between the different primary health care centers, most of the time there following (para-)medics

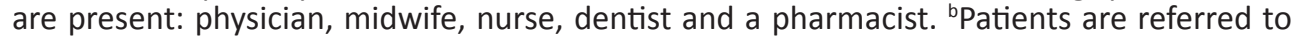
a district hospital closets to their primary health care centre. The district hospital provides secondary health care. 'Dr. Sardjito hospital provides tertiary care and is the referral hospital of the province Central Java and special region Yogyakarta.

\section{Statistical analysis}

Data management was performed using FileMaker Pro 13 Advanced and FileMaker Go and analyses were performed using IBM ${ }^{\circ}$ SPSS statistics version 22. TCAM usage in relation to the length of the time intervals was analyzed using a Kaplan-Meijer model. To evaluate the statistical significance of associations between TCAM use and categorical variables, e.g. gender, ethnicity, religion, chi-square tests were used and t-test was used for continuous variables, e.g. age. 


\section{Results}

Between November 2013 and January 2015141 newly diagnosed NPC patients completed the questionnaire. Two-third of the patients were men $(n=95)$ and age ranged from 18 till 73 years with an average age of 48 . The majority of the patients was Javanese (97.9\%), married (92.9\%) and Muslim (93.6\%). Only 6.4 per cent of the patients were diagnosed with stage I/II while the vast majority had advanced stage (III, IVa, or IVb) at diagnosis. Eighteen per cent of the patients already developed distant metastasis (stage IVc). Ninety-two per cent of the patients were not aware of their disease before diagnosis in the dr. Sardjito hospital. On average patient experienced a mild pain (mean 3.57 on a scale of 10) (Table 1).

\section{Time between different periods in referral system}

When asked about length of the first period between onset of symptoms and the first visit to the primary health care center most patients were incapable to make a good estimation. For this reason, this time interval (period 1, figure 1) was excluded. In addition, 28 questionnaires were excluded since the length of both intervals of period 2 and period 3 were unknown. Median interval of period 2 was 11 weeks (range 0-88) and period 3 was 4 weeks (range 0-96). The interval of period 2 combined with period 3 varied between 0 weeks and 144 weeks.

\section{TCAM usage}

Sixty-two per cent answered yes when asked if they ever used TCAM before. For each period patients were asked again if, during the interval, they used TCAM. This usage, assessed with a yes/no question, increased from 1.4 per cent in period 1, to 17.7 per cent in period 2 to 50.4 per cent in period 3 eventually. However, the actual TCAM usage - assessed by specific questions related to TCAM procedures and TCAM products- appeared to be higher than the perceived TCAM usage and also increased over time between the different periods: 25.5 to 45.4 to 55.0 percent. Overall, 82.3 per cent of the patients used TCAM at some point between first symptoms and diagnosis (figure 2). Patients who did not use TCAM after the onset of the symptoms and before diagnosis of NPC were older than those who did use TCAM respectively 54.5 years and 47.3 years of age $(p=0.007)$, and slightly higher educated ( 40.5 versus 56 who did not finish primary school) $(p=0.04)$ (table 1$)$. 
Table 1 | Characteristics of newly diagnosed patients with NPC

\begin{tabular}{|c|c|c|c|c|c|}
\hline Characteristics & \multicolumn{2}{|c|}{ TCAM user } & \multicolumn{2}{|c|}{ Non user } & p-value \\
\hline Age (years) & & & & & 0.007 \\
\hline \multirow[t]{2}{*}{ Mean and \pm SD } & \multicolumn{2}{|c|}{$47.3 \pm 12$} & \multicolumn{2}{|c|}{$54.5 \pm 12.1$} & \\
\hline & $\mathrm{N}$ & $\%$ & $\mathrm{~N}$ & $\%$ & \\
\hline Gender & & & & & 0.94 \\
\hline Male & 78 & 67.2 & 17 & 68 & \\
\hline Female & 38 & 32.8 & 8 & 32 & \\
\hline Ethnicity & & & & & 0.47 \\
\hline Java & 114 & 98.3 & 23 & 95.8 & \\
\hline Other & 2 & 1.7 & 1 & 4.2 & \\
\hline Education & & & & & 0.04 \\
\hline No school and primary school & 47 & 40.5 & 14 & 56 & \\
\hline Junior high and high school & 54 & 46.6 & 5 & 20 & \\
\hline Bachelor/ Master & 15 & 12.9 & 6 & 24 & \\
\hline Marital status & & & & & 0.13 \\
\hline Not married & 6 & 5.2 & 0 & 0 & \\
\hline Widow/widower & 4 & 3.5 & 0 & 0 & \\
\hline Married & 105 & 91.3 & 25 & 100 & \\
\hline Religion & & & & & 0.45 \\
\hline Islam & 110 & 94.8 & 22 & 88 & \\
\hline other & 6 & 5.1 & 3 & 12 & \\
\hline Distance & & & & & 0.28 \\
\hline$<50 \mathrm{~km}$ & 64 & 55.2 & 18 & 72 & \\
\hline $50-100 \mathrm{~km}$ & 33 & 28.4 & 5 & 20 & \\
\hline$>100 \mathrm{~km}$ & 19 & 16.4 & 2 & 8 & \\
\hline Health status (Likert scale 1-10) & & & & & 0.99 \\
\hline Mean and \pm SD & 3.57 & \pm 1.186 & 3.56 & \pm 1.609 & \\
\hline Stage & & & & & 0.97 \\
\hline$|-| \mid$ & 8 & 6.9 & 1 & 4 & \\
\hline III & 22 & 19 & 4 & 16 & \\
\hline IVa & 25 & 21.6 & 6 & 24 & \\
\hline IVb & 37 & 31.9 & 8 & 32 & \\
\hline IVc & 20 & 17.2 & 5 & 20 & \\
\hline missing & 4 & 3.4 & 1 & 4 & \\
\hline
\end{tabular}




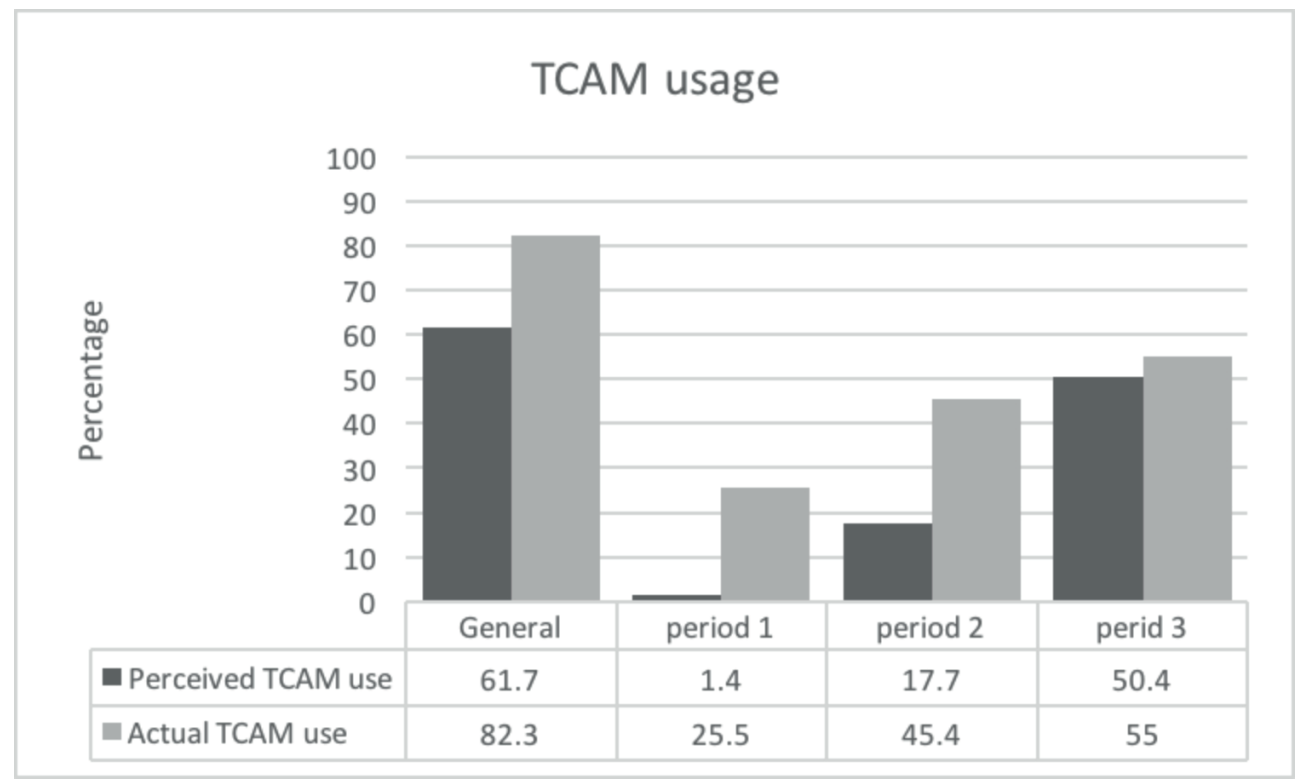

Figure 2 | TCAM usage over time in the different periods. Period 1: from the onset of the symptoms until visiting a physician at a primary health care center. Period 2: the time between visit at the primary health care center until the first appointment at the district hospital. Period 3: represents the time between the referral from the district hospital until the date of diagnosis

\section{TCAM procedures and products}

The main reported TCAM procedures were visiting a TCAM physician ( $n=91)$, herbalist $(n=15)$, local traditional healer $(n=2)$, masseur $(n=5)$, and other healers $(n=5)$. None of the patients underwent or went to acupuncture, chiropractor, hypnotist, meditation healer, naturalist, pranic healer, spiritual healer, or yoga practitioner, although they are common Indonesian TCAM procedures.

A wide variety of TCAM products where used such as daun sirsak (leaves from Soursop fruit), manggis (or mangosteen is a tropical fruit originated in Indonesia), jamu jawa (traditional Javanese herbal medicine), kunir putih (turmeric) and benalu (family of the mistletoe). Daun sirsak was the most commonly used, followed by manggis and jamu jawa. The perceived usefulness of visits to TCAM procedures and usage of TCAM products was assessed on a Likert scale ranging from 1 till 5 where 1 reflects 'not at all' and 5 'very helpful'. An average of 2.15 was found among the different TCAM procedures and an average of 2.57 among different TCAM products. 


\section{TCAM usage and length interval}

Firstly, we looked at period 2 and 3 separately. When patients visited their physician at the primary health care center but before referral to a district hospital (period 2) a significant delay can be found for those who underwent TCAM procedures compared to those who did not underwent any TCAM procedures $(p=0.031)$. Usage of TCAM products was non-significantly associated with a delay compared to non-users of TCAM products $(p=0.094)$. Combining TCAM procedures and TCAM products the mean delay was 22.9 weeks for users versus 14.8 weeks for non-users $(p=0.032)$ in period 2 (figure $3 A, 3 B, 3 C$ ). However, no significant difference for TCAM procedures, TCAM products, or a combination of the two, could be found when looking only at the period between the appointment at a district hospital and the diagnosis (period 3) (figure 3D, 3E, 3F).

Secondly, to gain more insight in usage from the first visit at the primary health care center until diagnosis, period 2 and 3 were combined. Depending on the type of TCAM (product, procedures or both) groups were defined as following: a) patients who did not use TCAM; b) TCAM in the period 2 but not in period 3 ; c) TCAM in period 3 but not in period 2; d) TCAM in both periods). Those who never used TCAM products were significantly earlier diagnosed than those who did use TCAM products $(p=0.006)$. There was no difference in delay between those who underwent TCAM procedures, or a combination of procedures and products, compared to those who did not use TCAM (figure $3 \mathrm{G}, 3 \mathrm{H}, 3 \mathrm{I}$ ).

There was no significant difference between those who never used any kind of TCAM products compared to those who used TCAM products in both periods (period 2 and 3), or between those who never underwent any form of TCAM procedures compared to those we who did during both time periods. However, when combining the TCAM products and procedures, patients who not did use any TCAM were diagnosed at a significant earlier time point compared to those who always used TCAM (mean delay 24 weeks versus 41 weeks; $p=0.03$ ) (figure $3 \mathrm{~J}, 3 \mathrm{~K}, 3 \mathrm{~L}$ ). 


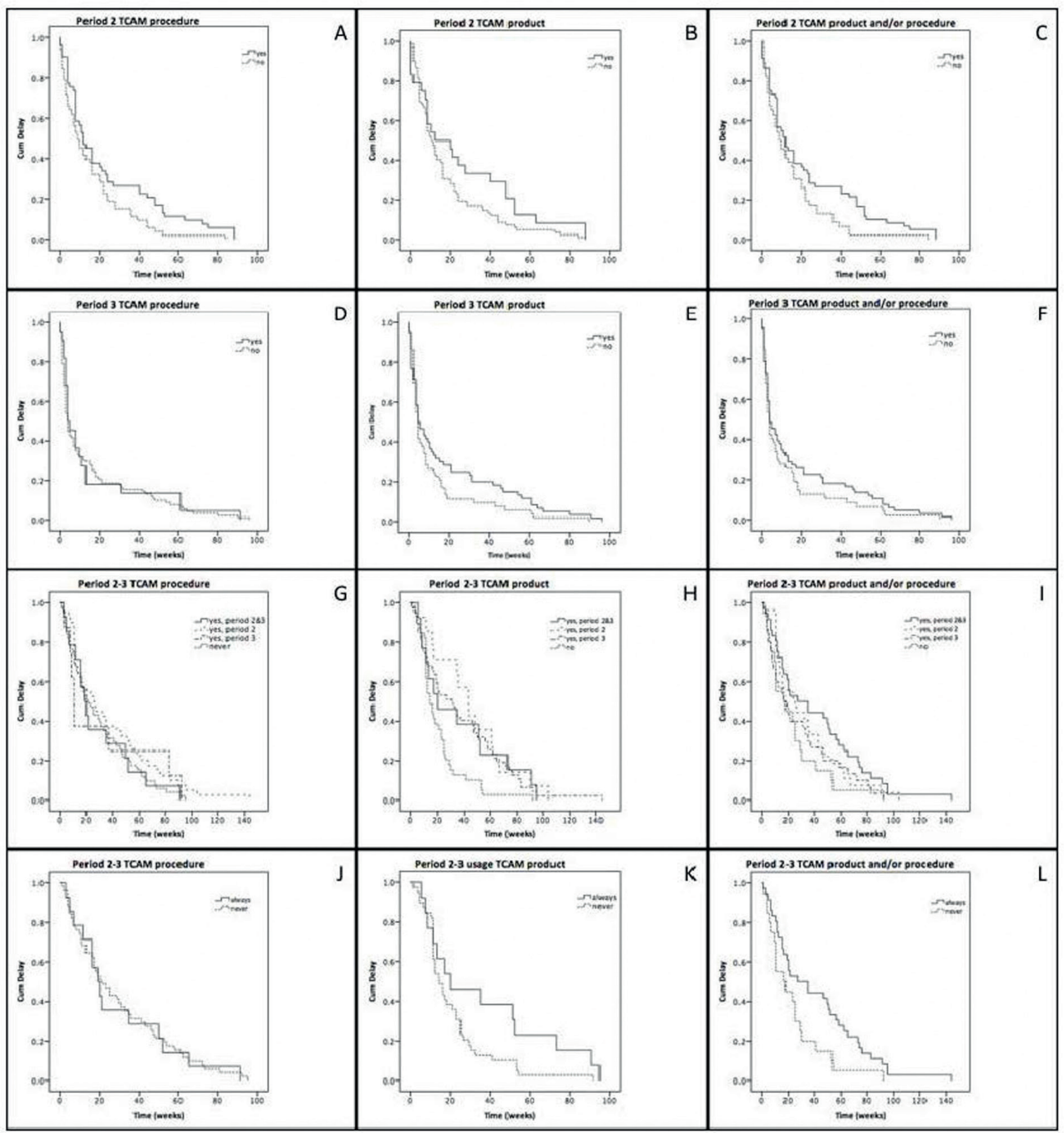

Figure 3 | Delay to diagnosis. A: Period 2 TCAM procedures; B: Period 2 TCAM product; C: Period 2 TCAM product and procedures; D: Period 3 TCAM procedures; E: Period 3 TCAM product; F: Period 3 TCAM product and procedures; G: Period 2-3 TCAM procedures four groups namely(no-TCAM; TCAM in the period 2 but not in period 3; TCAM in period 3 but not in period 2; TCAM in both periods) ; $\mathrm{H}$ : Period 2-3 TCAM product four groups (no-TCAM; TCAM in the period 2 but not in period 3; TCAM in period 3 but not in period 2; TCAM in both periods); I: Period 2-3 TCAM product and procedures four groups (no-TCAM; TCAM in the period 2 but not in period 3; TCAM in period 3 but not in period 2; TCAM in both periods); J: Period 2-3 TCAM procedures never versus always; K: Period 2-3 TCAM product never versus always; L: Period 2-3 TCAM product \& procedures never versus always. 


\section{TCAM information}

Those who used TCAM mainly gathered their information via friends or neighbors $(n=65)$ or relatives $(n=29)$. In 89 per cent of the cases the goal to use TCAM was to cure the disease. Seventy-four patients did not tell their physician they were using TCAM, those patients who did tell were advised to continue using TCAM in 79 per cent of the cases. The main motivations to use TCAM were the positive experiences of others in the past, followed by advice from family members and the fact that TCAM is relatively cheap. The median number of visits to a physician (in a primary health care center or district hospital) was 4; 19 patients were referred after more than 10 visits with one outlier who visited the physician 40 times before referral.

\section{Discussion}

TCAM is widely used among cancer patients in a Asian context [25,27-29]. The world health organization traditional medicine strategies for 2014-2023 includes harnessing the potential contribution of traditional medicine to health care and promoting safe and effective use of traditional medicine, whenever usage is appropriate [30]. In Javanees culture there is a strong belief that the healing process is also based on a fitness concept (cocok-cocokan), meaning not always only conventional medicine can help, and TCAM might even be more effective, but this depends on the disease and person. However, safe usage of TCAM entails that one should be aware of the consequences of the usage, especially in the treatment of cancer [31].

In this study we looked at the usage of TCAM of newly diagnosed patients with NPC before the diagnosis, and the effect of the possible delay until diagnosis. To our knowledge this is the first study looking at newly diagnosed patients with NPC and their TCAM usage and the delay until diagnosis specified in different time slots.

This study shows that TCAM is used widely amongst NPC patients. Interestingly, most patients started to use TCAM further in the referral process. Initially not many people were using TCAM, however, usage increased further on in the referral. Future research is needed to explore in more detail if this usage is due to increased complaints associated with NPC. 
In this study we see that patients who never underwent any kind of TCAM procedures or used TCAM products were diagnosed at an earlier stage compared to those who did use TCAM products. No difference was found in those who only used TCAM in a specific period, but not over the whole period. Suggesting a correlation between strong belief in TCAM and patience behavior influencing treatment decisions $[24,25,32-36]$.

The delay to diagnosis due to TCAM usage does not only affect patients with NPC, also in Indonesian breast cancer patients it is found the usage of TCAM was correlated with a delay to diagnosis $[24,25]$. With NPC as one of the most common type cancer in male and breast cancer as the most common type of cancer in female, possible improvement of treatment outcomes of these types of cancer by minimizing delay to diagnosis and enhance adherence to treatment, will have an impact on Indonesian society.

Most TCAM users did not disclose their physicians that they were using TCAM. A possible explanation could be that participants were not really aware they were using TCAM, since TCAM usage is so ingrained in the Indonesian culture or, alternatively, they were afraid it would affect their referral and treatment. For patients it is important to maintain the harmony with their medical doctor and keep the hierarchical respect towards people with a higher social status [37]. Also in childhood cancer TCAM is often used. Lim et al. described that two third of the patients are using TCAM mainly as a supportive adjunct to their conventional treatment. Here 55.1 per cent of the patients (or the parents of the patients) did not disclose this with their doctor, assuming the doctor already knew about the usage or fear that the doctor would be unsupportive or even stop ongoing treatment [27]. In contrary, Indonesian health care providers consider their knowledge concerning TCAM limited with regards to the safety and efficacy [29].

A main motivation to start with TCAM is to cure the disease. Participants believed in the ability of the TCAM to heal whilst they are not aware they were suffering from cancer. The perceived positive outcome of using TCAM is in line with other studies [36,38]. The information regarding TCAM is mostly gathered via family, friends, and neighbors. This highlights the idea of the strong interpersonal network in Indonesian culture, and is in accordance with Malaysian studies showing that patients diagnosed with cancer rely on family and friends [36,39]. 


\section{Limitations of the study}

The set-up of the questionnaire was in such a way that first patients were asked about their TCAM usage directly after the first onset of symptoms. The interval between the onset of the first symptoms and the date of diagnosis ranged between 1 and 144 weeks. Especially for those with long delay to diagnosis, it was difficult to recall if they actually used TCAM or not. This could possibly have been prevented when the periods would have been in reversed order starting with the questions for period 3 , followed by period 2 and latest period 1 .

Since TCAM usage is so embedded in the Indonesian culture that we only had a small group of patients we never used any kind of TCAM. Although we belief this is a fair representation of the real dispersion of TCAM usage, this might explain why some results are not significant. Also since TCAM usage is so common patients might not recognize the usage as such. To minimize this bias, questions regarding motivation to use TCAM were asked, and all patients answered their motivation to use TCAM was to minimize the symptoms of NPC or to cure the disease. We can only assume that given answers regarding TCAM usage in this questionnaire indeed only refer to the TCAM used to deal with the symptoms of NPC.

\section{Conclusions}

Our results show that TCAM is generally used among newly diagnosed NPC patients. This is often advised by family, friend, or neighbors. Those who never used TCAM products or underwent any form of TCAM procedures have significantly less delay to diagnosis compared to those who did. Delay in diagnosis is not solely depending on this TCAM use, but it is one of the influencing factors. Understanding of TCAM usage can help the integration with conventional treatment. By creating more awareness about the usage of TCAM and the importance of early diagnosis among community, patients might seek medical help at an earlier time point. Our findings can help to set up a community-based education program as well as an education program for health care providers in the primary health care centres to raise attention to the influence of TCAM on delay in diagnosis related to NPC. 


\section{Annex 1 | Questionnare}

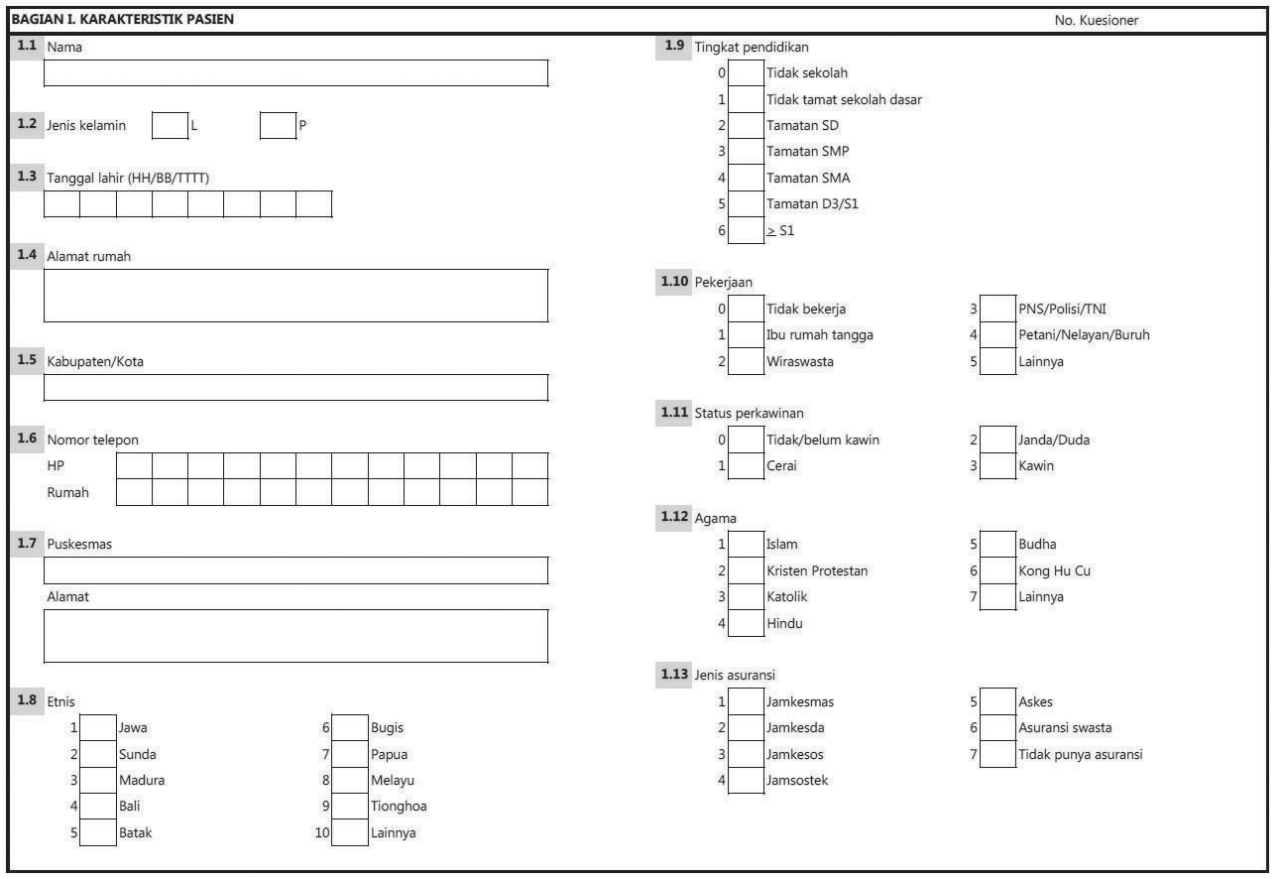

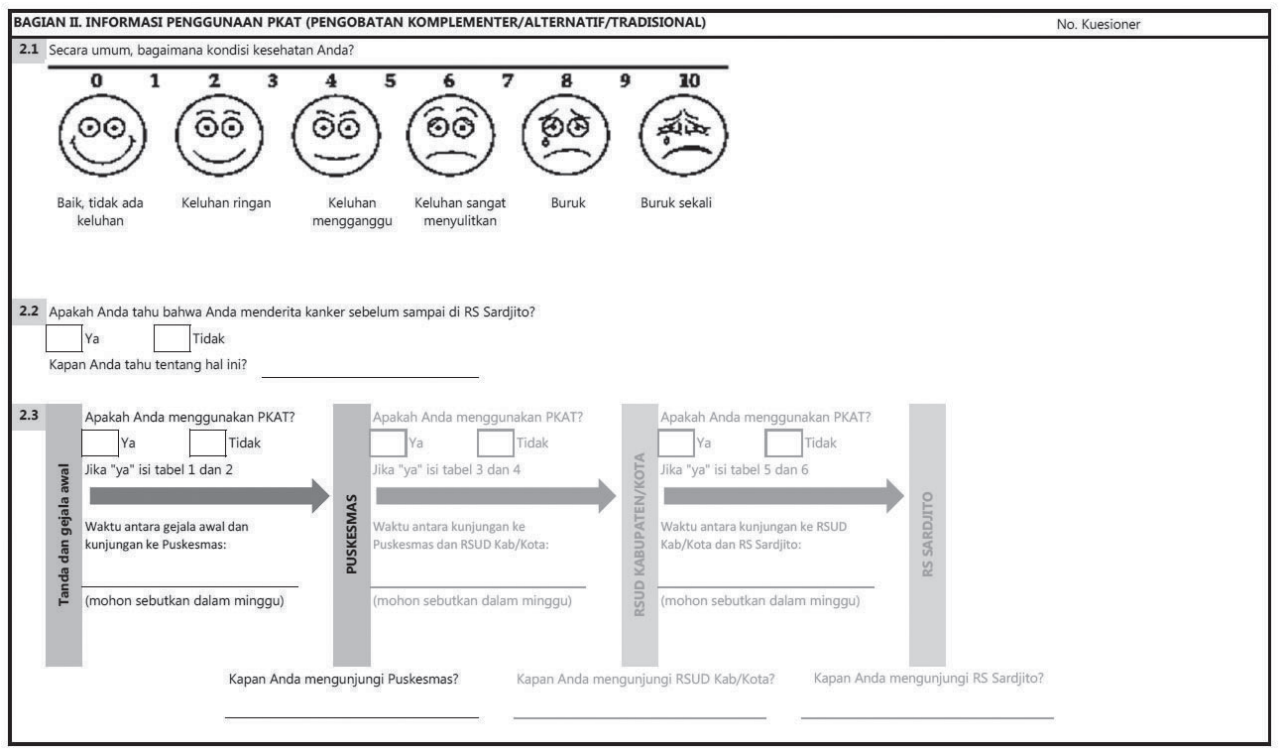




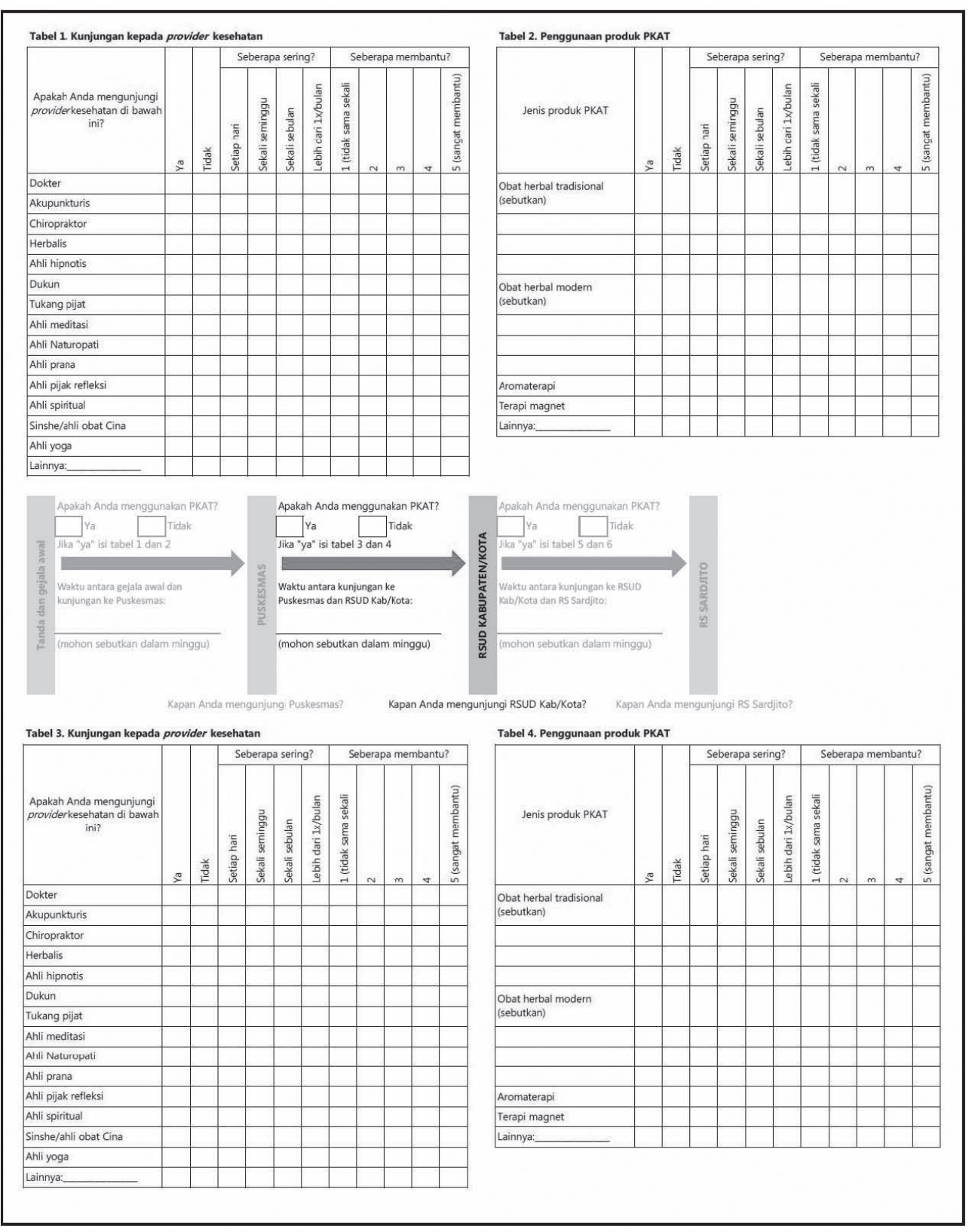




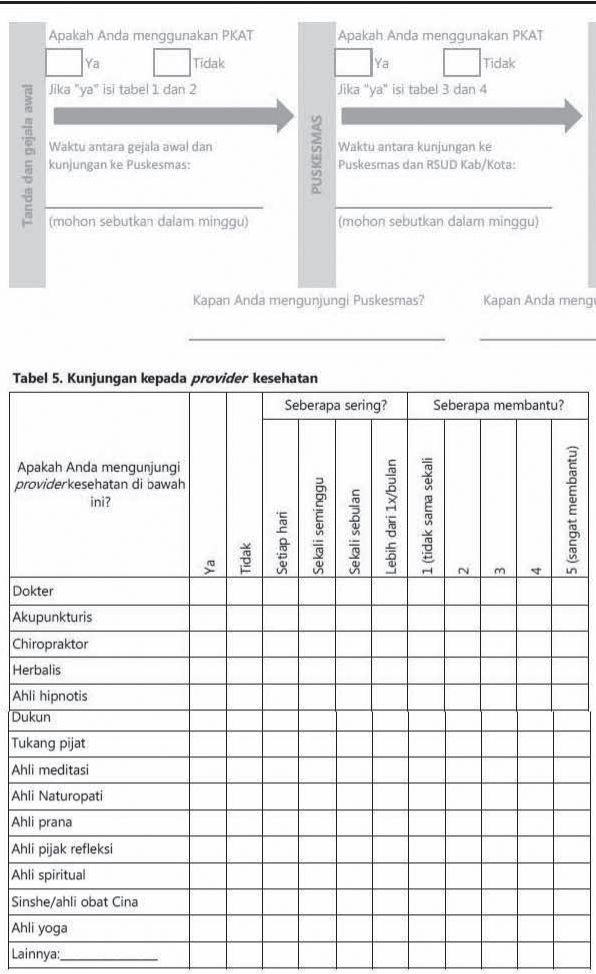

2.4 Dari mana Anda tahu tentang PKAT? (pilih semua yang sesuai)

\begin{tabular}{|l|l|}
\hline & Provider kesehatan (dokter, perawat, paramedis lainnya) \\
& Keluarga/kerabat \\
& Teman/tetangga \\
\hline & Ahli obat tradisional/Dukun \\
\hline & Media (Internet, TV, koran, radio, majalah) \\
\hline & Komunitas/kelompok tertentu \\
\hline & Pasien lain \\
\hline & Mencari sendiri
\end{tabular}

2.5 Mengapa Anda menggunakan PKAT?

\begin{tabular}{|l|l|}
\hline & Untuk mengurangi gejala \\
\hline & Untuk menyembuhkan penyakit \\
& Lainnya:
\end{tabular}

2.6 Setelah kunjungan pertama Anda ke dokter, apa yang dilakukannya?

\begin{tabular}{|l|l}
\hline & Memberikan obat-obatan \\
\hline & Tidak melakukan apa-apa/menunggu (observasi) \\
\hline & Meruuk ke RSUD Kab/Kota
\end{tabular}

Tidak melakukan apa-apa/menunggu (observasi)

Merujuk ke RSUD Kab/Kota
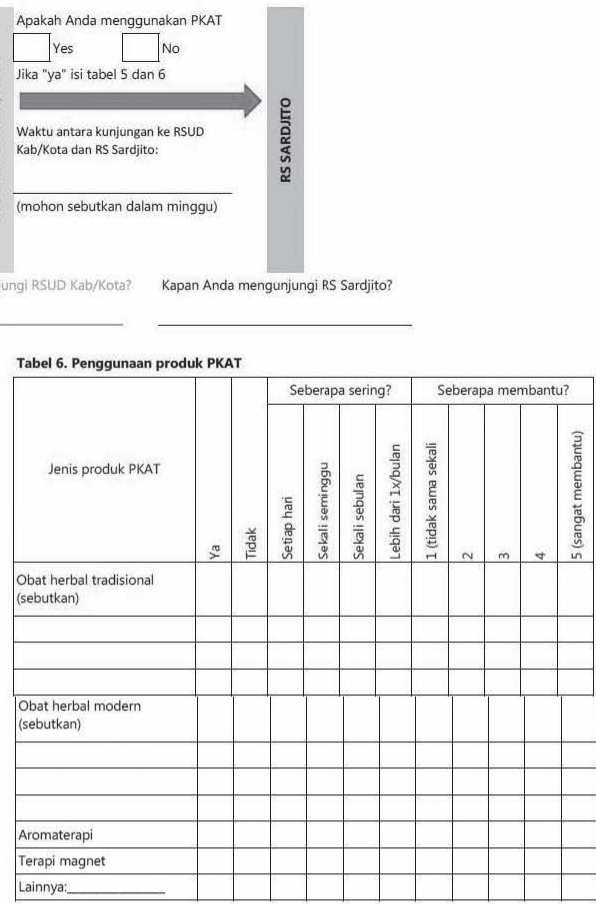

2.7 Apakah Anda memberitahu dokter Anda bila Anda memakai PKAT?

2.7 Apakah Anda memberitahu dokter Anda bi
$\square$ Ya

2.8 Apakah dokter Anda menyarankan untuk terus menggunakan PKAT? Ya Tidak

2.9 Berapa kali Anda mengunjungi dokter Anda sebelum dirujuk ke RSUD? (Sebutkan jumlah kunjungannya)

2.10 Apa motivasi Anda dalam menggunakan PKAT? (pilih semua yang sesuai) Percaya pada PKAT

Kredibilitas ahli PKAT

Rekomendasi dari keluarga dan teman-teman Biaya relatif murah

Pengalaman pribadi dari penggunaan sebelumnya

Pengalaman orang lain

Penyakit yang diderita belum parah

Kesulitan dalam mengakses dokter/rumah sakit

Takut menggunakan obat-obatan kimia

Lainnya: 


\section{References}

1. Adham, M. et al. Nasopharyngeal carcinoma in Indonesia: epidemiology, incidence, signs, and symptoms at presentation. Chin J Cancer-(2012). doi:10.5732/cjc.011.10328

2. Ferlay J, Shin H-R, Bray F, Forman D, Mathers C, Parkin DM. Estimates of worldwide burden of cancer in 2008: GLOBOCAN 2008. Int J Cancer. 2010 Jun 17;127(12):2893917.

3. Wildeman, M. A. et al. Can an online clinical data management service help in improving data collection and data quality in a developing country setting? Trials 12, 190 (2011).

4. Wildeman, M. A. et al. Primary treatment results of Nasopharyngeal Carcinoma (NPC) in Yogyakarta, Indonesia. PLoS ONE 8, e63706 (2013).

5. Stoker, S. D. et al. A prospective study: current problems in radiotherapy for nasopharyngeal carcinoma in yogyakarta, indonesia. PLoS ONE 9, e85959 (2014).

6. Astin, J. A. Why Patients Use Alternative Medicine: Results of a National Study. JAMA 279, (1998).

7. Barnes, P. M., Bloom, B. \& Nahin, R. L. Complementary and alternative medicine use among adults and children: United States, 2007. (2008).

8. Jauhari, A. H. Motivation and trust of patients in seeking medication in sinshe. Berita Kedokteran Masyarakat 1-7 (2008).

9. Broom, A., Wijewardena, K., Sibbritt, D., Adams, J. \& Nayar, K. R. The use of traditional, complementary and alternative medicine in Sri Lankan cancer care: Results from a survey of 500 cancer patients. Public Health 124, 232-237 (2010).

10. Bodeker, G. \& Kronenberg, F. A Public Health Agenda for Traditional, Complementary, and Alternative Medicine. 1-10 (2002).

11. Siti, Z. M. et al. Use of traditional and complementary medicine in Malaysia: a baseline study. Complementary Therapies in medicine 17, 292-299 (2009).

12. Quartey, N. K., Ma, P. H. X., Chung, V. C. H. \& Griffiths, S. M. Complementary and Alternative Medicine Education for Medical Profession: Systematic Review. EvidenceBased Complementary and Alternative Medicine 2012, 1-13 (2012).

13. Chaudhury, R. R. \& Rafei, U. M. Traditional medicine in Asia. ... (2001).

14. Dayhew, M., Wilkinson, J. \& Simpson, M. Complementary and alternative medicine and the search for knowledge by conventional health care practitioners. Contemporary Nurse 33, 1-9 (2009).

15. Peltzer, K., Friend-du Preez, N., Ramlagan, S., Fomundam, H. \& Anderson, J. Traditional complementary and alternative medicine and antiretroviral treatment adherence among HIV patients in Kwazulu-Natal, South Africa. Afr J Tradit Complement Altern Med 7, 125-137 (2010).

16. Gansler, T., Kaw, C., Crammer, C. \& Smith, T. A population-based study of prevalence of complementary methods use by cancer survivors. Cancer 113, 1048-1057 (2008).

17. Mao, J. J., Palmer, C. S., Healy, K. E., Desai, K. \& Amsterdam, J. Complementary and alternative medicine use among cancer survivors: a population-based study. J Cancer Surviv 5, 8-17 (2010).

18. Ernst et al. (1998) - The prevalence of CAM in cancer, a systematic review. 1-2 (2013).

19. Cassileth, B. \& Deng, G. Complementary and Alternative Therapies for Cancer. The oncologist 80-89 (2004).

20. Horneber, M. et al. How many cancer patients use complementary and alternative medicine: a systematic review and meta-analysis. Integr Cancer Ther 11, 187-203 (2012).

21. Zhang, X. General guidelines for methodologies on research and evaluation of traditional medicine. World Health Organisation (2000). 
22. Delima et al. gambaran praktik penggunaan jamu oleh dokter di enam provinsi di indonesia. Bulletin of health research 40, 109-122 (2012).

23. Supardi, S. \& Susyanty, A. L. The use of traditional medicine in self-medication in Indonesia. Bulletin of the World Health ... 38, 80-89 (2007).

24. Iskandarsyah, A. et al. Psychosocial and cultural reasons for delay in seeking help and nonadherence to treatment in Indonesian women with breast cancer: A qualitative study. Health Psychol 33 (2014).

25. Iskandarsyah, A., de Klerk, C., Suardi, D. R., Sadarjoen, S. S. \& Passchier, J. Consulting a traditional healer and negative illness perceptions are associated with non-adherence to treatment in Indonesian women with breast cancer. Psycho-Oncology n/a-n/a (2014). doi:10.1002/pon.3534

26. Broom, A. et al. Indian Cancer Patients' use of Traditional, Complementary and Alternative Medicine (TCAM) and delays in presentation to Hospital. Oman Med J 24, 99-102 (2009).

27. Lim, J. et al. Use of complementary and alternative medicine in paediatric oncology patients in Singapore. Ann. Acad. Med. Singap. 35, 753-758 (2006).

28. Hamidah, A. et al. Prevalence and parental perceptions of complementary and alternative medicine use by children with cancer in a multi-ethnic Southeast Asian population. Pediatr. Blood Cancer 52, 70-74 (2009).

29. Gunawan, S. et al. Comparing Health-Care Providers' Perspectives on Complementary and Alternative Medicine in Childhood Cancer Between Netherlands and Indonesia. Pediatr. Blood Cancer 63, 118-123 (2015).

30. World Health Organization. WHO traditional medicine strategy 2014-2023. (Geneva, 2015).

31. Permana, M. Penggunaan pengobatan alternatif dalam proses penyembuhan penyakit. (2012).

32. Agarwal, G. et al. Breast cancer care in developing countries. World J Surg 33, 20692076 (2009).

33. Hisham, A. N. \& Yip, C. H. Overview of Breast Cancer in Malaysian Women: A Problem with Late Diagnosis. Asian Journal of Surgery 27, 130-133 (2004).

34. Farooqui, M. et al. A qualitative exploration of Malaysian cancer patients' perspectives on cancer and its treatment. BMC Public Health 11, 525 (2011).

35. Wanchai, A., Armer, J. M. \& Stewart, B. R. Breast Cancer Survivors' Perspectives of Care Practices in Western and Alternative Medicine. Oncol Nurs Forum 37, 494-500 (2010).

36. Muhamad, M., Merriam, S. \& Suhami, N. Why breast cancer patients seek traditional healers. International Journal of Breast Cancer 2012, 689168-9 (2012).

37. Claramita, M., Utarini, A., Soebono, H., Van Dalen, J. \& Van der Vleuten, C. Doctorpatient communication in a Southeast Asian setting: the conflict between ideal and reality. Adv Health Sci Educ Theory Pract 16, 69-80 (2011).

38. Tovey, P., Chatwin, J. \& Ahmad, S. Toward an Understanding of Decision Making on Complementary and Alternative Medicine Use in Poorer Countries: The Case of Cancer Care in Pakistan. Integr Cancer Ther 4, 236-241 (2005).

39. Shariff, Z. M. \& Mansor, A. Z. Decision making in breast cancer treatment: a qualitative inquiry. Pertanika Journal (2008). 


\section{DOCTOR'S DELAY}

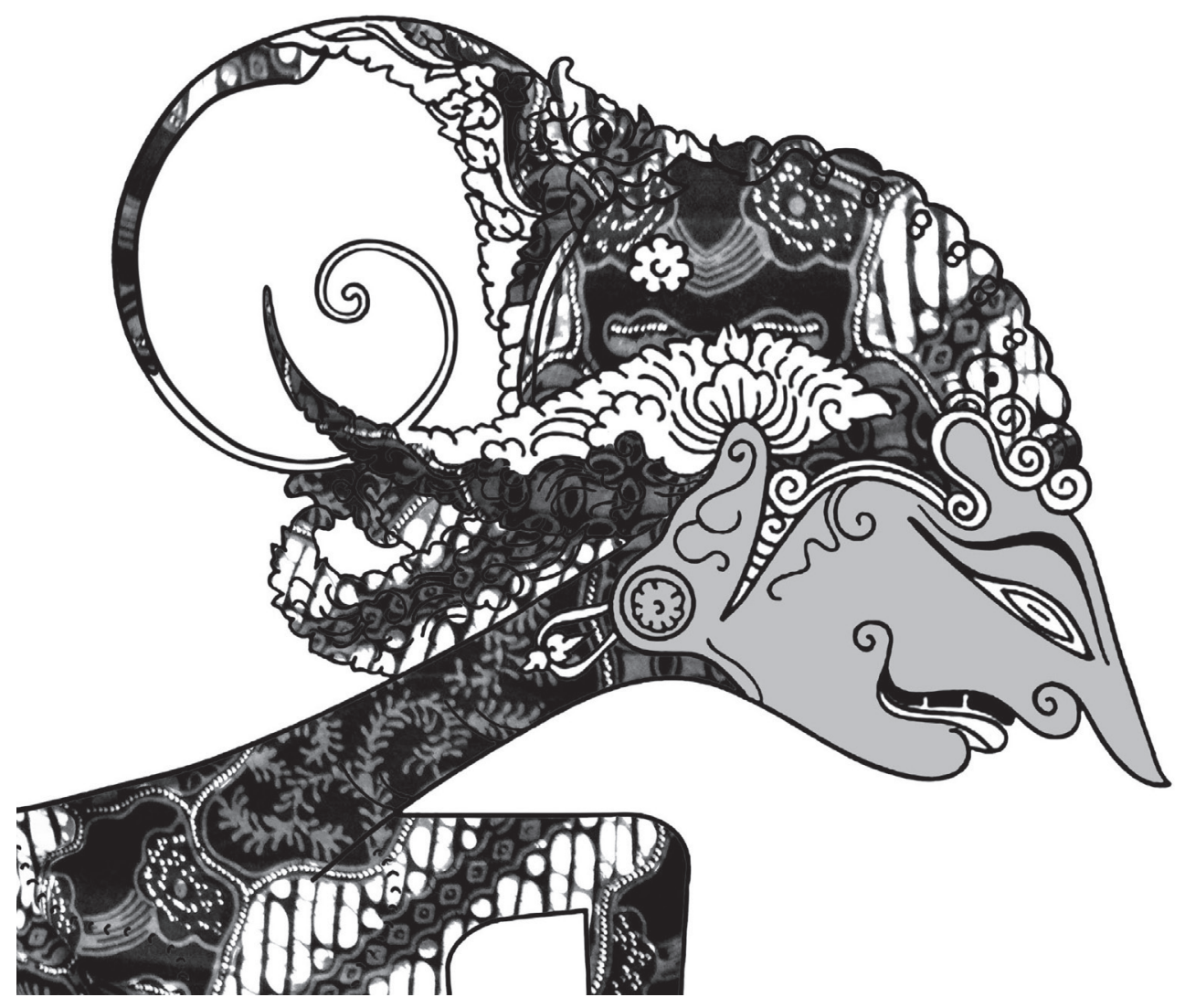




\title{
Chapter 5
}

\section{Knowledge of general practitioners about nasopharyngeal cancer at the puskesmas in Yogyakarta, Indonesia}

\author{
R. Fles* \\ MA. Wildeman* \\ B. Sulistiono \\ SM. Haryana \\ IB. Tan \\ * Both authors contributed equally
}

BMC Medical Education, 2010 Nov vol. 10 p.81 


\begin{abstract}
Background

Nasopharyngeal carcinoma (NPC) is one of the leading causes of cancer death in Indonesia. At initial diagnosis, $80 \%$ of the patients present with advanced stage disease. In Indonesia, primary medical care is generally provided by the health care centres; named Puskesmas. The lack of knowledge of various aspects of NPC of the General practitioners (GPs) working in these centers might contribute to the diagnostic delay. The aim of this study was to assess the knowledge of these GPs on different aspects of NPC including symptoms, risk factors and incidence.
\end{abstract}

\title{
Methods
}

One hundred six GPs in the Puskesmas in the Yogyakarta province were subjected to a questionnaire on different aspects of NPC based on literature and interviews with Head and Neck Surgeons.

\section{Results}

All GPs approached participated and in total 106 questionnaires were filled in. All participants were aware of NPC as a disease and $89 \%$ confirmed that it is a serious problem in Indonesia. However, 50\% of the participants believed NPC has a low incidence in their region. The question on early symptoms gave a mean 4.2 answers of which $50 \%$ were incorrect.

The GPs provided a total of 318 answers when asked for the risk factors of NPC, $75 \%$ of which were incorrect. Fifty seven GPs (54\%) stated that they did not receive sufficient education on NPC at the university and insufficient knowledge was gained during daily practice. Ninety-two percent of the GPs were interested in additional education, preferably in form of lectures, meetings or folders.

\section{Conclusion}

This study revealed that GPs in the Puskesmas in Yogyakarta lack knowledge on all aspects of NPC. This is an important finding as NPC is endemic in Indonesia and the Puskesmas are the institutions which provide primary medical health care in the country. Further education of the GPs in these endemic areas could be a first step to increase the rate of early detection. Therefore, we suggest 1) to conduct a medical awareness campaign for GPs on the most important subjects concerning NPC, and 2) as soon as NPC awareness among GPs has risen, provide further education on the risk factors, the early symptoms and the incidence, education to the community. We propose to extend this study to other areas in Indonesia (i.e. Jakarta, Surabaya, Central Java), using models that have been developed in Yogyakarta. 


\section{Background}

NPC is a rare malignancy in most parts of the world. In year 2000 there were approximately 65,000 new cases and 38,000 deaths worldwide [1]. However, NPC is endemic in a few of well-defined populations, for example in China, Southeast Asia, Arctic, Middle East/North Africa and North America [2]. The highest incidence has been observed in Hong Kong where approximately 1 out of 40 men developed a NPC before the age of 75 [3].

NPC in Indonesia has a relatively high incidence of at least 5.7 among men and 1.9 among women per 100.000 (www.iarc.fr) compared to the worldwide incidence 1.9 among men and 0.8 among women. It should be noted that the actual incidence of NPC in Indonesia is unknown due to poor cancer registries. For examples, the Ear, Nose and Throat (ENT) department of the Dr. Sardjito Hospital in Yogyakarta already has 200 new cases of NPC a year and is 1 of the 4 big hospitals in Yogyakarta (data of unpublished study).

One of the most important factors playing a role in the tumour development of NPC is the presence of the Epstein-Barr virus (EBV). The undifferentiated carcinoma (WHO type III) is always associated with EBV [4]. In addition, high levels of volatile nitrosamines in preserved food can be found in the high incidence regions, and has shown to be a putative carcinogen for the development of NPC [5]. Also, the consumption of salty-preserved fish has been strongly associated with an increased risk of developing NPC [6-12]. The non-environmental risk factors include: gender, ethnicity and the family history.

The non-specific nature of the early symptoms makes NPC a disease challenging to diagnose at early stage. The most common presenting symptom is a painless mass in the neck. Early symptoms like nasal dysfunction, aural dysfunction and headache are non-specific for NPC but should be a warning sign in endemic areas. Given these nonspecific of NPC, $80 \%$ of the patients present themselves with a stage 3 or 4 disease.

The choice of treatment for primary NPC is radiotherapy, with chemotherapy for advanced stage disease. Despite the radio responsiveness of nasopharyngeal tumours, good long-term survival is only achieved for patients with early disease and with minimal neck involvement [13-15]. 
Given that prognosis is better when treatment is started at an earlier stage of the disease, it is of major importance to determine the various factors that may possibly contribute to the diagnostic delay of NPC in Indonesia.

We hypothesized that one of the possible mechanisms leading to late NPC presentation observed in Indonesia is a lack of knowledge and awareness among primary health care workers; the GPs working in the primary health care centres; Puskesmas.

In this study we aimed to assess the current knowledge amongst GPs in the Puskesmas in Yogyakarta about NPC regarding risk factors, incidence and symptoms. The findings from this study will be useful to complement knowledge and awareness on this important public health issue in Indonesia.

\section{Methods}

Interview and questionnaire development

A questionnaire based on literature was designed appointing the most important aspects of NPC; including the risk factors, early symptoms, as well as the education possibilities and the interest in education. This first draft was discussed during a semi constructed interview with four Head and Neck surgeons from Universitas Indonesia, Jakarta, Universitas Gadjah Mada, Yogyakarta and The Netherlands Cancer Institute, Amsterdam. The questionnaire was adapted according to consensus opinions.

The second draft was filled in by 10 Indonesian ENT-specialist who gave oral and written comment. These ENT specialists listed the key aspects about NPC a GP should be familiar with, which include the awareness of early NPC symptoms and how to pursue if a patient shows these symptoms. GPs are often unaware to whom and when they should refer a patient. If they refer, patients are often referred to a general surgeon rather than to an ENT specialist.

\section{Questionnaire}

The questionnaire consists of four sections, assessing (1) general information about the GPs such as number of years of experience and the number of patients 
seen in one year; (2) knowledge on NPC such as early symptoms and risk factors (3) incidence, experience in daily practice regarding the extent to which the GPs had been confronted with NPC in their Puskesmas and how they dealt with patients suspected of NPC; and (4) ambition and wishes regarding future education on NPC.

The questionnaire contained open and closed questions. Possible responses were grouped together for the ease of presentation and understanding as described in the results. The open-ended questions featured the questions where multiple answers were possible, for instance when asked about risk factors or presenting symptoms.

\section{Study population}

The study population consisted of GPs from three different districts in the Yogyakarta province. In total there are 68 Puskesmas in these regions. With two or three GPs working in one Puskesmas, approximately 170 GPs are practicing in a Puskesmas in this area. One hundred and six GPs were approached in their Puskesmas to participate. They were asked to fill in the questionnaire directly in the presence of the researcher (RF).

\section{Results}

All 106 GPs approached participated in this study and completed their questionnaires (100\%). All participants know NPC as a disease and $89 \%$ confirmed it is a serious problem. Fifty-nine questionnaires were completed immediately during the visit of the interviewer. The other forty-seven were completed at a later time point. Patients waiting for medical attention, was the reason for completion questionnaire without the presence of the researcher. Thirty questionnaires were collected in the centre of Yogyakarta (Kota), the other 76 questionnaires were collected in the rural areas, Sleman and Bantul. The number years of work experience of the GPs varied from less than one year to 29 years (median= 5 years). There was no correlation between working experience and knowledge on NPC. Participant details are outlined in Table 1. 
Table 1 | Descriptive divided by the three district of the province Yogyakarta

\begin{tabular}{|lllll|}
\hline Questions & & Kota $(\mathbf{n = 3 0})$ & Selman $\mathbf{n = 4 2})$ & Bantul $(\mathbf{n = 3 4})$ \\
\hline How long you worked as a doctor? (in year) & & 8.2 & 8.1 & 6.7 \\
\hline Have you always worked in this area? & yes & 26 & 42 & 32 \\
\hline & no & 3 & 0 & 2 \\
\hline $\begin{array}{l}\text { From which university did you get you } \\
\text { medical degree? }\end{array}$ & missing & 1 & 0 & 0 \\
\hline $\begin{array}{l}\text { How many patients do you treat a year? } \\
\text { How many GP's are practicing in your }\end{array}$ & other & 18 & 26 & 21 \\
\hline $\begin{array}{l}\text { Huskesmas? } \\
\text { Pus }\end{array}$ & & 10364 & 7944 & 6236 \\
\hline
\end{tabular}

Overview of the descriptive variable over the three districts.

Knowledge about the early symptoms and risk factors

When asked to list early symptoms on NPC, the participating GPs gave a mean of 4.2 answers. However, $49 \%$ of these answers were incorrect (Table 2). The most frequent given answer provided was swelling in the neck $(n=78 ; 35 \%)$. Nasal obstructions and epitaxis, caused by presence of tumour mass in the nasopharynx, were mentioned 70 times (32\%). Tinnitus and hearing loss due to dysfunction of the Eustachian tube, associated with the lateroposterior extension of the tumour to the paranasopharyngeal space was stated 33 times (15\%). Headache, diplopia, facial pain and numbness was pointed out 25 (11\%) times, these symptoms are caused by skull-base erosion and palsy of the fifth and sixth cranial nerves, associated with the superior extension of the tumour.

Of the 106 participants only 20 participants provided four or more correct symptoms of NPC. The majority of the GPs (66\%) could give two correct answers. The most frequent incorrect NPC symptoms stated answers were hoarseness and dysphagia.

The risk factor questions yielded a total of 328 answers, of which only $36 \%$ were indeed risk factors for NPC (Table 2). Surprisingly, EBV was only mentioned 12 times, while smoking, which is not a risk factor for NPC in Indonesia, was answered 80 times. Seven out of the eight participants who provided only one answer gave an incorrect answer. 
Table 2 | Number of correct and incorrect answers

\begin{tabular}{|lccc|}
\hline & Correct & incorrect & total \\
\hline symptoms & $227(51 \%)$ & $215(49 \%)$ & 442 \\
\hline risk factors & $113(36 \%)$ & $203(64 \%)$ & 316
\end{tabular}

Overview of the total numbers of correct and incorrect answers when asked about the symptoms and the risk factors of NPC.

\section{Knowledge on incidence and referral}

Fifty percent of the participating GPs falsely believed that NPC has a low incidence in their region. Furthermore, only $45 \%$ was aware of the fact NPC can affect both children and adolescents (table 3). Seventy four percent of the GPs stated that they had never seen a patient with NPC in their Puskesmas. Enlarged lymph nodes is the most common presenting symptom for NPC. The differential diagnosis for these lymph node enlargements is limited and in most cases related to tumours in the ENT region. Strikingly, $80 \%$ of the GPs have seen patients with enlarged lymph nodes in the daily practice. In an open question on referral of a suspected NPC case, only $18 \%$ percent would refer the patient to an ENT specialist. Further details are shown in table 4.

Table 3 | General knowledge of the General Practitioners about NPC Indonesia

\begin{tabular}{|lcccccc|}
\hline $\begin{array}{l}\text { Have you ever heard of nasopharyngeal } \\
\text { carcinoma? }\end{array}$ & yes & no & & & missing \\
\hline & $106(100 \%)$ & 0 & & & & \\
\hline $\begin{array}{l}\text { NPC is a serious problem in Indonesia/ } \\
\text { Java }\end{array}$ & $\begin{array}{c}\text { strongly } \\
\text { agree }\end{array}$ & agree & neutral & disagree & $\begin{array}{c}\text { Strongly } \\
\text { disagree }\end{array}$ & missing \\
\hline & $19(18 \%)$ & $73(69 \%)$ & $9(8 \%)$ & $2(2 \%)$ & 0 & $3(3 \%)$ \\
\hline $\begin{array}{l}\text { The number of new people suffering } \\
\text { NPC on Indonesia per year. }\end{array}$ & $10-99$ & $100-249$ & $250-499$ & $500-999$ & $>1000$ & missing \\
\hline $\begin{array}{l}\text { From what age people can develop } \\
\text { NPC? }\end{array}$ & $6(6 \%)$ & $17(16 \%)$ & $21(20 \%)$ & $9(8 \%)$ & $25(24 \%)$ & $28(26 \%)$ \\
\hline $\begin{array}{l}\text { Which age category has the highest } \\
\text { incidence? }\end{array}$ & $8(8 \%)$ & $39(37 \%)$ & $37(35 \%)$ & $15(14 \%)$ & 0 & $7(7 \%)$ \\
\hline
\end{tabular}

General questions about NPC concerning the incidence, severity, age and relation to gender. 
Table 4 | Question related to the situation in the puskesmas

\begin{tabular}{|c|c|c|c|c|c|c|}
\hline \multirow{2}{*}{$\begin{array}{l}\text { Did you ever treat a patient with } \\
\text { NPC? }\end{array}$} & yes & no & & & & missing \\
\hline & 16 (15\%) & 89 (84\%) & & & & $1(1 \%)$ \\
\hline \multirow[t]{2}{*}{$\begin{array}{l}\text { Have you ever seen a patient with } \\
\text { NPC in your clinic? }\end{array}$} & never & $\begin{array}{l}<2 \text { times } \\
\text { per year }\end{array}$ & $\begin{array}{l}\text { 2-5 times } \\
\text { per year }\end{array}$ & $\begin{array}{l}\text { 5-10 times } \\
\text { per year }\end{array}$ & $>10$ times & missing \\
\hline & 78 (74\%) & $22(20 \%)$ & $4(4 \%)$ & $0(0 \%)$ & $1(1 \%)$ & $1(1 \%)$ \\
\hline \multirow{2}{*}{$\begin{array}{l}\text { The number of new people } \\
\text { suffering NPC in your region per } \\
\text { year? }\end{array}$} & $<100$ & $100-250$ & $250-500$ & $500-1000$ & $>1000$ & missing \\
\hline & $80(75 \%)$ & $0(0 \%)$ & $2(2 \%)$ & $0(0 \%)$ & $1(1 \%)$ & $23(22 \%)$ \\
\hline \multirow{2}{*}{$\begin{array}{l}\text { Have you seen a shift in the } \\
\text { number of people suffering NPC in } \\
\text { year clinic the last year? }\end{array}$} & $\begin{array}{l}\text { yes, more } \\
\text { patients }\end{array}$ & $\begin{array}{l}\text { yes, less } \\
\text { patients }\end{array}$ & no & & & missing \\
\hline & $7(7 \%)$ & $2(2 \%)$ & $91(86 \%)$ & & & $6(6 \%)$ \\
\hline \multirow{2}{*}{$\begin{array}{l}\text { How often do you, in average a } \\
\text { year, treat patients with enlarged } \\
\text { neck lymph nodes? }\end{array}$} & never & $\begin{array}{l}<2 \text { times } \\
\text { per year }\end{array}$ & $\begin{array}{l}\text { 2-5 times } \\
\text { per year }\end{array}$ & $\begin{array}{l}\text { 5-10 times } \\
\text { per year }\end{array}$ & $>10$ times & missing \\
\hline & $21(20 \%)$ & $32(30 \%)$ & 30 (28\%) & $13(12 \%)$ & $6(6 \%)$ & $4(4 \%)$ \\
\hline \multirow[t]{2}{*}{$\begin{array}{l}\text { How did you treat most of the } \\
\text { patients? }\end{array}$} & $\begin{array}{l}\text { No } \\
\text { treatment }\end{array}$ & medication & $\begin{array}{l}\text { local } \\
\text { surgery }\end{array}$ & $\begin{array}{l}\text { refer to } \\
\text { hospital }\end{array}$ & $\begin{array}{l}\text { medication } \\
\text { and referring } \\
\text { to a hospital }\end{array}$ & missing \\
\hline & $4(4 \%)$ & 15 (14\%) & $1(1 \%)$ & $62(58 \%)$ & $13(12 \%)$ & $10(9 \%)$ \\
\hline \multirow[t]{2}{*}{$\begin{array}{l}\text { What do you do when you } \\
\text { diagnose a patient with NPC? }\end{array}$} & $\begin{array}{l}\text { refer to } \\
\text { hospital }\end{array}$ & $\begin{array}{l}\text { refer to } \\
\text { academic } \\
\text { hospital }\end{array}$ & $\begin{array}{l}\text { refer } \\
\text { to ENT } \\
\text { specialist }\end{array}$ & $\begin{array}{l}\text { refer to } \\
\text { specialist }\end{array}$ & $\begin{array}{l}\text { refer in no } \\
\text { improvement } \\
\text { of treatment }\end{array}$ & missing \\
\hline & $58(55 \%)$ & $3(3 \%)$ & $13(12 \%)$ & $1(1 \%)$ & $1(1 \%)$ & $30(28 \%)$ \\
\hline
\end{tabular}

Questions related to the frequency of patients with NPC recognized by the GP, treatment and the referring system of the GP

When GPs were asked if they would be interested in additional education on NPC; $92 \%$ of the participants responded positive, 7\% were neutral and only one participant strongly disagreed. Although the differences between the preferences for the way to educate were small, $96 \%$ stated a lecture from an ENT-specialist is the best form of further education on NPC. A good alternative or addition could be a folder (88\%). Eighty two percent believes that receiving credits and a certification for participation is important. Finally, $40 \%$ of the participants recommended a refreshing course on NPC in the open comment box. 


\section{Discussion}

Our study revealed that knowledge on essential aspects of NPC among GPs in the Puskesmas in Yogyakarta, Indonesia is poor. This finding is of importance as NPC is endemic in Indonesia and the Puskesmas are institutions, which provided primary medical care in the country. This lack of basic knowledge of NPC might be a fundamental cause for late stage discovery of the disease by GPs.

The majority of the doctors believed that the incidence of NPC in their region is at least a tenfold lower than the estimated incidence. Together with the lack of knowledge on early NPC symptoms and risk factors we can conclude that the knowledge about NPC of these doctors is not sufficient.

Enlarged lymph nodes in the neck is the most common symptom of NPC at presentation. The participants of this study regularly see patients with enlarged neck lymph nodes, but stated they see very few cases of NPC. Combining the overall answers given regarding early symptoms and incidence, we think GPs often do not consider NPC when they see a patient with enlarged neck lymph nodes or other symptoms suspicious for NPC.

A possible solution could be education combined with a screening method. Fachiroh et al has established a cheap and sensitive screening method for NPC which could be easily adopted in the Puskasmas [16]. This method is based on the detection of the Epstein-Barr virus which is present in all NPCs in Indonesia. The combination of more knowledge and an easy way to screen might lead to early detection of NPC.

Following the answers provided by the participants, the number of NPC patients seen by the GPs is much lower compared to the incidence in this region. The results of our study imply that this may be due to the fact that GPs are unable to identify patients with NPC. It should be noted that the majority of the patients, who were treated at the ENT-departments either went directly to a hospital without referral by a GP, or were administered to a hospital as a medical emergency caused by the tumour, for example dyspnoea to massive neck metastasis. In an ongoing study we look into more detail at the referral system. 


\section{Study Limitations}

Not all questionnaires were completed in the presence of the researcher. This was mostly due to lack of time on the GPs side as patients were waiting for their appointments. Despite the statement in the questionnaire not to seek help from third parties, GPs may have searched or asked colleagues for answers in our absence. The results of these 47 participants, who filled in the questionnaires in the absence of the interviewer, were notable better but overall remained poor. For example, 9 of the 12 GPs who knew that EBV was related to NPC completed the questionnaire without supervision. This could imply that even if GPs would have searched for information elsewhere the correct information was not available.

In addition, some of the questions despite our testing may not have been understood completely by the participating GPs. For instance, there was a big variance between the answers provided for the number of patients seen a year, even if these doctors worked in the same Puskesmas. For example, in one Puskesmas two GPs stated that they see 18.000 patients a year, whilst the other GP only sees 4000 patients a year.

\section{Conclusion}

Based on the results of this survey it is clear that the knowledge of the GPs about NPC in the Puskesmas in Indonesia is not sufficient to deal with this important health issue. The problem concerning the identification of patients suffering from NPC is most likely bigger than expected. The number of patients with NPC registered in Sardjito Hospital in the period of 2004 and 2008 might only represent the tip of the iceberg since these are the patients who actually made it to the hospital.

A medical education program should be started to educate the GPs working in the Puskesmas in Indonesia about NPC. The next step could be a campaign to increase public awareness on NPC. Similar campaigns have been enrolled for cervix carcinoma and breast carcinomas [17]. The public needs to be informed to visit the Puskesmas when they have complaints or early NPC symptoms. 


\section{References}

1. Ferlay J,Bray F,Pisani P,Parkin DM: Globocan 2000: cancer incidence, mortality and prevalence worldwide. 2009

2. Chang ET, Adami HO. The enigmatic epidemiology of nasopharyngeal carcinoma. Cancer Epidemiol.Biomarkers Prev. 2006;15:1765-1777.

3. Parkin DM, Whelan SL Ferlay J Teppo L Thomas DB: Cancer. Cancer incidence in five continents, vol. VIII. IARC scientific publications No. 155. 2002.

4. Raab-Traub N. Epstein-Barr virus in the pathogenesis of NPC. Semin.Cancer Biol. 2002;12:431-441.

5. Poirier $\mathrm{S}$, Ohshima $\mathrm{H}$, de The $\mathrm{G}$ et al. Volatile nitrosamine levels in common foods from Tunisia, south China and Greenland, high-risk areas for nasopharyngeal carcinoma (NPC). Int J.Cancer 1987;39:293-296.

6. Guo X, Johnson RC, Deng H et al. Evaluation of nonviral risk factors for nasopharyngeal carcinoma in a high-risk population of Southern China. Int.J.Cancer 2009;124:29422947.

7. Zou J, Sun $Q$, Akiba $S$ et al. A case-control study of nasopharyngeal carcinoma in the high background radiation areas of Yangjiang, China. J.Radiat.Res.(Tokyo) 2000;41 Suppl:53-62.

8. Henderson BE, Louie E. Discussion of risk factors for nasopharyngeal carcinoma. IARC Sci.Publ. 1978 251-260.

9. Yu MC, Ho JH, Lai SH, Henderson BE. Cantonese-style salted fish as a cause of nasopharyngeal carcinoma: report of a case-control study in Hong Kong. Cancer Res. 1986;46:956-961.

10. Yu MC, Huang TB, Henderson BE. Diet and nasopharyngeal carcinoma: a case-control study in Guangzhou, China. Int.J.Cancer 1989;43:1077-1082.

11. Armstrong RW, Imrey PB, Lye MS et al. Nasopharyngeal carcinoma in Malaysian Chinese: salted fish and other dietary exposures. Int J.Cancer 1998;77:228-235.

12. Yuan JM, Wang XL, Xiang YB et al. Preserved foods in relation to risk of nasopharyngeal carcinoma in Shanghai, China. Int.J.Cancer 2000;85:358-363.

13. Chen $\mathrm{CL}$, Hsu MM. Second primary epithelial malignancy of nasopharynx and nasal cavity after successful curative radiation therapy of nasopharyngeal carcinoma. Hum. Pathol. 2000;31:227-2

14. Wei WI, Sham JS. Nasopharyngeal carcinoma. Lancet 2005;365:2041-2054.

15. Al Sarraf M, Reddy MS. Nasopharyngeal carcinoma. Curr.Treat.Options Oncol. 2002;3:2132.

16. Fachiroh J, Prasetyanti PR, Paramita DK et al. Dried-blood sampling for epstein-barr virus immunoglobulin $\mathrm{G}$ (IgG) and IgA serology in nasopharyngeal carcinoma screening. J.Clin.Microbiol. 2008;46:1374-1380.

17. Ali TS, Baig S. Evaluation of a cancer awareness campaign: experience with a selected population in Karachi. Asian Pac.J.Cancer Prev. 2006;7:391-395 


\section{Chapter 6}

Short-term effect of different teaching methods on nasopharyngeal carcinoma for general practitioners in Jakarta Indonesia

MA. Wildeman

R. Fles

M. Adham

ID. Mayangsari

I. Luirink

M. Sandberg

AD. Vincent

F. Fardizza

Z. Musa

Armiyanto

JM. Middeldorp

G. Gerritsen

R. Soewento

IB. Tan

PLoS One. 2012;7(3):e32756. 


\begin{abstract}
In Indonesia, Nasopharyngeal Carcinoma (NPC) is the most frequent cancer of the head and neck region. At first presentation in the hospital most patients already have advanced NPC. Our previous study showed that general practitioners (GPs) working in Yogyakarta, Indonesia lack the knowledge necessary for early detection of NPC. By providing training on early symptoms of NPC we hope that the diagnosis and referral will occur at an earlier stage. Here we assess the current NPC knowledge levels of GPs in Jakarta, evaluate improvement after training, compare the effectiveness of two training formats, and estimate the loss of recall over a two week period.
\end{abstract}

\title{
Methods
}

Two Indonesian GPs visited 31 Primary Health Care Centres (PHCCs) and provided a lecture on NPC. The alternative format consisted of a symposium at the Universitas Indonesia, Jakarta, presented by local head and neck surgeons, with all GPs in the region being invited. To evaluate the effect of both formats a questionnaire was conducted before and after.

\section{Results}

The lecture in the PHCCs was attended by 130 GPs. Sixty-six GPs attended the training in the university hospital and 40 GPs attended both. Pre training the NPC knowledge level was poor with an average of 1.6 symptoms being correctly identified out of a potential maximum of 12 , this was increased to 4.9 post training $(p<0.0001)$. GPs attending the PHCC course recorded a greater increase in correct symptoms than those attending the symposium (3.8 vs. $2.8 ; \mathrm{p}=0.01$ ). After a two week period the knowledge levels had declined slightly from 5.5 correctly identified symptoms to 4.2 ( $p=0.25)$.

\section{Conclusion}

These results confirm our findings regarding GPs insufficient knowledge of NPC. Lectures in the PHCC and a symposium have both been proven to be effective training tools in the education of GPs. 


\section{Introduction}

The Indonesian health care sector represents a mix of public and private providers. The government provides primary health care centres (PHCCs). There are more than 7600 of these centres in Indonesia. At the primary health care level, Indonesia has relatively adequate levels of provision, for every 30000 people one public health centre on average. [1] ,[2]. The PHCCs are the first recourse for Indonesians seeking medical attention, with referral to a hospital occurring when deemed necessary.

Cancer is increasingly recognized as leading cause of death in Indonesia, and nasopharyngeal carcinoma (NPC) is the most frequent cancer in the head and neck area and is the fourth most common tumour occurring in males. The incidence is estimated 6 per 100000, leading to at least 14000 new cases per year [3]. However this may be an underestimation due to poor cancer registration. In most countries NPC is an orphan disease with a worldwide incidence of 80000 new cases per year. However, in Southern China and most of South-East Asia NPC is endemic with a yearly incidence reaching as high as 20-50 cases per 100000 annually [4],[5].

NPC arises in the epithelial lining of the nasopharynx. This neoplasm is frequently seen at the pharyngeal recess (Rosenmüller's fossa) posteromedial to the medial crura of the eustachian tube opening in the nasopharynx [6].

NPC patients present themselves with symptoms from the following categories: (1) presence of tumour mass in the nasopharynx (epistaxis, nasal obstruction, nasal discharge); (2) dysfunction of the Eustachian tube (tinnitus, hearingloss); (3) skull base erosion and palsy of the 5th and 6th nerve (headache, diplopia, facial pain and numbness); and (4) neck mass (painless enlargement of the upper cervical lymph node). The early symptoms such as epistaxis and tinnitus are not specific for NPC, which makes it difficult to diagnose at an early stage [6].

The Epstein-Barr virus is known as the first tumour virus and was associated with NPC in 1970 [7]. Other risk factors of NPC are environmental co-carcinogens, i.e. high levels of volatile nitrosamines and butyrate derivatives in preserved food, especially in salty-preserved fish and dried meat, alcohol and smoking [8-11]. Nonenvironmental risk factors are gender, ethnicity and family history $[12,13]$. 
A majority of patients present with a loco-regional disease most often with an advanced lymph node metastasis in the neck $[14,15]$. Accordingly, the most common symptom at presentation is a painless mass in the neck [15]. Presently, at intake in the hospital Cipto Mangunkusumo hospital/ University of Indonesia, Jakarta $88 \%$ of new patients already have advanced NPC. (Adham et al; Chin J Cancer, submitted). The standard treatment for primary NPC is radiotherapy to which NPC is sensitive, however in advanced cases additional chemotherapy is needed. A recent metaanalysis proved the clinical benefit of concurrent chemoradiation therapy compared with radiotherapy alone in the treatment of advanced NPC in endemic areas [16]. The most important prognostic factor is presenting stage[6,17]. Patients with early stage disease ( $\mathrm{T} 1, \mathrm{~T} 2$ and N0-1 without distant metastasis) can achieve a five years overall survival of $85 \%$ compared to $66 \%$ in patients with late stage disease (T3, T4 and N2, N3 without distant metastasis) [17]. The 10-year disease free survival for early stage NPC is $67-71 \%$ while for late stage disease this is $29-54 \%$. [18].

One possible reason for the high percentage of patients with advanced NPC could be a delay in referral due to poor diagnosis. In our previous study we assessed the knowledge on NPC of the GPs working in the PHCC in the Yogyakarta region [19]. Our results indicated that the knowledge of GPs is insufficient with many not being aware of the high incidence of NPC in their region.

In this study we (1) assess the current knowledge concerning NPC of GPs working in the Jakarta region, (2) evaluate the improvement provided by additional training, (3) compare the effectiveness of two different training formats, and (4) estimate the loss of recall over a two-week period. By providing additional training about NPC and its early symptoms we hope to increase the diagnosis and referral of patients with early stage NPC. An early detection program for breast cancer, cervical cancer and NPC was proven to be effective for down staging breast cancer and cervical cancer, however the training was not sufficient to result in a down staging of NPC [20]. We anticipate our early detection training program to be more effective since we only focus on NPC. 


\section{Methods}

\section{Study population}

For this study we invited GPs from two of the five districts of the province Jakarta. The study population consists of three groups: (1) GPs who only attended the lecture at their own PHCC; (2) those who only attended the symposium at the hospital Cipto Mangunkusumo (Universitas Indonesia, Jakarta); and (3) those who attended the lecture at the PHCC followed by the symposium at the hospital Cipto Mangunkusumo.

Approval for both the visit at the PHCCs as well as for the symposium was given by the head of public health department for the province Jakarta, and a letter of approval was presented at each PHCC visited. For study design see figure 1.

\section{Questionnaire}

Data were collected utilizing a revised questionnaire, based on the one described in a previous study[19], which consisted of four sections: (1) general information questions concerning the GP, such as the number of years experience, and the number of patients seen per year; (2) questions concerning NPC, such as early symptoms and risk factors; (3) questions concerning the experience in daily practice regarding the extent to which a GP was confronted with NPC and his/her response for suspected NPC; and (4) questions regarding the ambition and wishes regarding future education on NPC.

The questions regarding early symptoms and risk factors allowed for the GP to list as many as he/she thought appropriate, while the questions concerning prevalence of NPC were multiple choice questions. The questionnaire was completed both prior to and after the NPC training session. All questionnaires were finished within 20 minutes, and were made in anonymity.

\section{Primary health care centres (PHCCS)}

PHCCs in the Jakarta region were visited by two physicians. The GPs working at these centres were invited to participate in the study. GPs were not informed forehand as to the purpose of the visit. The training session consisted of a lecture designed by a team of Head and Neck surgeons from Rumah Sakit CiptoMangunkusumo/University 
of Indonesia, Jakarta, Indonesia and the Netherlands Cancer Institute/ Antoni van Leeuwenhoek hospital. This lecture focused on all aspects of NPC, especially on early symptoms and best referral strategy. Two Indonesian physicians who have been trained and examined by the same Head and Neck surgeons presented the lecture. The lecture was given in the Indonesian language. The lecture lasted for 35 minutes and afterwards there was time for discussion.

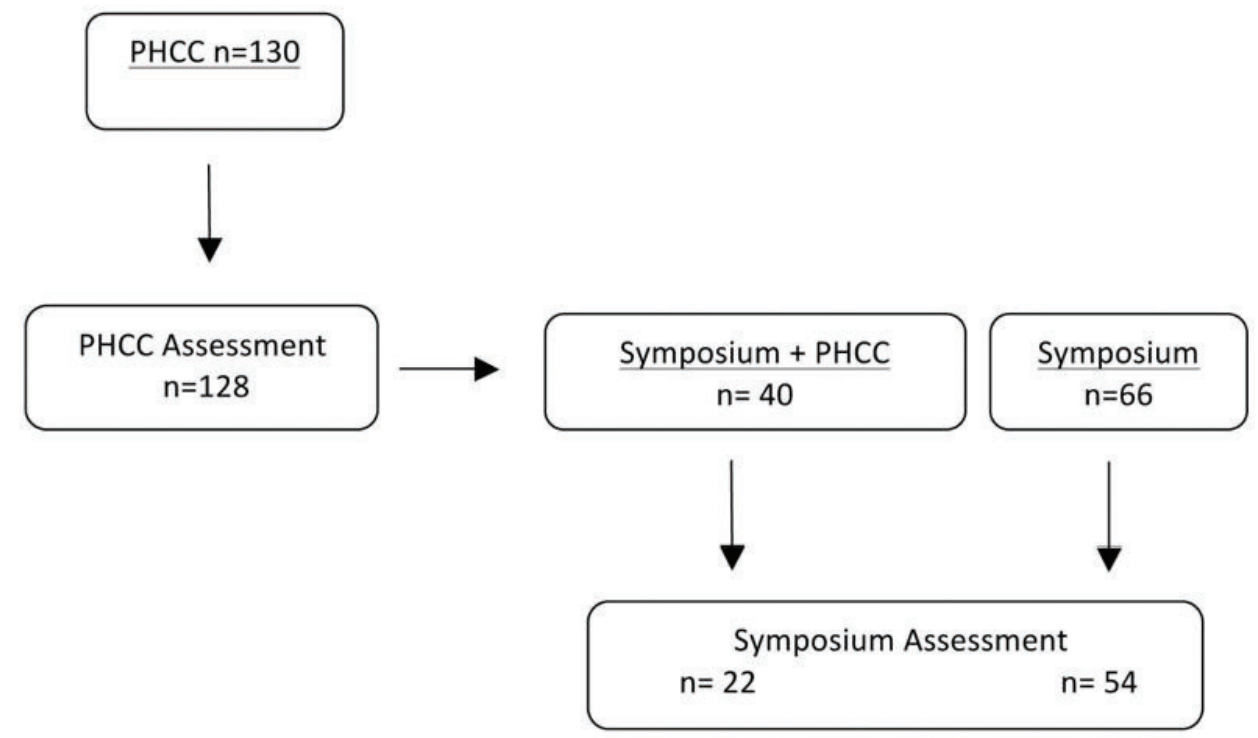

Figure 1 | Study design

\section{Symposium}

All GPs visited by the two physicians in the PHCCs were invited to a subsequent symposium on NPC (one to four weeks thereafter) at the Cipto Mangunkusumo University Hospital in Jakarta, Indonesia. The symposium consisted of a lecture on the risk factors, symptoms, incidence, referral system concerning NPC patient, in addition a physical examination training of the head and neck was provided. The symposium was accredited by the Indonesian Medical Association. The training and lectures lasted for four hours. 


\section{Statistical Methods}

Analyzed were the questions concerning NPC symptoms, risk factors and age at presentation. The listed NPC symptoms and risk factors were designated as being correct or incorrect, and in the case of the former being one of 12 possible correct symptoms. As a result the number of correctly listed symptoms was binomial (listed or not listed) for the 12 cases. Similarly for the questions concerning youngest and peak age at presentation the outcome was taken as correct or incorrect. While for the number of incorrectly listed symptoms, the number of correctly listed risk factors and the number of incorrectly listed risk factors, we assume the outcome to be Poisson distributed. These outcomes were modelled using generalized linear mixed effects models (GLMMs), either logistic or Poisson mixed effects models. In all models doctor ID is the random intercept with an unstructured covariance matrix. Fixed effect covariates included teaching format (PHCC vs. symposium), time (pre- or post-training), work experience (0-10, 11-20, 20+ years) and the pair-wise interactions of these. The 12 correct symptoms were divided into four categories (for details see figure 2); this covariate and its interaction with other covariates were also included as fixed effects in the model for correct symptoms. The only covariate missing data was the number of work experience years, which was imputed using the median. In these analyses only data from the doctors attending a training session for the first time was employed.

The symposium data from the doctors who had previously attending the PHCC trainings was used to assess the loss in recall over the 2 week period between PHCC and symposium training sessions. In these analyzes the GLMMs included a four level factor representing the four assessments for these individuals (PHCC pre-training, PHCC post-training, symposium pre-training, symposium post-training) as a fixed effect. The interest being in the change in knowledge between PHCC post-training session and the symposium pre-training session.

In all models, fixed effects were removed if their significance level was greater than 0.10 in a stepwise backwards procedure using log-likelihood ratio tests. No adjustments for multiple testing were performed. A Wilcox-Mann-Whitney test was performed to assess difference in work-experience years between the two groups. For all tests the level of significance set at 0.05 . 


\section{Results}

In total, training sessions were provided at 31 PHCCs involving 130 GPs. All GPs have voluntary participated. Two GPs could not participate in the assessment process as they were attending patients; the remaining present $128 \mathrm{GPs}$ completed the questionnaire both pre and post training. The average number of GPs who participated at a PHCC was 4.3 (median: 3; range 1-12). In total 106 GPs attended the symposium, of which 76 completed both the pre- and post- training questionnaire. Fifty-four of these had not attended the trainings in the PHCCs, while 22 attended both. The overall study population is presented in figure 1.

The clinicians attending the PHCC session had more years work-experience than those attending the symposium $(p=0.007)$. The median amount of years of work experience of clinicians attending the PHCC session was 9 years, with a minimum of one year and a maximum of thirty-three years. Participants at the symposium ranged in work experience from 0 to 27 years (median 9 years). Of the 182 participating clinicians 35 (19\%) had more than 20 years experience. Of these, 29 attended the PHCC sessions, while only 6 attended the symposium session.

\section{Symptoms}

The overall gain over both trainings was an increase from an average of 1.6 to 4.9 symptoms correctly identified ( $p<0.0001)$. However, in comparison with the PHCC group, the symposium group had a smaller overall improvement $(p=0.01)$. Prior to the training sessions an average of 1.4 symptoms were correctly listed at the PHCCs versus 1.7 at the symposium $(p=0.30)$. After training the average number of correct symptoms listed was 5.3 in the PHCC versus 4.5 at the symposium (Table 1 ).

Table 1 | The mean number of accurately listed symptoms both pre and post training, by GPs attending the PHCC and the symposium sessions.

\begin{tabular}{lllll} 
& PRE-TRAINING & \multicolumn{3}{c}{ POST-TRAINING } \\
& Symptoms correct & $95 \% \mathrm{CI}$ & Symptoms correct & $95 \% \mathrm{Cl}$ \\
\hline PHCC & 1.5 & $(1.3-1.7)$ & 5.3 & $(5.0-5.6)$ \\
SYMPOSIUM & 1.7 & $(1.4-2.0)$ & 4.5 & $(4.1-5.0)$
\end{tabular}

There was no difference between GPs with less work experience (0-10 years) and those with moderate work experience (11-20 years) ( $p=0.46)$. However, compared with these GPs, GPs with longer work experience (20+years) on average listed more 
symptoms correctly prior to training ( 1.9 vs. $1.5 ; \mathrm{p}=0.04$ ), but gained less from the training sessions (4.3 vs. 5.0; $\mathrm{p}<0.0001$ ). In the PHCC pre-training questionnaire $71 \%(129 / 182)$ of the GPs correctly identified neck mass as one of the correct symptoms of NPC, however only a few GPs could describe symptoms from one of the other 3 categories in the pre-training assessment (figure 2). Post training there was an increase of correct symptoms for the non-neck mass categories.
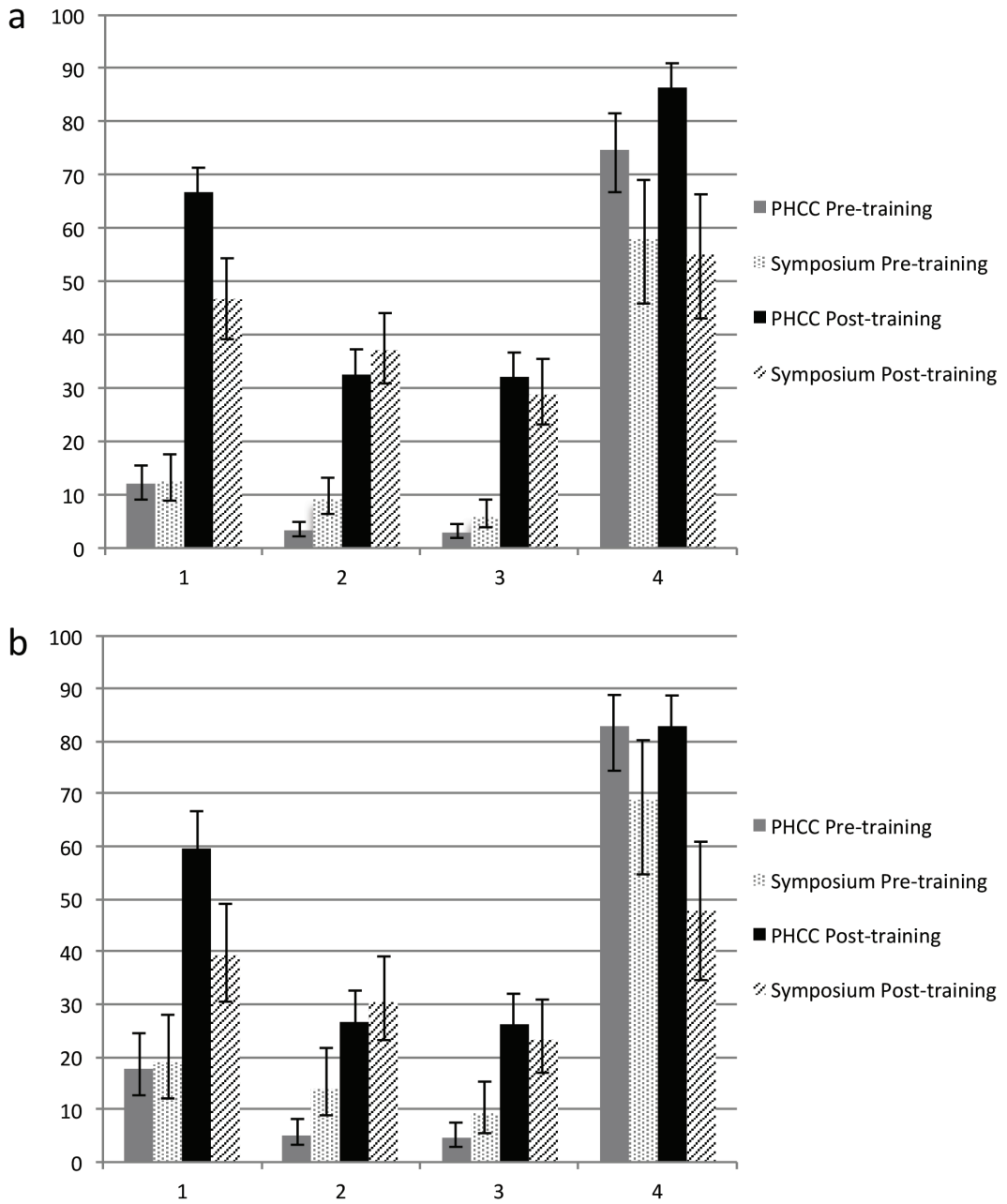

Figure 2 | Percentage of correct answers about the symptoms given by the GPs. a) Percentage of correct symptoms from the four different catagories given by GPs with less than 20 years of work experience. b) Percentage of correct symptoms from the four different catagories given by GPs with more than 20 years of work experience. (1) presence of tumour mass in the nasopharynx; (2) dysfunction of the eustachian tube, associated with the lateroposterior extension of the tumour to the paranasopharyngeal space; (3) skullbase erosion and palsy of the fifth and sixth cranial nerves, associated with the superior extension of the tumour; (4) neck masses. 
Training decreased the number of incorrect symptoms listed by GPs from 2.0 pretraining to 0.9 post-training $(p<0.0001)$. As with the correctly identified symptoms, this improvement was higher for GPs attending the PHCC training than those attending the symposium (see Table 2; $\mathrm{p}<0.0001$ ). However GPs attending the symposium recorded fewer incorrect symptoms pre-training than those attending the PHCC sessions (see Table 2; $p=0.002$ ). There was no association between the number of incorrect symptoms and number of years of work experience $(p=0.85)$.

Table 2 | The mean number of incorrect symptoms listed in the pre- and post-training assessments by GPs attending the PHCC and symposium training sessions.

\begin{tabular}{|c|c|c|c|c|}
\hline & \multicolumn{2}{|c|}{ PRE-TRAINING } & \multicolumn{2}{|c|}{ POST-TRAINING } \\
\hline & $\begin{array}{l}\text { Symptoms } \\
\text { incorrect }\end{array}$ & $95 \% \mathrm{Cl}$ & $\begin{array}{l}\text { Symptoms } \\
\text { incorrect }\end{array}$ & $95 \% \mathrm{Cl}$ \\
\hline PHCC & 2.4 & $(2.1-2.8)$ & 0.5 & $(0.4-0.6)$ \\
\hline SYMPOSIUM & 1.6 & $(1.2-2.0)$ & 1.2 & $(0.9-1.6)$ \\
\hline
\end{tabular}

The number of correctly listed risk factors increased after the training sessions from 1.5 pre-training to 4.1 post-training $(p<0.0001)$. This improvement was not affected by training format: PHCC vs. symposium $(p=0.76)$, nor was the number of years worked related to the number of correct risk factors listed by GPs ( $p=0.37)$. GPs attending the symposium knew more risk factors prior to training (and therefore after training) than those attending the PHCC only ( $p=0.001$ ) (Table 3 ).

Table 3 | The mean number of correctly identified risk factors listed in the pre- and posttraining by GPs attending the PHCC and symposium sessions.

\begin{tabular}{lllll} 
& $\begin{array}{l}\text { PRE-TRAINING } \\
\text { Risk factors } \\
\text { correct }\end{array}$ & $95 \% \mathrm{Cl}$ & $\begin{array}{l}\text { POST-TRAINING } \\
\text { Risk factors } \\
\text { correct }\end{array}$ & $95 \% \mathrm{Cl}$ \\
\hline PHCC & 1.3 & $(1.1-1.5)$ & 3.8 & $(3.5-4.1)$ \\
SYMPOSIUM & 1.6 & $(1.4-1.9)$ & 4.7 & $(4.2-5.3)$
\end{tabular}

Likewise, the number of incorrect risk factors decreased after training (see Table 4; $p=0.004)$; this improvement was not different between those GPs attending the PHCC or symposium sessions ( $p=0.16$ ); there was no association between the number of incorrect risk factors and number of years worked $(p=0.13)$; and GPs attending the symposium listed fewer incorrect risk factors pre-training than those attending the PHCC training $(p=0.02)$. 
Table 4 I The mean number of incorrect risk factors listed in the pre- and post-training assessments by GPs attending the PHCC and the symposium sessions.

\begin{tabular}{|c|c|c|c|c|}
\hline & \multicolumn{2}{|c|}{ PRE-TRAINING } & \multicolumn{2}{|c|}{ POST-TRAINING } \\
\hline & $\begin{array}{l}\text { Risk factors } \\
\text { incorrect }\end{array}$ & $95 \% \mathrm{Cl}$ & $\begin{array}{l}\text { Risk factors } \\
\text { incorrect }\end{array}$ & $95 \% \mathrm{Cl}$ \\
\hline PHCC & 0.8 & $(0.6-1.0)$ & 0.6 & $(0.4-0.7)$ \\
\hline SYMPOSIUM & 0.5 & $(0.4-0.7)$ & 0.4 & $(0.3-0.5)$ \\
\hline
\end{tabular}

Age of NPC presentation and peak incidence of age group

The questionnaire also contained questions about the youngest age of presentation and the peak age of incidence. GPs more often answered incorrectly the youngest age at presentation when compared with the peak age at presentation question $(p=0.03$; see Table 5). The training sessions resulted in an improvement in knowledge $(p<0.0001)$, with the PHCC training resulting in a slightly higher improvement than the symposium training $(p=0.04)$. There was no difference between GPs who had worked $0-10$ years and those who had worked $11-20$ years $(p=0.88)$, while GPs with the longest working experience (20+ years) more often got the youngest age of presentation question wrong $(p=0.03)$.

Table 5 | The probability (\%) of correctly answering questions concerning youngest age of presentation and peak age of incidence.

\begin{tabular}{|c|c|c|c|c|c|c|}
\hline & & \multirow[b]{2}{*}{ Work Exp. } & \multicolumn{2}{|c|}{ PRE-TRAINING } & \multicolumn{2}{|c|}{ POST-TRAINING } \\
\hline & & & $\%$ Correct & $95 \% \mathrm{Cl}$ & $\%$ Correct & $95 \% \mathrm{Cl}$ \\
\hline \multirow[t]{4}{*}{ YOUNGEST AGE } & PHCC & $0-20$ yrs & 22 & $(16-30)$ & 71 & $(63-78)$ \\
\hline & & $20+y r s$ & 13 & $(8-22)$ & 57 & $(43-71)$ \\
\hline & Symposium & $0-20$ yrs & 25 & $(17-37)$ & 59 & $(46-70)$ \\
\hline & & $20+y r s$ & 15 & $(8-29)$ & 43 & $(27-61)$ \\
\hline \multirow[t]{4}{*}{ PEAK AGE } & PHCC & $0-20$ yrs & 32 & $(25-40)$ & 81 & $(74-86)$ \\
\hline & & $20+y r s$ & 41 & $(28-55)$ & 86 & $(77-92)$ \\
\hline & Symposium & $0-20$ yrs & 20 & $(13-31)$ & 52 & $(40-63)$ \\
\hline & & $20+y r s$ & 27 & $(15-45)$ & 61 & $(43-76)$ \\
\hline
\end{tabular}

Assessment of loss of recall: GPs attended who attended both training sessions

GPs who attended both the PHCC and the symposium training sessions had a small reduction in the number of symptoms correctly identified between the end of the PHCC session and the start of the symposium session (5.5 vs. $4.2 ; p=0.25$ ), however 
this was still a gain when compared to their pre-training knowledge (4.2 vs. 1.3; $p$ $<0.0001$ ). Strikingly, GPs who came back for a second training session recorded twice the number of incorrect symptoms prior to the symposium training (1.1 vs. $0.5 ; p=0.05)$, however this was still a large reduction on the number of errors made prior to the PHCC training (1.1 vs. 2.8; $\mathrm{p}<0.0001$ ). GPs who came back for a second training session recorded slightly fewer correct risk factors pre-symposium training as compared to PHCC post-training ( 4.1 vs. $3.2 ; p=0.11$ ), but a significant increase when compared to their knowledge prior to their first training session (1.6 vs. 3.2; $\mathrm{p}=0.0008$ ). Similarly there was a decrease in the probability of correctly identifying the youngest and peak ages at presentation (Youngest: $84 \%$ vs. 59\%; Peak: $90 \%$ vs. 72\%; $p=0.39$ ), however GPs still knew more than what they knew prior to the PHCC session (Youngest: $13 \%$ vs. $59 \%$; Peak: $22 \%$ vs. $72 \%$; $p<0.0001$ ).

\section{Discussion}

NPC has a high incidence and mortality in Indonesia with late diagnosis being one of the reasons for numerous advanced disease and high mortality. GPs working in a PHCC are the first line of care for patients in need of medical attention. For a correct and early diagnosis of NPC the knowledge of these GPs, especially concerning early-stage symptoms is crucial. In a prior study in Yogyakarta, CentralJava, we have shown that the knowledge on NPC and related symptoms among GP's working in PHCCs is insufficient for the recognition of NPC and to initiate appropriate referral. Our ongoing studies in the Yogyakarta province and the study from the Jakarta region presented here confirm these results; the GPs working in the Jakarta region have, similar to the Yogyakarta region, insufficient knowledge to refer NPC suspects to the hospital. Besides confirmation of the lack of knowledge, we investigated if improvement of knowledge is possible by introducing a focussed education program. This is the first study that examines the effect of different teaching methods to educate Indonesian GPs on NPC. Early diagnosis will influence the type of treatment patient require; only in advanced stage of disease additional chemotherapy is required, while in early stages radiotherapy alone is sufficient. The addition of chemotherapy to the treatment leads to more serious side effects and a general weakening of the patient. Furthermore, early diagnosis of NPC should lead to fewer patients presenting with distant metastasis who currently cannot be treated with curative intent. 
In Malaysia prior studies have proved that the lack of awareness and knowledge of primary health care workers is one of the main reasons for delayed diagnosis. Given that presenting stage is the most important prognostic factor, the appropriate training of GPs is critical [21]. The relevance of adequate referral by GPs for head and neck carcinomas has been shown by Alho et al.[22], who found that in $20 \%$ of the 221 patients, subsequently to be diagnosed with head and neck carcinoma, were initially send home without referral. The risk of death in this group was significantly higher when compared with the patients who were immediately referred or received a follow up appointment. Although not statistically significant, patients who were initially sent home had higher cancer stage at diagnosis.

The same research team has also shown that time between GP referral and final diagnosis is a significant factor in patient outcome in other head and neck cancers [23]. Long delay in primary care resulted in a significant worsened prognosis especially by patients with laryngeal carcinoma [24].

Educational sessions at PHCCs by a team of two GPs and a symposium by local head and neck surgeons have both shown to be effective. In general, the pre-test knowledge at the symposium was higher than in the PHCC. The reason for this could be that visit in the PHCC was unannounced, while for the symposium the GPs received an invitation so they had some time to prepare for the meeting, or were being pre-informed about the NPC topic by colleagues who had previously attended the PHCC training sessions.

Comparing the two different training formats we see a greater gain in knowledge at the PHCCs. One explanation for this could be that the PHCC sessions provided a more focused approach and direct contact/confrontation with participants. Another reason could be that the lecture at the symposium was more extensive and perhaps did not delve too deeply into the most important aspects, but rather covered all aspects of NPC to broadly.

On the other hand, during the symposium GPs also received practical education for performing physical examination of the head and neck region and a testimonial of a NPC patient. We expect this additional training aspect to be important for the recognition of NPC patients. Another remarkable result is that the more experienced 
GPs knew more prior to the training but learned less in both interventions. Perhaps in future the education of longer serving doctors should be adjusted.

For the four different categories of symptoms, as described by Wei et al, we see at the pre-test the most often and only given correct answer is neck mass, which only occurs in advanced NPC. At the post test the GPs are also aware of symptoms in the other categories (see figure 2), most importantly, including symptoms of early stage NPC.

The doctors who attended both trainings showed a small decline in knowledge prior to the symposium when compared with their results directly after the session in the PHCC. However, they still knew far more than what they knew prior to the PHCC session. Unfortunately, we are only able to assess recall over an average of 8 days. It would be of great interest to assess changes in NPC awareness over a much longer duration.

Visiting the PHCC was a time consuming exercise as the PHCC are scattered throughout Jakarta. The symposium was more time-effective with all the general practitioners present at the same venue and date. Accreditation points are only accrued after the symposium and not the PHCC sessions, thus making the symposium session more attractive for the GPs. However, every GP visited in the PHCC was willing to participate, perhaps stimulated or convinced by the approval letter from the head of public health department of the Jakarta province.

Although this study demonstrates the effectiveness of education GPs about NPC, the time between the pre- and post-training assessments is short. The goal of achieving a down-staging of NPC at presentation is still to be proven. We believe the recent introduction of an online data management service will aid in the confirmation of earlier stage presentation of patients with NPC[25].

The NPC WHO III histological subtype is the most prevalent type in SE-Asia and Indonesia. This type is causally associated with the Epstein-Barr virus (EBV). Prior studies have shown that EBV-related markers can be used for early detection (screening) and prognostic monitoring. These markers include EBV (IgA) serology and EBV-DNA load since NPC patients have characteristic elevated IgG and IgA 
antibody titres to several EBV encoded antigens as well as increased EBV-DNA derived from shed (apoptotic) fragments from the tumour into the circulation. Increased IgA antibody levels are found against early antigen (EA), viral capsid antigen (VCA) and the latent Epstein-Barr nuclear antigen 1 (EBNA1) as well as inhibitory antibodies to the EBV specific DNase [26,27]. These antibody responses against defined viral antigens are the basis of a proposed screening test for NPC in high-risk populations. [28-30] Recent insight in the molecular basis and diversity of anti EBV IgA and IgG responses allowed the development of more defined serological tools[31-35]. A possible assay in the future could be EBV DNA load in the circulation and in nasopharyngeal brushings since both have been detected in a higher proportion of NPC patients than controls[36-40]. Especially EBV IgA serology testing appears to fulfil criteria as a screening tool in the future, since the price is relative low and easy to use when combined with finger-prick blood sampling $[34,41]$. Future education programs should include referencing to the availability of improved diagnostic procedures for screening and early detection. Improved education combined with a screening method could be a cheap and sensitive screening method for NPC in Indonesia and other high incidence countries. Importantly, the decision for serological or EBV-DNA based analysis has to be based on complaints and duration of complaints registered and interpreted by the GP. Our ongoing research is focussed on finding the best decision tree to accomplish effective early stage diagnosis in NPC high-risk groups (Hutajulu et al; manuscript submitted).

Currently the NPC awareness programme takes place in Jakarta, Yogyakarta and Surabaya. Hopefully in the future this program can be expanded to include all of Indonesia. We also hope to raise public awareness on importance of early-stage cancer and how and when to consult a GP in all layers of Indonesian society. However, as a first step we aim to raise the level of relevant knowledge in primary health care workers. Similar campaigns to educate society on breast and cervical cancer have proven to be highly effective $[42,43]$. Education of the GPs and society, and combined with improved diagnostic testing will ideally result in earlier detection of NPC, better treatment outcomes, and increased overall prognosis. 


\section{Conclusion}

The current level of knowledge regarding NPC diagnosis is poor, potentially contributing to an increased rate of late stage diagnosis. Additional training sessions increased the knowledge of key symptoms, in particular early-stage symptoms. This increase was observed after conducting both types of training format: a centralized symposium and lectures in local PHCC. With improved knowledge of NPC patients should be referred to hospital at an earlier stage of NPC and as such should have an improved chance of survival. 


\section{Reference List}

1. S.Plianbangchang. WHO Country Cooperation Strategy 2007-2011 Indonesia. 2007. Ref Type: Data File

2. DragerN, VieiraC. Tradeinhealthservices:global, regional, and countryperspectives. 2002. Ref Type: Data File

3. Ferlay J, Shin HR, Bray F, Forman D, Mathers C, Parkin DM: Estimates of worldwide burden of cancer in 2008: GLOBOCAN 2008. International journal of cancer Journal international du cancer 2010, 127: 2893-2917.

4. Yu MC, Yuan JM: Epidemiology of nasopharyngeal carcinoma. Semin Cancer Biol 2002, 12: 421-429.

5. Devi BC, Pisani P, Tang TS, Parkin DM: High incidence of nasopharyngeal carcinoma in native people of Sarawak, Borneo Island. Cancer Epidemiol Biomarkers Prev 2004, 13: 482-486.

6. Wei WI, Sham JS: Nasopharyngeal carcinoma. Lancet 2005, 365: 2041-2054.

7. zur Hausen H, Schulte-Holthausen H, Klein G, Henle W, Henle G, Clifford P et al.: EBV DNA in biopsies of Burkitt tumours and anaplastic carcinomas of the nasopharynx. Nature 1970, 228: 1056-1058.

8. Poirier S, Hubert A, De The G, Ohshima H, Bourgade MC, Bartsch H: Occurrence of volatile nitrosamines in food samples collected in three high-risk areas for nasopharyngeal carcinoma. IARC Sci Publ 1987, 415-419.

9. Guo X, Johnson RC, Deng H, Liao J, Guan L, Nelson GW et al.: Evaluation of nonviral risk factors for nasopharyngeal carcinoma in a high-risk population of Southern China. Int $J$ Cancer 2009, 124: 2942-2947.

10. Armstrong RW, Imrey PB, Lye MS, Armstrong MJ, Yu MC, Sani S: Nasopharyngeal carcinoma in Malaysian Chinese: salted fish and other dietary exposures. Int J Cancer 1998, 77: 228-235.

11. Armstrong RW, Imrey PB, Lye MS, Armstrong MJ, Yu MC, Sani S: Nasopharyngeal carcinoma in Malaysian Chinese: occupational exposures to particles, formaldehyde and heat. Int J Epidemiol 2000, 29: 991-998.

12. Chang ET, Adami HO: The enigmatic epidemiology of nasopharyngeal carcinoma. Cancer Epidemiol Biomarkers Prev 2006, 15: 1765-1777.

13. Parkin DM, Bray F, Ferlay J, Pisani P: Global cancer statistics, 2002. CA Cancer J Clin 2005, 55: 74-108.

14. Ozyar E, Atahan IL, Akyol FH, Gurkaynak M, Zorlu AF: Cranial nerve involvement in nasopharyngeal carcinoma: its prognostic role and response to radiotherapy. Radiation medicine 1994, 12: 65-68.

15. Lee AW, Foo W, Law SC, Poon YF, Sze WM, SK O et al.: Nasopharyngeal carcinoma: presenting symptoms and duration before diagnosis. Hong Kong Med J 1997, 3: 355361.

16. Zhang L, Zhao C, Ghimire B, Hong $\mathrm{MH}$, Liu $\mathrm{Q}$, Zhang $\mathrm{Y}$ et al.: The role of concurrent chemoradiotherapy in the treatment of locoregionally advanced nasopharyngeal carcinoma among endemic population: a meta-analysis of the phase III randomized trials. BMC Cancer 2010, 10: 558.

17. Lee AW, Sze WM, Au JS, Leung SF, Leung TW, Chua DT et al.: Treatment results for nasopharyngeal carcinoma in the modern era: the Hong Kong experience. Int J Radiat Oncol Biol Phys 2005, 61: 1107-1116.

18. Lee AW, Poon YF, Foo W, Law SC, Cheung FK, Chan DK et al.: Retrospective analysis of 5037 patients with nasopharyngeal carcinoma treated during 1976-1985: overall survival and patterns of failure. Int J Radiat Oncol Biol Phys 1992, 23: 261-270. 
19. Fles R, Wildeman MA, Sulistiono B, Haryana SM, Tan IB: Knowledge of general practitioners about nasopharyngeal cancer at the Puskesmas in Yogyakarta, Indonesia. BMC Med Educ 2010, 10: 81.

20. Devi BC, Tang TS, Corbex M: Reducing by half the percentage of late-stage presentation for breast and cervix cancer over 4 years: a pilot study of clinical downstaging in Sarawak, Malaysia. Ann Oncol 2007, 18: 1172-1176.

21. Prasad U, Pua KC: Nasopharyngeal carcinoma: a delay in diagnosis. Med J Malaysia 2000, 55: 230-235.

22. Alho OP, Teppo H, Mantyselka P, Kantola S: Head and neck cancer in primary care: presenting symptoms and the effect of delayed diagnosis of cancer cases. CMAJ 2006, 174: 779-784.

23. Koivunen P, Rantala N, Hyrynkangas K, Jokinen K, Alho OP: The impact of patient and professional diagnostic delays on survival in pharyngeal cancer. Cancer 2001, 92: 28852891.

24. Teppo H, Koivunen P, Hyrynkangas K, Alho OP: Diagnostic delays in laryngeal carcinoma: professional diagnostic delay is a strong independent predictor of survival. Head Neck 2003, 25: 389-394.

25. Wildeman MA, Zandbergen J, Vincent A, Herdini C, Middeldorp JM, Fles R et al.: Can an online clinical data management service help in improving data collection and data quality in a developing country setting? Trials 2011, 12: 190.

26. Cevenini R, Donati M, Caliceti U, Moroni A, Tamba I, Rumpianesi F: Evaluation of antibodies to Epstein-Barr virus in Italian patients with nasopharyngeal carcinoma. J Infect 1986, 12: 127-131.

27. Chen JY, Chen CJ, Liu MY, Cho SM, Hsu MM, Lynn TC et al.: Antibodies to Epstein-Barr virus-specific DNase in patients with nasopharyngeal carcinoma and control groups. J Med Virol 1987, 23: 11-21.

28. Ji MF, Wang DK, Yu YL, Guo YQ, Liang JS, Cheng WM et al.: Sustained elevation of EpsteinBarr virus antibody levels preceding clinical onset of nasopharyngeal carcinoma. $\mathrm{Br} J$ Cancer 2007, 96: 623-630.

29. Tamada A, Makimoto K, Yamabe H, Imai J, Hinuma Y, Oyagi A et al.: Titers of Epstein-Barr virus-related antibodies in nasopharyngeal carcinoma in Japan. Cancer 1984, 53: 430440.

30. de Vathaire F, Sancho-Garnier H, de The H, Pieddeloup C, Schwaab G, Ho JH et al.: Prognostic value of EBV markers in the clinical management of nasopharyngeal carcinoma (NPC): a multicenter follow-up study. Int J Cancer 1988, 42: 176-181.

31. Fachiroh J, Schouten T, Hariwiyanto B, Paramita DK, Harijadi A, Haryana SM et al.: Molecular diversity of Epstein-Barr virus IgG and IgA antibody responses in nasopharyngeal carcinoma: a comparison of Indonesian, Chinese, and European subjects. J Infect Dis 2004, 190: 53-62.

32. Fachiroh J, Paramita DK, Hariwiyanto B, Harijadi A, Dahlia HL, Indrasari SR et al.: Singleassay combination of Epstein-Barr Virus (EBV) E. J Clin Microbiol 2006, 44: 1459-1467.

33. Paramita DK, Fachiroh J, Artama WT, van Benthem E, Haryana SM, Middeldorp JM: Native early antigen of Epstein-Barr virus, a promising antigen for diagnosis of nasopharyngeal carcinoma. J Med Virol 2007, 79: 1710-1721.

34. Fachiroh J, Prasetyanti PR, Paramita DK, Prasetyawati AT, Anggrahini DW, Haryana SM et al.: Dried-blood sampling for epstein-barr virus immunoglobulin G (IgG) and IgA serology in nasopharyngeal carcinoma screening. J Clin Microbiol 2008, 46: 1374-1380.

35. Paramita DK, Fachiroh J, Haryana SM, Middeldorp JM: Two-step Epstein-Barr virus immunoglobulin A enzyme-linked immunosorbent assay system for serological screening and confirmation of nasopharyngeal carcinoma. Clin Vaccine Immunol 2009, 16: 706-711. 
36. Lin JC, Wang WY, Chen KY, Wei YH, Liang WM, Jan JS et al.: Quantification of plasma Epstein-Barr virus DNA in patients with advanced nasopharyngeal carcinoma. N Engl J Med 2004, 350: 2461-2470.

37. Stevens SJ, Verkuijlen SA, Hariwiyanto B, Harijadi, Fachiroh J, Paramita DK et al.: Diagnostic value of measuring Epstein-Barr virus (EBV) DNA load and carcinoma-specific viral mRNA in relation to anti-EBV immunoglobulin A (IgA) and IgG antibody levels in blood of nasopharyngeal carcinoma patients from Indonesia. J Clin Microbiol 2005, 43: 3066-3073.

38. Stevens SJ, Verkuijlen SA, Hariwiyanto B, Harijadi, Paramita DK, Fachiroh J et al.: Noninvasive diagnosis of nasopharyngeal carcinoma: nasopharyngeal brushings reveal high Epstein-Barr virus DNA load and carcinoma-specific viral BARF1 mRNA. Int J Cancer 2006, 119: 608-614.

39. Tune CE, Liavaag PG, Freeman JL, van den Brekel MW, Shpitzer T, Kerrebijn JD et al.: Nasopharyngeal brush biopsies and detection of nasopharyngeal cancer in a high-risk population. J Natl Cancer Inst 1999, 91: 796-800.

40. Tong JH, Tsang RK, Lo KW, Woo JK, Kwong J, Chan MW et al.: Quantitative Epstein-Barr virus DNA analysis and detection of gene promoter hypermethylation in nasopharyngeal (NP) brushing samples from patients with NP carcinoma. Clin Cancer Res 2002, 8: 2612 2619.

41. Ji MF, Yu YL, Cheng WM, Zong YS, Ng PS, Chua DT et al.: Detection of Stage I nasopharyngeal carcinoma by serologic screening and clinical examination. Chin J Cancer 2011, 30: 120-123.

42. Ali TS, Baig S: Evaluation of a cancer awareness campaign: experience with a selected population in Karachi. Asian Pac J Cancer Prev 2006, 7: 391-395.

43. Bhurgri H, Gowani SA, Itrat A, Samani S, Zuberi A, Siddique MS et al.: Awareness of cancer risk factors among patients and attendants presenting to a tertiary care hospital in Karachi, Pakistan. J Pak Med Assoc 2008, 58: 584-588 


\section{Chapter 7}

\section{Effectiveness of a multicentre nasopharyngeal carcinoma}

awareness programme in Indonesia

R. Fles

SR. Indrasari

C. Herdini

S. Martini

A. Isfandiari

AC. Romdhoni

M. Adham

ID. Mayangsari

E. van Werkhoven MA. Wildeman

B. Hariwiyanto

B. Hermani

WA. Kentjono

SM. Haryana

MK. Schmidt

IB. Tan

BMJ Open. 2016 Mar 1;6(3):e008571 


\section{Abstract}

Objective: To evaluate the effectiveness of a nasopharyngeal carcinoma (NPC) awareness programme on the short-term and long-term improvement of knowledge and referral of patients with NPC by primary healthcare centres (PHCCs) staff in Indonesia.

Design: The NPC awareness programme consisted of 12 symposia including a Train-The-Trainer component, containing lectures about early symptoms and risk factors of NPC, practical examination and the referral system for NPC suspects. Before and after training participants completed a questionnaire. The Indonesian Doctors Association accredited all activities. Participants: 1 representative general practitioner (GP) from each PHCC attended an NPC awareness symposium. On the basis of the Train-The-Trainer principle, GPs received training material and were obligated to train their colleagues in the PHCC. Results: 703 GPs attended the symposia and trained 1349 staff members: 314 other GPs, 685 nurses and 350 midwives. After the training, respondents' average score regarding the knowledge of NPC symptoms increased from 47 points (of the 100) to 74 points $(p<0.001$ ); this increase was similar between symposium and Train-The-Trainer component $(p=0.88)$. At $11 / 2$ years after the training, this knowledge remained significantly increased at 59 points $(p<0.001)$.

Conclusion: The initial results of this NPC awareness programme indicate that the programme effectively increases NPC knowledge in the short and long term and therefore should be continued. Effects of the improved knowledge on the stage at diagnoses of the patients with NPC will still need to be scrutinised. This awareness programme can serve as a blueprint for other cancer types in Indonesia and for other developing countries. 


\section{Background}

Nasopharyngeal carcinoma (NPC) is uncommon in most parts of the world; however, it is a major burden in Indonesia with 15000 new cases a year. [1] This number might even be an underestimation due to inadequate cancer registries. NPC is very sensitive to (chemo-) radiotherapy, resulting in a 2 and 3 year survival of $84 \%$ and $78 \%$, respectively, [2] provided that patients present themselves with early stage cancer. However, early symptoms of NPC are often minor and non-specific, making it difficult to recognise NPC suspects for timely referral. For example, $88-97 \%$ of patients with NPC in two major Indonesian hospitals (Dr. Cipto Mangunkusumo Hospital, Jakarta; and Dr. Sardjito Hospital, Yogyakarta) developed advanced NPC before presenting at the hospital. $[3,4]$ In line with this finding, an earlier observational study in Indonesia, including patients treated with curative intent, showed a complete response of $29 \%$ directly after treatment. [4]

The symptoms of NPC can be subdivided into four different categories, namely: (1) tumour mass in the nasopharynx causing blood-tinged secretion, nasal obstruction and sometimes epistaxis; (2) dysfunction of the Eustachian tube inducing fullness, hearing loss and tinnitus; (3) skull base erosion and palsy of the third to sixth cranial nerves provoking headache, diplopia, facial pain and numbness including eye symptoms such as strabismus and lagophthalmos [3] and (4) neck mass. [5] Well-established risk factors for NPC are the Epstein-Barr virus, [6] family history of NPC (4-10-fold increase), ethnicity and gender. [7-10] Environmental and lifestyle risk factors are the consumption of salted fish, [7 10-12] usage of herbal medicine, [10 13] wood dust exposure and other occupational exposures such as fume, smoke and chemicals. $[7,14,15]$ Multiple studies reported also on the increased risk of NPC caused by smoking. [8 16-18 ]

Midwives and nurses play an important supportive role in the work of the general practitioners (GPS) in the primary healthcare centres (PHCCS). In Indonesia, there are on average only 13 GPs available per 100000 inhabitants. Hence, the PHCCs are often without an attending GP, and the nurses and the midwives then take over their role as medical doctors without having the right educational degree or knowledge to do so. [19-21] We showed before that the knowledge on NPC of the GPs working 
in a PHCC is limited and that creating more awareness is of great importance to minimise doctors' delay. [22-26] Therefore, the NPC awareness programme started in 2009 in Jakarta, Yogyakarta and Surabaya. The first results showed an increase in the short-term knowledge of the GPs working in the PHCC using different teaching methods and evoked continuation and expansion of the NPC awareness programme to other cities. [27]

This study investigated the effects of the awareness symposia conducted at different locations in Indonesia, and of a Train-The-Trainer programme for all medical healthcare workers in the PHCC. The aim of this study was to evaluate the effectiveness of this combined NPC awareness programme on the short-term and long-term improvement of knowledge and referral of patients with NPC by PHCC staff.

\section{Methods}

Study population The study population comprised healthcare workers working in the PHCCs in the provinces of Yogyakarta, Jakarta and East Java.

\section{NPC awareness programme}

The NPC awareness programme consisted of two activities: GPs attended an NPC awareness symposium in their own region, and then organised a Train-TheTrainer programme. Participants of the symposium received course materials on a $C D$, which contained presentations about the symptoms, practical examination, referral, diagnostics and treatment of NPC. They also received posters, flyers and a booklet with information on NPC. Participants were obliged to train their colleagues in their own PHCC. The direct effects and, after a minimum interval of $11 / 2$ years, the long-term effect of these two training methods were measured using structured questionnaires. The awareness programme was held between January 2010 and December 2011 in different cities in the provinces Jakarta, Yogyakarta and East Java; the long-term effect was measured between November 2012 and February 2013 in the province of Yogyakarta (figure 1). 


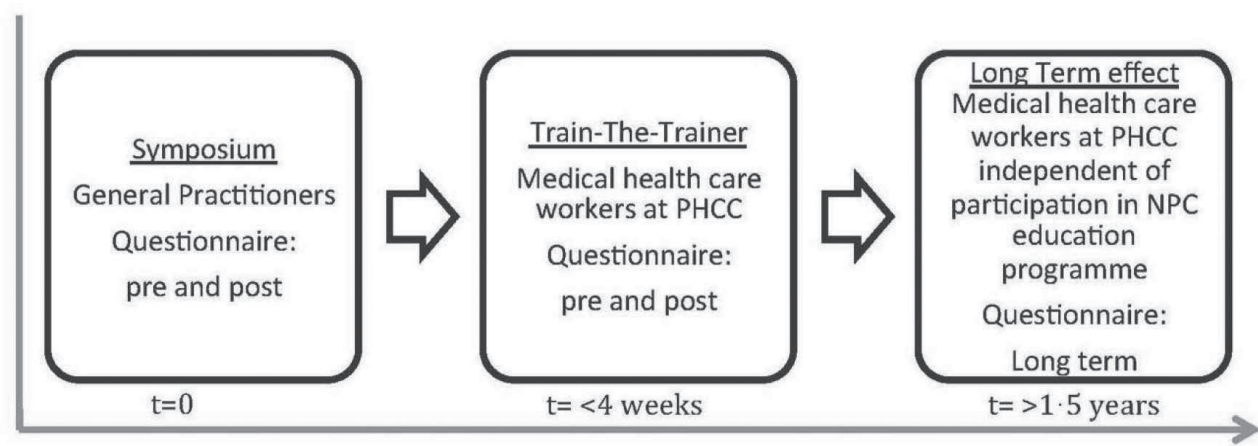

Figure 1 | Overview of the nasopharyngeal carcinoma (NPC) awareness programme. The Train-The-Trainer programme followed the symposium. One and a half year after this programme was finished, primary healthcare centres (PHCCs) were visited again to measure the long-term effect.

\section{NPC awareness symposium}

The NPC awareness symposium was a 1-day training session, which consisted of lectures focusing on the risk factors, symptoms and incidence of NPC; the referral system concerning NPC suspects; testimonials of patients; and demonstration videos. In addition, participants took part in a practical examination training of the head and neck areas in small groups. The Indonesia Doctors Association (IDI) accredited the event. The symposia were organised by the departments of otorhino- laryngology of the participating centres, in collaboration with the Netherlands Cancer Institute, Amsterdam. Additionally, in Yogyakarta and east Java, the departments of public health of, respectively, the Gadjah Mada University, Yogyakarta and the Airlangga University, Surabaya, were involved.

\section{NPC Train-The-Trainer programme}

In the provinces Yogyakarta and East Java, one GP per PHCC joined the NPC awareness symposium. After this training, the GP had the obligation to train his colleagues in the PHCC using the materials handed out during the symposium. This training in the PHCC took place within 1 month after the symposium and was supervised by one of the NPC awareness team members or a staff member from the local health department. In addition to GPs, this Train-The-Trainer programme was attended by nurses, midwives, dentists and other public healthcare workers. We removed 57 questionnaires from the data analyses, which were filled in by non-clinical staff. IDI also accredited this Train-The- 
Trainer programme. Credits and the certificate were awarded once the questionnaires of the participants were returned to a member of the NPC awareness team.

\section{Questionnaires}

Data were collected using a written, structured questionnaire before and after the symposia or Train-The-Trainer programme as described previously. [22] In short, the questionnaire consisted of questions assessing general information about the participants and their work environment, for example, years of work experience; general knowledge on NPC such as early symptoms and risk factors; and experience of dealing in daily practice with NPC suspects in their PHCC. In the questionnaire, participants were asked to list all NPC symptoms and risk factors, up to a maximum of seven. One and a half year after the NPC awareness programme, all PHCCs in the province Yogyakarta were revisited, and all present medical workers were asked to complete the same questionnaire. Questions about their attendance of previous NPC symposia or Train-The-Trainer programme, and if this training had resulted in diagnosing more NPC suspects in their PHCC, had been added. All questionnaires were completed anonymously.

\section{Participation and response}

The Public Health Offices (Dinas Kesehatan) of the provinces and districts approved the NPC awareness programme. Moreover, the Indonesian doctors associated approved and accredited the activities. By involving the public health offices at province and district levels, all participants received an official invitation to attend the awareness symposium, and participation was obligatory. In addition, they were obligated to train their colleagues in their own PHCC. A member from the NPC awareness team or a representative from the public health office supervised this training. For the follow-up questionnaires to measure the long-term effect, an NPC awareness team member visited all PHCCs in the province Yogyakarta that had joined the awareness programme; questionnaires were completed by the health staff present at the time of the visit(s).

\section{Statistical analysis}

Respondents' performance on symptoms and risk factors was assessed by analysis of the fraction of correct answers, weighted by the total number of answers, with a 
generalised linear model with binomial error distribution and identity link function. This model has the advantage that the estimates may be interpreted directly in terms of probabilities, whereas with a logistic model they would yield ORs. For convenience of representation and discussion, the probabilities were rescaled to percentage points (i.e., multiplied by 100). Answers to single questions were analyzed with logistic regression.

Training was grouped into pretraining, postsymposium and post-Train-TheTrainer programme. Profession (GP, midwife, nurse or other) and years of work experience $(<3,3-6,6-9$ or $>9$ years) were entered as covariates. Since many respondents $(n=1493)$ did not fill in the question about their work experience, a separate category was created for missing values. If any of the other variables were missing, the observation was removed from the analysis. A separate model with an interaction term was used to evaluate the Train-The-Trainer programme for different professions. Analyses were done using the R-package V.3.1.1; all presented $p$ values are two sided.

\section{Results}

Participants of the symposia and Train-The-Trainer programme In total, 5309 questionnaires were completed: at the symposia, 709 pretraining and 715 postsymposium, at the Train-The-Trainer programme 1577 pretraining and 1563 post-Train-The-Trainer programme, and 735 participants filled out the questionnaire $11 / 2$ years later (table 1 ). At the symposia, a representative GP from every PHCC was invited. The Train-The-Trainer programme was open to all medical healthcare workers in the PHCC of the representative; $21 \%$ of the participants were GPs. More than $50 \%$ of the participants, independent of profession or type of training, had $<6$ years' work experience. There were three or less GPs working in the PHCC of $72 \%$ of the participants. In order to obtain the long-term effect of the awareness programme, all PHCCs in Yogyakarta were revisited and all medical healthcare workers were asked to complete the same questionnaire again. Participants stated if they had participated in one of the NPC trainings previously; this was indicated by 180 (24\%) participants (table 1). 
Table 1 | Overview of the different trainings within the NPC awareness programme

\begin{tabular}{|c|c|c|c|c|c|c|c|c|c|c|c|c|}
\hline \multirow[t]{3}{*}{ Group } & \multicolumn{4}{|c|}{ Symposium } & \multicolumn{4}{|c|}{ Train-The-Trainer } & \multicolumn{4}{|l|}{ Long term } \\
\hline & \multicolumn{2}{|l|}{ Pre } & \multicolumn{2}{|l|}{ Post } & \multicolumn{2}{|l|}{ Pre } & \multicolumn{2}{|l|}{ Post } & \multicolumn{2}{|l|}{$\begin{array}{l}\text { With } \\
\text { education }\end{array}$} & \multicolumn{2}{|l|}{$\begin{array}{l}\text { Without } \\
\text { education }\end{array}$} \\
\hline & $\mathbf{n}$ & $\%$ & $\mathbf{n}$ & $\%$ & $\mathbf{N}$ & $\%$ & $\mathbf{n}$ & $\%$ & $\mathbf{n}$ & $\%$ & $\mathbf{n}$ & $\%$ \\
\hline Total & 709 & & 715 & & 1577 & & 1563 & & 180 & & 555 & \\
\hline \multicolumn{13}{|l|}{ City } \\
\hline Jakarta & 437 & 62 & 439 & 61 & .. &.. & .. & .. & .. &.. & .. & .. \\
\hline Surabaya & 154 & 22 & 151 & 21 & 1031 & 65 & 1015 & 65 &.. &.. &.. & .. \\
\hline Yogyakarta & 118 & 17 & 125 & 17 & 546 & 35 & 548 & 35 & 180 & 100 & 555 & 100 \\
\hline \multicolumn{13}{|l|}{ Profession } \\
\hline Doctor & 703 & 99 & 630 & 99 & 314 & 21 & 305 & 21 & 103 & 57 & 122 & 22 \\
\hline Midwife & 0 & 0 & 0 & 0 & 350 & 24 & 361 & 25 & 20 & 11 & 164 & 30 \\
\hline Nurse & 3 & 0 & 2 & 0 & 685 & 47 & 672 & 46 & 39 & 22 & 170 & 31 \\
\hline other & 1 & 0 & 3 & 0 & 115 & 8 & 111 & 8 & 18 & 10 & 90 & 16 \\
\hline NA & 2 & & 80 & & 113 & & 114 & & 0 & & 9 & \\
\hline \multicolumn{13}{|c|}{ Number of years of work experience } \\
\hline$<3$ & 213 & 34 & 193 & 35 & 360 & 35 & 333 & 38 & 33 & 19 & 132 & 25 \\
\hline 3-6 & 164 & 26 & 150 & 27 & 199 & 19 & 161 & 18 & 61 & 34 & 119 & 22 \\
\hline $6-9$ & 122 & 19 & 105 & 19 & 135 & 13 & 120 & 14 & 42 & 24 & 92 & 17 \\
\hline$>9$ & 127 & 20 & 102 & 19 & 344 & 33 & 272 & 31 & 42 & 24 & 195 & 36 \\
\hline NA & 83 & & 165 & & 539 & & 677 & & 2 & & & 17 \\
\hline \multicolumn{13}{|c|}{ Number of patients per day } \\
\hline$<20$ & 193 & 47 & .. & .. & 147 & 38 & .. &.. & 49 & 41 & 135 & 39 \\
\hline $20-50$ & 148 & 36 & .. &.. & 157 & 41 & .. &.. & 47 & 39 & 138 & 40 \\
\hline$>50$ & 72 & 17 &.. &.. & 83 & 21 & .. &.. & 23 & 19 & 75 & 22 \\
\hline NA & 296 & &.. &.. & 1190 & &.. &.. & 61 & & 207 & \\
\hline \multicolumn{13}{|c|}{ Number of GPs per PHCC } \\
\hline 1 & 136 & 22 &.. &.. & 87 & 8 &.. &.. & 37 & 22 & 75 & 15 \\
\hline 2 & 165 & 27 &.. &.. & 240 & 22 &.. &.. & 58 & 34 & 135 & 27 \\
\hline 3 & 125 & 20 &.. &.. & 244 & 22 & .. &.. & 45 & 26 & 151 & 30 \\
\hline 4 & 75 & 12 &.. &.. & 232 & 21 & .. & .. & 21 & 12 & 89 & 18 \\
\hline 5 & 52 & 8 &.. &.$\cdot$ & 170 & 15 &.. &.. & 8 & 5 & 26 & 5 \\
\hline 6 & 22 & 4 &.. &.. & 87 & 8 & .. &.. & 1 & 1 & 10 & 2 \\
\hline 7 & 15 & 2 &.. &.. & 18 & 2 & .. & .. & 1 & 1 & 7 & 1 \\
\hline 8 & 16 & 3 &.. &.. & 22 & 2 &.. &.. & 1 & 1 & 6 & 1 \\
\hline 9 & 2 & 0 &.. &.. & 1 & 0 &.. &.. & 0 & 0 & 3 & 1 \\
\hline 10 & 14 & 2 & .. &.. & 4 & 0 &.. &.. & 0 & 0 & 3 & 1 \\
\hline NA & 87 & & & & 472 & & & & 8 & & 50 & \\
\hline
\end{tabular}




\begin{tabular}{|c|c|c|c|c|c|c|c|c|c|c|c|c|}
\hline \multirow[t]{3}{*}{ Group } & \multicolumn{4}{|c|}{ Symposium } & \multicolumn{4}{|c|}{ Train-The-Trainer } & \multicolumn{4}{|l|}{ Long term } \\
\hline & \multicolumn{2}{|l|}{ Pre } & \multicolumn{2}{|l|}{ Post } & \multicolumn{2}{|l|}{ Pre } & \multicolumn{2}{|l|}{ Post } & \multicolumn{2}{|l|}{$\begin{array}{l}\text { With } \\
\text { education }\end{array}$} & \multicolumn{2}{|l|}{$\begin{array}{l}\text { Without } \\
\text { education }\end{array}$} \\
\hline & $\mathbf{n}$ & $\%$ & $\mathbf{n}$ & $\%$ & $\mathbf{N}$ & $\%$ & $\mathbf{n}$ & $\%$ & n & $\%$ & $\mathbf{n}$ & $\%$ \\
\hline \multicolumn{13}{|c|}{ Always worked in this area } \\
\hline Yes & 602 & 91 &.$\cdot$ &.$\cdot$ & 961 & 84 & .. &.$\cdot$ & 142 & 83 & 400 & 81 \\
\hline No & 60 & 9 &.$\cdot$ &.$\cdot$ & 180 & 16 & .. &.$\cdot$ & 28 & 16 & 91 & 18 \\
\hline Invalid & 1 & 0 & .. &.. & 2 & 0 & .. &.. & 1 & 1 & 4 & 1 \\
\hline NA & 46 & &.$\cdot$ & & 434 & & .. &.$\cdot$ & 9 & & 60 & \\
\hline
\end{tabular}

$N A=$ not available

\section{General NPC questions}

Before any kind of training, participants were asked if they thought NPC was a serious problem; 94\% of the participants agreed or strongly agreed with this statement; and $97 \%$ of the participants stated that patients had a better chance to survive when treated at an earlier stage. After the symposium and Train-The-Trainer programme, almost everybody agreed with those statements, respectively, 98\% and $99 \%$ ( $p$ values $<0.001$ ); at the $11 / 2$ years assessment, $96 \%$ of the participants stated that NPC was a serious problem ( $p=0.02)$, and $96 \%$ agreed that patients had a better chance to survive when treated at an earlier stage (not significant). Most participants of the symposia or Train-The-Trainer meetings already knew that NPC was more common in men than in women (72\%); after the trainings, this proportion was $88 \%$ ( $p<0001$ ); at the 11/2 years assessment, this was $73 \%$ (not significant). Similar results were found for the questions from which age NPC may develop and which age group has the highest incidence (see table 2 and online supplementary table S1).

Table 2 | General questions regarding NPC

\begin{tabular}{|llll|} 
& OR & $95 \% \mathrm{Cl}$ & p-value \\
\hline Risk for men versus women? & & & \\
\hline Pre-test & 1 & (reference) & $<0.001$ \\
Post symposium & 3.81 & {$[2 \cdot 93-4 \cdot 95]$} & $<0.001$ \\
Post Train-The-Trainer & 2.95 & {$[2 \cdot 47-3 \cdot 52]$} & 0.53 \\
Long term no education & 1.08 & {$[0.85-1 \cdot 37]$} & 0.092 \\
\hline Long term with education & 1.39 & {$[0.95-2 \cdot 03]$} & \\
\hline What age has the highest incidence? & & & (reference) \\
\hline Pre-test & 1 & & \\
\hline
\end{tabular}




\begin{tabular}{|c|c|c|c|}
\hline & OR & $95 \% \mathrm{Cl}$ & p-value \\
\hline Post Symposium & $1 \cdot 30$ & {$[1 \cdot 14-1 \cdot 48]$} & 0.001 \\
\hline Post Train-The-Trainer & $1 \cdot 89$ & {$[1 \cdot 59-2 \cdot 25]$} & 0.0001 \\
\hline Long term no education & 1.04 & {$[0 \cdot 84-1 \cdot 28]$} & 0.73 \\
\hline Long term with education & 0.75 & {$[0 \cdot 54-1 \cdot 05]$} & 0.096 \\
\hline \multicolumn{4}{|c|}{ From what age can people develop NPC? } \\
\hline Pre-test & 1 & (reference) & \\
\hline Post Symposium & 1.67 & {$[1.44-1.93]$} & $<0 \cdot 001$ \\
\hline Post Train-The-Trainer & $5 \cdot 55$ & {$[4 \cdot 62-6 \cdot 65]$} & $<0.001$ \\
\hline Long term no education & $1 \cdot 83$ & {$[1 \cdot 47-2 \cdot 28]$} & $<0.001$ \\
\hline Long term with education & $2 \cdot 03$ & {$[1 \cdot 46-2 \cdot 82]$} & $<0.001$ \\
\hline
\end{tabular}

\section{NPC symptoms}

The GP invited to the symposium was often the most senior GP working in the healthcare facility. However, no significant differences in knowledge were found between GPs prior to a symposium and prior to a Train-The-Trainer programme (data not shown); these were combined in further analyses. In table 3, model estimates for knowledge increase of symptoms of NPC are presented; the reference is a GP prior to any kind of training with $<3$ years of work experience. The estimates can be interpreted as absolute percentages. For example, nurses with 3-6 years' work experience scored $30(47-18+0.8)$ points of the 100 prior to training. After attending the Train-The-Trainer programme, the score increased to $57(47-18+0.8+27)$ and was $11 / 2$ years later still significantly increased at $42(47-18+0.8+12)$ points $(p<0.001)$. GPs scored better compared with nurses ( -18 points, $p=0.008)$ and midwives $(-20$ points, $p=0.009$ ). The number of years of work experience was negatively associated with knowledge of NPC, but the effect was very small: 3 points on a scale from 0 to 100 for those with 9years of work experience. Nurses increased their knowledge of symptoms on average with 12 points more than GPs $(p<0.001)$.

\section{NPC risk factors}

We estimated that before any kind of training the fraction of correct answers regarding the risk factors of NPC for a GP with $<3$ years' work experience was $36 \%$ (table 3). Again, baseline results of GPs were combined, though GPs completing the questionnaire before the Train-The- Trainer programme scored $1 \%$ better than their colleagues before the symposium. After the symposium and Train-TheTrainer programme, this fraction increased to $65 \%$ and $62 \%$, respectively. Nurses 
and midwives had lower scores at baseline compared with GPs, but significantly improved their knowledge from 23 points to 50 points $(p<0.001)$ direct after the Train-The-Trainer programme; the score remained at 40 points after $11 / 2$ years $(p<0.001$ vs baseline). Nurses increased their knowledge five points more than did GPs ( $p=0.01)$. An increase in the number of years of work experience was associated with less knowledge of NPC risk factors.

Table 3 | Symptoms and risk factors: fraction of correct answers given during the different activities adjusted for profession and years of work experience

\begin{tabular}{|c|c|c|c|c|}
\hline \multicolumn{5}{|l|}{ Fraction of correct symptoms } \\
\hline & Estimate & SE & $95 \% \mathrm{Cl}$ & p-value \\
\hline Reference (pre-test; GP; 3 years' work experience) & 0.47 & 0.006 & {$[0 \cdot 458-0 \cdot 483]$} & $<0.001$ \\
\hline \multicolumn{5}{|l|}{ Activity } \\
\hline Post symposium & 0.269 & 0.009 & {$[0 \cdot 253-0 \cdot 286]$} & $<0.001$ \\
\hline Post Train-The-Trainer & $0 \cdot 268$ & 0.007 & {$[0 \cdot 255-0 \cdot 281]$} & $<0.001$ \\
\hline Long- term without training & 0.002 & 0.009 & {$[-0 \cdot 017-0 \cdot 021]$} & $0 \cdot 856$ \\
\hline Long- term with training & $0 \cdot 118$ & 0.015 & {$[0 \cdot 089-0 \cdot 148]$} & $<0.001$ \\
\hline \multicolumn{5}{|l|}{ Profession } \\
\hline Midwife & $-0 \cdot 2$ & 0.009 & {$[-0 \cdot 217-0 \cdot 183]$} & $<0.001$ \\
\hline Nurse & $-0 \cdot 182$ & 0.008 & {$[-0 \cdot 197-0 \cdot 168]$} & $<0.001$ \\
\hline Other & $-0 \cdot 155$ & 0.012 & {$[-0 \cdot 178-0 \cdot 131]$} & $<0.001$ \\
\hline \multicolumn{5}{|l|}{ Years of work experience } \\
\hline 3-6 & 0.008 & 0.008 & {$[-0 \cdot 008-0 \cdot 024]$} & $0 \cdot 312$ \\
\hline 6-9 & -0.008 & 0.009 & {$[-0 \cdot 026-0 \cdot 010]$} & $0 \cdot 388$ \\
\hline$>9$ & -0.03 & 0.008 & {$[-0 \cdot 046-0 \cdot 013]$} & $<0.001$ \\
\hline \multicolumn{5}{|l|}{ Fraction of correct risk factors } \\
\hline & Estimate & SE & $95 \% \mathrm{Cl}$ & p-value \\
\hline Reference (pre-test; GP; 3 years' work experience) & $0 \cdot 36$ & 0.006 & {$[0 \cdot 347-0 \cdot 372]$} & $<0.001$ \\
\hline \multicolumn{5}{|l|}{ Activity } \\
\hline Post symposium & $0 \cdot 285$ & 0.009 & {$[0 \cdot 267-0 \cdot 302]$} & $<0.001$ \\
\hline Post Train-The-Trainer & 0.259 & 0.006 & {$[0 \cdot 246-0 \cdot 271]$} & $<0.001$ \\
\hline Long- term without education & 0.042 & 0.009 & {$[0 \cdot 024-0 \cdot 060]$} & $<0.001$ \\
\hline Long- term with education & $0 \cdot 157$ & 0.015 & {$[0 \cdot 127-0 \cdot 187]$} & $<0.001$ \\
\hline \multicolumn{5}{|l|}{ Profession } \\
\hline Midwife & $-0 \cdot 127$ & 0.009 & {$[-0 \cdot 144-0 \cdot 110]$} & $<0.001$ \\
\hline Nurse & $-0 \cdot 134$ & 0.007 & {$[-0 \cdot 149-0 \cdot 120]$} & $<0.001$ \\
\hline Other & $-0 \cdot 138$ & 0.011 & {$[-0 \cdot 159-0 \cdot 116]$} & $<0.001$ \\
\hline
\end{tabular}




$\begin{array}{llllll}\text { Years of work experience } & & & & & \\ \text { 3-6 } & -0.013 & 0.008 & {[-0.029-0.004]} & 0.132 \\ \text { 6-9 } & -0.03 & 0.009 & {[-0.048-0.012]} & 0.001 \\ >9 & -0.051 & 0.008 & {[-0.067-0.035]} & <0.001\end{array}$

Calculation of the estimated fraction of correct answers depending profession, years of work experience and type of education: A GP without any training with less than 3 years' work experience was taken as reference. For the symptoms this means the fraction of correct answers given by a nurse with 3-6 years' work experience was $0 \cdot 470-0 \cdot 182+0 \cdot 008=0 \cdot 30$. This fraction increased programme to $0 \cdot 470-0 \cdot 182+0 \cdot 008+0 \cdot 268=0.57$ directly after the Train-The-Trainer programme. At the long-term assessment this fraction was $0 \cdot 470-0 \cdot 182+0 \cdot 008+0 \cdot 118=0 \cdot 414$. A similar calculation can be made for the risk factors regarding NPC. A nurse with 6-9 years' work experience scored 0.360-0.134-0.030=0.20 prior to training. After attending the TrainThe-Trainer programme this fraction was 0.360-0.134-0.030+0.259=0.455. At the long-term assessment this fraction was $0 \cdot 353(0 \cdot 360-0 \cdot 134-0 \cdot 030+0 \cdot 157)$.

\section{Long-term effects}

Forty-one per cent $(n=73)$ of all participants who filled in the questionnaire at $11 / 2$ years after the training indicated having counselled NPC suspects. Almost all (72 of 73) were referred, 25 (34\%) specifically to an ear, nose and throat (ENT) specialist. As discussed above, knowledge of symptoms and risk factors had overall remained higher compared with before the NPC awareness programme. However, this higher knowledge did not differ between those participants who completed the questionnaire for the long-term effect and claimed never to have followed any kind of training before (76\%) and those who did participate in the NPC aware-ness programme (24\%).

\section{Need for additional education}

GPs attending the first symposium held in Yogyakarta were also asked what kind of education methods would be sufficient, whether the accreditation is important, and how much time they would like to spend on additional education. In total, $97 \%$ of the participants $(n=41)$ agreed that a lecture of an ENT specialist would be an appropriate education; and $47 \%$ indicated that personal education by an ENT specialist would be appropriate. Accreditation was important for $90 \%$ of the participants and $36 \%$ wished to spend $>1$ day on additional education (see online supplementary table S2). 


\section{Discussion}

This is the first multicentre study conducted in Indonesia demonstrating that the effect of additional training for NPC symptoms and diagnosis can be successful. Moreover, knowledge of the healthcare workers working in the PHCC was still increased after 11/2 years. The long-term effect was only tested in Yogyakarta since the area is more transparent and easy to visit. However, there were no differences in short-term knowledge increase between participants in the different cities. Therefore, we assume that the results obtained in Yogyakarta are representative of those for the other cities where the NPC awareness was conducted.

Considering the training for nurses and midwives, it was not surprising to find lower scores compared with GPs. Nevertheless, in the long term, their knowledge remained improved, suggesting that the programme is effective for different health professions working in the PHCC. It should be noted that in our analyses all observations were treated as independent measurements, and not individually paired scores, because all questionnaires were completed anonymously. This was important to improve the likeliness of honest answers in the questionnaires. Since only GPs were invited to the symposium, we could only test the association between profession and improvement in knowledge for the Train-The-Trainer programme. Indeed, nurses and midwives had less knowledge than GPs, but after the TrainThe-Trainer programme it was increased more than the knowledge of the GPs, suggesting that different professions have different learning curves. Taking the role of the nurses in the PHCC into account, it only emphasises the importance of their participation in the programme.

In Malaysia, where the incidence of NPC is also high, Balachandran et al likewise discovered that the knowledge of first-line medical healthcare workers in the PHCC on NPC is limited. They also found that when medical doctors in Malaysia were asked if they thought they had enough knowledge to diagnose NPC, 88.7\% of the participants answered no. [25] Prasad and Pua noticed a 'doctors-delay' of 127 days before diagnosis, acknowledging that there is a need to create more awareness among first-line doctors. However, it is not just the GP in the PHCC who plays an important role in the late presentation at diagnosis. The behaviour of the 
patient also causes a delay. [26] This will need to be investigated in more detail to understand the reasons why patients wait before they seek medical help.

A previous study of Devi et al [28] showed that a 2-day training programme was effective for downstaging breast cancer and earlier referral of patients with cervical cancer. Even though this study did not show downstaging for patients with NPC, the number of patients with NPC increased, suggesting a better referral programme. In 2009, an NPC data management system was introduced in Yogyakarta. All new patients with NPC at the Dr. Sardjito Hospital in Yogyakarta are being registered. Future studies can investigate the effect of awareness training on stage at NPC diagnosis.

Seventy-six per cent of those who completed the long- term questionnaire indicated that they had not attended an extra NPC awareness training. This percentage was expected to be smaller, based on the number of years the participant has been working in their PHCC and the interval between the activities. However, we suspect, based on a personal communication with Indonesian colleagues, that one reason for this is that participants do not want to admit that they attended any kind of additional training to prevent losing face when not all questions were answered correctly. In addition, there can be a spillover effect, which proves the importance of the awareness programme. This is not unlikely since all participants of the symposium received training materials, such as folders and flyers, to share with their colleagues. When we visited the PHCCs at the $11 / 2$ years' assessment, some of them still had an NPC poster on the wall.

Besides strengths, our study also had some limitations. For each training, all healthcare workers working in the PHCC were invited and the training was obligatory. However, since it was not feasible to register non- attendees, there may have been a bias towards more motivated health staff attending the trainings. Importantly, every attendant filled in the questionnaires because this was part of the training and it was obligatory to receive the certificate. Therefore, we expect response bias to be very limited. Another limitation is that we were only able to evaluate the long-term effect of the programme in Yogyakarta. On the other hand, we have no indications to believe that the long-term effect would be different in the other provinces; at least, the short-term effects of the symposia were similar among centres (data not shown). 
Unfortunately, we were unable to evaluate whether the training has an effect on the timely referral of patients leading to a diagnosis of NPC at an earlier stage. Indonesia does not have a nationwide cancer registry. The referral system is complex and not all suspects of NPC will have been referred directly to one of the hospitals involved. Moreover, in January 2014, the Indonesian government introduced a universal healthcare insurance (Badan Penyelenggara Jaminan Sosial). The referral system is now more regulated: patients first visit primary care and may be referred by the physician to a specialist in a secondary care unit, who can refer the patient to a tertiary care hospital. Therefore, we choose to evaluate the effect of the training programme using an effectiveness measure early in the chain of effects, that is, increased knowledge.

\section{Future}

Cancer is increasingly becoming the world's leading cause of death, with an estimated 12.7 million new cancer cases and 76 million deaths in 2008.1 The number of people dying because of cancer is significantly higher in developing countries than in developed countries, owing to the lack of early detection, prevention and limited access to and capacity of sufficient healthcare. [29 30] Early referral and optimal usage of the limited capacity of avail- able equipment is therefore of major importance.

Access to healthcare facilities may improve for many people by the introduction of the new healthcare insurance and is likely to increase the workload of the GPs in the PHCC. Therefore, it will assume greater importance if GPs are able to recognize the early symptoms and refer the patients to the correct specialist.

Our research shows that the NPC awareness programme is an effective tool to increase the knowledge of the primary healthcare workers. In this way, we wish to achieve diagnosis of NPC suspects at an earlier stage through referral at the onset of the disease. Once the medical specialists are trained, public awareness should be the next step. Patients' attitudes towards the health care system, resulting in a delay in diagnosis, needs to be investigated in more detail before initiating more community awareness. 


\section{References}

1. Ferlay J, Shin H-R, Bray F, Forman D, Mathers C, Parkin DM. Estimates of worldwide burden of cancer in 2008: GLOBOCAN 2008. Int J Cancer. 2010 Jun 17;127(12):2893917.

2. Wee JJ, Tan EHE, Tai BCB, Wong HBH, Leong SSS, Tan TT, et al. Randomized trial of radiotherapy versus concurrent chemoradiotherapy followed by adjuvant chemotherapy in patients with American Joint Committee on Cancer/International Union against cancer stage III and IV nasopharyngeal cancer of the endemic variety. Journal of Clinical Oncology. 2005 Sep 19;23(27):6730-8.

3. Adham M, Kurniawan AN, Muhtadi Al, Roezin A, Hermani B, Gondhowiardjo S, et al. Nasopharyngeal carcinoma in Indonesia: epidemiology, incidence, signs, and symptoms at presentation. Chin J Cancer. 2012 Feb 7;:- .

4. Wildeman MA, Fles R, Herdini C, Indrasari RS, Vincent AD, Tjokronagoro M, et al. Primary treatment results of Nasopharyngeal Carcinoma (NPC) in Yogyakarta, Indonesia. PLoS ONE. 2013;8(5):e63706.

5. Wei WI, Sham JST. Nasopharyngeal carcinoma. Lancet. 2005 Jun;365(9476):2041-54.

6. Raab-Traub N. Epstein-Barr virus in the pathogenesis of NPC. Seminars in Cancer Biology. 2002 Dec;12(6):431-41.

7. Guo X, Johnson RC, Deng H, Liao J, Guan L, Nelson GW, et al. Evaluation of nonviral risk factors for nasopharyngeal carcinoma in a high-risk population of Southern China. Int J Cancer. 2009 Jun 15;124(12):2942-7.

8. Ji X, Zhang W, Xie C, Wang B, Zhang G, Zhou F. Nasopharyngeal carcinoma risk by histologic type in central China: impact of smoking, alcohol and family history. Int J Cancer. 2011 Aug 1;129(3):724-32.

9. Jia W-H, Qin H-D. Non-viral environmental risk factors for nasopharyngeal carcinoma: A systematic review. Seminars in Cancer Biology. Elsevier Ltd; 2012 Apr 1;22(2):117-26.

10. Jia W-H, Luo X-Y, Feng B-J, Ruan H-L, Bei J-X, Liu W-S, et al. Traditional Cantonese diet and nasopharyngeal carcinoma risk: a large-scale case-control study in Guangdong, China. BMC Cancer. 2010;10(1):446.

11. Gallicchio L, Matanoski G, Tao XG, Chen L, Lam TK, Boyd K, et al. Adulthood consumption of preserved and nonpreserved vegetables and the risk of nasopharyngeal carcinoma: A systematic review. Int J Cancer. 2006;119(5):1125-35.

12. Armstrong RW, Imrey PB, Lye MS, Armstrong MJ, Yu MC, Sani S. Nasopharyngeal carcinoma in Malaysian Chinese: salted fish and other dietary exposures. Int I Cancer. 1998 Jul 17;77(2):228-35.

13. Hildesheim A, West S, DeVeyra E, De Guzman MF, Jurado A, Jones C, et al. Herbal medicine use, Epstein-Barr virus, and risk of nasopharyngeal carcinoma. Cancer Res. 1992 Jun 1;52(11):3048-51.

14. Henderson BE, Louie E, SooHoo Jing J, Buell P, Gardner MB. Risk factors associated with nasopharyngeal carcinoma. N Engl J Med. 1976 Nov 11;295(20):1101-6.

15. Vaughan TL, Stewart PA, Teschke K, Lynch CF, Swanson GM, Lyon JL, et al. Occupational exposure to formaldehyde and wood dust and nasopharyngeal carcinoma. Occup Environ Med. 2000 Jun;57(6):376-84.

16. Fachiroh J, Sangrajrang S, Johansson M, Renard H, Gaborieau V, Chabrier A, et al. Tobacco consumption and genetic susceptibility to nasopharyngeal carcinoma (NPC) in Thailand. Cancer Causes Control. 2012 Oct 20;:- .

17. Cheng YJ, Hildesheim A, Hsu MM, Chen IH, Brinton LA, Levine PH, et al. Cigarette smoking, alcohol consumption and risk of nasopharyngeal carcinoma in Taiwan. Cancer Causes Control. 1999 Jun;10(3):201-7. 
18. Xue WQ, Qin HD, Ruan HL, Shugart YY, Jia WH. Quantitative Association of Tobacco Smoking With the Risk of Nasopharyngeal Carcinoma: A Comprehensive Meta-Analysis of Studies Conducted Between 1979 and 2011. American Journal of Epidemiology. 2013 Jul 30;178(3):325-38.

19. Chaudhury N, Hammer J, Kremer M, Muralidharan K, Rogers FH. Missing in action: teacher and health worker absence in developing countries. J Econ Perspect. 2006;20(1):91-116.

20. Old problems, fresh solutions: Indonesia's new health regime. 2010 Sep 21;:1-24.

21. Ngana FR, Myers BA, Belton S. Health reporting system in two subdistricts in Eastern Indonesia: Highlighting the role of village midwives. Midwifery. Elsevier; 2012 Dec 1;28(6):809-15.

22. Fles R, Wildeman MA, Sulistiono B, Haryana SM, Tan IB. Knowledge of general practitioners about nasopharyngeal cancer at the Puskesmas in Yogyakarta, Indonesia. BMC Med Educ. BioMed Central Ltd; 2010 Nov 18;10(1):81.

23. Amgad M, Shash E, Gaafar R. Cancer education for medical students in developing countries: Where do we stand and how to improve? Critical Reviews in Oncology / Hematology. Elsevier Ireland Ltd; 2012 Feb 29;:1-8.

24. Aswani J, Baidoo K, Otiti J. Establishing a head and neck unit in a developing country. J Laryngol Otol. 2012 Apr 19;126(06):552-5.

25. Balachandran R, Philip R, Avatar S, Simon R, Mann GS, Benedict CTW, et al. Exploring the knowledge of nasopharyngeal carcinoma among medical doctors at primary health care level in Perak state, Malaysia. Eur Arch Otorhinolaryngol. 2011 Jun 21;269(2):64958.

26. Prasad U. Nasopharyngeal Carcinoma: A delay in Diagnosis. Medical Journal Malaysia. 2000 Jan 4;2:1-6.

27. Wildeman MA, Fles R, Adham M, Mayangsari ID, Luirink I, Sandberg M, et al. Shortterm effect of different teaching methods on nasopharyngeal carcinoma for general practitioners in Jakarta, Indonesia. PLoS ONE. 2012;7(3):e32756.

28. Devi B, Tang T, Corbex M. Reducing by half the percentage of late-stage presentation for breast and cervix cancer over 4 years: a pilot study of clinical downstaging in Sarawak, Malaysia. Annals of Oncology. 2007 Aug 3;18(7):1172-6.

29. Kanavos P. The rising burden of cancer in the developing world. Annals of Oncology. 2006 Jul 1;17(Supplement 8):viii15-viii23.

30. Gondhowiardjo SA, Prajogi GB, Sekarutami SM. History and growth of radiation oncology in Indonesia. Biomed Imaging Interv J. 2008;4(3). 



\section{SYSTEM DELAY}

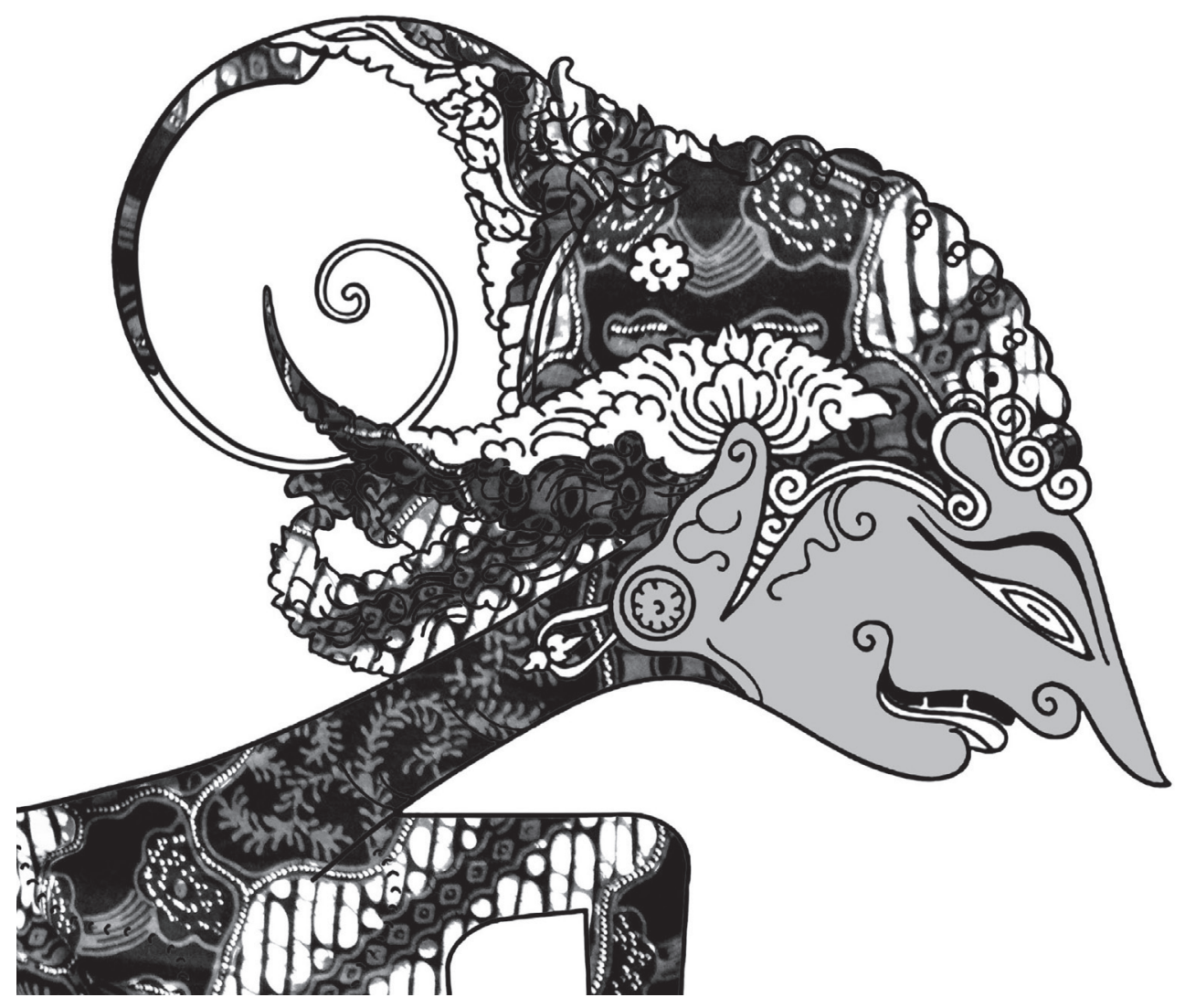




\section{Chapter 8}

A prospective study: Current problems in radiotherapy for nasopharyngeal carcinoma in Yogyakarta, Indonesia

SD. Stoker

MA. Wildeman

R. Fles

SR. Indrasari

C. Herdini

PL. Wildeman

JNA. van Diessen

M. Tjokronagoro

IB. Tan

PLoS One; 2014 Jan vol. 9 p. e85959 


\begin{abstract}
Nasopharyngeal carcinoma (NPC) has a high incidence in Indonesia. Previous study in Yogyakarta revealed a complete response of $29 \%$ and a median overall survival of less than 2 years. These poor treatment outcomes are influenced by the long diagnose-to-treatment interval to radiotherapy (DTI) and the extended overall treatment time of radiotherapy (OTT). This study reveals insight why the OTT and DTI are prolonged.
\end{abstract}

\title{
Method
}

All patients treated with curative intent radiotherapy for NPC between July 2011 until October 2012 were included. During radiotherapy a daily diary was kept, containing information on DTI, missed radiotherapy days, the reason for missing and length of OTT.

\section{Results}

Sixty-eight patients were included. The median DTI was 106 days (95\% Cl: 98- 170). Fifty-nine patients (87\%) finished the treatment. The median OTT for radiotherapy was 57 days (95\% Cl: 57-65). The main reason for missing days was an inoperative radiotherapy machine (36\%). Other reasons were patient's poor condition (21\%), public holidays (14\%), adjustment of the radiation field (7\%), power blackout (3\%), inoperative treatment planning system $(2 \%)$ and patient related reasons $(9 \%)$. Patient's insurance type was correlated to DTI in disadvantage for poor people.

\section{Conclusion}

Yogyakarta has a lack of sufficient radiotherapy units which causes a delay of 3-4 months, besides the OTT is extended by 10-12 days. This influences treatment outcome to a great extent. The best solution would be creating sufficient radiotherapy units and better management in health care for poor patients. The growing economy in Indonesia will expectantly in time enable these solutions, but in the meantime solutions are needed. Solutions can consist of radiation outside office hours, better maintenance of the facilities and more effort from patient, doctor and nurse to finish treatment in time. These results are valuable when improving cancer care in low and middle income countries. 


\section{Introduction}

Cancer is the leading cause of death worldwide. About $70 \%$ of all cancer deaths occur in middle and low-income countries [1]. Although this burden increases every year, health-care systems in these countries are even at present not prepared for the high number of patients. In high-income countries survival rates are increasing due to improving treatment facilities and protocols, while low-income countries lack facilities and medication. Besides, funding for research on how to cope with these limitations is missing. The gap in treatment results between high-income and low-income countries is therefore widening [2].

While many politicians and scientists have emphasized the need to improve cancer care in low and middle-income countries, only a minority reported about the actual problems [3-5]. Before cancer care in these countries can be improved, research should focus on the current limitations in these health-care systems.

Indonesia is a low to middle-income country in which nasopharyngeal cancer (NPC) is one of the commonest types of cancer. Although NPC is highly sensitive to radiotherapy and chemo-radiotherapy, a previous study in Yogyakarta, Indonesia showed that the complete treatment response was less than $29 \%$ directly after therapy, compared to a 3-year-disease-free survival of $70 \%$ in international studies. Furthermore, the median overall survival in Yogyakarta was less than 2 years (21 months), compared to a 3-year overall survival of $80 \%$ in international literature [6-8].

Two important problems encountered in the studies in Yogyakarta were a diagnosisto-treatment-interval of approximately 4 months and an overall radiotherapy treatment time of 62 days, which is 15-17 days too long. Optimally, a total dose of 66 to 70 Gray should be given in 33 to 35 fractions in a maximum 45 to 47 days. For each day by which radiotherapy treatment is extended, effective dose is lost, and the success rate declines rapidly [9-11].

As greater insight into the current problems in Indonesia's cancer-care system might support the search for solutions, this study aims to explore reasons for the extended overall radiotherapy treatment time (OTT). Also the actual length of the OTT and the diagnose-to-treatment interval (DTI) are evaluated and factors that influenced these will be identified. In particularly, the association with type of insurance was 
investigated, since there is a wide variation in patient's financial resources and these might have a great impact on DTI and OTT.

\section{Methods}

\section{Patient population}

An official letter with confirmation of exemption of review was obtained from the medical ethical board of Dr. Sardjito Hospital, Universitas Gadjah Mada, Yogyakarta. All patients treated with curative intent radiotherapy for NPC in the period from July 2011 until October 2012 in Dr. Sardjito Hospital were included in this study. Sixtyeight patients were analyzed for inclusion. One patient never started radiotherapy and was excluded from all analysis. A total of 67 patients met the inclusion criteria. Information on patient characteristics was obtained by the medical chart. All data was analyzed anonymously. In table 1, patient characteristics and stage of disease are shown. Staging was performed by CT-scan of the head and neck, ultrasound of the abdomen, $x$-ray of the thorax and a bone scan. The median age was 47 years. Stage at diagnosis was available for 60 patients, advanced stage was predominantly seen. All patients were treated with $2 \mathrm{D}$ and/ or 3D external beam radiotherapy in fractions of 2 Gray to a total dose 60-72 Gray.

Table 1 | Patient and tumor characteristics

\begin{tabular}{llll} 
Category & Subcategory & $\mathbf{N}=67$ & $70 \%$ \\
\hline Sex & Male & 47 & $30 \%$ \\
Median age & Female & 20 & IQR $40-60$ \\
Insurance type & Jamkesmas insurance (poor) & 47 & $22 \%$ \\
& Askes insurance (civil servants) & 15 & $21 \%$ \\
AJCC-stage & Self finance & 14 & $57 \%$ \\
& I & 38 & $1 \%$ \\
& Ila & 1 & $1 \%$ \\
IIb & 1 & $6 \%$ \\
II & 4 & $33 \%$ \\
IVa & 22 & $16 \%$ \\
IVb & 11 & $31 \%$ \\
Missing & 21 & $10 \%$
\end{tabular}

$I Q R=$ inter quartile range 


\section{Data collection}

The diagnosis-to-treatment interval (DTI) was calculated from the date a positive biopsy was obtained to the date radiotherapy was initiated. The overall treatment time (OTT) was calculated from time of radiotherapy initiation to the last day the patients received radiotherapy. During radiotherapy treatment, a nurse monitored daily the treatment of each patient and collected these data in a record form. This contained information on age, insurance type, the start date of radiotherapy and information on which days the patient did or did not get radiated. If the patient missed a treatment day, the reason for the missing day was recorded.

\section{Statistical analysis}

The major statistical endpoint of this study was the total number of radiotherapy days wherein all fractions of radiotherapy were administered. An assessment was made on the number of missed days and why this delay occurred. A comparison was made between patient and hospital related factors.

Secondary endpoint of this study was the length of the DTI. Both DTI and OTT were evaluated for correlation to insurance type. The insurance system in Indonesia is complex and differs per district. In general Yogyakarta has three types of insurances; jamkesmas (insurance for poor people), askes (insurance for civil servants) and patients with self-finance health care. Jamkesmas is a tax-funded health insurance, providing free health services in community health centres (puskesmas) and 3rd class (basic level) wards in government hospitals and some designated private hospitals. Expenses of health care will be paid if the head of the area confirms that the patient and the family have no resources and when the responsible doctor clarifies the need for health care. These approvals are time consuming and can cause a delay in diagnosis and treatment. Askes insurance is for civil servants, they contribute two per cent of their salaries and the government matches the contribution and covers almost all the diagnostic procedures and treatments [12]. Almost half of the Indonesian health care expenses are private health expenditures. This includes out of the pocket payment, private social insurance and other private insurance [13]. In this study we refer to these patients with the term 'self-finance'. 
To test for differences in distribution between the three insurance types the Kruskal Wallis test was used. When a difference was found the Mann-Whitney $U$ was used to identify which group differed. For statistic analysis SPSS version 20 was used and a $p$-value of less than $p=0.05$ was defined as significant.

\section{Results}

\section{Patients}

Sixty-eight patients were evaluated for inclusion in this study. One patient was excluded because she never started radiotherapy because of a poor physical condition, accordingly 67 patients were included. The median age was 47 years (range 9-81, inter quartile range (IQR) 40-60).

Type of insurance was distributed as followed; 38 patients (57\%) financed their health care themselves, 15 patients (22\%) had jamkesmas insurance and 14 patients (21\%) had askes insurance. Fifty-nine patients finished radiotherapy treatment. Eight patients did not finish treatment; of them 4 patients refused further treatment due to anxiety for side effects, 1 patient went to another hospital, 1 patient died after 12 fractions of radiotherapy and 2 patients never returned to the hospital for unknown reason.

One patient received 18 Gray from March to April 2011, but then stopped for unknown reasons and started treatment again in September 2011 and received another 70 Gray. In this case, for calculation of DTI the start date of the first treatment was used. For OTT and analysis of the missed days the second course was used.

\section{Diagnosis-to-treatment interval}

The precise date of biopsy proven diagnosis of NPC could not be retrieved in 3 patients. These patients were excluded for calculation of DTI. The median DTI was 106 days (IQR 53-66). Table 2 presents the median DTI and the start day of the radiotherapy treatment. Table 3 presents the day on which the radiotherapy was initiated. 
Table 2 | Diagnosis-to-treatment interval

\begin{tabular}{lll} 
DTI in days & Median in days & Mean in days \\
\hline Total ( $\mathbf{n = 6 4 )}$ & 106 (IQR 38-176) & 134 (95\% Cl: 98- 170) \\
Jamkesmas insurance (poor) & 192 (IQR 125-279) & $214(95 \% \mathrm{Cl}: 143-284)$ \\
Askes insurance (civil servants) & 122 (IQR 51-143) & 107 (95\% Cl: 72- 143) \\
Self finance & 54 (IQR 24-136) & 111 (95\% Cl: 55- 167)
\end{tabular}

$D T I=$ diagnosis-to-treatment interval

Table 3 | Day of initiation of the radiotherapy treatment

\begin{tabular}{ll} 
Start day $(\mathrm{n}=67)$ & Number of patients (percentage) \\
\hline Monday & $26(39 \%)$ \\
Tuesday & $13(19 \%)$ \\
Wednesday & $15(22 \%)$ \\
Thursday & $12(18 \%)$ \\
Friday & $1(2 \%)$
\end{tabular}

A difference in median and mean DTI was seen between the different types of insurance (table 2, Fig. 1). Kruskal Wallis test showed a significant difference between the three types of insurance $(p=0.003)$. Mann-Whitney $U$ test showed that patient's with jamkesmas insurance had a significant longer DTI than patients who had askes insurance $(p=0.016)$ and who financed their health care themselves $(p=0.001)$. Although a difference of 68 days between askes and self finance was seen, no significant difference was found $(p=0.325)$. One patient with private insurance had an interval to radiotherapy of 922 days (*62 in Fig. 1). She went first for alternative treatment with herbal medicine. Excluding this patient will make the differences between the insurance types stronger, although for askes versus self finance still no significance was achieved ( $p=0.243)$. 


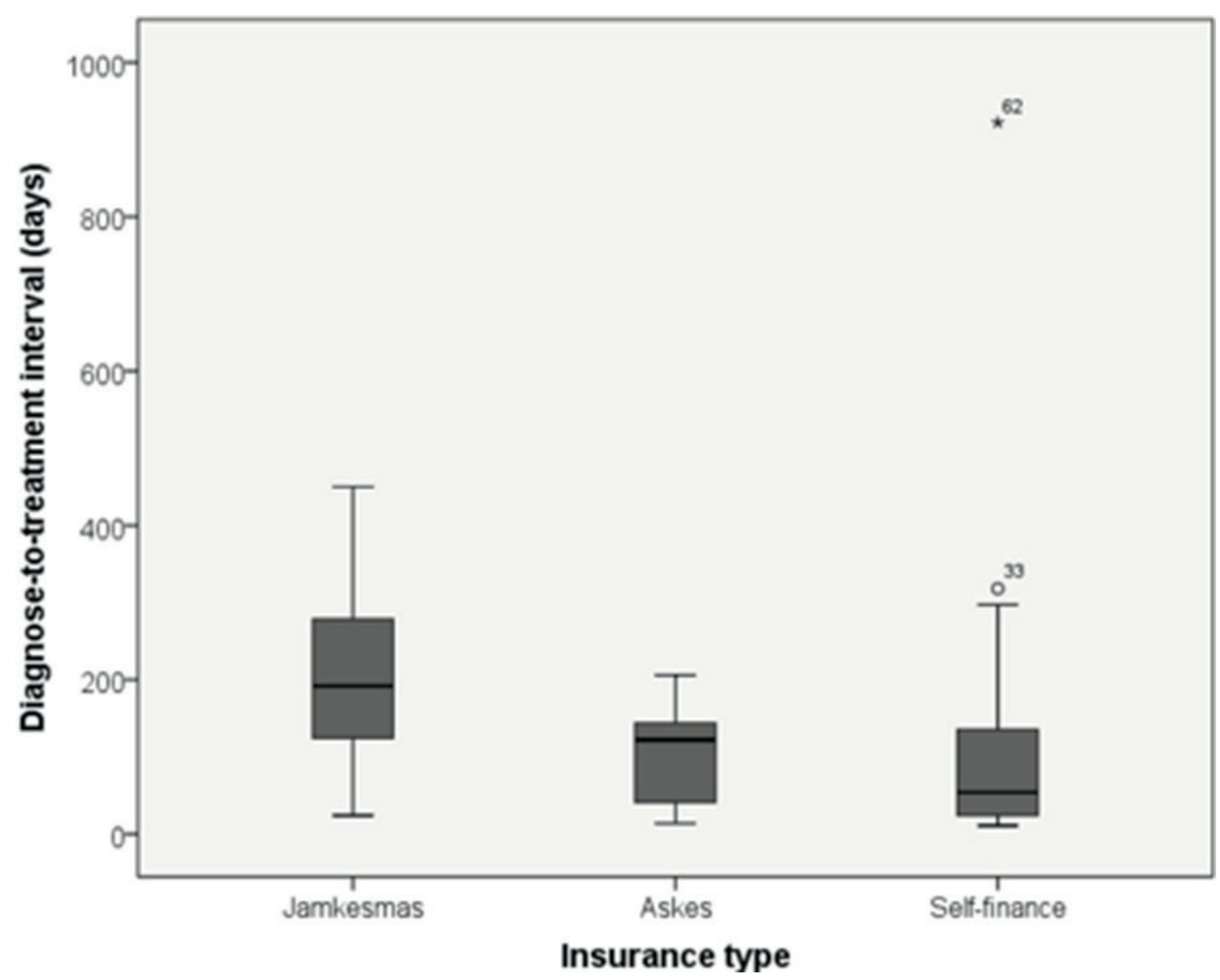

Figure 1 | Distribution of diagnose-to-treatment interval and insurance type

\section{Overall treatment time}

For 59 patients the OTT was analysed. The median OTT was 57 days. In total 584 days were missed, with a mean of 10 days per patient. A difference in median and mean OTT was seen between the different types of insurance, in favour of the patients with self finance (table 4, and Fig. 2). Kruskal Wallis test showed no significant difference $(p=0.28)$. One patient with jamkesmas insurance (*37 in Fig. 2 ) had an OTT of 144 days due to a poor physical condition. Excluding his patient did not change the significance of OTT versus insurance type. 
Table 4 | Overall treatment time and missed days

\begin{tabular}{lll}
\hline OTT in days $(\mathbf{n = 5 9 )}$ & Median in days & Mean in days \\
\hline Total & 57 (IQR 53- 66$)$ & 61 (95\% Cl: $57-65)$ \\
Jamkesmas insurance (poor) & 59 (IQR 57- 66$)$ & 68 (95\% Cl: 53-83) \\
Askes insurance (civil servants) & 58 (IQR 51- 66) & 58 (95\% Cl: 52-64) \\
Self finance & 56 (IQR 52- 64) & $59(95 \% \mathrm{Cl}: 55-63)$ \\
Number of missed days per patient & 8 (IQR 4- 13) & $10(95 \% \mathrm{Cl}: 8-12)$ \\
Dose (in Gray) & 66 (range 60-72) & $67(95 \% \mathrm{Cl}: 66-68)$
\end{tabular}

$O T T=$ overall treatment time, $I Q R=$ inter quartile range, $\mathrm{Cl}=$ confidence interval

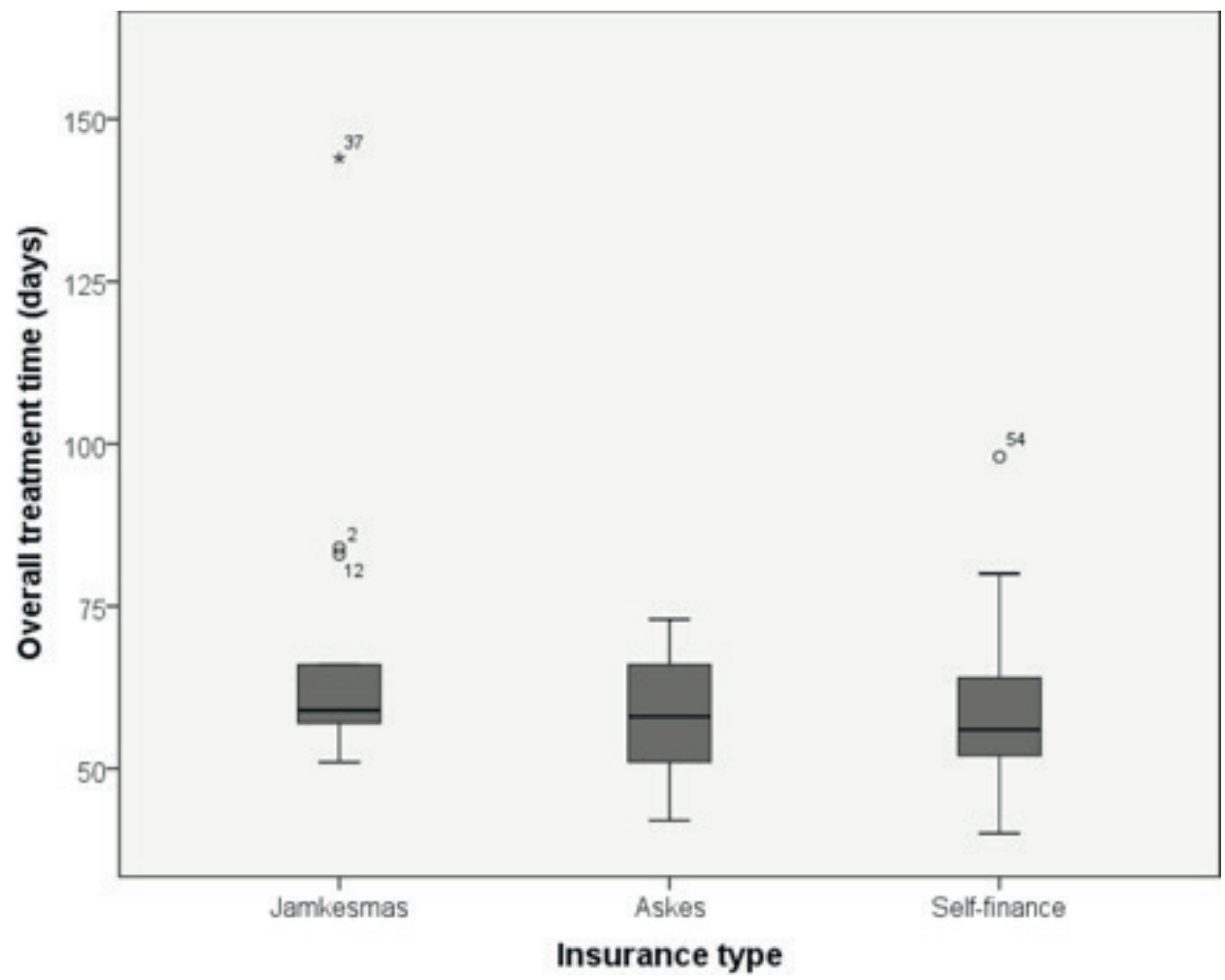

Figure 2 | Distribution of overall treatment time and insurance type. The dark line in the middle of the boxes is the median. The bottom and top of the boxes indicate the 25th and the 75th percentile. The T-bars are the inner fences of all subjects and extend to a maximum of 1.5 times the inter quartile range. ${ }^{*}$ are outliers until 3 times the inter quartile range, ${ }^{\circ}$ are outliers exceeding 3 times the quartile range 
Table 5 presents the reasons for the missed days of treatment per category. An inoperative radiotherapy machine was the most frequent seen reason for missing treatment days. On 31 days the treatment planning system (TPS) was inoperative or there was a power black out. Forty-three patients (73\%) missed one or more days because of problems with the facilities; an inoperative radiotherapy machine, TPS or a power black out.

The poor physical condition of the patient was the next most frequent reason for treatment extension, 23 patients (39\%) were delayed because of their clinical condition. In all these cases the poor condition was related to therapy or treatment. The third most frequent reason was calendar holidays, 39 patients (66\%) were delayed for this matter.

When 2-dimension radiotherapy is given the radiation field has to be adjusted after 40 Gray to protect the spinal cord, 26 patients (44\%) missed one or more days because of these adjustments. Patient related causes for a prolonged treatment were seen in $10,5 \%$. Reasons were an extra day off after calendar holidays $(n=7,17$ days), to take care of their family ( $n=2,3$ days), because of lack of financial resources to pay for the treatment or transport to the hospital ( $n=4,29$ days) and 1 patient had a motor accident ( $n=1,6$ days). Other reasons were miscommunications about the moment when facilities were in progress again ( $n=2,2$ days), a shift from 2 dimensional radiation to 3 dimensional radiation ( $n=1,1$ day) or problems with the chemotherapy ( $n=2,7$ days).

Table 5 | Reasons for missed treatment days

\begin{tabular}{lllll} 
Reason for missed days (n=59) & $\begin{array}{l}\text { Number of } \\
\text { missed days }\end{array}$ & $\begin{array}{l}\text { Percentage of } \\
\text { total missed days }\end{array}$ & $\begin{array}{l}\text { Number of } \\
\text { patients }\end{array}$ & $\begin{array}{l}\text { Percentage number } \\
\text { of patients }\end{array}$ \\
\hline Radiation system was inoperative & 212 & $36.3 \%$ & 40 & $67.8 \%$ \\
TPS was inoperative & 11 & $1.9 \%$ & 9 & $15.3 \%$ \\
Black out & 20 & $3.4 \%$ & 14 & $23.7 \%$ \\
Patient's poor physical conditions & 125 & $21.4 \%$ & 23 & $39.0 \%$ \\
Calendar holiday & 83 & $14.2 \%$ & 39 & $66.1 \%$ \\
Adjustment of radiation field & 40 & $6.8 \%$ & 26 & $44.1 \%$ \\
Patient related & 55 & $9.4 \%$ & 13 & $22.0 \%$ \\
Other & 10 & $1.7 \%$ & 4 & $6.8 \%$ \\
Unknown & 28 & $4.8 \%$ & 3 & $5.1 \%$
\end{tabular}

TPS= treatment planning system 


\section{Discussion}

This is the first study showing that the DTI and the OTT for radiotherapy in Indonesia are extended compared to international standards. This can be an explanation for the poor treatment outcome of NPC in Yogyakarta. At present, the answer to locally advanced NPC, which is one of the most common cancers in Indonesia, is concurrent chemo-radiation. Chemotherapy can be administered in most well equipped hospitals within Indonesia, whereas radiotherapy for most patients is limited. In several centres radiotherapy can be administered according to international standards, but the scarcity makes this only available for a very limited number of patients. In 2008 there were 25 units (accelerator and cobalt) available in Indonesia with a population of 229 million, whereas 6 were under commission, resulting in 0.13 units per million inhabitants [14]. This is in stark contrast with Europe, where in high-resource countries 5.5 accelerators are available per million inhabitants, 3.5 in medium-resource countries, and 2 per million in low resource countries [15]. The recommended number of treatment units per population differs widely; European guidelines recommend on average 5.9 units per million inhabitants $[16,17]$.

The vast lack of equipment, inadequate treatment procedures and preferential treatments for patients with self finance insurance results in excessive waiting lists. The very wealthy patients choose to receive their treatment in hospitals abroad, resulting in an outflow of substantial health care dollars to adjacent countries such as Malaysia, Singapore, and Australia [18]. Due to this loss in health care dollars, the less fortunate individuals cannot receive this quality of treatment. Currently, the Indonesian government offers a reimbursement for lower incomes, placing even more pressure on waiting lists [12].

In this study the median DTI was 3 to 6 months ( $95 \% \mathrm{Cl}$ for all patients). This is too long when comparing to international standards, with quality indicators of DTI of maximum 1 month [19]. Chen at al. showed in a systematic review that a delay in starting radiotherapy for head and neck cancer was significantly associated with higher recurrence rates and lower survival. They found an absolute increase in the risk of local recurrence of 3,7 \% per month delay [20]. The median intervals presented in those studies were all less than 2 months. With the intervals presented in our study and the high number of patients with already advanced disease at diagnosis, the risk on recurrence and poor survival is expectantly even higher, 
since the higher possibility of disease progression to an even more advanced stage $[21,22]$. In a sequel study we would like to reveal the disease progression during the waiting time, since we expect that a number of patients might have progression to a incurable stage.

The length of DTI was associated with type of insurance. Poor patients with jamkesmas insurance had significantly longer delay to treatment, varying between 5 to 9 months $(95 \% \mathrm{Cl})$. This might be caused by the management of healthcare within jamkesmas insurance. After the positive biopsy for NPC, staging has to be performed by CT-scan of the head and neck region, ultra sound of the abdomen, bone scan and $x$-ray of the thorax. With jamkesmas insurance the government and treating doctor have to give approval for every diagnostic investigation and treatment. A solution to overcome this problem could be a diagnostic package deal, including all needed studies when biopsy is proven positive for NPC. This will shorten the DTI cause patients can be put on the waiting list for radiation earlier.

Another reason for the difference between the insurance types is that more resourced patients get a priority treatment. There is a different waiting list for radiotherapy for every type of insurance. Patients who can pay the treatment out of the pocket can even start within 2 weeks. Adaptations in the management for the poor will be beneficial in reducing the delay to complete diagnosis, but the absence of sufficient radiation units will still be a problem.

The OTT was 57 days, 10-12 days longer than recommended. Optimally, a total dose of 66 to 70 Gray should be given in 33 to 35 fractions and the best therapy response is achieved when the total dose is administered in 45 to 47 days. Each day of prolongation of the radiotherapy has a detrimental effect by a loss of the effective dose. During prolonged intervals tumour cells repopulate and will therefore influence the treatment success to a great extent $[9,10,23]$. Platek et al. presented in patients treated with radiation for head and neck cancer, an 8-fold increase on locoregional progression if treatment time was prolonged to $>57$ days. Their results are in accordance to literature which the detrimental effect of treatment interruption on survival and local control vary between $1-5 \%$ per day [23].

The main reasons for the prolonged OTT were the radiotherapy facilities being intermittently operational ( $48 \%$ of the days were missed due to inoperative radiotherapy machines or treatment planning system, power black out and 
readjustment of radiation field). The hospital is already aware of the intermittently operating radiotherapy facility and got a maintenance contract for the radiation unit 4 months before start of this study. This contract is still going on. We see some improvement when comparing to earlier data of an OTT of 62 days, although better maintenance is still needed [6].

The next most frequent reason for an extended OTT was the patient's physical condition due to the disease and side effects of the treatment. A next study has to investigate the actual physical problems, to find interventions to keep the patients fitter during treatment. By our experience we know that the nutritional status of some patients is poor and might worsen due to low intake by swallowing problems due to side effects of the treatment. To decrease the number of missed days due to patient's condition, protocols to be more aggressive with earlier start of tube feeding and/or anti-fungal treatment of oral mucositis might give improvement.

Other causes for the delay in OTT were poor efficiency regarding calendar holidays. There were no schedule adaptations, like radiation in weekends or two times daily, to compensate for these days. Besides, half of the patients started on a Wednesday or later in the week. When 30-33 radiation days are needed, it is better to start on Monday or Tuesday, since the OTT will extend with two extra days by including an extra weekend in the schedule.

Patient-related delay accounted for only a small fraction of the delay, although still $22 \%$ of the patients missed days due to this reason (in total 55 days for 13 patients). Remarkable is that the OTT of 57 days is 5 days shorter than in the previous study conducted in Yogyakarta. This can be the result of the maintenance contract for the radiotherapy facilities as noted before or of a reduction in patient related delay, due to the committed attention of the monitoring nurse, who phoned the patient when they did not show up for treatment. With more awareness of the patients on the importance of a short OTT, the number of patient-related missed treatment days can be reduced further.

Differences between the types of insurance were found for OTT, although not significant (56, 58, 59 days, respectively self finance, askes and jamkesmas). This implies that all patients suffer in the same amount from the factors contributing to an extended OTT. There might be a significant difference when the study population is larger, since there is a trend in benefit for the self finance group. The reason for 
this benefit could be that these wealthier patients might have more counselling during treatment, accordingly physical deterioration will be noticed earlier and they have sufficient resources for supplemental nutrition and blood transfusions. Patient related reasons, like no money for transport will also be less among the richer patients.

With radiotherapy remaining the cornerstone of cancer treatment today, the results found here confirm that patient with NPC cannot be treated effectively. Probably, this also holds for the majority of other cancer patients, because most types of cancers need radiotherapy [24]. At the moment of initiation of radiotherapy the stage of disease might already be incurable. Full dose radiotherapy schedules for these patients have to be prevented. Future projects have to analyse if the current diagnostic system needs adjustments. Screening for distant metastasis should be repeated after the long waiting time, just before start of radiotherapy, since patients with distant metastasis are beyond cure and will be better served with adequate palliation. By only treating patients with a fair chance for cure the waist of limited resources can be prevented and shorten the waiting time.

The best way to address the current concerns in Indonesia should be to create sufficient radiotherapy facilities with well-trained staff, and raise awareness on the effect of an extended DTI and OTT. The growing economy in Indonesia will expectantly in time, enable these solutions, although it will take at least a decade to accomplish this, since also bunkers has to be build and doctors, nurses and technical staff have to be trained. In the meantime small-scale and easy to implement solutions are needed. Possible solutions could be more radiation hours per treatment unit outside office hours, in weekends and on holidays, better maintenance of the treatment units and planning system, including a power back up system and more awareness and dedication of the doctor, patient and nurse to complete the treatment in 47 days. We think that the problems found in this study are not specific for the treatment of nasopharyngeal cancer in Yogyakarta, Indonesia only. Also when treating other types of cancer which need radiation treatment or in other regions with comparable health systems, the same problems might be encountered. Therefore, these results can be helpful when facing the challenges in improving the treatment of cancer in other low- and middle income countries. 


\section{Reference List}

1. Boyle P, Levin B (2008) World Cancer Report 2008; IARC Library Cataloguing in Publication Data.

2. Soerjomataram I, Lortet-Tieulent J, Parkin DM, Ferlay J, Mathers C et al. (2012) Global burden of cancer in 2008: a systematic analysis of disability-adjusted life-years in 12 world regions. Lancet 380: 1840-1850.

3. Kimman M, Norman R, Jan S, Kingston D, Woodward M (2012) The burden of cancer in member countries of the Association of Southeast Asian Nations (ASEAN). Asian Pac J Cancer Prev 13: 411-420.

4. Anderson BO, Cazap E, El Saghir NS, Yip CH, Khaled HM et al. (2011) Optimisation of breast cancer management in low-resource and middle-resource countries: executive summary of the Breast Health Global Initiative consensus, 2010. Lancet Oncol 12: 387398.

5. Farmer P, Frenk J, Knaul FM, Shulman LN, Alleyne G et al. (2010) Expansion of cancer care and control in countries of low and middle income: a call to action. Lancet 376: 1186-1193.

6. Wildeman MA, Fles R, Herdini C, Indrasari SR, Vincent AD et al. (2013) Primary treatment results of Nasopharyngeal Carcinoma (NPC) in Yogyakarta, Indonesia. PLoS One "2012 VOL. 8 (5) P E63706"

7. Al Sarraf M, LeBlanc M, Giri PG, Fu KK, Cooper J et al. (1998) Chemoradiotherapy versus radiotherapy in patients with advanced nasopharyngeal cancer: phase III randomized Intergroup study 0099. J Clin Oncol 16: 1310-1317.

8. Wee J, Tan EH, Tai BC, Wong HB, Leong SS et al. (2005) Randomized trial of radiotherapy versus concurrent chemoradiotherapy followed by adjuvant chemotherapy in patients with American Joint Committee on Cancer/International Union against cancer stage III and IV nasopharyngeal cancer of the endemic variety. J Clin Oncol 23: 6730-6738.

9. Akimoto T, Mitsuhashi N, Hayakawa K, Sakurai H, Murata O et al. (1997) Split-course accelerated hyperfractionation radiotherapy for advanced head and neck cancer: influence of split time and overall treatment time on local control. Jpn J Clin Oncol 27: 240-243.

10. Platek ME, McCloskey SA, Cruz M, Burke MS, Reid ME et al. (2012) Quantification of the effect of treatment duration on local-regional failure after definitive concurrent chemotherapy and intensity-modulated radiation therapy for squamous cell carcinoma of the head and neck. Head Neck ;35(5):684-8

11. Kwong DL, Sham JS, Chua DT, Choy DT, Au GK et al. (1997) The effect of interruptions and prolonged treatment time in radiotherapy for nasopharyngeal carcinoma. Int J Radiat Oncol Biol Phys 39: 703-710.

12. Satriana S, Schmitt V (2012) Social protection assessment based national dialogue: Towards a nationally defined social protection floor in Indonesia/ International Labour Organization. Available at: http://www.ilo.org/jakarta/whatwedo/publications/ WCMS_195572/lang--en/index.htm . Accesed at April 2013

13. Tangcharoensathien V, Patcharanarumol W, Ir P, Aljunid SM, Mukti AG et al. (2011) Health-financing reforms in southeast Asia: challenges in achieving universal coverage. Lancet 377: 863-873.

14. Gondhowiardjo S, Prajogi G, Sekarutami S (2008) History and growth of radiation oncology in Indonesia. Biomed Imaging Interv J 4: e42.

15. Slotman BJ, Cottier B, Bentzen SM, Heeren G, Lievens Y et al. (2005) Overview of national guidelines for infrastructure and staffing of radiotherapy. ESTRO-QUARTS: work package 1. Radiother Oncol 75: 349-354. 
16. Bentzen SM, Heeren G, Cottier B, Slotman B, Glimelius B et al. (2005) Towards evidencebased guidelines for radiotherapy infrastructure and staffing needs in Europe: the ESTRO QUARTS project. Radiother Oncol 75: 355-365.

17. Rosenblatt E, Izewska J, Anacak Y, Pynda Y, Scalliet P et al. (2013) Radiotherapy capacity in European countries: an analysis of the Directory of Radiotherapy Centres (DIRAC) database. Lancet Oncol 14: e79-e86.

18. Jakarta Globe (2012) SBY Tells Indonesians To Stop Seeking Medical Treatment Abroad. Available at: http://www.thejakartaglobe.com/health/sby-tells-indonesians-to-stopseeking-medical-treatment-abroad/534677. Accessed April 2013.

19. Waaijer A, Terhaard CH, Dehnad H, Hordijk GJ, van Leeuwen MS et al. (2003) Waiting times for radiotherapy: consequences of volume increase for the TCP in oropharyngeal carcinoma. Radiother Oncol 66: 271-276.

20. Chen Z, King W, Pearcey R, Kerba M, Mackillop WJ (2008) The relationship between waiting time for radiotherapy and clinical outcomes: a systematic review of the literature. Radiother Oncol 87: 3-16.

21. Ho AC, Lee VH, To VS, Kwong DL, Wei WI (2011) Natural course and tumor doubling time of nasopharyngeal carcinoma. A study of 15 patients. Oral Oncol 47: 742-746.

22. Wei WI, Sham JS (2005) Nasopharyngeal carcinoma. Lancet 365: 2041-2054.

23. Marks LB, Dewhirst M (1991) Accelerated repopulation: friend or foe? Exploiting changes in tumor growth characteristics to improve the "efficiency" of radiotherapy. Int J Radiat Oncol Biol Phys 21: 1377-1383.

24. Barton MB, Frommer M, Shafiq J (2006) Role of radiotherapy in cancer control in lowincome and middle-income countries. Lancet Oncol 7: 584-5 


\section{Chapter 9}

The impact of the overall radiotherapy time on clinical outcome of patients with nasopharyngeal carcinoma; a retrospective study

SD. Stoker

R. Fles

C. Herdini

FJF. Rijntjes

M. Tjokronagoro

SR. Dwidanarti

K. Sikorska

CR. Leemans

MK. Schmidt

A. Al-Mamgani

MA. Wildeman

SM. Haryana

SR. Indrasari

IB. Tan

PLoS One. 2016 Mar 31;11(3):e0151899. 


\begin{abstract}
Purpose

In Yogyakarta, nasopharyngeal carcinoma (NPC) shows a poor response to radiotherapy treatment. Previous study showed a prolonged overall treatment time (OTT), due to interruptions during treatment. This study explores the association between clinical outcome and OTT. Secondary, the relation between clinical outcome and disease stage, waiting time to radiation (WT) and chemotherapy schedule was explored.
\end{abstract}

\title{
Methods
}

In this retrospective cohort, 142 patients who started curative intent radiotherapy for NPC between March 2009 and May 2014, with or without chemotherapy, were included. The median follow up time was 1.9 years. Data was collected on WT, OTT, disease stage, and chemotherapy schedule. Time factors were log-transformed. Clinical outcome was defined as therapy response, loco-regional control (LRC), disease free survival (DFS) and overall survival (OS).

\section{Results}

The median WT was 117 days (range 12-581) and OTT was 58 days (43-142). OTT and disease stage were not associated to any of the clinical outcome parameters. The log- WT was associated to poor therapy outcome (HR 1.68; 95\% ci: 1.09 2.61), LRC (HR 1.66; 95\% ci: 1.15-2.39), and DFS (HR 1.4; 95\% ci: 1.09-1.81). In the multivariable analysis, significant hazard risk for poor therapy response, LRC, DFS and OS were seen for patients who didn't received concurrent chemotherapy.

\section{Conclusion}

Not receiving concurrent chemotherapy showed the strongest risk for poor outcome. Since the choice of chemotherapy is related to a variety of factors, like the WT and patient's physical condition when radiation can start, careful interpretation is needed. Reason for not finding a relation between OTT and clinical outcome might be the low number of patients who finished radiotherapy within 7 weeks, or by a stronger detrimental effect of other factors. 


\section{Introduction}

Nasopharyngeal cancer (NPC) is the most common malignancy in the head and neck region in Indonesia [1]. The incidence is estimated at 6:100 000, which is probably an underestimation since many patients living in the rural areas might stay undiagnosed [2]. In literature, 3-year overall survival for NPC are reported as 70 to $80 \%$, or even higher. Studies in Indonesia showed a 3-year overall survival of only $30 \%[3,4]$. Most of the studies with the high survival rates are derived from clinics with advanced and readily available treatment facilities. More than $85 \%$ of the NPC patients are diagnosed in low- and middle-income countries, with less advanced equipment and limited capacity $[2,5]$. Therefore, actual NPC survival will be much lower than reported in literature and more likely to be in the range of Yogyakarta. This study aims to identify factors associated with poor clinical outcome.

The best treatment for advanced NPC is radiotherapy in combination with chemotherapy, 60-70 Gray (Gy) to the nasopharynx and neck metastases and an elective dose of 40-50 Gy to the uninvolved parts of the neck [3, 6]. For stage I (AJCC 6th edition), radiotherapy alone gives satisfactory results [7-9]. General consensus for radiotherapy is that treatment should be given without interruptions. When treatment is interrupted repopulation of tumour cells can occur, which is believed to be a significant risk for treatment failure [10-13]. This phenomenon has been proven in both xenograft animal models and clinical studies with cervical cancer, bladder cancer and head and neck cancer [13-19]. One of the largest studies in head and neck cancer concerning the effect of overall radiotherapy treatment time (OTT) on clinical outcome is from the Danish group [20]. They proved the benefit of 6 fractions a week above 5 fractions per week. Unfortunately, NPC was excluded.

It is assumable that treatment interruption during radiotherapy in NPC will also negatively affect clinical outcome, but multiple, large studies confirming this, are lacking. Besides, controversial results are found [17, 21-27]. One of the most recently published studies is from Li et al. [27]. They included 321 patients treated with radiotherapy for NPC, but they couldn't proof the negative effect of a long OTT on local-regional control and distant metastases free survival [27]. Another way to shorten OTT is by using accelerated radiation schemes. However, also in these studies conflicting results are shown with regard to the impact on outcome [24, 25- 
26]. Pan et al. found improved loco-regional control (LRC) and overall survival (OS) [25], but Lee et al. and Theo et al. only showed more side effects without improved clinical outcome $[24,26]$.

Previous study in Yogyakarta showed a mean number of missed days of 10 per patient. Meaning that to complete the full course of treatment, the OTT was prolonged by two weeks, since radiotherapy is only given on weekdays [28]. In the discussion was hypothesized that the interruptions during radiotherapy, and thus the length of the OTT, could have influenced clinical outcome to a great extent. Therefore, the aim of the current study is to explore the association between OTT and clinical outcome in NPC. If these results show a significant disadvantage in clinical outcome when the OTT is longer, a first step is made in finding solutions for the problem of the poor prognosis of patients with NPC. Since, the OTT can be shortened if effort is made [28]. It is likely that clinical outcome is also related to disease stage, waiting time to start radiotherapy (WT), and the chemotherapeutic schedule (neo-adjuvant and/or concurrent), therefore these factors were also taken in analysis.

The preferred treatment of choice for NPC in this institute is concurrent chemo radiotherapy. For many patients it was not exceptional that the waiting time for radiotherapy exceeded 3 months. To prevent disease progression in this period, neo-adjuvant chemotherapy was given. In some patients the physical condition was deteriorated to such extend that another course of chemotherapy was not an option anymore, so they received radiation without chemotherapy.

\section{Method}

\section{Study design and eligibility}

This retrospective study was conducted in Dr. Sardjito hospital, Gadjah Mada University, in Yogyakarta, Indonesia. Ethical approval was obtained from this institution's review board. Data was obtained from the hospital's medical records and the online data-management system introduced in 2008 [29]. Patient information was anonymized and de-identified before analysis. Patients were deemed eligible when they started curative intent radiotherapy, with or without chemotherapy, for histologically confirmed NPC (World Health Organization type 1, 2 or 3). There is 
an overlap of patients with the studies published in 2013 and 2014 [4, 28]. There were no medical intervention in these or the current study, therefore no separate analysis was performed.

Between March 2009 and May 2014, 193 patients started radiotherapy for NPC. Fifty-one patients (26\%) were excluded. Reasons for exclusion were; drop out during radiotherapy (due to side effects $(n=12)$, death $(n=5)$, financial problems $(n=4)$ or unknown reason $(n=8)$ ), suspect distant metastasis $(n=9)$, unreliable staging $(n=7)$, second primary $(n=1)$, or a short ( $<3$ months) post-treatment follow up period $(n=5)$. Subsequently, 142 patients were included for study outcome analysis. Staging at diagnosis was performed by computed tomography (CT) scan of the head and neck, ultrasound of the abdomen, X-ray of the thorax and a bone survey, and scored according to the 6th edition of the American Joint Committee on Cancer (UICC) AJCC).

\section{Treatment}

All patients were treated with external beam radiotherapy, 2 dimensional or 3 dimensional, in fractions of 2 Gy per day, 5 times a week (not in the weekends). The protocol for NPC was 60 Gy for T1 disease and 66-70 Gy for T2-4 to the nasopharynx; and 40-46 Gy for N0-1 and 50 Gy for N2-3 to the whole neck (including the supraclavicular fossa). Persistent nodes were radiated up to 66-70 Gy. The overall treatment time (OTT), starting from the first day of radiotherapy until the last day of radiotherapy, could be finished within 42-47 days. The waiting time to radiotherapy (WT) is calculated from the day of diagnosis until start radiotherapy.

Different schedules for chemotherapy were used. The schedule depended on the patient's physical status, type of insurance, availability of the drugs and waiting time for radiotherapy at that time. When the waiting time to radiotherapy was long (in particular in case of poor patients), neo-adjuvant chemotherapy was given to prevent progression. Concurrent chemotherapy was the preferred choice, but physical deterioration made this schedule not possible for all patients. Neo-adjuvant chemotherapy consisted of; cisplatin, carboplatin, fluorouracil, capecitabine, docetaxel, or paclitaxel. Concurrent chemotherapy regimens consisted of weekly cisplatin or carboplatin. Patients were categorized into 4 groups; concurrent, concurrent and neo-adjuvant, neo-adjuvant or no neo-adjuvant or concurrent 
chemotherapy. In five cases, adjuvant chemotherapy was given. Adjuvant chemotherapy consisted of carboplatin, paclitaxel and/or capecitabine. Adjuvant chemotherapy was ignored for group categorization.

\section{Clinical outcome}

Clinical outcome was measured by 4 parameters, i.e.; therapy response, localregional control (LRC), disease free survival (DFS) and overall survival (OS).

\section{Therapy response}

Post-treatment protocol for treatment response was endoscopy, biopsy of the primary local tumour site, CT-scan of the head and neck area, ultra-sound of the abdomen, x-ray of the thorax and a bone survey. Unfortunately, not all patients completed this protocol. Therapy response was set as complete response or incomplete response. In case of uncertainty about therapy response, patients were excluded for therapy response analysis. Complete response was defined as; 1 ) all imaging studies, including biopsy showed no disease, and there was no recurrent disease within 6 months or, 2) in case of clinical examination only (including endoscopy), and there was no suspicion for disease, and no suspicion of recurrent disease in the following 2 years. Incomplete response was defined as; 1 ) local or regional disease confirmed by biopsy, or cytology within 6 months post-treatment or, 2) a suspect CT scan for loco-regional residual disease and died within 1 year or, 3) distant metastases within 6 months after radiotherapy, confirmed by progression during follow up. Exclusion criteria for therapy response analysis were 1) no clinical follow up in the first 6 months or, 2) suspected incomplete response (never confirmed by biopsy or progression during follow-up), but alive without complaints for at least 2 years.

\section{Local-regional control}

LRC was defined as the time between the last day of radiotherapy till the date of local and/or regional disease. In case of persistent disease, the date of event was set at 3 days post-treatment. Patients were censored if they were alive without local-regional disease. In case of uncertainty about the local-regional status they were excluded for this analysis. 


\section{Disease free survival}

DFS was defined as the time between the last day of radiation till the date of recurrent disease (local, regional or distant) or the date of death. In case of persistent disease, the date of event was set at 3 days post-treatment. Patients who had no evidence of disease at last follow-up were censored at the date of last contact.

\section{Overall survival}

OS was defined as the time between start date of radiotherapy till the date of death. A different starting point was chosen, since the length of OTT time differed considerably, which would affect OS. Patients who were alive at last follow up were censored. Patients who died due to a second primary tumour were excluded from this analysis.

\section{Statistical analysis}

The main interest was to relate OTT and WT to therapy response, LRC, DFS and OS. These time-related predictors (OTT and waiting time) were skewed to the right, and therefore transformed into (normal) log scale. Log-transformed OTT and WT were analyzed in univariable logistic regression and Cox models. Shapes of the relationships for the time to event outcomes were evaluated using martingale residuals plots. In the multivariable models we included WT, OTT as well as chemotherapy treatment schedule and tumor stage as possible confounders. For the time to event outcomes an independence test based on log rank statistics was used to find a cut-off, which separates best patients with good and poor prognosis. The analyses were performed using SPSS software (version 22) and R software (version 3.1.0). P-values $<0.05$ were considered statistically significant.

\section{Results}

\section{Patients \& treatment description}

From the 142 patients, 97 (68\%) were male. The histological type of NPC was WHO 3 in $94 \%$ of the cases. At diagnosis, $84 \%$ had late stage disease. Chemotherapy was administered in $90 \%$ of the patients (Table 1). For 6 (4\%) patients there was 
ambiguity about the actual given chemotherapy. The median WT was 117 days (range 12-581). The median dosage was $66 \mathrm{~Gy}$ (range 60-76). The median OTT was 58 days (range 43-142). The median follow up time was 708 days (1.9 years) (calculated from the start of radiotherapy).

Table 1 | Tumour stage at diagnosis \& treatment

\begin{tabular}{|c|c|c|c|c|c|c|c|c|c|}
\hline \multirow{3}{*}{$\begin{array}{l}\text { Tumour stage } \\
\text { AJCC }\end{array}$} & \multirow{3}{*}{$\begin{array}{l}\text { Patients } \\
\text { Total (\%) }\end{array}$} & \multicolumn{8}{|c|}{ Chemotherapy schedule } \\
\hline & & \multicolumn{2}{|l|}{ Group 1} & \multirow{2}{*}{$\begin{array}{l}\text { Group } 2 \\
\text { Conc \& } \\
\text { neo }\end{array}$} & \multicolumn{2}{|l|}{ Group 3} & \multicolumn{3}{|l|}{ Group 4} \\
\hline & & Conc & Conc \& adj & & Neo & $\begin{array}{l}\text { Neo \& } \\
\text { adj }\end{array}$ & Adj & $\begin{array}{l}\text { No } \\
\text { chemo }\end{array}$ & Missing \\
\hline I & $3(2.1)$ & 0 & 0 & 0 & 0 & 0 & 0 & 1 & 2 \\
\hline Ila & $1(0.7)$ & 0 & 0 & 0 & 1 & 0 & 0 & 0 & 0 \\
\hline IIb & $16(13)$ & 6 & 0 & 2 & 5 & 1 & 0 & 4 & 1 \\
\hline III & $50(35)$ & 19 & 0 & 6 & 23 & 0 & 0 & 1 & 1 \\
\hline IVa & 20 (14) & 6 & 0 & 0 & 11 & 0 & 2 & 0 & 1 \\
\hline IVb & $49(35)$ & 9 & 1 & 6 & 29 & 0 & 1 & 2 & 1 \\
\hline Total (\%) & $142(100)$ & $40(28)$ & $1(0.7)$ & $14(10)$ & $69(49)$ & $1(0.7)$ & $3(2.1)$ & $8(5.6)$ & $6(4)$ \\
\hline
\end{tabular}

$A J C C=$ American joint Committee for Cancer $6^{\text {th }}$ edition; conc= concurrent chemotherapy; neo= neo-adjuvant chemotherapy; adj=adjuvant chemotherapy

\section{Association between OTT and outcome}

\section{Therapy response}

Therapy response was available for 120 patients, 60 patients had a complete response. Disease stage was not associated to response. Patients with a complete response had an equal median OTT as patients with an incomplete response, 58 days (Table 2). The median WT was 101 versus 140 days for patients with a complete or incomplete response, respectively (Kruskal-Wallis $p<0.01$ ) (Table 2 ). Also in the univariable analyses, wherein time parameters were transformed into a (normal) log scale, significant odds ratios for poor therapy outcome were found for log WT, and not for log OTT (Table 3). A plot summary was made to visualize the clinical interpretation of the increased risk when the WT is increased (Fig. 1). In the multivariable analysis for therapy response, only chemotherapy schedule remained significant (Table 4). 
Table 2 | OTT \& WT and complete or incomplete therapy response

$\begin{array}{lllll} & \text { Total } & \text { Complete response } & \text { Incomplete response } & \\ & \text { Days (range) } & \text { Days } & \text { Days } & \text { Mann Whitney U } \\ \text { Median OTT } & 58(43-142) & 58 & 58 & \mathrm{p}=0.26 \\ \text { Median WT } & 117(12-581) & 101 & 140 & \mathrm{p}=0.01^{*}\end{array}$

OTT= overall radiation treatment time; WT= waiting time to radiotherapy; *significant outcome

Table 3 | Univariable logistic regression (therapy response), and Cox model (LRC, DFS and OS)

\begin{tabular}{llllllllll} 
& \multicolumn{2}{c}{ Therapy response } & LRC & \multicolumn{3}{c}{ DFS } & \multicolumn{3}{c}{ OS } \\
& OR & P-value & HR & P-value & HR & P-value & HR & P-value \\
\hline Log OTT & 2.3 & 0.37 & $1.4^{1}$ & 0.49 & 1.2 & 0.73 & 2.0 & 0.21 \\
Log WT & 1.7 & $0.02^{*}$ & 1.7 & $0.01^{*}$ & 1.4 & $0.01^{*}$ & 1.3 & 0.09
\end{tabular}

$O R=$ odds ratio; $H R=$ hazard ratio; $L R C=$ loco-regional control; $D F S=$ disease free survival; $O S=$ overall survival; OTT= overall radiation treatment time; $W T=$ waiting time to radiotherapy; *significant outcome; $1=$ based on a cut-off point of 72 days

Table 4 | Multivariable analysis

\begin{tabular}{|c|c|c|c|c|c|c|c|c|}
\hline & \multicolumn{2}{|c|}{$\begin{array}{l}\text { THERAPY } \\
\text { RESPONSE }\end{array}$} & \multicolumn{2}{|l|}{ LRC } & \multicolumn{2}{|l|}{ DFS } & \multicolumn{2}{|l|}{ os } \\
\hline & OR & P-VALUE & HR & P-VALUE & HR & P-VALUE & HR & P-VALUE \\
\hline LOG OTT & 3.6 & 0.22 & $1.5^{1}$ & 0.39 & 1.4 & 0.52 & 2.0 & 0.27 \\
\hline LOG WT & 1.0 & 0.98 & 1.1 & 0.87 & 1.0 & 0.92 & 0.9 & 0.67 \\
\hline \multicolumn{9}{|l|}{ CHEMOTHERAPY } \\
\hline CONCURRENT & 1.0 & & 1.0 & & 1.0 & & 1.0 & \\
\hline CONC \& NEO-ADJ & 0.9 & 0.90 & 1.0 & 0.98 & 1.0 & 0.991 & 0.4 & 0.29 \\
\hline NEO-ADJUVANT & 6.4 & $0.01 *$ & 4.4 & $0.03 *$ & 3.0 & $<0.01^{*}$ & 3.1 & $0.02 *$ \\
\hline NONE & 6.1 & $0.03 *$ & 3.8 & $0.04 *$ & 2.5 & 0.07 & 2.4 & 0.19 \\
\hline \multicolumn{9}{|l|}{ TUMOR STAGE } \\
\hline IVB & 1.0 & & 1.0 & & 1.0 & & 1.0 & \\
\hline IVA & 0.9 & 0.90 & 1.0 & 0.99 & 1.0 & 0.99 & 0.7 & 0.34 \\
\hline III & 1.0 & 0.98 & 1.0 & 0.90 & 0.9 & 0.68 & 0.5 & $0.02 *$ \\
\hline IIB & 1.8 & 0.39 & 1.3 & 0.64 & 1.0 & 0.89 & 0.6 & 0.23 \\
\hline IIA & 0.6 & 0.72 & 0.5 & 0.59 & 0.4 & 0.36 & 0.3 & 0.31 \\
\hline
\end{tabular}

$O R=$ odds ratio; $H R=$ hazard ratio; $L R C=$ loco-regional control; $D F S=$ disease free survival; $O S=$ overall survival; OTT= overall radiation treatment time; $W T=$ waiting time to radiotherapy; *significant outcome; $1=$ based on a cut-off point of 72 days 


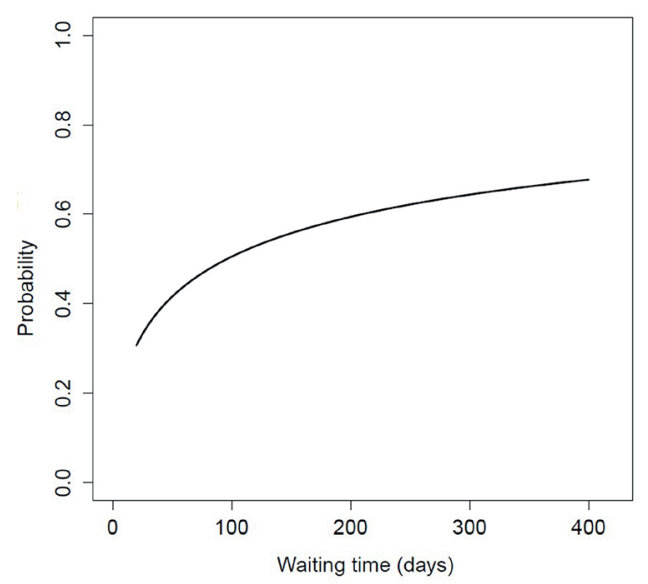

Figure 1 | Probability of incomplete response as function of the waiting time (WT). Probability of 0 is a complete response and 1.0 an incomplete response. The WT is shown as transformed back into a continuous scale. In the first 3 months, the increase of probability of incomplete response is steeper than when the length of WT is longer. The probability on incomplete response seems to reach a plateau level.

\section{Local regional control}

For LRC analysis, 81 patients were available, 43 events occurred. The 2-year LRC was 48\% (median 1.77 years) (Fig. 2a). Univariable Cox model showed a significant HR for poor LRC when the log WT was increased. Based on the exploratory analysis the association of log OTT and LRC was not linear. The optimal cut-off point was selected for 72 days, however this was statistically not significant (log rank p-value 0.49) (table 3). A significant optimal cut-off point for the WT, which separates good and poor LRC, was found at 130 days (Fig. 3a, log rank $p<0.001$ ). In the multivariable Cox-model only chemotherapy remained significant (Table 4, Fig. 4a).
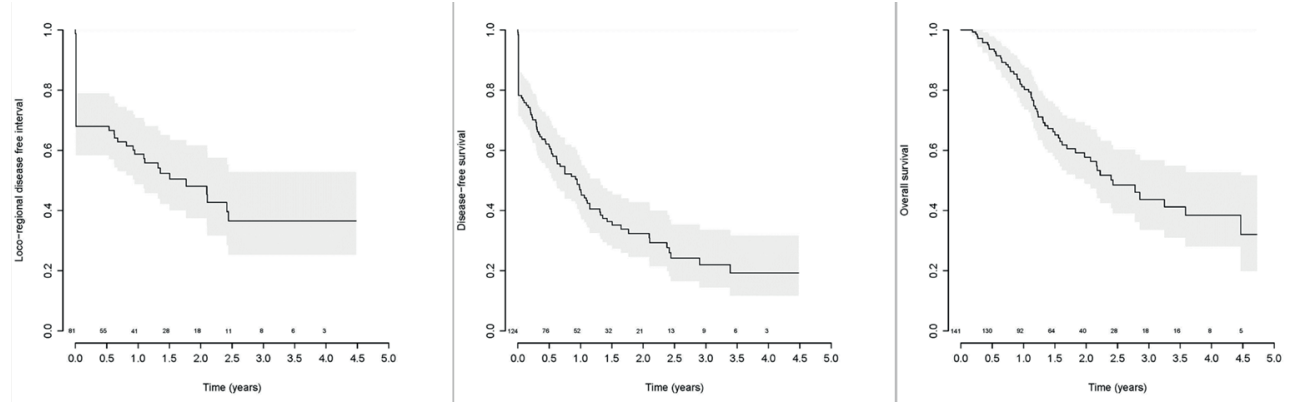

Figure 2 | Survival plots. (a) local regional control, (b) disease free survival and (c) overall survival. Above the $x$-axis is the number of patients at risk. 

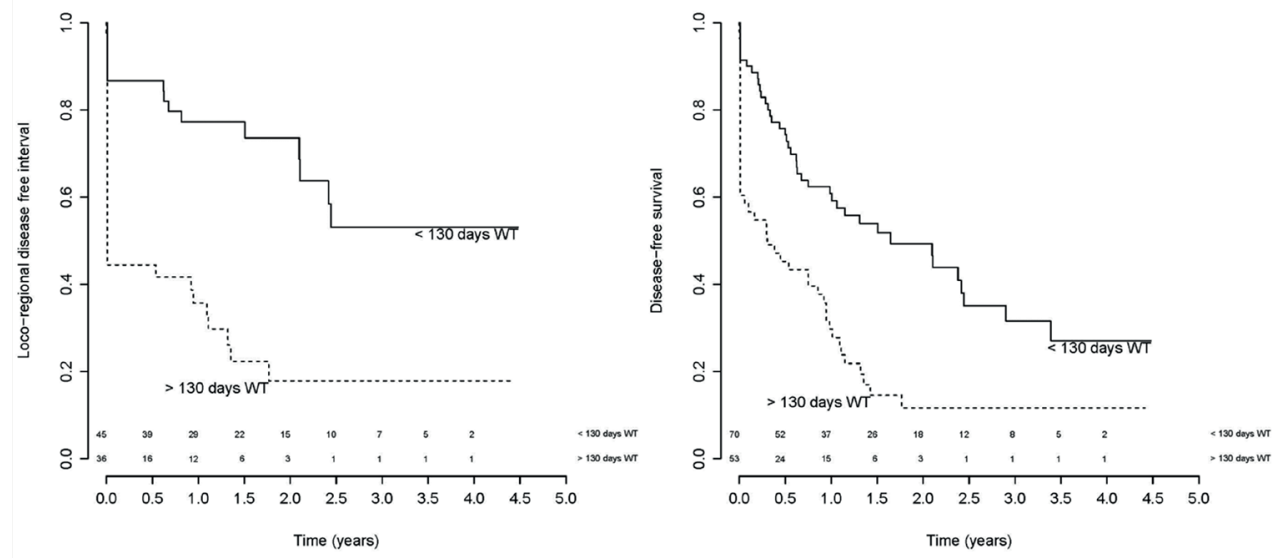

Figure 3 | Survival plots, stratified for waiting time. (a) local-regional control and (b) disease free survival stratified for a waiting time longer or shorter than 130 days (log rank for both plots $<0.001$ ). Above the $x$-axis is the number of patients at risk.

\section{Disease free survival}

For DFS analysis, 124 patients were available, 86 events occurred. The 2-year DFS was 32\% (median 0.94 years) (Fig. 2b). Univariable Cox model showed a significant HR for poor DFS when the log WT was increased. Log OTT was not significantly associated to DFS (Table 3). A significant optimal cut-off point for the WT, which separates good and poor DFS, was found at 130 days (Fig. 3b, log rank p<0.001). In the multivariable Cox-model only chemotherapy schedule remained significant; patients who only received neo-adjuvant chemotherapy had the poorest DFS (Table 4, Fig 4b).

\section{Overall survival}

For OS analysis 141 patients were available, 59 events occurred. The 2-year OS was 58\% (median 2.4 years) (Fig. 2c). Univariable Cox model didn't show association between the probabilities of poor survival and log OTT or log WT (Table 3). In the multivariable Cox-model chemotherapy schedule and disease stage remained significant; patients who only received neo-adjuvant chemotherapy or who had stage III disease had the poorest OS (Table 4, Fig. 4c). 

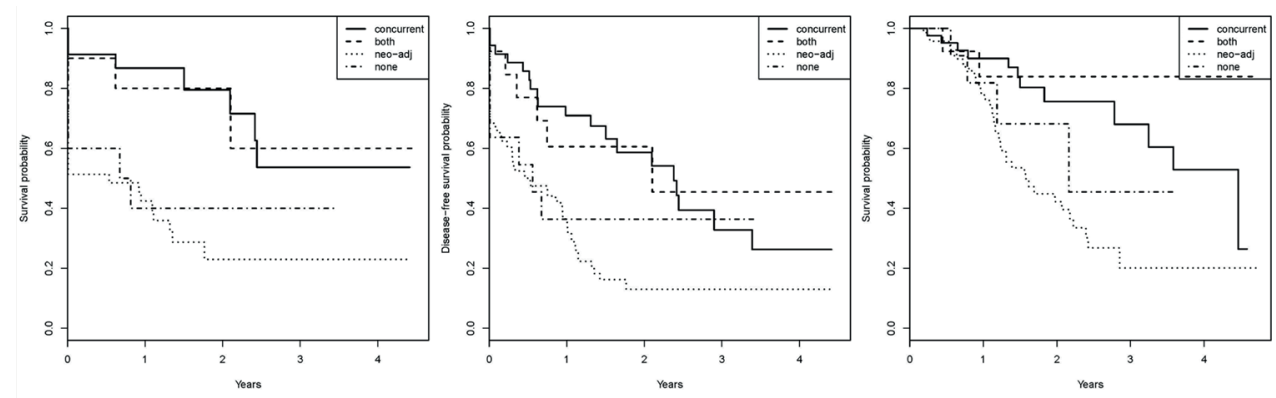

Figure 4 | Survival plots, categorized per chemotherapy schedule. (a) local regional control, (b) disease free survival and (c) overall survival.

\section{Discussion}

The current study showed no correlation between overall treatment time and clinical outcome in patients with NPC. It was expected that a prolonged OTT was related to unfavourable clinical outcome, based on several studies that confirmed the benefit on tumour control and survival when radiotherapy for head and neck cancer was given without interruptions [13, 16-20]. Nevertheless, studies confirming this effects for NPC are limited [17, 21-23, 27]. Some studies focussed on the benefit of accelerated schedules of NPC, but also these results are conflicting $[24,25]$. The current study analysed 142 patients with NPC only, all treated with curative intent for primary NPC. Therefore it was expected to be of great value for estimating the impact of an interrupted radiotherapy treatment in NPC. Besides, it could proof the focus for improving the clinical outcome of NPC patients.

Clinical outcome was defined in 4 parameters i.e.; treatment response, LRC, DFS and OS. This was based on experience from previous studies where we found difficulties completing follow up data [4, 30]. For every analysis, some patients had to be excluded due to uncertainty. Not only because of deviation in the follow up protocol, but also due to difficulties in estimating disease status. For therapy response, the combination of imaging studies and clinical follow up was used. LRC was the preferable outcome parameter, because the given treatment was primarily a loco-regional treatment. Unfortunately, only 81 (57\%) patients could be analysed for LRC, due to the lack of local-regional status data. DFS also includes patients who died without information about their disease stage. It is assumable that these 
patients died because of recurrent disease, therefore DFS was also a valuable outcome parameter. OS gave a good impression about the general prognosis for these patients. Except for one, all patients could be analysed for OS.

Unexpectedly, our results did not show an increased risk for poor clinical outcome when OTT was prolonged. Although all odds and hazard ratios were $>1$, no significance was reached. Based on these results it would be short-sighted to conclude that OTT does not affect therapy outcome for NPC. Studies that showed the increased risk on local failure in head and neck cancer when OTT was prolonged used a cut-off point between 7-8 weeks [21]. Also these cut-off points (49 days or 56 days) did not show significant increased risk (data not shown). This might be explained by the low number of patients who finished treatment within the recommended 7 weeks $(n=16)$. An explanation for not finding increased risk ratios in the continuous scale analysis might be that the effect of missing 2-4 weeks is not worse than missing 1-2 weeks. Another explanation could be that the OTT was overruled by other factors, and that the sample size was too small. As also concluded by others, larger, multiinstitutional studies are needed to estimate the safe range OTT for NPC [27].

Another remarkable finding was that disease stage at diagnosis was not related to clinical outcome. The long waiting time can be an explanation. The negative effect of long WT is frequently described [31]. In the current study the median delay to initiation of radiation treatment was 4 months. The probability of an incomplete response, depending on waiting time, had the shape of a log-function (Fig. 1). This means, in the first months it is of great importance to prevent delay, but at a certain time, the probability of poor outcome reaches a maximum despite a longer WT. Many patients received neo-adjuvant chemotherapy to overcome the waiting time. Nevertheless, disease progression and deterioration of the physical condition in this period is inevitable. The disease stage at diagnosis might not be representative for the actual stage that is treated. Some patients might have developed distant metastasis, which affects prognosis tremendously. In a currently on-going study we are evaluating the disease progression during the WT. Patients with a WT exceeding 3 months will be re-staged. Besides better insight in the actual disease stage, patients who develop stage IVc can be prevented from treatment that is deemed unsuccessful and has a high morbidity. Unnecessary use of the treatment units can be prevented, which will decrease WT for other patients. In that on-going study, also 
the physical deterioration during the WT will be analysed. A poor physical condition is frequently related to poor treatment outcome $[18,19]$.

Another shortcoming in disease stage are the methods used for confirming disseminated disease. Ultra sound, $x$-ray of the thorax and bone survey ( $x$-ray of the bones) have low sensitivity for bone and lung metastasis. PET-scan was not available and bone scintygraphy is only used (and covered by insurance) in case of suspected bone lesions on the bone survey. Therefore, the presence of distant metastases might have been underestimated.

The group of patients that didn't receive concurrent chemotherapy had significant worse clinical outcome. This factor remained significant for all outcome parameters in multivariable analysis. Also here careful interpretation is needed. Several other studies found the beneficial effect of concurrent chemo-radiotherapy above neoadjuvant chemotherapy $[32,33]$. Nevertheless, our results are probably biased by the choice of treatment. In general, patients who received concurrent chemotherapy are either 'poor' patients in a good condition after neo-adjuvant chemotherapy to overcome the waiting time, or 'rich' patients with a short waiting time who can start concurrent treatment immediately. The deterioration of the physical condition by neo-adjuvant treatment made concurrent chemotherapy too toxic for many patients.

While waiting for expanding the radiation facilities, other treatment modalities are needed to overcome the waiting time. These modalities should prevent progression, without deterioration of the patient's condition and remain the possibility of concurrent chemo-radiotherapy, since concurrent chemo-radiotherapy treatment modality has been shown repeatedly as the most effective for advanced NPC [32].

The 2-year overall survival was 58\%. When interpreting these statistics please note that patients who did not finish radiotherapy treatment were excluded from analysis, and therefore better than the rate reported in the introduction [4]. During the waiting time and during treatment patients died or dropped out, which would have had affected the overall survival negatively. The reason for excluding these patients in the current study was the different study aim.

In conclusion, although OTT and the WT are probably of influence on clinical outcome, this study showed the strongest effect for chemotherapy schedule. Every 
patient with advanced stage disease should get concurrent chemo-radiotherapy [33]. Only by reducing the waiting time, this can be accomplished. Therefore, radiation facilities should be expanded. However this is a time consuming process, and will not help to improve the life of cancer patients at short notice. While waiting for more units, more effectively use of the already available machines can be a step forward, like longer operational hours and better maintenance to prevent technical problems. Also, alternative (new) treatment modalities to overcome the waiting time, which prevent progression and avoid physical deterioration, might be helpful to remain the possibility to give concurrent chemotherapy.

Recently, problems have only increased. In the study period, the median waiting time for radiotherapy was 4 months. Due a change in the insurance system since January 2014, aiming to provide national health care insurance for all inhabitants of Indonesia, nowadays the waiting time for radiotherapy exceeds 1,5 year. Eightyfive per cent of the NPC patients are diagnosed in low-income countries, therefore Indonesia is not the only country who is struggling $[1,5]$. This is confirmed in a recently published article that showed the shortfall of radiotherapy capacity by country [34]. 


\section{References}

1. Ferlay J, soerjomataram I, Ervik M, Dikshit R, Eser S. GLOBOCAN 2012 v1. 0, Cancer Incidence and Mortality Worldwide: IARC CancerBase No. 11. 2013, International Agency for Research on Cancer. http://globocan. iarc. fr, 2014.

2. Adham M, Kurniawan AN, Muhtadi Al, Roezin A, Hermani B, Gondhowiardjo S, et al. Nasopharyngeal carcinoma in Indonesia: epidemiology, incidence, signs, and symptoms at presentation. Chin J Cancer. 2012.

3. Lee AW, Lin JC, Ng WT. Current management of nasopharyngeal cancer. Semin Radiat Oncol. 2012;22(3):233-44.

4. Wildeman MA, Fles R, Herdini C, Indrasari RS, Vincent AD, Tjokronagoro M, et al. Primary Treatment Results of Nasopharyngeal Carcinoma (NPC) in Yogyakarta, Indonesia. PLoS One. 2013;8(5):e63706.

5. Lee AW. Global pattern of nasopharyngeal cancer in correlation to access to radiotherapy. NPC 2015 Yogyakarta, 7th International Nasopharyngeal Carcinoma Biannual Meeting Symposium. 2015.

6. Wei WI, Kwong DL. Current management strategy of nasopharyngeal carcinoma. Clin Exp Otorhinolaryngol. 2010;3(1):1-12.

7. Su SF, Han F, Zhao C, Chen CY, Xiao WW, Li JX, et al. Long-term outcomes of early-stage nasopharyngeal carcinoma patients treated with intensity-modulated radiotherapy alone. Int J Radiat Oncol Biol Phys. 2012;82(1):327-33.

8. Song $\mathrm{CH}, \mathrm{Wu} \mathrm{HG}, \mathrm{Heo}$ DS, Kim KH, Sung MW, Park Cl. Treatment outcomes for radiotherapy alone are comparable with neoadjuvant chemotherapy followed by radiotherapy in early-stage nasopharyngeal carcinoma. Laryngoscope. 2008;118(4):663-70.

9. Chua DT, Sham JS, Kwong DL, Au GK. Treatment outcome after radiotherapy alone for patients with Stage I-II nasopharyngeal carcinoma. Cancer. 2003;98(1):74-80.

10. Yang J, Yue JB, Liu J, Yu JM. Repopulation of tumor cells during fractionated radiotherapy and detection methods (Review). Oncol Lett. 2014;7(6):1755-60.

11. Marks LB, Dewhirst M. Accelerated repopulation: friend or foe? Exploiting changes in tumor growth characteristics to improve the "efficiency" of radiotherapy. Int J Radiat Oncol Biol Phys. 1991;21(5):1377-83.

12. Akimoto T, Mitsuhashi N, Hayakawa K, Sakurai H, Murata O, Ishizeki K, et al. Split-course accelerated hyperfractionation radiotherapy for advanced head and neck cancer: influence of split time and overall treatment time on local control. Jpn J Clin Oncol. 1997;27(4):240-3.

13. Platek ME, McCloskey SA, Cruz M, Burke MS, Reid ME, Wilding GE, et al. Quantification of the effect of treatment duration on local-regional failure after definitive concurrent chemotherapy and intensity-modulated radiation therapy for squamous cell carcinoma of the head and neck. Head Neck. 2012.

14. Kim JJ, Tannock IF. Repopulation of cancer cells during therapy: an important cause of treatment failure. Nat Rev Cancer. 2005;5(7):516-25.

15. Fatema CN, Zhao S, Zhao Y, Murakami M, Yu W, Nishijima K, et al. Monitoring tumor proliferative response to radiotherapy using (18)F-fluorothymidine in human head and neck cancer xenograft in comparison with Ki-67. Ann Nucl Med. 2013;27(4):355-62.

16. Sher DJ, Posner MR, Tishler RB, Sarlis NJ, Haddad RI, Holupka EJ, et al. Relationship between radiation treatment time and overall survival after induction chemotherapy for locally advanced head-and-neck carcinoma: a subset analysis of TAX 324. Int J Radiat Oncol Biol Phys. 2011;81(5):e813-8.

17. Cannon DM, Geye HM, Hartig GK, Traynor AM, Hoang T, McCulloch TM, et al. Increased local failure risk with prolonged radiation treatment time in head and neck cancer treated with concurrent chemotherapy. Head Neck. 2014;36(8):1120-5. 
18. Rades D, Stoehr M, Kazic N, Hakim SG, Walz A, Schild SE, et al. Locally advanced stage IV squamous cell carcinoma of the head and neck: impact of pre-radiotherapy hemoglobin level and interruptions during radiotherapy. Int J Radiat Oncol Biol Phys. 2008;70(4):1108-14.

19. McCloskey SA, Jaggernauth W, Rigual NR, Hicks WL, Jr., Popat SR, Sullivan M, et al. Radiation treatment interruptions greater than one week and low hemoglobin levels (12 $\mathrm{g} / \mathrm{dL}$ ) are predictors of local regional failure after definitive concurrent chemotherapy and intensity-modulated radiation therapy for squamous cell carcinoma of the head and neck. Am J Clin Oncol. 2009;32(6):587-91.

20. Overgaard J, Hansen HS, Specht L, Overgaard M, Grau C, Andersen E, et al. Five compared with six fractions per week of conventional radiotherapy of squamous-cell carcinoma of head and neck: DAHANCA 6 and 7 randomised controlled trial. Lancet. 2003;362(9388):933-40.

21. Kwong DL, Sham JS, Chua DT, Choy DT, Au GK, Wu PM. The effect of interruptions and prolonged treatment time in radiotherapy for nasopharyngeal carcinoma. Int J Radiat Oncol Biol Phys. 1997;39(3):703-10.

22. Lee AW, Chan DK, Fowler JF, Poon YF, Foo W, Law SC, et al. Effect of time, dose and fractionation on local control of nasopharyngeal carcinoma. Radiother Oncol. 1995;36(1):24-31.

23. Su SF, Han F, Zhao C, Chen CY, Xiao WW, Li JX, et al. The effect of overall treatment time on local control in nasopharyngeal carcinoma patients treated with intensity modulated radiation therapy. Zhonghua Yi Xue Za Zhi. 2011;91(7):469-72.

24. Lee AW, Ngan RK, Tung SY, Cheng A, Kwong DL, Lu TX, et al. Preliminary results of trial NPC-0501 evaluating the therapeutic gain by changing from concurrent-adjuvant to induction-concurrent chemoradiotherapy, changing from fluorouracil to capecitabine, and changing from conventional to accelerated radiotherapy fractionation in patients with locoregionally advanced nasopharyngeal carcinoma. Cancer. 2015;121(8):132838.

25. Pan ZQ, He XY, Guo XM, Ye M, Zhang Z, He SQ, et al. A phase III study of late course accelerated hyperfractionated radiotherapy versus conventionally fractionated radiotherapy in patients with nasopharyngeal carcinoma. Am J Clin Oncol. 2012;35(6):600-5.

26. Teo PM, Leung SF, Chan AT, Leung TW, Choi PH, Kwan WH, et al. Final report of a randomized trial on altered-fractionated radiotherapy in nasopharyngeal carcinoma prematurely terminated by significant increase in neurologic complications. Int J Radiat Oncol Biol Phys. 2000;48(5):1311-22.

27 Li PJ, Jin T, Luo DH, Shen T, Mai DM, Hu WH, Mo HY. Effect of prolonged radiotherapy treatment time on survival outcomes after intensity- modulated radiation therapy in nasopharyngeal carcinoma PLoS One 2015 vol. 10 (10) pp. e 0141332-14

28. Stoker SD, Wildeman MA, Fles R, Indrasari SR, Herdini C, wildeman PL, et al. Prospective study: Current problems in radiotherapy for Nasopharyngeal Carcinoma in Yogyakarta, Indonesia. NPC conference 2013 Istanbul. 2013.

29. Wildeman MA, Zandbergen J, Vincent A, Herdini C, Middeldorp JM, Fles R, et al. Can an online clinical data management service help in improving data collection and data quality in a developing country setting? Trials. 2011;12:190.

30. Adham M, Stoker SD, Wildeman MA, Rachmadi L, Gondhowiardjo S, Atmakusumah D, et al. Current status of cancer care for young patients with nasopharyngeal carcinoma in Jakarta, Indonesia. PLoS One. 2014;9(7):e102353.

31. Chen Z, King W, Pearcey R, Kerba M, Mackillop WJ. The relationship between waiting time for radiotherapy and clinical outcomes: a systematic review of the literature. Radiother Oncol. 2008;87(1):3-16. 
32. Langendijk JA, Leemans CR, Buter J, Berkhof J, Slotman BJ. The additional value of chemotherapy to radiotherapy in locally advanced nasopharyngeal carcinoma: a metaanalysis of the published literature. J Clin Oncol. 2004;22(22):4604-12.

33. Blanchard P, Lee A, Marguet S, Leclercq J, Ng WT, Ma J, et al. MAC-NPC Collaborative Group. Chemotherapy and radiotherapy in nasopharyngeal carcinoma: an update of the MAC-NPC meta-analysis Collaborative Group: www.thelancet.com/oncology Published online May 7, 2015. Lancet Oncol. 2015 ;16(6):645-55.

34. Atun R, Jaffray DA, Barton MB, Bray F, Baumann M, Vikram B, et al. Expanding global access to radiotherapy. Lancet Oncol. 2015 Sep;16(10):1153-5 
Chapter 10
General discussion and future prospects

Chapter 10
assion and future prospects
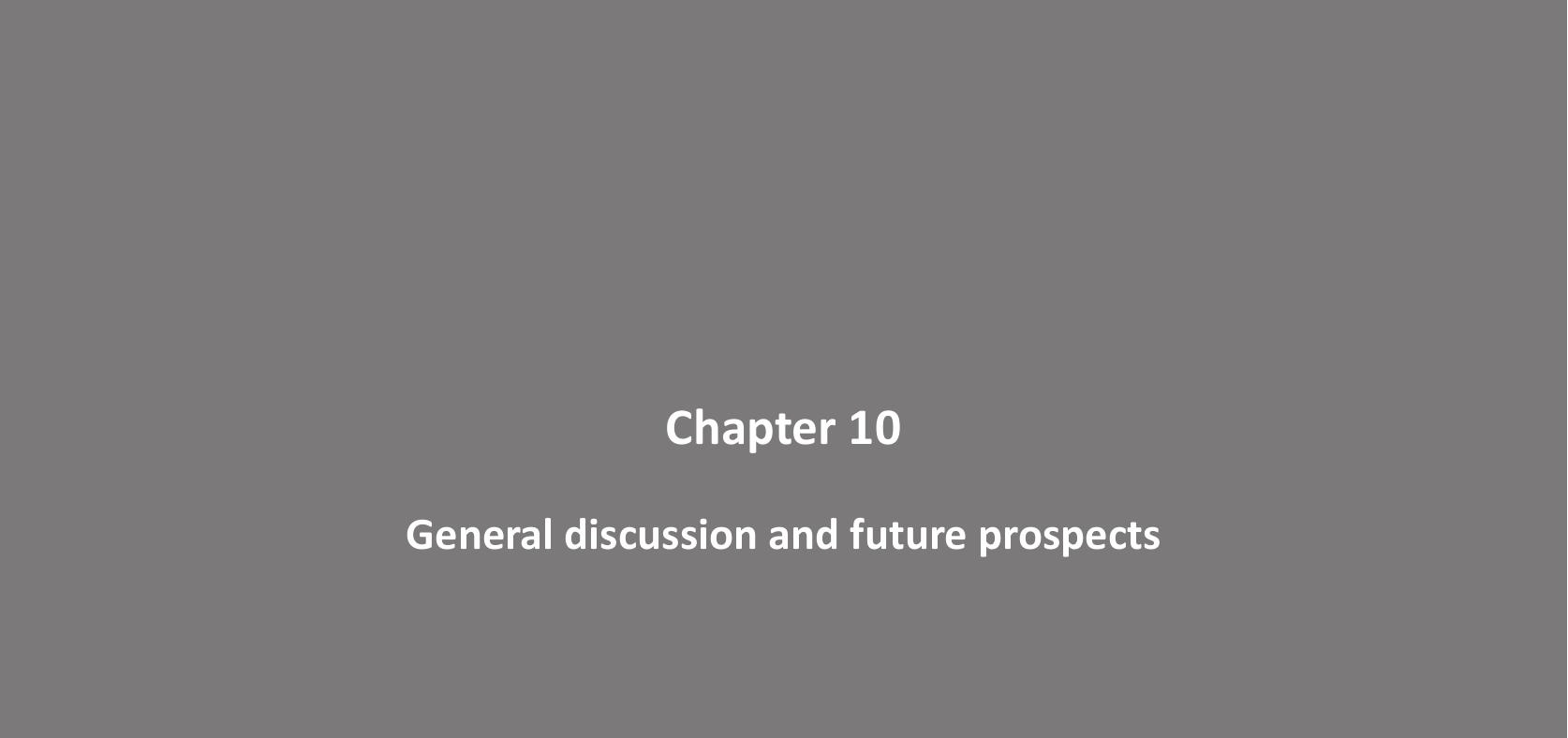


\section{Total patient delay}

This thesis focused on Total Patient Delay of patients diagnosed with nasopharyngeal carcinoma (NPC) in Yogyakarta, Indonesia. It is preferable for head and neck cancer to be treated within the first month after diagnosis [1-3]. Delay in cancer diagnosis and treatment may have a negative influence on treatment outcomes [4-8]. The delay to diagnosis and treatment has been a topic of concern and research for many years [9-12]. One of the most common models used to investigate delay is 'The General Model of Total Patient Delay' describes the process from the onset of symptoms until treatment starts [11]. Within this model different types of delay are described, namely: appraisal delay, illness delay, behavior delay, scheduling delay and treatment delay [11]. However, the three main intervals of potential delay are: the interval between the onset of the symptoms until the first visit to a doctor (patient delay), the first visit until diagnosis (doctor's delay), and the interval between diagnosis and starting the treatment (system delay) $[13,14]$.

At the start of the project, we mainly focused on Total Patient Delay as a linear process, however, as the project progressed, we determined that the total delay of patients diagnosed with NPC in Yogyakarta is actually affected by multiple parallel processes at the same time. Therefore, we used a swim lane model (cross functional diagram) to show not only the sequence of events, but also how different events may cause additional delay in different components of the total process (figure 1). In order to visualize the process, we assigned patient delay, doctor's delay and system delay to different lanes. Each lane has its own processes and outcomes which may result in delay within that lane or potentially even in a step back into the previous lane. For example; when a doctor does not recognize the symptoms this may cause an additional delay within the doctor's lane, however it is also possible that the patient goes home and waits for a longer period of time before seeking medical help again. In this way the progress of referral is moving back and it's up to the patient again to take the next step. Also, when a patient seeks medical help at an earlier stage this does not guarantee that he or she will finish treatment in time, since the patient still relies on the doctor's delay and system delay. Another example is when a patient waits too long before seeking medical help, then the speed of the processes following this initial step become less important because the patient will be diagnosed with high stage disease and no curative treatment is possible anymore. Contrary to previous models, we believe that system delay does 
not stop after initiating treatment. We also see prolonged treatment time for most patients, a delay which may also influence treatment outcomes [15].

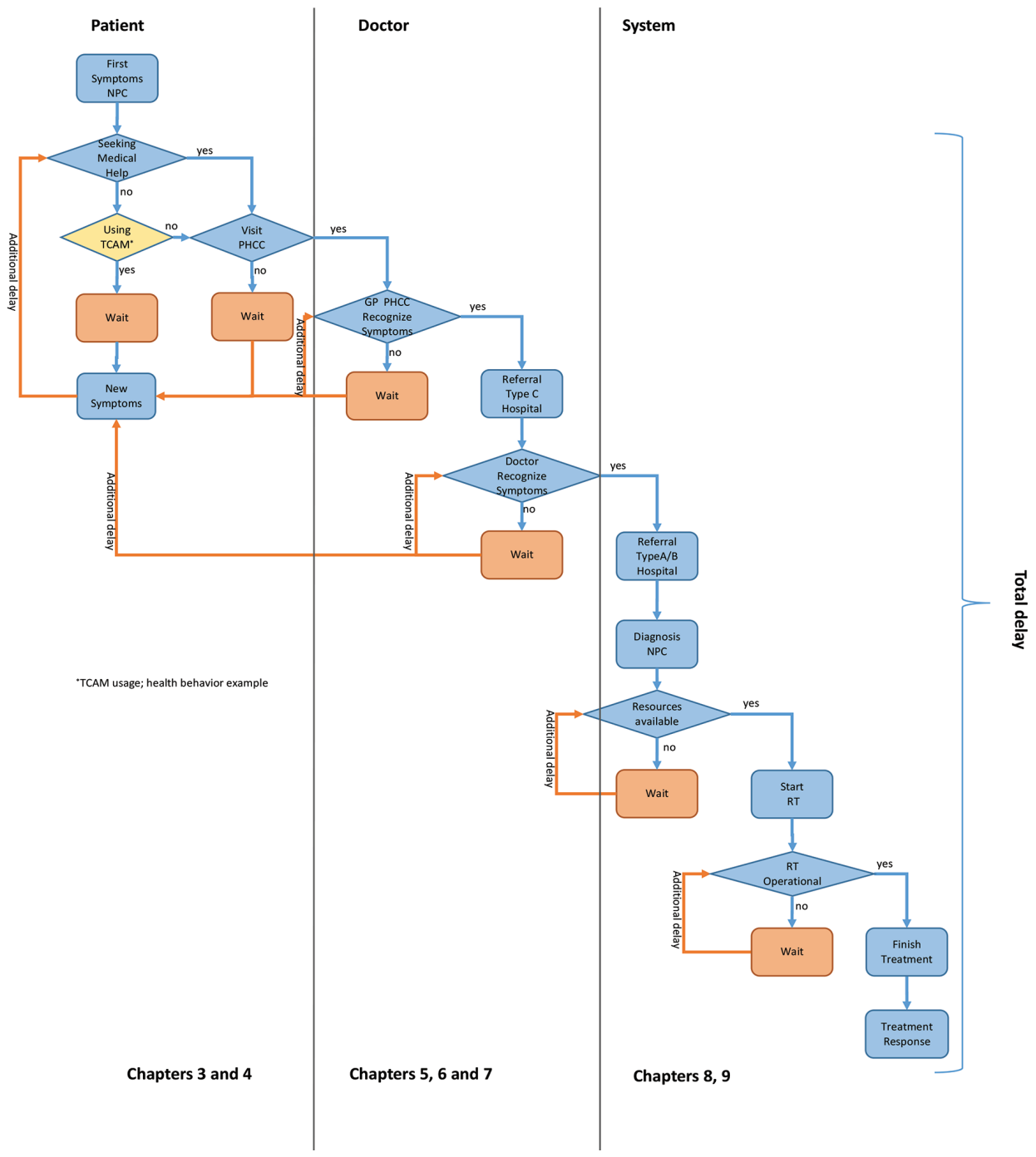

Figure 1 | Cross functional diagram of total patient delay. Three different lanes can be distinguished. Patient, Doctor and System. In the first lane the patient plays the most important role. He/she can seek medical help or wait, depending on health behavior e.g. example the usage of traditional complementary and alternative medicine. In the second lane the knowledge of the doctors is of great importance. Without the adequate knowledge the doctor will not be able refer a patient with symptoms suspected for NPC in time. And the last lane is the lane where the functioning of the system including availability of resources and functioning of equipment influences the total patient delay. 
By using the terms patient delay, doctor's delay and system delay the purpose is to try to identify who can influence this delay and not to judge or criticize the parties within this delay. However, it should be clear what is meant with each interval, since this varies a lot among different studies $[16,17]$.

\section{Patient delay}

In chapters 3 and $\mathbf{4}$ we discuss patient delay. Our first aim was to gain more insight into patients' motivation for their delay in seeking medical help. This first step towards diagnosis depends on patient health behavior and the capability of patients to recognize the first symptoms as something severe enough to be checked by a doctor. Patient behavior is influenced by their environment, social-economic status, health literacy, but also culture and religion (Chapter $\mathbf{3}$ ). In the Indonesian culture a patient considers himself or herself healthy as long as the symptoms do not hinder their daily activities. This health behavior often results in patients waiting longer before visiting their doctor [18]. Once they do visit a doctor the hierarchical respect for the medical doctors often results in a one-way form of communication, leaving questions from patients unanswered and delays referral [19] (Chapter 3).

Unawareness of early symptoms is a reason for delayed presentation [20-22]. This is in line with our findings, as patients did not recognize the first symptoms of NPC, which mimic a common cold and these symptoms did not hinder their daily activities. Therefore, patients waited to seek medical help until symptoms became more severe. Increase of awareness may be reached by health education. For example, for breast cancer many health education programs are provided on the community level and have proven to be effective [23-27]. However, a solid community-based awareness program for NPC in high-incidence areas has not yet effectively been established. Distributing folders and flyers at hospitals or clinics in combination with a single education program by community nurses for the people living in the village was unsuccessful for NPC, but was effective for breast and cervical cancer [28]. Therefore, alternative solutions are essential.

We found that many patients diagnosed with NPC used traditional, complementary and alternative medicine (TCAM) including visiting a herbalist, masseurs or a local traditional healer before diagnosis. Patients who never used any form of TCAM were diagnosed earlier (Chapter 4). This delay due to TCAM usage is also very common for other tumor sites like breast cancer $[29,30]$. However, TCAM usage is ingrained 
in Indonesian culture. There is a strong belief that the healing process is based on a fitness concept (cocok-cocokan), meaning that conventional medicine can help to a certain extent, but that TCAM might even be more effective [31]. However, safe usage of TCAM entails that one should be aware of the consequences of the usage, especially in the treatment of cancer [32]. TCAM can contribute to health care when it is provided in a safe and effective way [33]. However, it is worrying that TCAM use may delay diagnosis and jeopardize successful treatment of NPC by proven regimens.

\section{Doctor's delay}

Once a patient decides to seek medical help the role of the doctor becomes more apparent in the referral process [34-36]. Doctor's delay is often associated with a more advanced stage of disease diagnosis.

In chapters 5, 6 and 7 we explored the knowledge of doctors working in the primary health care centers, set-up an NPC awareness program and were able to evaluate the effect of this awareness program on the short and long term. The time between visiting the doctor and the diagnosis plays an important role in other head and neck cancer treatment outcomes [37]. Improving early referral depends on access to and the knowledge of (para-) medics. In Chapter 5 we showed that the knowledge of the doctors working in the primary health care centers is limited. Most doctors were interested in receiving additional education. In line with our study, Prasad et al confirmed that a doctor's delay can take up to six months for one third of the NPC patients in Malaysia. The main reason for this delay was the lack of knowledge of the doctors [38]. The review of Amgad et al. extents these observations, showing that there is inadequate medical knowledge in oncology, especially amongst doctors in developing countries [39].

To improve the knowledge on NPC of (para-)medical staff we set-up an NPC awareness program consisting of a symposium and a train-the-trainer program. While preparing for this NPC awareness program we observed the role of paramedics working at the same primary health care centers. The assumption that patients with NPC-like complaints were seen and referred by their doctor was incorrect. The role of the paramedics was larger than expected and reason for us to involve them in the NPC awareness program. Doctors working in the primary health care centers have many responsibilities and limited time to see all of their patients. As a result, 
the primary health care centers often have no GP on site. Both the nurses and the midwives then take over their role as medical doctors without having the correct educational degree or knowledge to do so [40-42].

The NPC awareness program was set up in such a way that is was easy to implement in different cities. Thanks to a train-the-trainer program, numerous health care workers could be trained with limited resources. The education program was purposely organized in the neighborhoods of big academic hospitals. This made it possible to measure the effect of the NPC awareness program in two ways. Firstly, we were able to measure the knowledge of the participants after one and a half years after receiving a training. We found that after one and a half years, participants had still retained their knowledge. Nevertheless, it became clear that it is still necessary to continue with the program since the turnover of people working in the primary health care centers is high and the new (para-)medical staff need additional training. Secondly, it was possible to observe whether newly diagnosed patients at the Ear, Nose and Throat department of the Dr. Sardjito hospital had been down staged, since all patients were registered in our database. Unfortunately, there were no cases of down staging. The lack of down staging may be due to limited coverage of the training or too quick turn over of the health staff. It may also be that even though the knowledge improved, still insufficient experience existed in daily practice to recognize and refer patients timely. Moreover, as discussed above, down staging does not only depend on the knowledge of the (para-)medical staff, but also on patient behavior or changes in the referral system which cause a possible delay in diagnosis.

\section{System delay}

The poor treatment outcomes as shown in chapter 2 required further insight. Earlier studies have shown associations between longer period between diagnosis and start treatment modality (surgery, radiotherapy or chemoradiation) and prognosis in head and neck cancer [43]. In our study all patients were waiting for radiotherapy and received chemotherapy to bridge the waiting time. Between 2008 and 2011, the average diagnosis to start of treatment interval (DTI) was four months for people who were diagnosed with NPC and who were eligible for the health insurance for people with low income (Jamkesmas) (chapter 2). We evaluated the DTI of patients who actually started radiotherapy. Out of 188 newly diagnosed patients only 78, 
who started curative treatment within the study period, were eligible for inclusion. To our best knowledge the other fifty-nine per cent $(n=110)$ did not receive curative treatment at all. Almost half of the excluded patients did not receive treatment due to financial problems, other reasons were that patients were diagnosed with distant metastasis, logistic reasons, or patients decided to start with traditional treatment. Between 2011 and 2012 the mean DTI was still around 4 months however, the DTI had increased to 7 months for patients with a Jamkesmas .

In chapter $\mathbf{2}$ we also discussed possible explanations for unsuccessful treatment outcomes e.g. advanced stage of the tumor at diagnosis, the waiting time before starting radiotherapy and the duration of the radiotherapy. In Chapter 8 we confirmed that the time between referral and starting treatment is longer (up to 1012 days) than international standards [44]. In chapter 9 we investigated the actual impact of the prolonged overall treatment time. When treatment is interrupted it prolongs the treatment time, which can have a negative effect on the treatment outcome [45-48] However, comparable to findings of Li et al [49], we did not find an association between prolonged overall treatment time and worse survival in our patient group. This is most likely due to the limited number of patients who started treatment within one month or finished treatment, without interruptions during treatment. Also, in our study, tumor stage did not affect the treatment outcome. One possible explanation for this could be that most patients were diagnosed with advanced stages of disease. Moreover, imaging was only done at diagnosis (not just before treatment) and as a result, tumor progression in the lower stage patients may have occurred during DTI.

We believe that the small number of radiotherapy units available and the increasing demand for cancer treatment is of great influence on survival outcomes in Indonesia. Although the number of radiotherapy units has increased over the years, this is still only a fraction of the total units needed in Indonesia. Per radiotherapy unit 450 patients per year has been recommended as suitable machine throughput $[50,51]$. Based on the inventory of Datta et al and Atun et al. it was calculated that the deficit of radiotherapy infrastructure and staffing in Indonesia in 2014 amounted to 380 radiotherapy units, 712 radiation oncologists, 375 medical physicists and 1111 radiation therapy technologists [51,52]. 
The introduction of national health insurance (explained below) in 2014 was to provide all patients with appropriate health care. However, we observed new problems in the area of cancer care. Due to increased demand, a steep increase in the DTI for all patients was inevitable and in August 2016 the DTI increased to 35 months. Obviously this is a theoretical waiting time since most patients will not wait this long. They either die before treatment starts, go overseas, receive treatment in other hospitals or decide to start with alternative treatment.

\section{Indonesian health care system}

During our study we were confronted with drastic changes in the Indonesian health care system. Health care became affordable for all inhabitants and the Indonesian government is striving for equity in health care. This had an impact on our studies and likely caused that patients diagnosed with NPC experienced a prominent increase in the waiting time for radiotherapy in Yogyakarta from early 2014 onwards.

The transformation, the Indonesian health care system was undergoing, included the following: in 2012 an estimated 150 million of the approximately 246 million inhabitants had some kind of insurance, fifty per cent of those with insurance were proven to be poor and eligible for a Jamkesmas (Table 1) which was paid for by the government. It gave them access to third class wards (basic level) in governmental hospitals and some assigned private hospitals [53,54]. All other health care costs were out-of- pocket payments.

Table 1 | Types of health insurance in Indonesia before January 2012

\begin{tabular}{ll}
\hline TYPE OF HEALTH INSURANCE & PERSONS \\
\hline Jamkesmas participants (health insurance for the poor) & $76,400,000$ \\
Askes participants (civil servants) & $17,274,520$ \\
Tni/polri (military and police) & $2,200,000$ \\
Jamsostek participants (workers' social security) & $5,600,000$ \\
Jamkesda (regional governments' health insurance) & $31,866,390$ \\
Corporate insurance (self-insured) & $15,351,532$ \\
Commercial health insurance participants & $2,856,539$ \\
Total & $151,548,981$
\end{tabular}

In January 2014 Indonesia introduced the Universal Health Care (UHC), the Badan Penyelenggara Jaminan Sosial (BPJS). For a monthly fee of 2.2 US\$ people could join a third-class plan. A second class plan became available for 3.6 US\$ a month and 
for 5.1 US\$ a month, citizens who signed up for BPJS could join the first class plan. All three plans cover more expensive medical interventions like dialysis, open-heart surgery and cancer therapy. However, the Indonesian government is still struggling with financing this insurance system and is expecting a deficit of 0.5 billion US\$ in 2016. As of April 2016 the monthly fee for the first and second class plan had to be adjusted. The monthly fee for the first class plan is now 6.8 US\$ and second class monthly fee is now 4.4 US\$. However, considering that those with the lowest income will only sign up for health care when it becomes urgent and can only afford the third class plan, it is questionable as to whether this fee increase for first and second class will solve the problem.

The lack of balance between insurance fees and health expenses might be partially due to the fact that Indonesians with sufficient income travel to Malaysia or Singapore for medical care. With an estimated 1.2-11.5 billion US\$ spent overseas on health care, Indonesians represent $70 \%$ of the foreign patients in Singapore and Malaysia ${ }^{b}, 55$. The shortage of eligible staff ${ }^{b}$ in Indonesia is the main reason behind this mass expenditure abroad. For example, in 2011 there were no oncologists available in the Eastern Provinces of Indonesia [55].

Also, Indonesia is facing a so called double burden with regards to hospital bed utilization. In 2011 there were 6.3 hospital beds per 10.000 inhabitants unequally distributed over the different provinces. However, the utilization of the beds was low with an occupation rate between 55 and 60 per cent in public and private hospitals in 2010 [55]. This is far below the ideal ratio between 80 and 85 per cent [56]. A possible explanation for this could be a poorly functioning health system, epidemiological and demographic transitions, high percentage out-of-pocketpayment discouraging hospital visits, and a hospital care financing system which placed more importance on the number of beds than the occupation rate. Once the occupation rate exceeds the ideal ratio this indicated poor hospital safety and efficiency [56].

With the introduction of new health care insurance in 2014, the referral system also changed. Previously, patients had the choice to visit primary, secondary or tertiary

b allianceexperts.com/en/knowledge/countries/asia/the-indonesia-healthcare-market.itij.com/ feature/indonesian-challenge) 
healthcare. Now this system is more regulated. Patients should first visit primary care and are referred by the doctor to a specialist in a secondary institute who can refer them further to a tertiary institute, if necessary. Since the UHC has started covering visits to the doctor at the PHCC, the number of visits has soared from 66.8 million to 100.62 million $^{c}$.

However, the introduction of the UHC was criticized by many, because the number of adequate healthcare providers appeared to be insufficient. In a pilot study in Jakarta, in which the first 5 million people categorized as poor received health insurance, it was concluded that this directly resulted in long queues. Newspapers also reported that hospitals were overcrowded with not enough hospital beds, waiting time for treatment increased and medication was becoming scarcec. The bed utilization in highly populated areas increased over 100 per cent, indicating the need for additional beds as patients were administered although no official beds were available [56]. These observations support the increased waiting time we observed in our studies and personal observations of the treatment scheduling books in the Sardjito hospital during the study period.

\section{Conclusion}

The number of new cancer cases is still increasing worldwide, but the number of cancer deaths is increasing predominantly in low and middle income countries [5759]. The gap in survival rates between high income countries and low and middle income countries is growing. Access to health care in low and middle income countries is often limited due to the scarcity of resources and an unequal distribution of these resources [60-62]. The majority of patients with NPC are diagnosed in low and middle income countries $[63,64]$, where resources are limited. In Indonesia the estimate incidence is 6.2 resulting in 15,000 new patients per year [65]. However, we do believe that this is an underestimation caused by a non-existent nationwide registration system.

Due to larger number of cancer patients and the limited resources at the dr. Sardjito hospital, patients diagnosed with NPC, irrespective of patient or doctor's delay, may face a system delay of up to three years. The chances of actually receiving

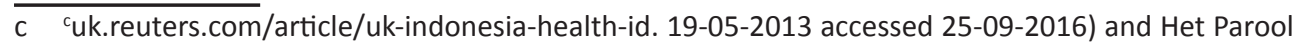
20-04-2013 
adequate treatment are limited due to tumor progression while bridging the waiting time. During this waiting time patient receive chemotherapy. The length of the waiting time in combination with this chemotherapy caused deterioration of the physical condition of the patient, making concurrent chemotherapy too toxic for many patients. One can question whether it is justifiable and ethical to diagnose people when treatment options are very limited available. On the other hand, one may argue that there is the right to know even if this considers serious disease with limited chance for cure. Importantly, if patients would not be diagnosed, the magnitude of the actual problem, including the high demand for radiotherapy, resulting in long queues due to too limited resources, will not be exposed. Exposure may be necessary to achieve awareness of these problems in the health care system and taking the right governmental decisions to improve the situation for cancer patients.

For NPC, access to treatment facilities and survival rates are strongly correlated [64]. Cancer care in low and middle income countries needs to be vastly improved [52,58,66-71], with radiotherapy as the cornerstone of treatment. If NPC is diagnosed at an early stage and radiotherapy treatment is available, 5 years overall survival rates over 80 per cent [72-74] . It is clear that there is an enormous shortage of oncologists and treatment facilities in Indonesia and other low/moderate income countiries [51]. Short term simple adjustments in the current system or novel treatment modalities are needed in combination with better trained staff in the primary health care centers, raising public awareness, and introducing cancer prevention programs.

In this thesis we investigated different types of delay and possible solutions. With the implementation of the NPC awareness program we aimed at down staging NPC by creating more awareness among doctors. Though the awareness program was successful in improving knowledge, we did not observe a difference in tumor stage at diagnosis and the treatment outcomes have not improved. We did observe several other factors at the level of the patient and the system that influenced treatment delay. This emphasizes the importance of a multi-level approach to improve cancer care and minimize total patient delay (Figure 1).

As described in this discussion and in the various chapters, there are several criticisms to make about the studies in this thesis, and we were confronted with 
many challenges and also changes in the health care system, which may have influenced our findings. However, supported by multiple measurements within our own studies and by other studies in literature, we do not think that in ideal situations we would have reached different conclusions. For example, we repeatedly over time showed the impact on knowledge of the NPC education program (chapters 6 and 7); the impact of health behavior and usage of TCAM on delay was shown by others as well $[22,29,30,75-79]$; and the system delay was also seen in other studies $[44,48,80,81]$. The strength of this research conducted in Yogyakarta, Indonesia is that we were able to collect our data prospectively. This gave us the possibility to compile a complete database with relatively little lacking patient information. Up until now, treatment results published in our studies and in those of our peers have only described the treatment outcomes of patients who actually received treatment. However, this is only a fraction of the total number of patients diagnosed with NPC. We are now able to obtain the real waiting time and establish what happens to patients diagnosed with NPC in Yogyakarta, Indonesia, since only a limited number of patients actually receive treatment. An ongoing observational study conducted in Yogyakarta will clarify what process patients follow once they are diagnosed with NPC.

\section{Future prospects}

Our current clinical research conducted in a single center in Indonesia, Yogyakarta, was only possible thanks to a devoted team of data managers and assistants. In Indonesia, there is no nationwide cancer registry, incidences are estimated and survival rates are based on these estimated incidences [64]. We assume that the real incidence is much higher, since not everyone with NPC symptoms are diagnosed and those who are diagnosed, are not always in a registered database. The existing registration system for radiotherapy at the Dr. Sardjito hospital is not digital. This makes it difficult to determine which patient started treatment and which patient dropped out. For future treatment efficiency, effort should be put into digitalizing this system so that drop-outs can directly be replaced by other patients.

Major investments by the Indonesian government are needed to improve access to cancer care. This access not only entails sufficient available treatment facilities but also well trained doctors, affordable treatment and community awareness. 
On a community-based level, effort should be put into cancer prevention by highlighting positive lifestyle changes (e.g. avoiding smoking and the consumption of preserved/ salted food). In Indonesia, smoking among males increased from 54.8 per cent to 75.9 percent between 2001 and 2015, while this prevalence decreased in other ASEANs (Association of Southeast Asian Nations). In ASEANs, tobacco smoking is attributable to 27 to 47.8 per cent of cancer in males, in Indonesia this is 44.4 per cent $[82,83]$. Lifestyle changes have been shown to decrease incidence of NPC. For example,in Hong Kong, the incidence rate declined between 1983 and 2008 , which was related to the gradual reduction of environmental and other nonviral risk factors $[84,85]$. Also in Taiwan a decrease in NPC was registered between 1981 and 2000, attributable to changes in lifestyle [86].

Community-based cancer prevention programs do exist for example in Malaysia, however they are not very successful ${ }^{28}$. Setting up a successful cancer prevention program for NPC should be done in close collaboration with the public health 'kader'. A 'kader' is a man or woman chosen by the community who can be seen as a layperson between the community and the primary health care centers. The principle behind the 'kader' is to improve the efficiency of limited health care services and use them optimally, while simultaneously taking the local culture into account. Printing simple infographics which can be handed out by the 'kader' could be a simple first step towards raising more awareness for NPC and other health issues.

The NPC awareness program has improved the knowledge of (para-) medics working in the primary health care centers. In combination with a train-the-trainer program, it was possible to train many (para-)medics with limited resources. Even though we showed that knowledge of NPC remained higher compared to baseline, without refreshment courses part of the knowledge will be lost after a few years. However additional training courses alone will not be enough. The burden on the health care system has increased and doctors have even less time than ever before. There is a need for more well-trained doctors in the primary health care centers. Therefore, it is hopeful that the implementation of the NPC awareness program was noticed by our peers in Malaysia and in the future similar programs will be held in Malaysia as well. 
Within the curriculum of medical students there is no specific NPC training. All medical students follow a general oncology course. Training medical students on NPC could already be beneficial, as all new medical doctors are obliged to work as a doctor in a primary health care center for a certain period of time. In 2013 during their internship at the Ear Nose and Throat department at the dr. Sardjito hospital in Yogyakarta, medical students were required to participate in additional training on NPC. The effect of this additional training was measured (two weeks after the training) and an increased knowledge was observed. No comparison was made between additional training and student who never received additional training on NPC. Nevertheless, in 2014 an additional training regarding NPC was introduced for all medical students at the Gadjah Mada University in Yogyakarta.

Treatment delay needs the biggest investment. The lack of radiotherapy facilities is immense and with current waiting times close to three years, it will take time to solve this problem. Meanwhile, small adjustments to the current system can make a difference. Since it is clear that there is a shortage of equipment, equipment should be used as efficiently as possible by running it 24 hours a day and ensuring a maintenance schedule.

In addition, novel treatment modalities can play a role in the waiting time. One example is Photodynamic therapy (PDT). PDT is a treatment based on a light sensitive drug, which is intravenously administered and causes cell destruction when illuminated by a laser with $652 \mathrm{~nm}$ wavelength. This procedure is fairly simple, since it is a one hit treatment and in the case of NPC it can be performed under local anesthesia. The light sensitive drug Temoporfin (Foscan ${ }^{\circledR}$ ), has a penetration depth of 1 centimeter. In a phase I and a phase II study, conducted in Yogyakarta, 43 patients (22 phase I and; 21 phase II) with recurrent and persistent NPC limited to the nasopharynx were included $[87,88]$. The phase I study showed that therapy was relatively simple to perform and tolerable under local anesthesia. The phase II study showed that PDT was an effective treatment for local failures of NPC with a 2-years overall survival rate of 65 per cent. The effectiveness of PDT for these local failures suggests that PDT maybe also be used in a more neo-adjuvant setting. Currently patients receive chemotherapy to overcome the waiting time, however this chemotherapy often causes physical deterioration, which complicates the actual treatment or can even cause death. Future research should investigate the 
possibility of using PDT in a more neo-adjuvant setting or pre-radiotherapy setting, since PDT is more bearable than chemotherapy.

Better communication between doctors, specialists and patients can be another key to improving system delay. Currently, limited resources force patients to return home untreated and come back the next day. Indonesia has a very good and extensive mobile network. Almost everyone owns a mobile phone with internet access. This information can be used to develop mobile applications informing patients when there is a place available or when treatment starts.

This thesis showed the complexity of the referral system to diagnosis and treatment of NPC in Yogyakarta, Indonesia. Only when intervening on all levels in the cross functional model (Figure 1) successes can be accomplished, since all the different lanes in the model have different key persons who can influence the process within their lane. The problems described in this thesis are not specific for NPC or Indonesia. In fact, the used methods to identify the biggest drawback in the referral system and the suggested interventions can be used as a blue print for other tumor sites, but also in other low and middle income countries, who facing comparable problems. Some of the suggested interventions are costly and time-consuming and depending on governmental involvement (e.g. expansion of radiotherapy facilities). However, this should not be a discouragement to continue with other interventions, as other interventions can be small, inexpensive and easy to implement; e.g. community based interventions focusing on cancer preventions and the continuation of the NPC awareness program. 


\section{References}

1. Jensen, A. R., Nellemann, H. M. \& Overgaard, J. Tumor progression in waiting time for radiotherapy in head and neck cancer. Radiother Oncol 84, 5-10 (2007).

2. Webb, C. J., Benton, J., Tandon, S., Jones, T. M. \& Roland, N. J. Head and neck cancer waiting times. Clin Otolaryngol 32, 293-296 (2007).

3. National Cancer Intelligence network. Going further on cancer waits. Available at: (Accessed: 4 May 2015)

4. Afzelius, P., Zedeler, K., Sommer, H., Mouridsen, H. T. \& Blichert-Toft, M. Patient's and doctor's delay in primary breast cancer. Prognostic implications. Acta Oncol 33, 345351 (1994).

5. Richards, M. A., Westcombe, A. M., Love, S. B., Littlejohns, P. \& Ramirez, A. J. Influence of delay on survival in patients with breast cancer: a systematic review. The Lancet 353, 1119-1126 (1999).

6. Jensen, A. R., Mainz, J. \& Overgaard, J. Impact of delay on diagnosis and treatment of primary lung cancer. Acta Oncol 41, 147-152 (2002).

7. Fortin, A. et al. Effect of treatment delay on outcome of patients with early-stage headand-neck carcinoma receiving radical radiotherapy. Radiation Oncology Biology 52, 929-936 (2002).

8. Chen, P.-C. et al. The impact of time factors on overall survival in patients with nasopharyngeal carcinoma: a population-based study. Radiation Oncology 1-7 (2016). doi:10.1186/s13014-016-0638-2

9. Pack, G. T. \& Gallo, J. S. The Culpability for Delay in the Treatment of Cancer. The American Journal of Cancer 33, 443-462 (1938).

10. Antonovsky, A. \& Hartman, H. Delay in the Detection of Cancer: A Review of the Literature. Health Education \& Behavior 2, 98-128 (1974).

11. Andersen, B. L. \& Cacioppo, J. T. Delay in seeking a cancer diagnosis: delay stages and psychophysiological comparison processes. Br J Soc Psychol 34 ( Pt 1), 33-52 (1995).

12. Hansen, R. P., Olesen, F., Sørensen, H. T., Sokolowski, I. \& Søndergaard, J. Socioeconomic patient characteristics predict delay in cancer diagnosis: a Danish cohort study. BMC Health Serv Res 8, 49 (2008).

13. Olesen, F., Hansen, R. P. \& Vedsted, P. Delay in diagnosis: the experience in Denmark. Br. J. Cancer 101, S5-S8 (2009).

14. Hansen, R. P., Vedsted, P., Sokolowski, I., Søndergaard, J. \& Olesen, F. Time intervals from first symptom to treatment of cancer: a cohort study of 2,212 newly diagnosed cancer patients. BMC Health Serv Res 11, 284 (2011).

15. Sher, D. J. et al. Relationship between radiation treatment time and overall survival after induction chemotherapy for locally advanced head-and-neck carcinoma: a subset analysis of TAX 324. Int. J. Radiat. Oncol. Biol. Phys. 81, e813-8 (2011).

16. Dobson, C. M., Russell, A. J. \& Rubin, G. P. Patient delay in cancer diagnosis: what do we really mean and can we be more specific? 14, 1-6 (2014).

17. Freitas, A. G. Q. \& Weller, M. Patient delays and system delays in breast cancer treatment in developed and developing countries. Cien Saude Colet 20, 3177-3189 (2015).

18. Dewi, F. S. T., Weinehall, L. \& Ohman, A. 'Maintaining balance and harmony': Javanese perceptions of health and cardiovascular disease. Glob Health Action 3, (2010).

19. Claramita, M., Utarini, A., Soebono, H., Van Dalen, J. \& Van der Vleuten, C. Doctorpatient communication in a Southeast Asian setting: the conflict between ideal and reality. Adv Health Sci Educ Theory Pract 16, 69-80 (2011).

20. Iskandarsyah, A. et al. Psychosocial and cultural reasons for delay in seeking help and nonadherence to treatment in Indonesian women with breast cancer: a qualitative study. Health Psychol 33, 214-221 (2014). 
21. Taib, N. A., Yip, C. H. \& Low, W. Y. Recognising symptoms of breast cancer as a reason for delayed presentation in Asian women--the psycho-socio-cultural model for breast symptom appraisal: opportunities for intervention. Asian Pac. J. Cancer Prev. 12, $1601-$ 1608 (2011).

22. Brouha, X. D. R., Tromp, D. M., de Leeuw, J. R. J., Hordijk, G.-J. \& Winnubst, J. A. M. Laryngeal cancer patients: Analysis of patient delay at different tumor stages. Head Neck 27, 289-295 (2005).

23. Hajian, S., Vakilian, K., Najabadi, K. M., Hosseini, J. \& Mirzaei, H. R. Effects of education based on the health belief model on screening behavior in high risk women for breast cancer, Tehran, Iran. Asian Pac. J. Cancer Prev. 12, 49-54 (2011).

24. Karbani, G. et al. Culture, attitude and knowledge about breast cancer and preventive measures: a qualitative study of South Asian breast cancer patients in the UK. Asian Pac. J. Cancer Prev. 12, 1619-1626 (2011).

25. Burgess, C. C., Ramirez, A. J., Richards, M. A. \& Love, S. B. Who and what influences delayed presentation in breast cancer? Br. J. Cancer 77, 1343-1348 (1998).

26. Rajan, S. S., Lim, J. N. W. \& Haq, A. Late presentation and management of South Asian breast cancer patients in West Yorkshire, United Kingdom. Asian Pac. J. Cancer Prev. 12, 1615-1618 (2011).

27. Kisuya, J. et al. Impact of an educational intervention on breast cancer knowledge in western Kenya. Health Educ Res 30, 786-796 (2015).

28. Devi, B., Tang, T. \& Corbex, M. Reducing by half the percentage of late-stage presentation for breast and cervix cancer over 4 years: a pilot study of clinical downstaging in Sarawak, Malaysia. Annals of Oncology 18, 1172-1176 (2007).

29. Iskandarsyah, A., de Klerk, C., Suardi, D. R., Sadarjoen, S. S. \& Passchier, J. Consulting a traditional healer and negative illness perceptions are associated with non-adherence to treatment in Indonesian women with breast cancer. Psycho-Oncology n/a-n/a (2014). doi:10.1002/pon.3534

30. Broom, A. et al. Indian Cancer Patients' use of Traditional, Complementary and Alternative Medicine (TCAM) and delays in presentation to Hospital. Oman Med J 24, 99-102 (2009).

31. Triratnawati, A., Wulandari, A. \& Marthias, T. The Power of Sugesti in Traditional Javanese Healing Treatment. Jurnal Komunitas 6, 280-293 (2014).

32. Permana, M. Penggunaan pengobatan alternatif dalam proses penyembuhan penyakit. (2012).

33. world health Organization. WHO traditional medicine strategy 2014-2023. (Geneva: World Health Organization, 2015).

34. Öztürk, Ç., Fleer, J., Hoekstra, H. J. \& Hoekstra-Weebers, J. E. H. M. Delay in Diagnosis of Testicular Cancer; A Need for Awareness Programs. PLoS ONE 10, e0141244 (2015).

35. Smith, M. M., Abrol, A. \& Gardner, G. M. Assessing delays in laryngeal cancer treatment. The Laryngoscope n/a-n/a (2015). doi:10.1002/lary.25734

36. Unger-Saldaña, K. Challenges to the early diagnosis and treatment of breast cancer in developing countries. World J Clin Oncol 5, 465-477 (2014).

37. Koivunen, P. The impact of patient and professional diagnostic delays on survival in pharyngeal cancer. Cancer 1-7 (2001). doi:10.1002/cncr.10119

38. Prasad, U. \& Pua, K. C. Nasopharyngeal Carcinoma: A delay in Diagnosis. Medical Journal Malaysia 2, 1-6 (2000).

39. Amgad, M., Shash, E. \& Gaafar, R. Cancer education for medical students in developing countries: where do we stand and how to improve? Critical Reviews in Oncology / Hematology 84, 122-129 (2012). 
40. Chaudhury, N., Hammer, J., Kremer, M., Muralidharan, K. \& Rogers, F. H. Missing in action: teacher and health worker absence in developing countries. J Econ Perspect 20, 91-116 (2006).

41. Wood, J. \& Line, D. Old problems, fresh solutions: Indonesia's new health regime. (Economist intelligence unit, 2010).

42. Ngana, F. R., Myers, B. A. \& Belton, S. Health reporting system in two subdistricts in Eastern Indonesia: Highlighting the role of village midwives. Midwifery 28, 809-815 (2012).

43. van Harten, M. C. et al. The association of treatment delay and prognosis in head and neck squamous cell carcinoma (HNSCC) patients in a Dutch comprehensive cancer center. Oral Oncol 50, 282-290 (2014).

44. Waaijer, A. et al. Waiting times for radiotherapy: consequences of volume increase for the TCP in oropharyngeal carcinoma. Radiother Oncol 66, 271-276 (2003).

45. Cannon, D. M. et al. Increased local failure risk with prolonged radiation treatment time in head and neck cancer treated with concurrent chemotherapy. Head Neck 36, 1120 1125 (2014).

46. Yang, J., Yue, J. B., Liu, J. \& Yu, J. M. Repopulation of tumor cells during fractionated radiotherapy and detection methods (Review). Oncology Letters 7, 1755-1760 (2014).

47. Marks, L. B. \& Dewhirst, M. Accelerated repopulation: friend or foe? Exploiting changes in tumor growth characteristics to improve the 'efficiency' of radiotherapy. Radiation Oncology Biology 21, 1377-1383 (1991).

48. Platek, M. E. et al. Quantification of the effect of treatment duration on local-regional failure after definitive concurrent chemotherapy and intensity-modulated radiation therapy for squamous cell carcinoma of the head and neck. Head Neck 35, 684-688 (2013).

49. Li, P.-J. et al. Effect of Prolonged Radiotherapy Treatment Time on Survival Outcomes after Intensity-Modulated Radiation Therapy in Nasopharyngeal Carcinoma. PLoS ONE 10, e0141332-14 (2015).

50. International Atomic Energy Agengy. Planning National Radiotherapy Services: A Practical Tool. 1-100 (2011).

51. Datta, N. R., Samiei, M. \& Bodis, S. Radiation Therapy Infrastructure and Human Resources in Low- and Middle-Income Countries: Present Status and Projections for 2020. Radiation Oncology Biology 89, 448-457 (2014).

52. Atun, R., Jaffray, D. A., Barton, M. B., Bray, F. \& Baumann, M. Expanding global access to radiotherapy. The Lancet (2015). doi:10.1016/s1470-2045(15)00222-3

53. Widjaja, M. \& Simanjuntak, R. A. 'Social protection in East Asia - Current state and challenges', ERIA Research Project Report 2010, No. 9.

54. Satriana, S. \& Schmitt, V. Towards a nationally defined social protection floor in Indonesia. 1-94 (2012).

55. Awofeso, N., Rammohan, A. \& Asmaripa, A. Exploring Indonesia's 'low hospital bed utilization-low bed occupancy-high disease burden' paradox. Journal of Hospital Administration 2, p49 (2012).

56. Ripe for investment: the Indonesian health care industry post introduction of universal health coverage. 1-76 (2015).

57. de Souza, J. A., Hunt, B., Asirwa, F. C., Adebamowo, C. \& Lopes, G. Global Health Equity: Cancer Care Outcome Disparities in High-, Middle-, and Low-Income Countries. Journal of Clinical Oncology 34, 6-13 (2016).

58. Bray, F., Jemal, A., Grey, N., Ferlay, J. \& Forman, D. Global cancer transitions according to the Human Development Index (2008-2030): a population-based study. Lancet Oncol. 13, 790-801 (2012). 
59. Boyle, P. \& Levin, B. International Agency of Research Against Cancer: World cancer report 2008. (... Agency of Research Against Cancer: World ..., 2008).

60. Daniels, N. Equity of Access to Health Care: Some Conceptual and Ethical Issues. The Milbank Memorial Fund Quarterly. Health and Society 60, 51 (1982).

61. Whitehead, M. The concepts and principles of equity and health. Int J Health Serv 22, 429-445 (1992).

62. Levesque, J.-F., Harris, M. F. \& Russell, G. Patient-centred access to health care: conceptualising access at the interface of health systems and populations. International Journal for Equity in Health 12, 1-1 (2013).

63. Ferlay, J. et al. Cancer incidence and mortality worldwide: sources, methods and major patterns in GLOBOCAN 2012. Int. J. Cancer 136, E359-86 (2015).

64. Lam, K.-O. et al. Global Pattern of Nasopharyngeal Cancer: Correlation of Outcome With Access to Radiation Therapy. Int. J. Radiat. Oncol. Biol. Phys. 94, 1106-1112 (2016).

65. Adham, M. et al. Nasopharyngeal carcinoma in Indonesia: epidemiology, incidence, signs, and symptoms at presentation. Chin J Cancer-(2012). doi:10.5732/cjc.011.10328

66. Goss, P. E., Lee, B. L. \& Badovinac-Crnjevic, T. Planning cancer control in Latin America and the Caribbean. The Lancet (2013). doi:10.1016/S1470-2045(13)70048-2

67. Enwerem-Bromson, N. \& Abdel-Wahab, M. Expanding global access to radiotherapy: the IAEA perspective. 1-2 (2015). doi:10.1016/S1470-2045(15)00287-9

68. Jaffray, D. A. et al. Global Task Force on Radiotherapy for Cancer Control. 1-3 (2015). doi:10.1016/S1470-2045(15)00285-5

69. Weng, F. K. Radiotherapy in southeast Asia: room to grow. 1-2 (2015). doi:10.1016/ S1470-2045(15)00291-0

70. Coleman, C. N. \& Minsky, B. D. The verdict is in: the time for effective solutions to the global cancer burden is now. 1-2 (2015). doi:10.1016/S1470-2045(15)00276-4

71. Coburn, C. \& Collingridge, D. The intersection of global health with cancer control. 1-1 (2015). doi:10.1016/S1470-2045(15)00297-1

72. Xiao, C. et al. Long-term results of concurrent chemoradiotherapy for T3/T4 locally advanced nasopharyngeal carcinoma. Mol Clin Oncol 1, 507-510 (2013).

73. Song, C. H. et al. Treatment outcomes for radiotherapy alone are comparable with neoadjuvant chemotherapy followed by radiotherapy in early-stage nasopharyngeal carcinoma. The Laryngoscope 118, 663-670 (2008).

74. Su, S.-F. et al. Long-term outcomes of early-stage nasopharyngeal carcinoma patients treated with intensity-modulated radiotherapy alone. Int. J. Radiat. Oncol. Biol. Phys. 82, 327-333 (2012).

75. Hall, N. et al. Symptom appraisal and healthcare-seeking for symptoms suggestive of colorectal cancer: a qualitative study. BMJ Open 5, e008448 (2015).

76. Mostert, S. et al. Socio-economic Status Plays Important Roles in Childhood Cancer Treatment Outcome in Indonesia. Asian Pac. J. Cancer Prev. 13, 6491-6496 (2012).

77. Sitaresmi, M. N., Mostert, S., Schook, R. M., Sutaryo \& Veerman, A. J. P. Treatment refusal and abandonment in childhood acute lymphoblastic leukemia in Indonesia: an analysis of causes and consequences. Psycho-Oncology 19, 361-367 (2010).

78. Farooqui, M. et al. Complementary and Alternative Medicine (CAM) use by Malaysian oncology patients. Complementary and alternative medicine 18, 114-120 (2012).

79. Muhamad, M., Merriam, S. \& Suhami, N. Why breast cancer patients seek traditional healers. International Journal of Breast Cancer 2012, 689168-9 (2012).

80. Kwong, D. L. et al. The effect of interruptions and prolonged treatment time in radiotherapy for nasopharyngeal carcinoma. Radiation Oncology Biology 39, 703-710 (1997). 
81. Chen, Z., King, W., Pearcey, R., Kerba, M. \& Mackillop, W. J. The relationship between waiting time for radiotherapy and clinical outcomes: a systematic review of the literature. Radiother Oncol 87, 3-16 (2008).

82. Kristina, S. A., Endarti, D. \& Thavorncharoensap, M. Burden of cancer attributable to tobacco smoking in member countries of the Association of Southeast Asian Nations (ASEAN), 2012. Cancer Epidemiol 44, 84-90 (2016).

83. WHO global report on trends in prevalence of tobacco smoking 2015. 1-359 (2015).

84. Xie, W.-C., Chan, M.-H., Mak, K.-C., Chan, W.-T. \& He, M. Trends in the incidence of 15 common cancers in Hong Kong, 1983-2008. Asian Pac. J. Cancer Prev. 13, 3911-3916 (2012).

85. Lee, A. W. M. et al. Changing epidemiology of nasopharyngeal carcinoma in Hong Kong over a 20-year period (1980-99): an encouraging reduction in both incidence and mortality. Int. J. Cancer 103, 680-685 (2003).

86. Hsu, C. et al. Difference in the incidence trend of nasopharyngeal and oropharyngeal carcinomas in Taiwan: implication from age-period-cohort analysis. Cancer Epidemiol. Biomarkers Prev. 15, 856-861 (2006).

87. Nyst, H. J. et al. Temoporfin mediated photodynamic therapy in patients with local persistent and recurrent nasopharyngeal carcinoma after curative radiotherapy: a feasibility study. Photodiagnosis Photodyn Ther 9, 274-281 (2012).

88. Stoker, S. D. et al. Photodynamic therapy as salvage therapy for patients with nasopharyngeal carcinoma experiencing local failures following definitive radiotherapy. Photodiagnosis Photodyn Ther 1-18 (2015). doi:10.1016/j.pdpdt.2015.04.005 
Nasopharyngeal Carcinoma (NPC) is a rare malignancy in most parts of the world, with an incidence rate of less than 1 per 100000 person-years. However, in Indonesia the estimated incidence rate is 6.2 per 100000 person-years, resulting in over 15000 new cases of NPC per year. Most patients in Indonesia are diagnosed with an advanced stage of disease. Standard treatment for NPC is radiotherapy, with or without the combination of chemotherapy, depending on tumor stage. Radiotherapy consists of a total dose of 66 to 70 Gray, delivered in 33 to 35 fractions. Preferably treatment should start one month after diagnosis, and radiotherapy schedule should be without unnecessary interruptions. International literature reports 5-year survival rates reaching 70 to 80 per cent. However, the survival rates observed in our studies, performed in Indonesia, are much lower and a 2-year survival rate around 50 per cent was found.

The overall aim of this thesis was to identify reasons for delayed diagnosis and poor treatment outcome, in Indonesia. We differentiated three types of delay during the time between the onset of symptoms and the end of the treatment, namely; patient delay, doctor's delay and system delay. Each type of delay has its own key influencing factors that effect a timely diagnosis. In the first section, relating to patient delay, the patient's behavior was evaluated. In the second section, regarding doctor's delay, we evaluated the knowledge of doctors and paramedics working in the primary health care centers. An education program was introduced and the effect of the training, on the short and long term, was measured. The third section focuses on system delay including the referral system, the waiting time to treatment (radiotherapy), and evidence for prolonged treatment times.

However, first in chapter 2 the current situation of treatment delay and clinical outcome after treatment is discussed. All patient data described refers to patients treated at the dr. Sardjito Hospital in Yogyakart Indonesia.

The study descibired in Chapter 2 was performed between September 2008 and January 2011 at the dr. Sardjito Hospital with NPC. The study aimed to evaluate the clinical outcome after treatment for NPC. All newly diagnosed patients were deemed elegible for inclusion ( $n=188$ ). Seventy-eight patients could actually be included in the study. The main reason for exclusion was the patient's insufficiency for funding for the treatmentcosts. The median waiting time to start radiotherapy exceeded 4 months. The median treatment duration was more than 62 days, which should be 
45 days in most favorable circumstances. Directly after treatment 29 per cent of the patients showed complete remission. An equal number of patients had died before the treatment response could be assessed. Patients showed a median overall survival of 21 months from the moment of diagnosis. Possible explanations for these poor treatment outcome were the advanced stage at diagnosis, long waiting time for radiotherapy and the prolonged treatment time due to interruptions. Interesting to mention is that at inclusion, more than $50 \%$ of the patients were excluded for this study, since they never started treatment.

\section{Patient delay}

Chapter 3 focuses on NPC patients' healthcare-seeking behavior. In-depth interviews with newly diagnosed patients showed that patients have limited knowledge regarding NPC. The average delay was 6 months before seeking medical help. Other barriers for these patients were the complexity of the referral system and the fact that non-direct medical costs, i.e. transportation, were not covered by the health insurance. However, the new health insurance introduced in 2014 did motivate these patients to seek medical help. We found that patients were strongly bound to their Javanese culture and therefore we believe that any community-based intervention should take these cultural aspects into account in order to succeed.

The usage of traditional, complementary and alternative medicine (TCAM) is an important aspect ingrained in the Indonesian culture and may a play role in patient's behavior. To get more insight in the actual TCAM usage and its role in causing delay in seeking conventional medical help, we set up the study discussed in chapter 4. We used questionnaires for newly diagnosed NPC patients. These questionnaires were designed based on a desk-study. In total, 142 NPC patients were included in the study. All visited the Ear, Nose and Throat (ENT) department between November 2013 and January 2015. Over 82 per cent of the patients used traditional products or procedures in the period before diagnosis. Patients who had not used any form of traditional products or visited tradionional healers were diagnosed significantly earlier. The mean delay for those who never used TCAM was 24 weeks versus 41 weeks for those who used TCAM ( $p=0.03$ ). Most of the patients did not disclose this TCAM usage to their doctors as either they felt their doctors may take a disparaging view of its use or due to the fact they were not aware they should disclose this to their doctor. 


\section{Doctor's delay}

Another key factor in the referral process is the medical doctor working in the primary health care center. This doctor is the first who has to recognize the symptoms of NPC and refer the patient to the right next doctor for further evaluation. This should be the ENT department of a hospital. Knowledge about the disease is essential in these. Chapter $\mathbf{5}$ describes the knowledge of doctors working in the primary health care centres. In total 106 doctors from three different districts in the province Yogyakarta participated by completing a questionnaire. This study revealed that the knowledge about NPC of doctors working in the primary health care centers was limited. Furthermore, they were interested in additional education. The next step was to evaluate what would be the most effective training method to ensure that in the near future patients with NPC-like symptoms can be referred properly and with an earlier stage of disease.

Chapter 6 describes the different training methods that were evaluated among primary health care centers in Jakarta. We compared training at the primary health care centers for a small number of persons with a bigger symposium where over 100 persons participated. The training at the primary health care centers consisted of a lecture focusing on several aspects of NPC, especially on early symptoms and best referral strategy. The symposium consisted of a lecture and additional training on physical examination of the head and neck. All participants completed the same questionnaire as used before in chapter 5 before and directly after the training. Participants attended a training at their primary health care center showed more improvement of knowledge than those attending the symposium. However, by organizing a bigger symposium more people could be reached at the same time. In conclusion, both types of training had a positive effect of the knowledge of doctors working in the primary health care centers. These results have encouraged us to continue with an NPC awareness program.

This NPC awareness program was held several times in Jakarta, Yogyakarta and Surabaya, and was designed such that many health care workers could be easily reached (chapter 7). Doctors were invited to attend the NPC awareness symposium and to complete a questionnaire before and at the end of the symposium. After the symposium, they had the obligation to train their colleagues at the primary health care center within one month. Not only the doctors were trained, also paramedics 
working in the primary health care centers were trained. Nurses and midwives play a key role in primary health care, often taking over the doctor's tasks. Therefore, it was of great importance to train them as well. They were not included in the symposiums but rather were trained at their primairy health care centre by the doctors who had attanded the NPC symposium. All participants of this so-called train the trainer program completed the same questionnaire before and afterwards. A year and a half later, we returned to the same primary health care centers in the province of Yogyakarta to measure the effect of the training. People/centers who had joined the training had still a better knowledge compared to those who never attended any form of training. However, knowledge levels were lower in comparison to those directly after the training. We concluded that the NPC awareness program is an effective tool to increase the knowledge of health care workers working in the primary health care center. That being said, follow-up training on a regular basis would be necessary to maintain a high knowledge level.

\section{System delay}

The last two chapters focus on the delay related to the health care system. Suggestions for the poor clinical outcomes after treatment, discussed in chapter 2 are a long waiting time to treatment, and the poor treatment schedule due to interruption of radiatherpy resulting in prolonged treatment time. In chapter 8 a prospective study is presented wherein we looked in more detail at the possible causes of the long waiting time and prolonged treatment time. In this study the waiting time to treatment was set as the interval from the day of a biopsy proven NPC until the start date of radiotherapy, and the overal treatment time from the first till last day of radiotherapy. Sixty-eight patients were included in this study. The median waiting time exceeded 3.5 months. The mean overall treatment time was 57 days, which is 10 to 12 days longer than treatment under ideal circumstances. Reasons for prolonged treatment time was often (in more than 40 per cent of the cases) related to malfunctioning of the radiotherapy facilities.

Chapter 9 focuss on the study where we looked at the effect of the prolonged treatment time on clinical outcome. In total, 142 patients who received (chemo-) radiotherapy in a curative intent schedule were included. Clinical outcome was defined by the parameters; therapy response, local-regional control, disease free survival and overall survival. Patients with a complete response had an equal median 
overall treatment time as patients with an incomplete response, namely 58 days. Although it was expected that those with a prolonged treatment time would have poorer treatment outcomes, no correlation was found between overall treatment time and clinical outcome. This result may be explained by the low number of patients who finished treatment within the recommended 7 weeks or the advanced tumor stage at the beginning of the treatment.

The Indonesian government is striving for equity in health care since the introduction of the new health insurance in January 2014. This insurance is aiming for a nationwide coverage within the next couple of years. In this way everyone should have access to health care. Though this new health insurance was not a specific topic of our study, it may have influenced our results due to the increased demand on the Indonesian health care system.

Our study shows that improvement in NPC related care is highly warranted. Improvement of clinical outcomes can only be achieved when patients decide to seek medical help at an early time-point (patient delay), doctors at the primary health care centers are aware when and to whom to refer (doctor's delay) and referred patients should be able to start and finish treatment within a reasonable timeframe (system delay). This requires a multilevel approach. New interventions are required at a community level to improve health seeking behavior and medical training is necessary to aid health care professionals in the early recognition of the symptoms, early referral and ultimately, an early diagnosis. There is also need for treatment which can be accessed in a timely fashion

The results of this thesis while relating to NPC in Indonesia can be generalized to the situation of care for other types of cancer in other low and middle income countries suffering with comparable problems. Solutions as proposed in this thesis may serve as a blue print for other type of cancer or countries who are struggling with the same problems. 

Samenvatting 
Nasopharynxcarcinoom (NPC) is een zeldzame tumor in de meeste delen van de wereld, die wereldwijd bij minder dan 1 per 100000 personen per jaar voorkomt. Het betreft een tumor in het hoofdhalsgebied die, wanneer tijdig ontdekt, goed te behandelen is. In Indonesië is de geschatte incidentie 6.2 per 100000 personen wat resulteert in meer dan 15000 nieuwe gevallen van NPC per jaar. De meeste patiënten worden gediagnosticeerd met een vergevorderd stadium van de ziekte. De standaardbehandeling voor NPC is radiotherapie, alleen of in combinatie met chemotherapie. Radiotherapie bestaat uit 33 tot 35 behandelingen met een totale dosis van 66 tot 70 Gray en moet het liefst zonder onnodige onderbrekingen worden ingezet. Bij voorkeur zou er binnen een maand na diagnose moeten worden begonnen met behandeling. Internationale literatuur laat zien dat de 5-jaarsoverleving voor patiënten die een curatieve behandeling krijgen 70 tot 80 procent is. Deze overlevingscijfers in Indonesië zijn op dit moment echter een stuk lager.

Het doel van dit proefschrift is om te kijken naar mogelijke oorzaken van de late diagnose en de slechte behandelresultaten in Indonesië. Om meer inzicht te krijgen hebben we gekeken naar drie categorieën van vertraging die een patiënt in Indonesië tegenkomt vanaf het moment van de eerste symptomen tot aan het afronden van de behandeling. Deze categorieën zijn: vertraging waarbij de patiënt een belangrijke rol speelt, vertraging waarbij de artsen een belangrijke rol spelen, en vertraging waarbij het systeem de mogelijke oorzaak is. Elk van deze categorieën heeft zijn eigen beïnvloedende factoren die het proces kunnen versnellen of juist kunnen zorgen voor extra vertraging.

In het eerste deel van dit proefschrift richten we ons op de vertraging waarbij de patiënt een belangrijke rol speelt. Hierbij hebben we gekeken naar de manier waarop patiënten met hun gezondheid omgaan, oftewel het gezondheidsgedrag van de patiënten. Het gebruik van traditionele medicijnen is één van de redenen die voor een extra vertraging kunnen zorgen bij het zoeken naar conventionele hulp. Het tweede deel van dit proefschrift beschrijft mogelijke vertraging tot aan de diagnose, veroorzaakt door het gebrek aan kennis van artsen en paramedici die werkzaam zijn in de huisartsenposten. Ook introduceerden we een onderwijsprogramma in Yogjakarta, Surabaya en Jakarta en keken we naar het effect van deze training, zowel op de korte als op de lange termijn. In het laatste deel van dit proefschrift keken we naar de mogelijke systeemvertragingen. Hierbij bekeken we de huidige 
problemen in de radiotherapie voor NPC en het effect van de lange wachttijd voor de behandeling en de lange behandelingsduur in vergelijking met de internationale standaard.

Hoofdstuk 2 beschrijft allereerst de resultaten van de studie waarbij meer inzicht werd verkregen in de behandeling en de behandelresultaten. Alle patiëntengegevens beschreven in dit proefschrift zijn afkomstig van patiënten die gediagnosticeerd en al dan niet behandeld zijn in het dr. Sardjito ziekenhuis in Yogyakarta.

Hoofdstuk 2 beschrijft de behandelresultaten van patiënten met NPC in Yogyakarta, Indonesië. Tussen september 2008 en januari 2011 zijn er in het dr. Sardjito ziekenhuis 188 patiënten met NPC gediagnosticeerd. Achtenzeventig patiënten werden geïncludeerd in deze observationele studie. Voornaamste reden voor exclusie was onvoldoende financiering van de patiënt om de behandeling te kunnen betalen. Van de patiënten die geïncludeerd werden vertoonde 29 procent direct na de behandeling een volledige remissie. Een gelijk aantal patiënten was al overleden voordat het effect van de behandeling beoordeeld kon worden. De gemiddelde wachttijd voorafgaand aan de bestraling was 4 maanden. De mediane duur van de behandeling bedroeg 62 dagen, welke in de meest gunstige omstandigheden 45 dagen zou kunnen zijn. Patiënten hadden een mediane overleving van 21 maanden gemeten vanaf het moment van diagnose. Mogelijke verklaringen voor deze korte overleving zijn de lange wachttijd totdat men kan beginnen met de radiotherapie, de lengte van de behandeling en het vergevorderde stadium van ziekte bij diagnose. In dit hoofdstuk hebben we alleen gekeken naar de patiënten die uiteindelijke behandeld werden. Meer dan 50 procent van de nieuwe gediagnosticeerde patiënten hebben überhaupt geen behandeling gekregen.

\section{Vertraging waarbij de patiënt een rol speelt}

In hoofdstuk 3 hebben we gekeken naar het gezondheidsgedrag van NPCpatiënten. Diepte-interviews met nieuw gediagnosticeerde patiënten toonden aan dat patiënten maar een beperkte kennis van de ziekte hadden voor diagnose. Deze beperkte kennis resulteerde in een gemiddelde vertraging van 6 maanden voordat men medische hulp zocht. Andere barrières voor deze patiënten waren de complexiteit van het doorverwijssysteem en het feit dat niet-directe medische kosten, zoals bijvoorbeeld het vervoer, niet gedekt werden door de zorgverzekering. Een nieuwe zorgverzekering geïntroduceerd in 2014 droeg er in veel gevallen 
aan bij dat toch medische hulp kon worden gezocht. Een andere bevinding was dat de patiënten sterk gebonden waren aan hun Javaanse cultuur. Dat uitte zich bijvoorbeeld in de relatie tussen patiënt en specialist, waarbij de patiënt zich niet kritisch durfde op te stellen, of het gebruik van alternatieve medicatie. Wij zijn daarom van mening dat een interventie op gemeenschapsniveau altijd rekening zal moeten houden met deze cultuur wil het kans van slagen hebben.

Het gebruik van traditionele, complementaire en alternatieve geneesmiddelen (TCAM) is ingeworteld in de Indonesische cultuur en kan dus een belangrijke rol spelen wanneer we kijken naar het gezondheidsgedrag van NPC-patiënten. Om meer inzicht te krijgen in het TCAM-gebruik en de mogelijke vertraging bij het zoeken naar conventionele medische hulp, hebben we gebruik gemaakt van vragenlijsten die we afnamen bij nieuw gediagnosticeerde NPC-patiënten (hoofdstuk 4). Deze vragenlijsten werden ontworpen op basis van een bureau-onderzoek. In totaal waren er 142 NPC-patiënten die een bezoek brachten aan de afdeling Keel-, Neusen Oorkunde (KNO) in het dr. Sardjito ziekenhuis tussen november 2013 en januari 2015 en bereid waren mee te doen aan de studie. Meer dan 82 procent van de patiënten gebruikte traditionele producten of procedures in de periode voordat de diagnose werd gesteld. Bij patiënten die geen enkele vorm van traditionele producten of procedures gebruikten werd significant eerder een diagnose gesteld. De gemiddelde vertraging voor degenen die nog nooit TCAM gebruikten was 24 weken, versus 41 weken voor degenen die TCAM gebruikten $(p=0.03)$. Het merendeel van de patiënten deelde niet met hun huisarts dat ze TCAM gebruikten uit angst om de arts-patiënt relatie te verstoren, of simpelweg omdat de patiënt niet bewust was van het feit dat hij TCAM gebruikte.

\section{Vertraging waarbij de (huis)arts een rol speelt}

Een andere belangrijke factor in het doorverwijzingsproces is de rol van de arts werkzaam in de huisartsenpost. Deze arts zou de symptomen van NPC moeten herkennen en indien nodig de patiënt doorverwijzen naar de afdeling KNO in het ziekenhuis voor verder onderzoek. Probleem hierbij is dat de symptomen aspecifiek zijn en op een gewone verkoudheid lijken.

Hoofdstuk 5 beschrijft de kennis van huisartsen. Dit hebben we getest met vragenlijsten die we zonder vooraankondiging aan de huisartsen in de huisartsenpost hebben voorgelegd. In totaal hebben 106 huisartsen uit drie verschillende districten 
in de provincie Yogyakarta deelgenomen. Deze studie toonde aan dat de kennis van deze huisartsen met betrekking tot NPC beperkt was. Wel waren ze geïnteresseerd in extra onderwijs betreffende dit onderwerp. De volgende stap was dan ook om te kijken wat dan de meest effectieve trainingsmethode zou zijn om de kennis van huisartsen, te verbeteren zodat in de toekomst een patiënt, met symptomen passend bij NPC, tijdig doorverwezen kan worden.

Hoofdstuk 6 beschrijft twee verschillende trainingsmethoden. Deze twee trainingsmethoden werden geëvalueerd in Jakarta. Hier vergeleken we een training in de huisartsenposten voor een klein aantal deelnemers, met een groter opgezet symposium waar meer dan honderd huisartsen aan deelnamen. De training in de huisartsenposten bestond uit een presentatie die inging op de belangrijkste aspecten van NPC. Met name kwamen aan bod: de vroege symptomen en de doorverwijzing van een patiënt met symptomen passend bij NPC. Alle deelnemers vulden voor aanvang en na afloop van de training eenzelfde vragenlijst in zoals eerder gebruikt in hoofdstuk 5. Het symposium bestond uit een vergelijkbare presentatie en een aanvullende training in lichamelijk onderzoek van hoofd en hals. Ook hier werden dezelfde vragenlijsten vooraf en na afloop ingevuld door de deelnemers. Bij de deelnemers die de training in hun eigen huisartsenpost hadden gevolgd zagen we iets meer toegenomen kennis na de training in vergelijking met de deelnemers van het symposium. Echter, door het organiseren van een groter symposium konden we meer mensen in één keer bereiken en ook zagen we bij deze training een positief effect; toegenomen kennis van de huisartsen werkzaam in de huisartsenpost. De resultaten van deze studie waren dan ook aan aanleiding voor het opzetten van het NPC-awareness programma.

Het NPC-awareness programma werd meerdere keren in onder andere Jakarta, Yogyakarta en Surabaya georganiseerd. Het programma was op zo'n manier opgezet dat met beperkte middelen toch een groot aantal mensen bereikt kon worden en bestond uit een symposium en een train-de-trainer programma (hoofdstuk 7). Huisartsen werden uitgenodigd om deel te nemen aan het NPC-awareness symposium. Na afloop van dit symposium hadden zij de verplichting om ook hun collegae, artsen en paramedici, werkzaam in de huisartsenpost te trainen. In Indonesië spelen verpleegkundigen en ook verloskundigen, dit zijn gespecialiseerde verpleegkundigen, vaak een grote rol bij eerstelijnszorg. Zij zijn verbonden aan de huisartsenposten en nemen vaak de rol van de huisarts over. We vonden het daarom 
essentieel dat ook deze groep meer zou weten over NPC. Bij zowel het symposium als de training in de huisartsenpost werden vooraf en na afloop vragenlijsten ingevuld. Anderhalf jaar na de training keerden we terug naar alle huisartsenposten in de provincie Yogyakarta om het effect van de training te meten. Uiteindelijk zagen we dat deelnemers ook anderhalf jaar later nog steeds meer wisten dan de huisartsen die nooit een training hadden gehad. De kennis was in de loop van de tijd wel afgenomen in vergelijking met de kennis direct na een training. Uiteindelijk konden we concluderen dat het NPC-awareness programma een doeltreffend instrument is om de kennis van (para-)medici die werken in de huisartsenposten te verhogen. Desalniettemin zou een follow-up awareness programma nodig zijn om dit kennisniveau te behouden.

\section{Vertraging als gevolg van het systeem}

De laatste twee hoofdstukken richten zich op de vertraging veroorzaakt door het zorgsysteem. Hierbij gaat het om de lange wachttijden, langere behandelduur en andere obstakels die een negatieve invloed kunnen hebben op de behandeling. In hoofdstuk 2 hebben we al de slechte behandelresultaten beschreven. In een nieuwe prospectieve studie beschreven in hoofdstuk 8 laten we zien dat de wachttijden voor de radiotherapie en de lengte van de behandeling te lang zijn wanneer deze vergeleken worden met de internationale standaard. De lengte van de wachttijd werd berekend vanaf de dag dat de uitslag van het biopt positief was tot aan de dag van de start van de radiotherapie. Dit interval was 3,5 maanden. Achtenzestig patiënten die daadwerkelijk de radiotherapie af hebben gerond werden in dit onderzoek geïncludeerd. De gemiddelde duur van de behandeling was 57 dagen, dat is 10 tot 12 dagen langer dan de behandeling onder ideale omstandigheden zou duren. In meer dan 40 procent van de gevallen was de oorzaak van de vertraging gerelateerd aan de planning en het niet functioneren van de radiotherapiefaciliteiten.

Hoofdstuk 9 presenteert de resultaten van onze studie waarin we keken naar het effect van deze langere behandelduur op de klinische uitkomst. In totaal werden 142 patiënten geïncludeerd bij wie een curatieve behandeling was gestart. Klinische resultaten waren therapierespons, locoregionale controle, ziektevrije overleving en de totale overleving. Patiënten met een volledige respons hadden een gelijke mediane behandelduur als patiënten met een niet volledige respons, namelijk 58 dagen. Hoewel de verwachting was dat mensen met een langere behandelduur een 
slechtere klinische respons zouden hebben, werd geen correlatie gevonden. Dit kan mogelijk worden verklaard door het kleine aantal patiënten die de behandeling binnen de aanbevolen periode afrondden, of het vergevorderde stadium van ziekte voor aanvang van de behandeling.

\section{Conclusie}

Sinds de invoering van een nieuwe zorgverzekering in januari 2014 streeft de Indonesische overheid naar gelijkheid in de gezondheidszorg. Binnen een paar jaar moet er sprake zijn van een landelijke dekking, zodat gezondheidszorg voor iedereen toegankelijk wordt. Hoewel de nieuwe zorgverzekering geen onderdeel was van onze studie heeft het mogelijk onze resultaten beïnvloed door een toegenomen vraag naar zorg.

Onze studies tonen aan dat de verbetering van de kankerzorg, met name voor NPC noodzakelijk is. Ook tonen de studies aan dat een verbetering van de klinische resultaten alleen kan worden bereikt wanneer patiënten besluiten om tijdig medische hulp te zoeken, huisartsen zich bewust zijn wanneer en naar wie ze patiënten moeten doorverwijzen en wanneer een patiënt gediagnosticeerd is met NPC hij dat ook binnen een redelijke termijn kan beginnen aan de behandeling en deze daadwerkelijk af kan maken. Dit vereist een gelijktijdige aanpak op verschillende niveaus. Nieuwe interventies zijn nodig om dit te bereiken. Deze interventies moeten plaatsvinden op gemeenschapsniveau en in de huisartsenposten. Tegelijkertijd moeten er -wanneer de patiënt gediagnosticeerd is met een vroeg stadium van ziekte -voldoende behandelmogelijkheden zijn om de behandeling naar behoren af te ronden.

Op basis van literatuur, denken wij dat de resultaten uit dit proefschrift zich niet beperken tot NPC of Indonesië. Ze weerspiegelen de situatie van de zorg voor andere vormen van kanker in andere lage en middeninkomens landen met vergelijkbare problemen. Oplossingen zoals in dit proefschrift voorgesteld zouden kunnen dienen als een blauwdruk voor andere vormen van kanker of voor andere landen die worstelen met dezelfde problemen. 

Kanker Nasofarings (KNF) adalah penyakit keganasan yang jarang terjadi pada sebagian besar belahan dunia, dengan tingkat kejadian kurang dari 1 per 100.000 orang setiap tahun. Namun, di Indonesia diperkirakan tingkat kejadiannya adalah 6,2 yang mengakibatkan lebih dari 15.000 kasus baru KNF per tahun. Pengobatan standar KNF adalah radioterapi, tunggal atau dikombinasikan dengan kemoterapi, tergantung pada stadium tumor. Pengobatan sebaiknya mulai dilaksanakan satu bulan setelah diagnosis, dan radioterapi diberikan tanpa interupsi. Literatur internasional melaporkan bahwa tingkat kelangsungan hidup 5 tahun mencapai 70 sampai 80 persen dengan pengobatan kuratif. Namun, pengamatan tingkat kelangsungan hidup yang dilakukan dalam studi kami di Indonesia ini jauh lebih rendah dengan tingkat kelangsungan hidup 2 tahun sekitar 50 persen.

Tujuan keseluruhan tesis ini adalah untuk mengidentifikasi penyebab keterlambatan diagnosis dan hasil pengobatan yang yang buruk, khususnya hambatan bagi para pasien KNF. Untuk mendapatkan pemahaman yang lebih mendalam pada keterlambatan diagnosis KNF, kami membedakan tiga jenis keterlambatan dari timbulnya gejala sampai akhir pengobatan yaitu: keterlambatan pasien, keterlambatan dokter dan keterlambatan sistem. Setiap jenis keterlambatan memiliki faktor yang berpengaruh pada proses diagnosis yaitu mempercepat atau menyebabkan keterlambatan tambahan. Pada bagian pertama tentang keterlambatan pasien, perilaku pasien dievaluasi. Pada bagian kedua tentang keterlambatan dokter, kami mengevaluasi pengetahuan dokter dan paramedis yang bekerja di pusat kesehatan masyarakat, memperkenalkan program pendidikan dan mengukur efek dari pelatihan jangka pendek dan panjang. Bagian ketiga berfokus pada keterlambatan sistem termasuk sistem rujukan yang kompleks, waktu tunggu untuk radioterapi, dan bukti bertambah panjangnya waktu pengobatan.

Bab 2 menjelaskan hasil pengobatan pasien KNF di Yogyakarta, Indonesia. Dalam kurun waktu antara September 2008 sampai dengan Januari 2011, terdapat 188 pasien di Rumah Sakit Dr Sardjito dengan KNF. Tujuh puluh delapan pasien dimasukkan dalam penelitian ini. Alasan utama eksklusi adalah pasien kekurangan dana. Segera setelah pengobatan, 29 persen dari pasien menunjukkan remisi lengkap (respon komplit= complete response). Jumlah yang sama pula, pasien meninggal sebelum pengobatan dapat dikaji. Rata-rata waktu tunggu sebelum dimulainya radioterapi melebihi 4 bulan. Durasi pengobatan lebih dari 62 hari, yang seharusnya 45 hari. Pasien menunjukkan kelangsungan hidup secara keseluruhan 
rata-rata 21 bulan dari saat terdiagnosis. Alasan yang paling mungkin adalah karena waktu pengobatan yang bertambah panjang, lamanya waktu tunggu untuk radioterapi dan stadium lanjut pada saat terdiagnosis. Artikel ini difokuskan pada pasien yang benar-benar memulai pengobatan, oleh sebab itu lebih dari 50 persen dari pasien yang baru terdiagnosis dieksklusi, karena tidak mendapat pengobatan apapun setelah terdiagnosis. Ternyata hasil pengobatan yang buruk tidak hanya bergantung pada pengobatan yang diterima tetapi juga pada penyebab lain seperti keterlambatan pasien, keterlambatan dokter dan keterlambatan sistem.

\section{Keterlambatan Pasien}

Bab 3 fokus pada perilaku pencarian layanan kesehatan pasien KNF. Wawancara mendalam dengan pasien yang baru didiagnosis menunjukkan bahwa pasien memiliki pengetahuan yang terbatas tentang KNF. Pengetahuan yang terbatas ini mengakibatkan keterlambatan rata-rata 6 bulan sebelum mencari bantuan medis. Hambatan lain untuk pasien ini adalah kompleksitas sistem rujukan dan fakta bahwa biaya non-medis, yaitu transportasi, tidak ditanggung oleh asuransi kesehatan. Namun, asuransi kesehatan baru yang diperkenalkan pada tahun 2014 tidak memotivasi pasien untuk mencari bantuan medis. Kami menemukan bahwa pasien sangat terikat dengan budaya Jawa dan oleh karena itu kami percaya bahwa setiap intervensi berbasis masyarakat harus mempertimbangkan penggunaan aspek-aspek budaya agar berhasil.

Penggunaan obat tradisional, komplementer dan alternatif (TCAM) adalah salah satu aspek penting yang tertanam dalam budaya Indonesia dan berperan penting dalam perilaku pasien. Untuk mendapatkan wawasan lebih luas dalam penggunaan TCAM dan kemungkinan penundaan dalam mencari bantuan medis konvensional, kami menggunakan kuesioner untuk pasien KNF baru terdiagnosis (bab 4). kuesioner ini dirancang berdasarkan studi literatur. Total 142 pasien KNF di Bagian THT-KL antara November 2013 dan Januari 2015 yang dimasukkan dalam penelitian ini. Lebih dari 82 persen dari pasien menggunakan produk atau pengobatan tradisional pada periode sebelum diagnosis. Pasien yang tidak menggunakan segala bentuk produk atau pengobatan tradisional secara signifikan didiagnosis lebih cepat. Rerata Penundaan bagi mereka yang tidak pernah menggunakan TCAM adalah 24 minggu dibandingkan 41 minggu bagi mereka yang digunakan TCAM ( $p=0,03$ ). Sebagian besar pasien tidak mengungkapkan penggunaan TCAM ini pada dokter 
untuk mempertahankan hubungan dokter-pasien yang baik atau karena mereka tidak menyadari bahwa mereka seharusnya mengungkapkan hal ini kepada dokter.

\section{Keterlambatan Dokter}

Faktor lain dalam proses rujukan adalah dokter yang bekerja di Pusat Kesehatan Masyarakat (Puskesmas). Dokter ini harus mengenali gejala KNF dan merujuk pasien ke Rumah Sakit untuk mendapatkan pemeriksaan lebih lanjut. Bab 5 menjelaskan pengetahuan dokter-bekerja di Puskesmas dengan mengisi kuesioner mengenai KNF. Total 106 dokter dari tiga Kabupaten yang berbeda di Provinsi Yogyakarta ikut berpartisipasi. Studi ini mengungkapkan bahwa pengetahuan KNF pada dokter yang bekerja di Puskesmas sangat terbatas. Tetapi mereka sangat tertarik untuk mendapatkan tambahan pengetahuan. Langkah selanjutnya adalah mempertimbangkan metode pelatihan yang paling efektif untuk diberikan.

Bab 6 menjelaskan metode pelatihan yang berbeda, yang dilakukan pada beberapa Puskesmas di Jakarta. Kami membandingkan peserta yang mengikuti pelatihan di Puskesmas dalam jumlah orang yang lebih sedikit dibandingkan dengan seminar dengan jumlah yang lebih dari 100 orang. Pelatihan di Puskesmas terdiri dari pengajaran yang difokuskan pada semua aspek KNF, terutama pada gejala awal dan strategi rujukan yang tepat. Seminar terdiri dari pengajaran dan pelatihan tambahan pada pemeriksaan fisik pada kepala dan leher. Peserta yang mengikuti pelatihan di Puskesmas menunjukkan peningkatan pengetahuan yang lebih daripada peserta yang hadir dalam seminar besar. Namun, dengan mengadakan seminar yang lebih besar, lebih banyak orang yang dapat diraih dalam satu waktu. Sebagai kesimpulan, kedua jenis pelatihan mempunyai efek positif pada pengetahuan para dokter yang bekerja di Puskesmas. Untuk itu, hasil dari studi ini mendorong kami untuk melanjutkan program kewaspadaan KNF.

Program kewaspadaan KNF diselenggarakan di Jakarta, Yogyakarta dan Surabaya selama beberapa kali, dan didesain dengan sedemikian rupa sehingga para pekerja kesehatan dengan mudah dapat ikut serta. (bab 7). Tidak hanya para dokter yang dilatih, tetapi juga paramedis yang bekerja di Puskesmas. Perawat dan bidan juga memiliki peranan penting di Puskesmas, karena sering menggantikan tugas para dokter. Oleh sebab itu, sangat penting untuk melatih mereka juga. Para dokter diundang untuk menghadiri seminar kewaspadaan KNF dan mengisi kuesioner sebelum dan sesudah seminar berlangsung. Setelah seminar selesai, mereka 
diwajibkan untuk melatih rekan kerja mereka di Puskemas dalam jangka waktu satu bulan. Peserta dalam pelatihan yang disebut program Melatih Pelatih ini juga mengisi kuesioner yang sama sebelum dan sesudah pelatihan. Satu setengah tahun kemudian, kami kembali di Puskesmas yang sama di Propinsi Yogyakarta untuki menilai efek dari pelatihan sebelumnya. Orang-orang yang pernah mengikuti pelatihan masih memiliki pengetahuan yang lebih baik daripada mereka yang tidak pernah menghadiri pelatihan apapun. Tetapi, penilaian tingkat pengetahuan lebih rendah dibandingkan dengan yang dilakukan langsung setelah pelatihan. Kami menyimpulkan bahwa program kewaspadaan adalah alat yang efektif untuk meningkatkan pengetahuan para pekerja kesehatan yang bekerja di Puskesmas. Namun, pelatihan lanjutan secara reguler sangat penting untuk tetap menjaga tingginya tingkat pengetahuan.

\section{Keterlambatan sistem}

Dua bab terakhir fokus pada keterlambatan yang disebabkan oleh sistem kesehatan. Hal ini termasuk lamanya waktu tunggu, bertambah panjangnya waktu pengobatan dan hambatan lain yang mempunyai pengaruh negatif pada pengobatan. Pada bab 2, kami telah menjelaskan hasil pengobatan yang buruk. Dalam studi dengan prospektif baru yang disajikan pada bab 8 kami melihat lebih detil pada kemungkinan penyebab lamanya waktu tunggu dan bertambah panjangnya waktu pengobatan. Pada studi ini, interval dihitung dari hari sejak terdiagnosis dengan bukti hasil biopsi sampai hari dimulainya radioterapi. Waktu Interval melebihi waktu 3,5 bulan. Enam puluh delapan pasien yang sudah menyelesaikan radioterapi dimasukkan kedalam studi ini. Waktu pengobatan secara keseluruhan adalah 57 hari, melebihi 10 sampai 12 hari untuk waktu ideal pengobatan. Alasan penambahan waktu pengobatan ini lebih sering (lebih dari 40 persen dari keseluruhan kasus) berhubungan dengan gangguan pada fungsi fasilitas radioterapi.

Bab 9 menjabarkan hasil studi kami yaitu melihat efek penambahan waktu pengobatan pada luaran klinis. Secara keseluruhan, 142 pasien diobati dengan pengobatan kuratif diinklusi. Luaran klinis terdiri dari respon terapi, kontrol lokalregional, kelangsungan hidup bebas penyakit dan kelangsungan hidup secara keseluruhan. Pasien dengan respons komplit mempunyai waktu pengobatan keseluruhan yang rata-rata sama dengan pasien yang tidak lengkap responsnya, yaitu 58 hari. Walaupun diharapkan bahwa mereka yang mendapatkan perpanjangan 
waktu pengobatan akan mempunyai hasil pengobatan yang lebih buruk, tidak ada korelasi yang ditemukan antara waktu pengobatan secara keseluruhan dan luaran klinis. Hal ini mungkin dapat dijelaskan dengan rendahnya jumlah pasien yang menyelesaikan pengobatan dalam yang waktu 7 minggu yang direkomendasikan atau tingkat stadium lanjut pada saat pengobatan dimulai.

Pemerintah Indonesia sedang berjuang untuk kesetaraan dalam hal jaminan kesehatan sejak diperkenalkannya asuransi kesehatan yang baru pada bulan Januari 2014. Asuransi ini bertujuan untuk dapat memiliki cakupan keseluruh negeri dalam beberapa tahun mendatang. Dengan cara ini setiap orang harus memiliki akses ke jaminan kesehatan. Meskipun asuransi kesehatan yang baru ini bukanlah topik spesifik dari penelitian kami, hal ini mungkin mempengaruhi hasil kami karena meningkatnya permintaan dalam sistem jaminan kesehatan Indonesia.

Studi kami menunjukkan bahwa perbaikan dalam pengobatan kanker, terutama untuk KNF sangat diperlukan. Peningkatan luaran klinis hanya dapat dicapai jika pasien memutuskan untuk mencari bantuan medis di awal waktu (keterlambatan pasien), dokter di pusat kesehatan masyarakat mengetahui kapan dan kepada siapa dalam merujuk pasien (keterlambatan dokter) dan setelah dirujuk, pasien harus dapat memulai dan menyelesaikan pengobatan dalam jangka waktu yang tepat (keterlambatan sistem). Semua Ini membutuhkan pendekatan dalam berbagai tingkat. Cara intervensi baru dibutuhkan untuk meningkatkan luaran klinis dan fokus pada perilaku pasien, penemuan gejala awal, rujukan dini dan diagnosis dini. Dibutuhkan pula pilihan pengobatan dan kesempatan untuk mendiagnosis pasien pada stadium awal.

Hasil tesis ini tidak spesifik untuk KNF atau Indonesia, tapi juga mencerminkan kemungkinan besar situasi pengobatan untuk kanker jenis lain di negara belum berkembang dan negara berkembang lainnya yang mempunyai masalah yang sama. Solusi yang diusulkan dalam tesis ini dapat digunakan sebagai kerangka kerja bagi negara lain yang berjuang dengan masalah yang sama. 
Knowledge valorization implies the transfer of scientific knowledge into daily practice. This chapter describes how the science community and health staff in Indonesia might benefit from our scientific findings presented in this dissertation.

\section{Relevance}

Indonesian health care is undergoing major changes in the last few years. Since the introduction of the new health care insurance in January 2014, Indonesia is striving for equity in health care. However, Indonesia is facing an imbalance between supply and demand for this health care. Patients diagnosed with nasopharyngeal carcinoma (NPC) in Indonesia encounter many challenges before diagnosis and completion of the treatment. Prior to diagnosis patients are often not aware of the first symptoms of the disease, do not know where to seek medical help or lack the financial means to do so. Upon engaging with primary care many patients are not appropriately referred, as some medical doctors are not aware of the severity of the disease. Once diagnosed patients have to deal with an inefficient and convoluted referral system.

Indonesian cancer care is decentralized and a nation-wide cancer registry does not exist. For that reason, survival rates and incidence rates are often estimates. The first survival rates of NPC patients included in our studies in Yogyakarta in Indonesia revealed lower figures than presented in international literature.

When patients do not finish their treatment it might affect their treatment response. Or in case they start curative treatment when cure is not possible anymore, it may only do harm and valuable places for treatment for those who could be cured are occupied. Better referral, communication and follow-up could prevent this.

We predict that the ongoing research in Yogyakarta will reveal that the waiting time for radiotherapy for any form of cancer is only increasing. Patients diagnosed in October 2016 are planned for treatment by November 2019. Suffice to say that this may well be too late for most patients with advanced NPC. Improvement in the access to health care is required and this access not only entails sufficient available facilities, but also well trained doctors, affordable treatment and community awareness. 
This thesis focused on the current problems in the diagnosis and treatment of NPC and has revealed the necessity of a multilevel approach encompassing patient awareness, primary health care education and an expansion of tertiary care facilities in order to facilitate an improvement in treatment results.

\section{Target groups}

The results presented in this dissertation focus on NPC. However, this dissertation can function as a blue print for other types of cancer in Indonesia or in fact also for other low and middle-income countries, struggling with comparable problems, in the cancer care system. The findings of this dissertation can be of interest to many institutions and agencies working in the field of cancer. It may be helpful for civil society groups, including non-governmental organizations to provide cancer awareness on a community or professional level. In order to place cancer awareness and improvement of cancer care on the agenda of the policy makers, evidence of the problem is needed to convince key persons to invest time, money and personnel.

\section{Implementations}

The output as described in the dissertation is the results of a longstanding collaboration between the NPC research team in Jakarta, Yogyakarta, Surabaya and The Netherlands. Continuation of the projects is guaranteed with the introduction of new stakeholders from different institutes.

Based on the interviews with the patients as described in chapter $\mathbf{3}$ it became clear people with NPC-like symptoms often did not want to be referred to the Dr. Sardjito hospital for a variety of reasons. For those who refused referral, a new intervention was implemented. In ongoing research patients are offered to have a biopsy taken in the district hospital in Wonosari, one of the districts of the province Yogyakarta. Preliminary results show that over 30 per cent of the participants who originally refused a biopsy were diagnosed with an advanced stage of NPC. This proves the importance of community-based activities creating more awareness among community and primary health care workers. These patients would most probably not have been diagnosed if biopsies were not offered in a smaller, more accessible hospital. 
In addition, a collaboration between Dr. Sardjito hospital, the district hospital in Wonosari (province Yogyakarta) and the district hospital in regency Banyumas (province central Java), will show the effect of the introduction of a trans-oral brush as a novel screening tool. The aim of this collaboration is to start a study to determine whether trans-oral brushing and quantitative Epstein-Barr virus (EBV) PCR is sensitive and specific enough to become a screening test for nasopharyngeal carcinoma in a risk stratified Indonesian population.

The NPC awareness symposium introduced in this dissertation is a great example of an education program that can be implemented in a cost effective way. With limited resources, many health professionals working in the primary health care centers can be reached, by using the train-the-trainer system. Continuation of this program would be of great value. Based on the NPC awareness program, additional education for medical students on NPC was introduced at the Gadjah Mada University in Yogyakarta. This is a preliminary step; we need to strive for additional training nationwide.

In this dissertation we investigated the possible causes for the patient delay. We introduced an NPC awareness program for doctors to decrease doctor's delay and we revealed the possible causes of poor treatment outcome taking the system delay into account. The biggest challenge will be the changes needed on a system delay level. This dissertation shows the need for a massive increase and improvement of radiotherapy resources.

\section{Innovation}

Our findings that improvement of cancer care requires interventions on multiple levels, is the innovative conclusion that we have arrived to in this dissertation. This implies that effort should be put in all the different levels within the cancer care system. So that once a patient is diagnosed with an early stage of disease, a delay of 3 years to treatment can be prevented.

The availability of the right level of resources is a major obstacle, and once this obstacle is removed we have to ensure that people with suspected NPC will seek medical help and will be diagnosed in time for early start of curative treatment. 


\section{Other possible implementations}

On a community-based level we now have more insight into patient behavior so interventions should focus on the biggest obstacles to not seeking medical help. Any form of community-based intervention should take into account the cultural nuances of Indonesian engagement with healthcare and focus on health literacy. Community members should be aware when to seek medical help but also where to seek medical help. As suggested in this dissertation the development of simple infographics can be of great help.

The implementation of a better communication system could have a direct effect on all three levels of delay as defined in this dissertation (patient delay, doctor's delay and system delay). Currently we are developing a mobile application to improve the communication between the communities, patients, doctors and specialists. Difficulties during our studies were the often changing mobile numbers of our patients. This mobile application could avoid loss to follow-up. It could be used as a NPC awareness tool for both patients as well as for (para-)medics working in the primary health care centers and function as a tool to provide information regarding treatment and resources available. In this way, unnecessary traveling can be avoided and reminders can be sent when patients are required to attend the hospital. Also, this mobile application can provide the information required to convince local government to invest in better and more resources for cancer patients.

Findings as described in this dissertation together with our future findings may contribute to recommendations to improve cancer care. Our results strengthen the idea that on all the levels in cancer care e.g. patient delay, doctor's delay and system delay improvement is needed. All of our publications are open access publications to ensure anyone interested in this field can access our information. 

En dan in ene is het zover en is dit proefschrift af en nog sneller dan verwacht.

Onderzoek doen doe je nooit alleen en ik ben dan ook blij dat ik eindelijk de kans krijg om iedereen te bedanken die de afgelopen jaren met me samengewerkt hebben, me uit de brand of uit de put hebben geholpen, of diegene die me wisten te motiveren, te stimuleren en uit te dagen.

Mijn promotor, professor Tan. Beste Bing, weet niet waar ik moet beginnen, maar ik wil je danken voor al je vertrouwen en support. Hoofd-hals chirurg zal ik wel nooit worden, maar er zijn een hoop andere dingen die ik van jou heb kunnen leren. Ik heb dan ook enorm veel bewondering voor de manier waarop jij tegen dingen aankijkt en weet te relativeren. Als je dingen maar vanuit de juiste hoek bekijkt dan is er altijd wel een zonnige kant. Wat was/ is het mooi om deel uit te maken van jouw team. Ik heb genoten van onze vakanties in Indonesië. Never a dull moment.

Mijn copromotor, Marjanka Schmidt. Lieve Marjanka, hoe bijzonder is het dat jij, als borstkanker specialist, dit project wilde doen (en met name dat je er tijd voor had) en dat je nu mijn copromotor bent. Als geen ander weet je hoe het is om onderzoek in Indonesië te doen. Dank voor je kritische, maar altijd duidelijke commentaar, waardoor ik mijn oogkleppen weer eens af kon zetten.

My copromotor, professor Haryana. Dear prof Rika, thank you for your unlimited support and the fact that you always had time for me even when I walked in unannounced. I hope we will continue our collaborations in the future.

De leden van de promotiecommissie:

Prof. dr. B. Kremer, Prof. dr. M. van den Brekel, Dr. F. Hoebers, Prof. dr. A. Scherpbier en Prof. dr. ir. M. Weijenberg: Ik wil u allen danken voor de tijd die u heeft vrijgemaakt om mijn proefschrift te lezen en te beoordelen.

The NPC Yogya team: Thanks a lot for the great time I had in Yogya, every time I was there. Dear dr. Sari and dr. Camelia, thanks for your support and making especially the NPC awareness meeting a great success.

Dear Noni, I hope you realize how extraordinary you are. You are essential for the whole team. It's great to have you as a friend and it only took a couple of years before you understood the Dutch sense of humor $(-)$. Vika, Yunita and Yuni and Tati..... without the determination of the four of you, we would have never been able to collect all our data. Thanks for all the good work and the nice collaboration. 
Beni... HOPLA! Dear dr. Fatwa and dr. Supri it was so nice to be adopted by your department. And despite your busy schedules, you always managed to schedule some time to discuss our projects. dr. Karika, Prof. M. Tjokronagoro ${ }^{\dagger}$, dr. Wigati, dr. Retno and dr. Lina. Thanks for the collaboration on the projects so now we can really see what happens with the NPC patients. Dr. Ima, thanks for your enthusiasm for our NPC awareness activities and our ongoing research in your hospital in Wonosari.

Dear Dewi, Susan, Neni, Jajah in 2009 I was so lucky to be your roommate for three months. It was a great time and I enjoyed our diners the last couples of years. And Jajah thanks for the coffee breaks so we had time to catch up.

Matthias and Liam, thanks for the collaboration and looking forward to our future projects!

From Surabaya I would like to thank Santi Martini and Atoilah Isfandiari from the Department of Public Health of Airlangga University, you made me feel so welcome in Surabaya and together with Prof. Widodo Ario, dr. Bakti Surarso, dr. Muhtarum Yusuf, dr. Achmad C. Romdhoni the NPC awareness program was very succesfull in your province.

From Jakarta, first I would like to thank dr. Marlinda! Not only for your collaboration but also for your hospitality and kindness. Never a dull moment also applies for you (:)! And of course the rest of the NPC awareness-team: Prof. Bambang Hermani, dr Armyanto, dr. Zanil Musa, dr. Ika Dewi, dr. Mayangsari and dr. Ezzy Fardizza there was nothing stopping us... we even made it to Lampung, Sumatra!

Maarten, dank de samenwerking en je betrokkenheid bij de projecten. Jouw onderzoek zorgde ervoor dat we inzagen dat alleen een goede behandeling niet voldoende was om patiënten te kunnen genezen.

Ook wil ik graag alle coauteurs bedanken voor de samenwerking die voor de totstandkoming van alle artikelen heeft gezorgd.

Stichting hoofd-hals kanker Indonesië; Geerten en Peter, dank voor jullie vertrouwen en jullie hulp bij het opzetten van de projecten (ook al gaat dat soms samen met de nodige administratie(:)

Beste Jan-Paul en Jelle, dank allereerst voor de gezelligheid in Yogya, maar ook jullie betrokkenheid bij onze projecten. 
In de loop van de jaren zijn er een hoop studenten geweest die aan onze projecten verbonden waren. Marlies, Annemarie, Ilse, Mara, Jacqueline, Fokko, Charlotte, Josephine, Nathalie, Karen, Jantien, Frank, Boudewijn, Amanda en Jose. Dankzij jullie hebben we een hoop projecten draaiende kunnen houden, wat geresulteerd heeft in meerdere publicaties.

En dan zijn er heel veel mensen binnen de HOD die ik graag wil bedanken. Allereerst alle hoofd-hals chirurgen. Ook al was ik dan een vreemde een in de bijt, toch heb ik me altijd thuis gevoeld op de afdeling. Baris, vanaf dag een was het meteen gezellig. Dat PDT-kosteneffectiviteitsproject heeft ons maar mooi van de straat gehouden. Dank voor je luisterend oor, toen ik het hardst nodig had.

Henny en Marion, onmisbaar zijn jullie voor de afdeling, dank voor al jullie hulp afgelopen jaren! Mede-onderzoekers en (oud)HHC-collega's: Amy, Liset, Ann-Jean, Rob, Jos, Marije, Tessa, Hannah, Joan, Lisette, Klaske Merel, Irene, Anne, Ellen, Cindy, Michel, Mischa, Sophie Maarten, Matthijs en Merijn dank voor de gezelligheid.

Team Marjanka: Sten, Renske, Erik, Susanne, Sander, Danielle, Delal, Sandra, Heleen, Maria, Marcello, Iris en Anna, hoe fijn was het dat ik bij jullie groep mocht horen. Ook hier was ik weer een klein beetje het buitenbeentje met m'n nasopharynx gebeuren in de hele borstkanker groep, het voelde toch als een warm bad. Dank voor de gezelligheid, de uitjes en etentjes de afgelopen jaren.

En dan zijn er nog heel veel collega's die niet direct iets met je proefschrift te maken hebben, maar er wel voor gezorgd hebben dat het AvL voor mij de perfecte werkplek was om zo lang te blijven hangen. Petra, bij jou is het allemaal begonnen, na al die jaren voel ik me nog steeds thuis op jouw afdeling, mede dankzij de rest van jouw team. En dan natuurlijk mijn collega's op het oude H6. Een paar wil ik toch graag noemen want uit het oog is zeker niet uit het hart. Christie, Marleen en Britta, jullie waren in mijn ogen de beste en meest hardwerkende PhD studenten die ik me kon voorstellen. Wat had (en nog steeds) ik een bewondering voor jullie toewijding en overgave. Ingrid, Linde, Thea, Hans, Annegien, Petra, Astrid, jullie waren er vanaf dag een en nog steeds voelt het als een soort familie.

Vrienden uit Amsterdam, alhoewel velen niet meer in Amsterdam wonen: Christie, Winny, Jelmer, Angels, Emma, Joe, maar natuurlijk ook de 'Russen': Michael, Ivanna, Alex, Oksana, Olga en Barend en Irina, dank voorde vriendschap de afgelopen jaren. 
Buurvrouw, Lieve Laura, die laatste loodjes, dankzij jou waren die minder zwaar en ik beloof je dubbel en dwars terug te betalen. Ik kijk uit naar nog meer gezellige borrels ook met Jeroen.

Punt en Merrie (:), dank voor de vele jaren vriendschap, de borrels en de dagjes sauna. Zeker als we allemaal naar dezelfde sauna gingen, en wanneer dat het geval was, we er dan ook daadwerkelijk aankwamen.

Meiden, SMF-ers, lieve Mik, Maike, Marlien, Nico, Maaike, Marjo, Irm en Loes. Wat is onze vriendschap bijzonder. Al zeker 20 jaar (en voor sommige al langer) delen we lief en leed. Dankzij de whatsapp zijn we altijd van alles op de hoogte! Genieten is het altijd weer tijdens onze borrels, carnaval en onze weekendjes weg. De laatste jaren hebben we een hoop hoogtepunten mogen beleven en waren we er voor elkaar in minder leuke tijden. Ik kijk uit naar ons volgende hoogtepunt!

Lieve Yogya-dames en Eelco, naar Yogya komen was altijd een feest. Alhoewel het laatste jaar steeds moeilijker werd om van huis te zijn hebben jullie er altijd voor gezorgd dat de tijd voorbijvloog. Dank dat jullie deel wilden zijn van mijn 'second life'.

Lieve Greet, dank voor het introduceren van kunst en cultuur! Zodat we lekker 'ontspannen' bij de Appel zaten of weer genoten van modern ballet.

En dan mijn paranimfen:

Lieve Frank, al voor ik ooit zou promoveren was het al duidelijk dat jij ooit mijn paranimf zou gaan worden. Hoe leuk is het dat jij nu naast mijn zijde staat op deze bijzondere dag.

dr. Stoker, lieve Sharon hoe tof dat mijn paranimf wilde zijn, en ik de jouwe mag zijn. Ik heb het idee dat we een dit echt samen hebben gedaan en zonder jou waren een hoop dingen mij nooit gelukt of waren juist twee keer zo snel gegaan :)! Dank voor de gezellige tijd in het AvL maar ook in Yogya en natuurlijk dank voor het introduceren van de Yogya-sling!

Als laatste wil ik mijn familie bedanken.

Nieske en Armin; Marnix, Leonie en Mace; Deniz, Karina, Luca en Sam en Madelon, Thijs en Vic. Denk niet dat er veel mensen uit zo een gevarieerde familie komen, maar een ding hebben jullie gemeen en dat is doorzettingsvermogen. Jullie lieten 
me inzien dat als je gelooft in je doelen je ver kunt komen. Dank voor jullie steun en ik hoop dat jullie trots op me zijn!

Dear in laws, Boris, Svetlana, Anna and Michi, thank you for your support and the way you have welcomed me into your family.

Pappa en Gurgul, lieve pappa, hoe verdrietig dat je er niet bij kan zijn, maar ik weet dat je trots bent. Samen met Gurgul hebben jullie mij altijd gesteund en hebben jullie me laten inzien dat niets onmogelijk was, ook al duurde het vaak even voordat ik dat zelf door had.

Lieve Andre en mamma, dank voor de veilige haven die jullie mij altijd hebben geboden. Jullie onvoorwaardelijke steun in al mijn keuzes, hebben mij gevormd tot de persoon die ik nu ben. Wat fijn dat ik nog altijd op jullie terug kan vallen.

Lieve lieve Dmitry, waar zou ik zijn zonder jou? Je bent mijn rots in de branding en wanneer ik weer denk dat dit echt echt echt het einde van de wereld is, weet jij mij weer met beide benen op de grond te zetten. Samen met Maxim kijk ik uit naar de rest van onze toekomst samen. Ik hou van jullie en wat hebben we het goed zo!!! 


\section{Related to this dissertation}

1. Use of traditional, complementary and alternative medicine delays diagnosis of nasopharyngeal carcinoma in Indonesia

R Fles, JO Schutter, FST Dewi, Supriyati, D Hartati, F Amelia, L Lazuardi, C Herdini, J Fachiroh, SR Indrasari, SM Haryana, MK Schmidt, IB Tan

BMC complementary and alternative medicine submitted 2016 October

2. The role of health behavior of Indonesian patients in delaying the diagnosis of nasopharyngeal carcinoma

R Fles, ACRK Bos, Supriyati, D Rachmawati3, E waliyanti, IB Tan, SM Haryana, MK Schmidt, FST Dewi

BMC Public Health submitted 2016 June

3. The impact of the overall radiotherapy time on clinical outcome of patients with nasopharyngeal carcinoma; a retrospective study

SD Stoker, R Fles, C Herdini, FJF Rijntjes, SR Dwidanarti, K Sikorska, CR Leemans, MK Schmidt, A Al-Mamgani, MA Wildeman, SM Haryana, SR Indrasari, IB Tan

PLoS One 2016 Jan

4. Effectiveness of a multicentre nasopharyngeal carcinoma awareness programme in Indonesia

R Fles, SR Indrasari, C Herdini, S Martini, Isfandiari, AC Romdhoni, M Adham, ID Mayangsari, E van Werkhoven, MAM Wildeman, B Hariwiyanto, B Hermani, WA Kentjono, SM Haryana, MK Schmidt, IB Tan

BMJ open 2016 January

5. Can Epstein-Barr virus DNA load in nasopharyngeal brushings or whole blood predict recurrent nasopharyngeal carcinoma in a non-endemic region? A prospective nationwide study of the Dutch Head and Neck Oncology Cooperative Group

Stoker SD, Wildeman MA, Novalic Z, Fles R, van der Noort V, de Bree R, Braunius WW, van den Broek GB, Kreike B, Kross KW, Juwana H, Ramayanti O, Verkuijlen S, de Boer JP, Greijer AE, Middeldorp JM, Tan IB

European Archives of Oto-rhino-laryngology 2015 May

6. Photodynamic therapy as salvage therapy for patients with nasopharyngeal carcinoma experiencing local failures following definitive radiotherapy

Stoker SD, Indrasari SR, Herdini C, Hariwiyanto B, Karakullukcu B, Dhamiyati W, Widayati K, Romdhoni AC, Fles R, Haryana SM, Wildeman MA, Tan IB

Photodiagnosis Photodynamic Therapy 2015 April

7. Current status of cancer care for young patients with nasopharyngeal carcinoma in Jakarta, Indonesia

Adham M, Stoker SD, Wildeman MA, Rachmadi L, Gondhowiardjo S, Atmakusumah D, Gatot D, Fles R, Greijer A, Hermani B, Middeldorp J, Tan IB

PLoS One 2014 July

8. A prospective study: current problems in radiotherapy for nasopharyngeal carcinoma in yogyakarta, indonesia

Stoker SD, Wildeman MA, Fles R, Indrasari SR, Herdini C, Wildeman PL, van Diessen JN, Tjokronagoro M, Tan IB

PLoS One 2014 January

9. Primary treatment results of Nasopharyngeal Carcinoma (NPC) in Yogyakarta, Indonesia Wildeman MA, Fles R, Herdini C, Indrasari RS, Vincent AD, Tjokronagoro M, Stoker S, Kurnianda J, Karakullukcu B, Taroeno-Hariadi KW, Hamming-Vrieze O, Middeldorp JM, Hariwiyanto B, Haryana SM, Tan IB

PLoS One 2013 May 
10. Lower mortality from nasopharyngeal cancer in The Netherlands since 1970 with differential incidence trends in histopathology

Arnold M, Wildeman MA, Visser O, Karim-Kos HE, Middeldorp JM, Fles R, Tan IB, Coebergh JW

Oral Oncology 2013 March

11. Short-term effect of different teaching methods on Nasopharyngeal Carcinoma for general practitioners in Jakarta Indonesia

MA Wildeman; R Fles; M Adham; ID Mayangsari; I luirink; M Sandberg; A Vincent; F Fardizza; Z Musa; Armiyanto; JM Middeldorp; G Gerritsen; R Soewento; IB Tan

PLoS One 2012 March

12. Can an Online Clinical Data Management service help in improving data collection and data quality in a developing country setting?

Wildeman MA, Zandbergen J, Vincent A, Herdini C, Middeldorp JM, Fles R, Dalesio O, van der Donk E, Tan IB

Trials 2011 August

13. Knowledge of general practitioners about nasopharyngeal cancer at the Puskesmas in Yogyakarta, Indonesia

Fles $\mathbf{R}$, Wildeman MA, Sulistiono B, Haryana SM, Tan IB

BMC Medical Education 2010 November

\section{List of other publications}

14. Estrogen receptor $\alpha$ wields treatment-specific enhancers between morphologically similar endometrial tumors

Marjolein Droog*, Ekaterina Nevedomskaya*, Gwen Dackus, Renske Fles, Harry Hollema, Marian Mourits, Petra Nederlof5, Hester van Boven, Flora E van Leeuwen, Sabine C Linn, Lodewyk FA Wessels and Wilbert Zwart

Proceedings of the National Academy of Sciences USA submitted 2016 August

15. Additional value of the 70-gene signature and levels of ER and PR for the prediction of outcome in tamoxifen-treated ER-positive breast cancer

M Kok; RH Koornstra; S Mook; M Hauptmann; R Fles; MP Jansen; EM Berns; SC Linn; L van't Veer

The Breast 2012

16. Genomic profile of endometrial tumors depends on morphological subtype, not on tamoxifen exposure

Fles R, Hoogendoorn WE, Platteel I, Scheerman CE, de Leeuw-Mantel G, Mourits MJ, Hollema H, van Leeuwen FE, van Boven HH, Nederlof PM

Genes Chromosomes Cancer 2010 August

17. PKA-induced phosphorylation of ER $\alpha$ at serine 305 and high PAK1 levels is associated with sensitivity to tamoxifen in ER-positive breast cancer

Kok M, Zwart W, Holm C, Fles R, Hauptmann M, Van t Veer LJ, Wessels LF, Neefjes J, Stål O, Linn SC, Landberg G, Michalides R

Breast Cancer Res Treat 2011 January

18. Mammosphere-derived gene set predicts outcome in patients with ER-positive breast cancer

Kok M, Koornstra R,Margarido T, Fles R, Armstrong N, Linn S, Van t Veer L, Weigelt B Journal of Pathology 2009 July 
19. Phosphorylation of the oestrogen receptor alpha at serine 305 and prediction of tamoxifen resistance in breast cancer

Holm C, Kok M, Michalides R, Fles R, Koornstra RH, Wesseling J, Hauptmann M, Neefjes J, Peterse JL, Stål O, Landberg G, Linn SC Journal of Pathology 2009 February

20. Prognosis of uterine corpus cancer after tamoxifen treatment for breast cancer Hoogendoorn WE, Hollema H, van Boven HH, Bergman E, de Leeuw-Mantel G, Platteel I, Fles R, Nederlof PM, Mourits MJ, van Leeuwen FE; Comprehensive Cancer Centers TAMARISK-group

Breast Cancer Res Treat 2008 November

21. Baseline human papillomavirus status of women with abnormal smears in cervical screening: a 5-year follow-up study in The Netherlands

Prinsen CF, Fles R, Wijnen-Dubbers CW, de Valk HA, Klaassen $\mathrm{CH}$, Mravunac $\mathrm{M}$, Horrevorts AM, Thunnissen FB

British Journal of Obstetrics and Gynaecology 2007 August

22. A multiplex PCR predictor for aCGH success of FFPE samples $\vee$ Beers EH, Joosse SA, Ligtenberg MJ, Fles R, Hogervorst FB, Verhoef S, Nederlof PM

British Journal of Cancer 2006 January 
Renske Fles was born on the $13^{\text {th }}$ of March 1979, and grew up in Zelhem, The Netherlands. She graduated from secondary school (HAVO 1996 and VWO 1998) and started her study Biomedical Health Science at the Radboud University Nijmegen, The Netherlands. After changing direction in 1999 she graduated from the HAN university of applied science in Nijmegen in 2003 completing her study Cytology, Histology and Pathology. Thereafter, she worked as a research technician at the Netherlands Cancer Institute, focusing on tamoxifen related topics. In the meantime, in 2007 she started a master program: management, policy analysis and entrepreneurship in health and life science with a specialization International Public Health at the Free University in Amsterdam. After finishing her master internship in 2009 at the Gadjah Mada University Yogyakarta she returned to the Dutch Cancer Institute to work as a project coordinator in the group of professor IB Tan on a multicenter cost-effectiveness study to evaluate a novel treatment in The Netherlands: Photodynamic therapy for the treatment of advanced incurable head and neck cancer, for whom prior conventional treatments have failed. Funded by the Eureko Achmea foundation she coordinated and organized the NPC awareness program which was held for several times in Jakarta, Yogyakarta, Surabaya, Lampung and Makassar. Together with to Prof IB. Tan, Prof SM. Haryana and MK. Schmidt PhD, she successfully applied for and received a grant from KWF (Dutch Cancer Society) in 2012 for 5 years and started to work as a PhD candidate/ Project Coordinator. This project resulted in the studies presented in this dissertation.

With her ongoing interest in cancer care and equity in health care, Renske aims to pursue a career in this field.

Renske Fles is married to Dmitry Milovanov and has one son: Maxim 

